\title{
DATATECTURE: CREATING A REAL HOME FOR A VIRTUAL IDENTITY
}

by

\section{SCOTT MEEKINGS}

\author{
A thesis \\ submitted to the Victoria University of Wellington \\ in partial fulfilment of the requirements for the degree of \\ Master of Architecture
}

Victoria University of Wellington 2017 
ABSTRACT 
It is increasingly common to live in continual flux between reality and virtuality - for architecture this means a dwindling focus on the built environment. For the architectural discipline to respond to these rapidly changing user-demands, a proactive relationship with our digital environment is required. It is proposed that a key occupation of the architectural discipline in the near future will be designing architecture that caters to our 'real-world' selves but takes advantage of the broad range of data available to us from the digital realm. This thesis proposes that within the big data stored about all those who engage with the digital environment, lies data that can influence and benefit the architectural discipline and allow us to respond convincingly to the increasing focus on digital and virtual engagement.

As people increasingly 'live online' architects can now derive information about clients not only from meeting them in person but also by scraping data on their digital lives and constructing what is referred to in this thesis as a digital identity. The digital identity can include data about a myriad of architectural influences such as taste, activity and lifestyle.

This thesis considers which data may become available over the next decade, how architectural designers can embrace it without specialist data-centric skillsets and how it may help personalise architecture. A large amount of data is collected on the author from both 'real-world' scenarios and 'virtual' inhabitation of digital space. This data, along with other public sources of data are explored in terms of architectural potential, culminating in a vision for a new data-based and ultimately more efficient method for personalising and inhabiting architecture.
Key Words:

Big Data,

Digital Identity,

Built Environment, Social Media 
0.1 FOR
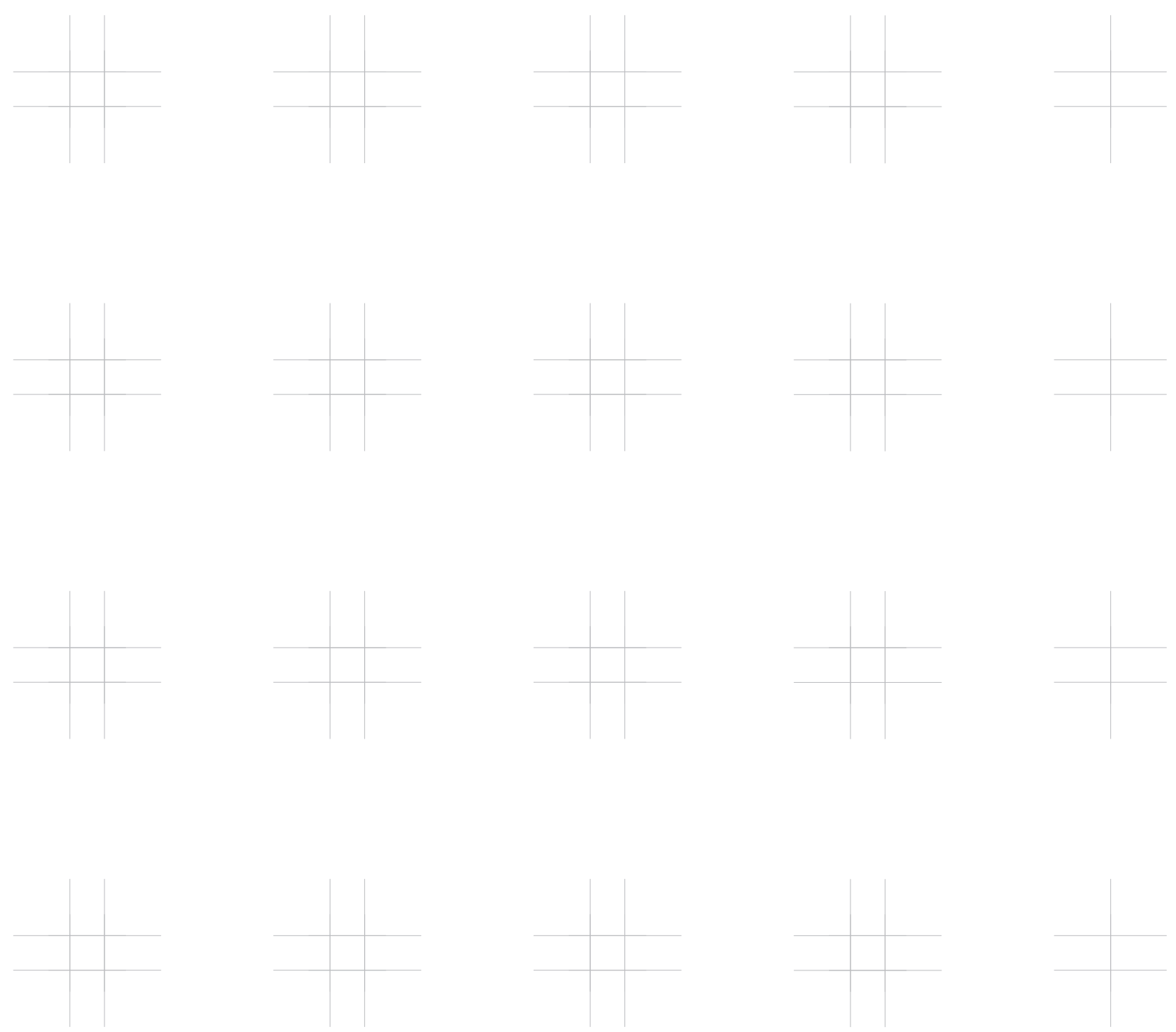

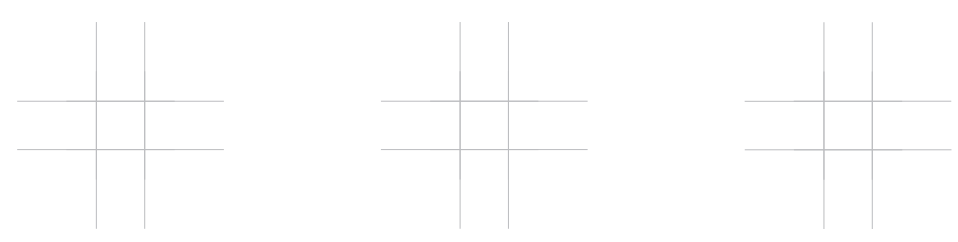

my girlfriend,

my supervisor,

my mentors,

my colleagues,

and everyone pushing the digital agenda

for a change in architecture.
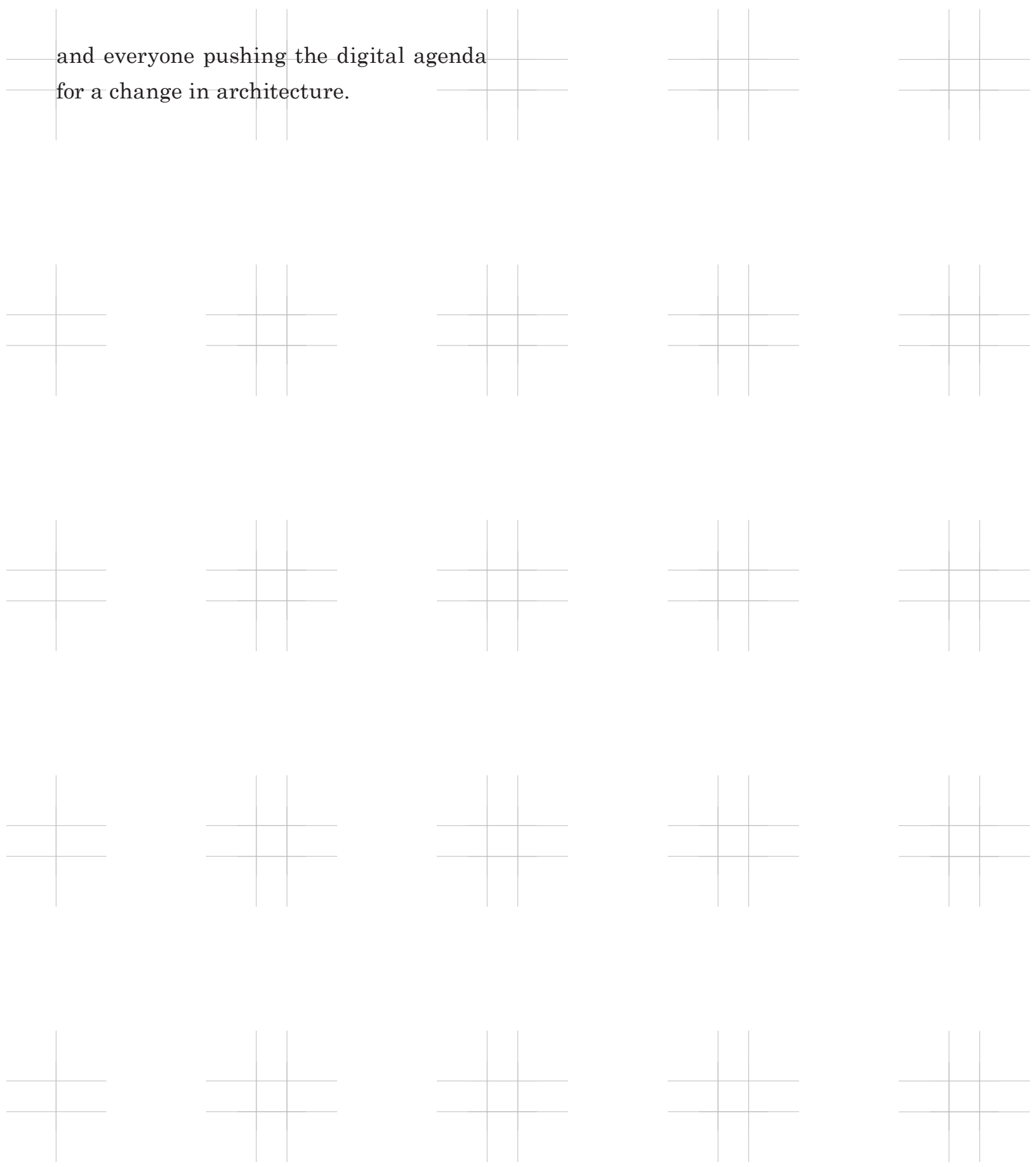


\section{TABLE OF CONTENTS}

\begin{tabular}{r|l|} 
& \\
\hline $\mathrm{i}$ & Abstract \\
$\mathrm{iii}$ & 0.1 For \\
$\mathrm{vii}$ & 0.2 External Videos \\
& \\
1 & 1.0 Introduction \\
7 & 1.1 Objectives + Structure \\
\hline 9 & 1.2 Scope \\
\hline 11 & 2.0 Programme + Context Analysis \\
17 & 2.1 Data Gathering
\end{tabular}
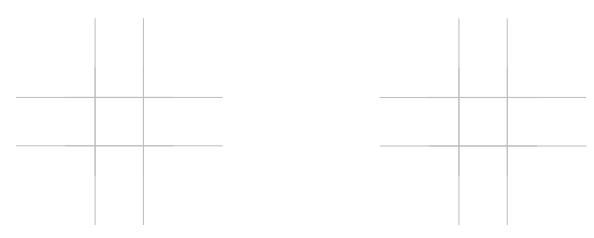

31

3.0 Literature Review

$39 \quad 3.1$ Collective and Social Intelligence

$41 \quad 3.2$ Physical Data

$43 \quad 3.3$ Supplementation of Conventional Architecture

$45 \quad 4.0$ Project Review

$47 \quad 4.1$ Mini Vision Next 100

$51 \quad 4.2$ Hemnet Home

$53+4.3$ Monolitt
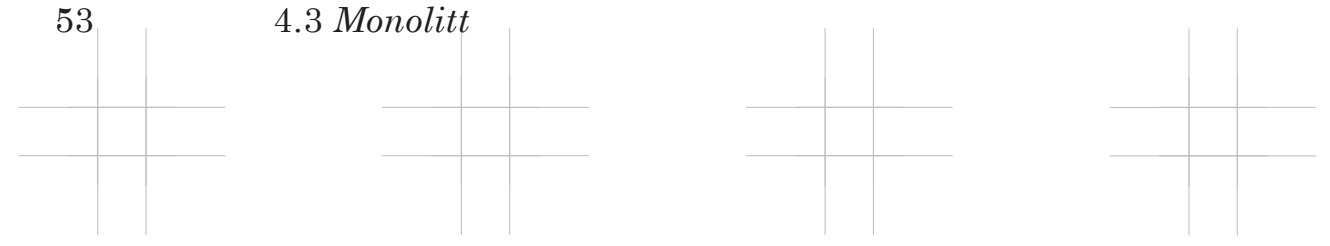

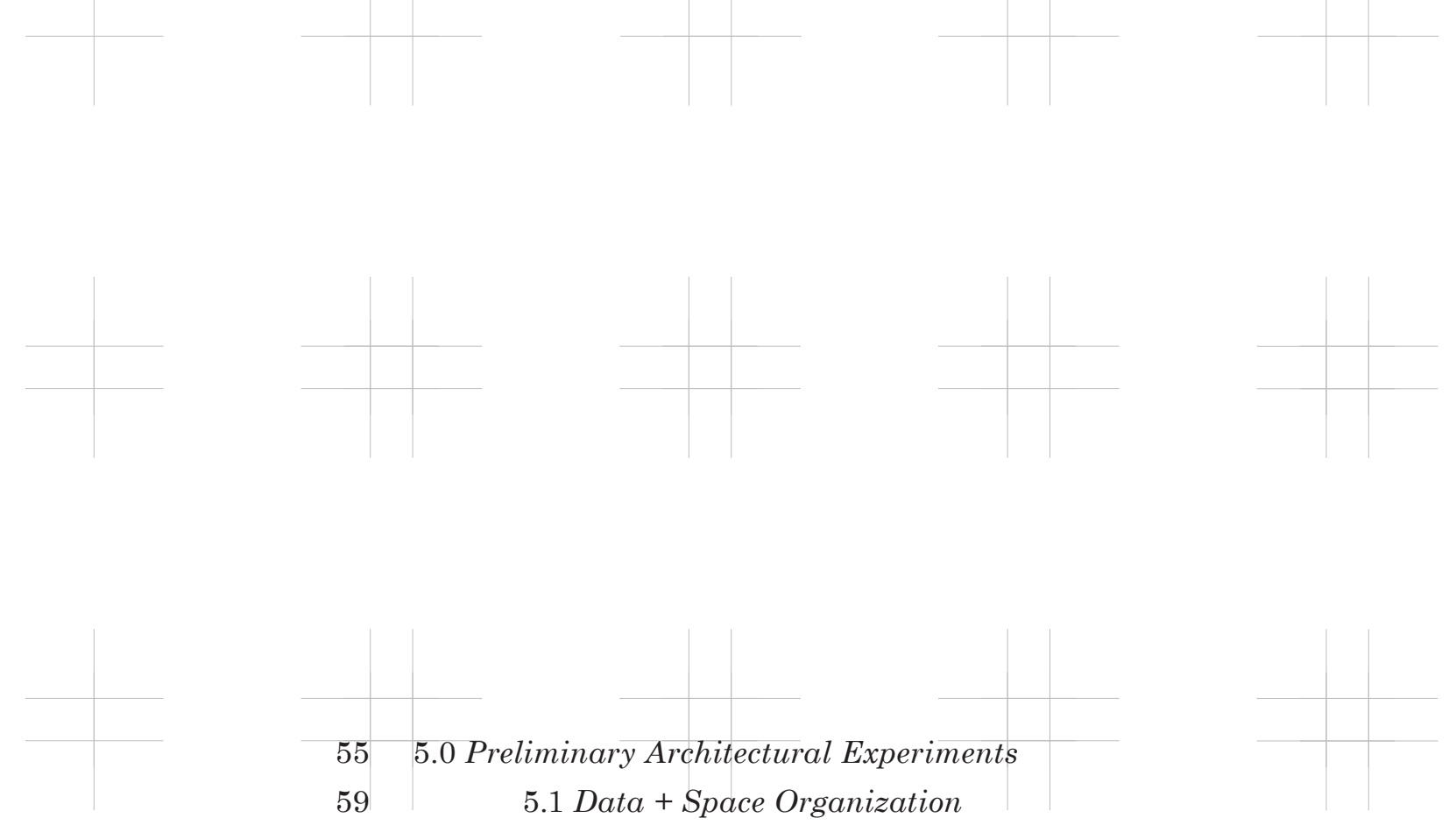

\begin{tabular}{r|r} 
& \\
\hline 55 & $5.0 P$ \\
59 & \\
63 & \\
81 & \\
89 & \\
97 & \\
103 & \\
115 & \\
123 &
\end{tabular}
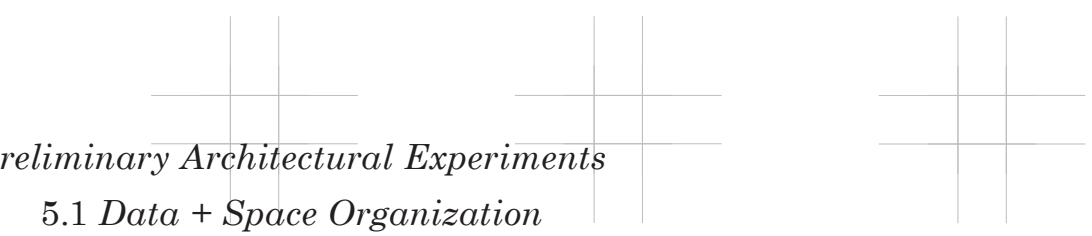

5.1 Data + Space Organization

5.1.1 Diffusion Limited Aggregation Algorithm

5.2 [Web]Site

5.3 Atmosphere

5.4 Data Interaction and Ownership

5.5 Forms + Aesthetics within Digital Space

5.6 Materiality within Digital Space

5.7 Conglomeration

131 6.0 Developed Architectural Experiments

$135 \quad 6.1$ Developing Data-Based Conceptual Architecture

$153 \quad 6.2$ Developing Data-Based Modes of Living

157

6.3 A New Typology Concept

1617.0 Discussion

$167 \quad 7.1$ Critical reflection

1698.0 Bibliography

1749.0 Appendix

\begin{tabular}{l|l}
177 & 9.1 Figures \\
\hline 178 & 9.2 External Video Links
\end{tabular}
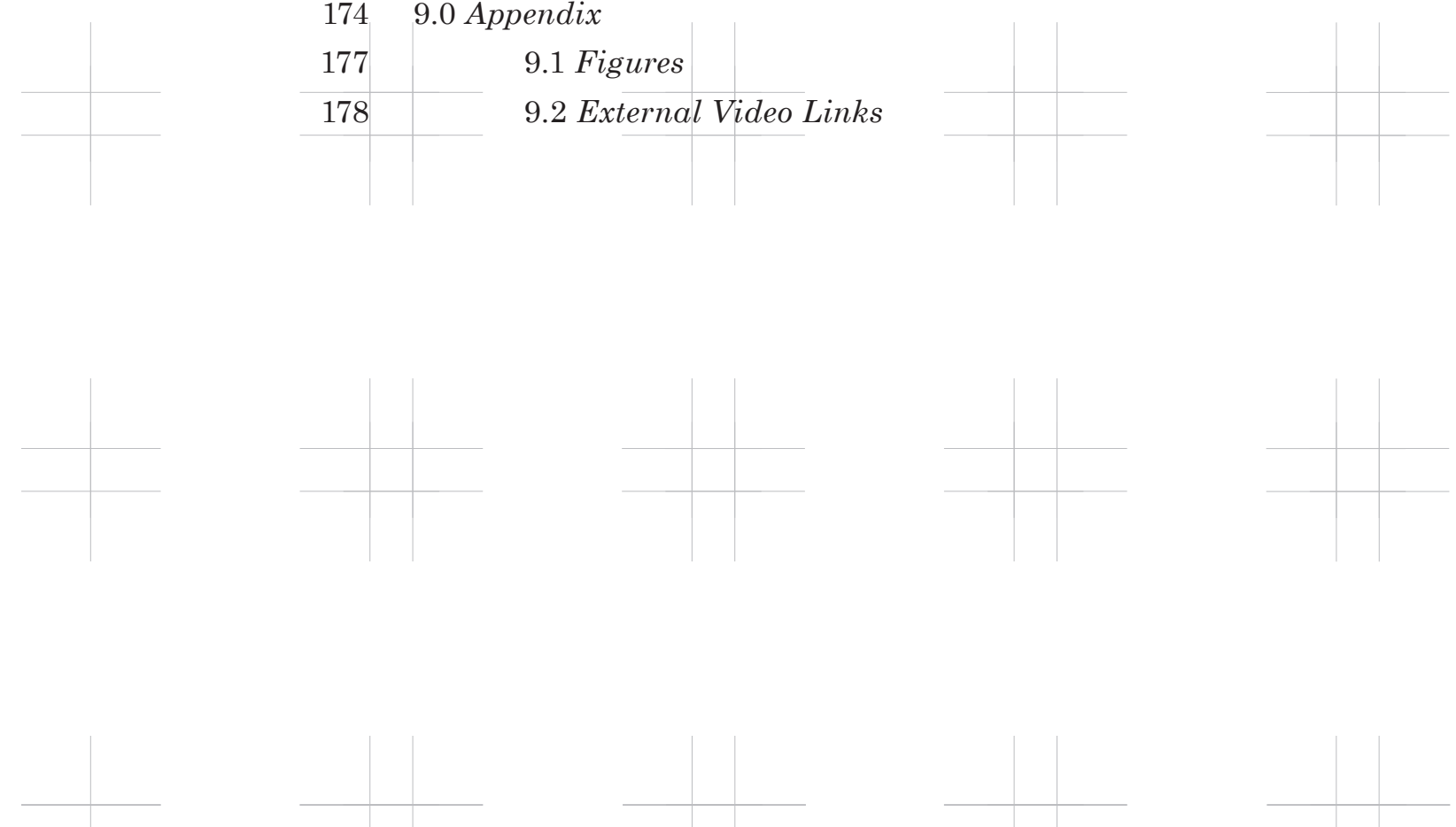


\subsection{EXTERNAL VIDEOS}

Throughout this thesis there are links to video's of content that cannot be entirely displayed in static images. To access these scan the QR code on your mobile phone with a $\mathrm{QR}$ code scanning app, visit: scottmeekings.com/thesis-videos or use the included flash-drive.
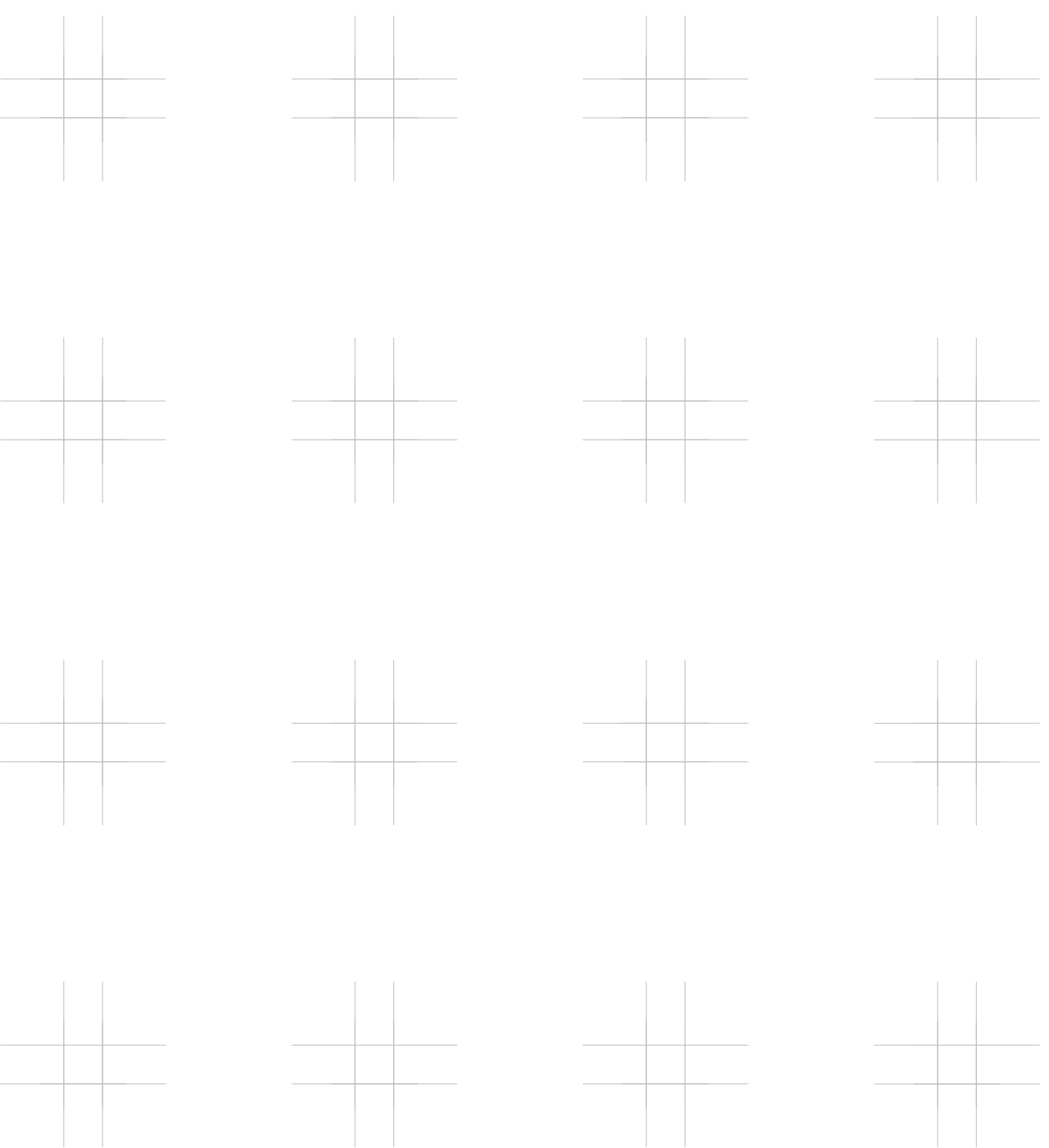

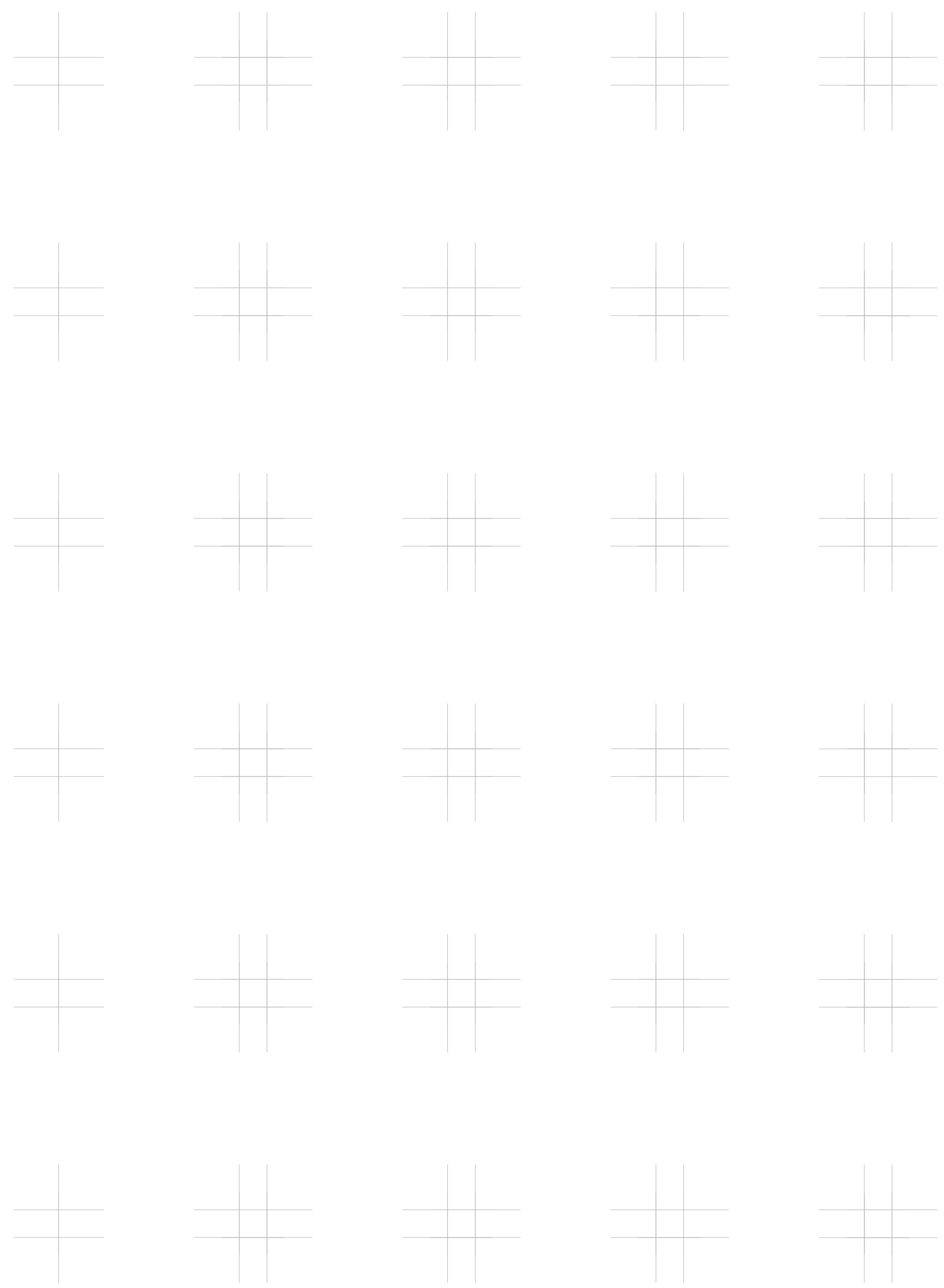

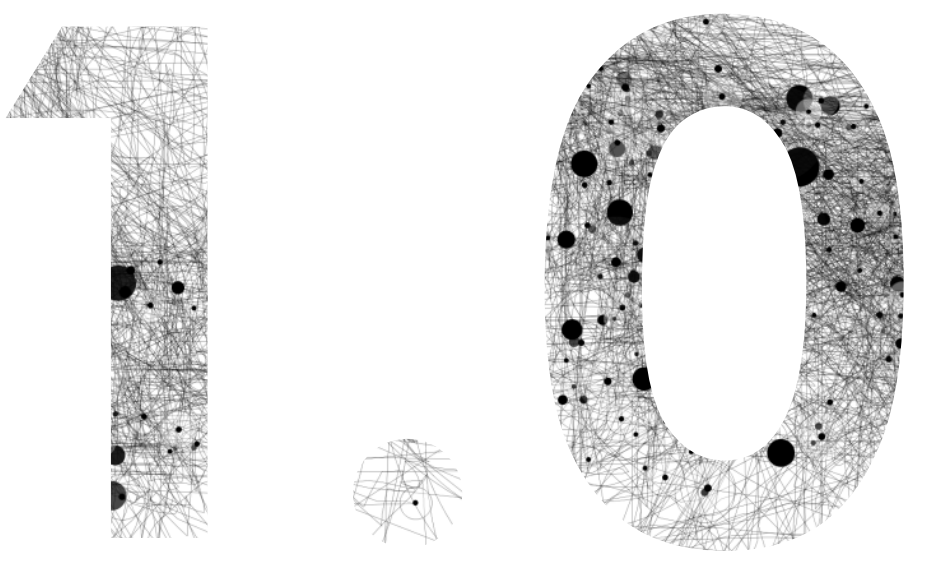

INTRODUCTION 
${ }^{66}$ Increasingly, we are living our lives at the points where electronic information flows, mobile bodies, and physical places intersect in particularly useful and engaging ways these points are becoming the occasions for a characteristic new architecture of the twenty-first century."

—William J. Mitchell 
Architecture is a rapidly changing field which is currently searching for ways to integrate with the 'digitization' of people's lives as social media and the Internet of Things become increasingly prevalent throughout the world (Bausch and Han, 2006). The internet of things is central to this thesis and is the idea that all sorts of previously unconnected objects are becoming a part of the internet - pedometers, cars, heating systems and toasters. This is currently spilling into architectural design with hybrid furniture-electronics such as ORI by Yves Behar and the MIT Media Lab (Ori Systems, 2016). Many aspects of modern life are now quantified and uploaded to the internet, incrementally forming a digital representation of each of us. Similarly the increasing use of social media to portray ourselves online paints another digital-picture of who we are.These are digital identities. A digital identity is acknowledged as being a shallow, quantified and formulaic version of a real person. This research questions how this digital identity could be used to form personalised space in the future and what effects this could have on the relationship between people and architecture by focusing on personalised data and its implications for architecture.

It is becoming apparent that there is the potential for our digital lives to eclipse our conventional interactions in the near future, as evidenced by the youngest generation who are now often considered "digital natives" (Prensky, 2001). This is already apparent in many aspects of life, communications for example have been heavily digitised and in many cases we 'talk' with people without ever physically meeting - although now the words their emails contain could now be harvested as data to tell us something of their 


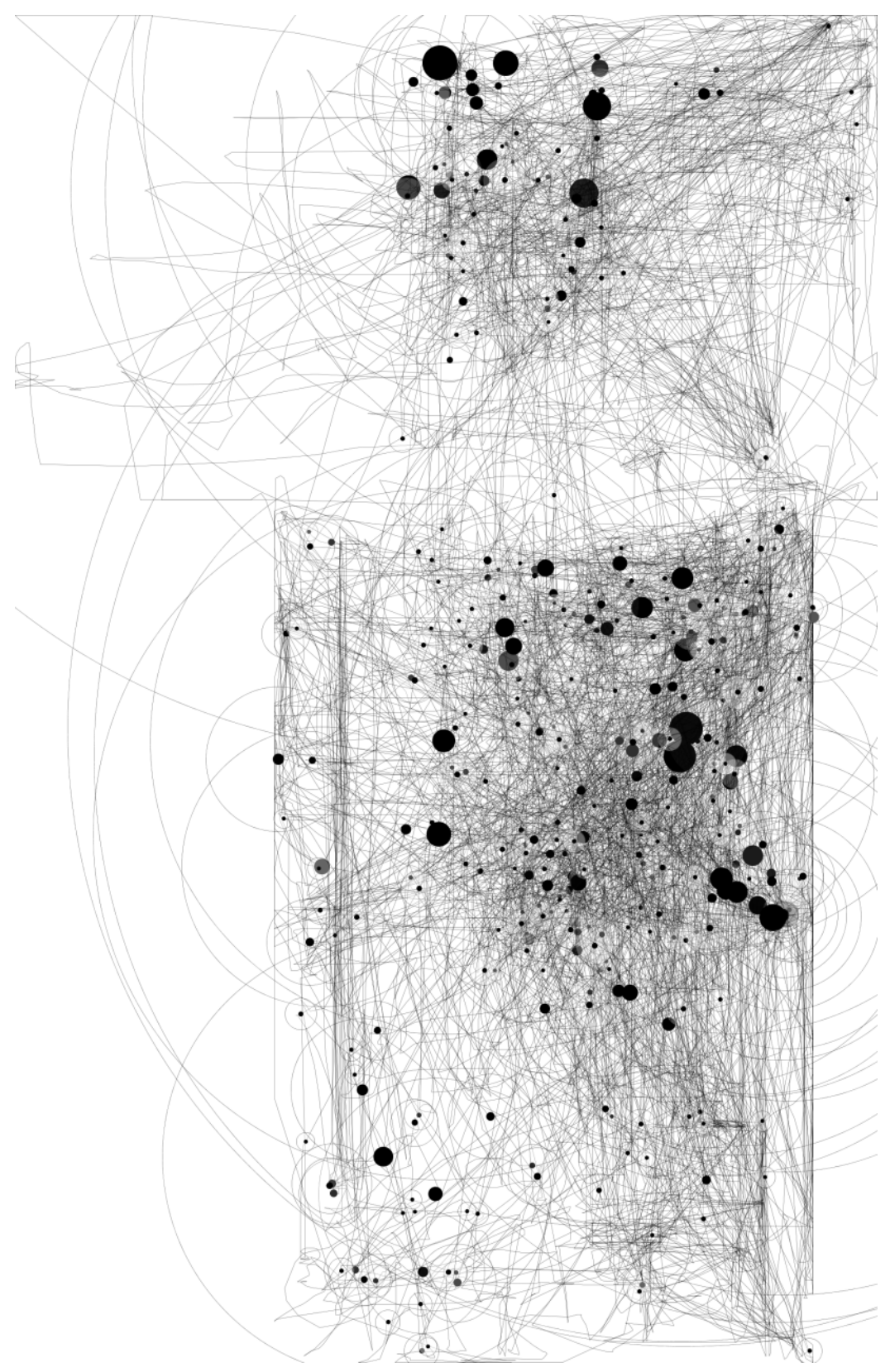

$\overline{\text { Figure_1 }}$

Design experiment using data collected from mouse movements using io.graphia software for one day of work on this thesis over two screens, rotated ninety degrees anti-clockwise. $\uparrow$ 
personality. This influx of digital interactions, and subsequent reduction of conventional, physical interactions makes digital identity an important consideration for the architectural discipline, while also providing a plethora of new ways for data to inform architectural design processes.

The use of data in architecture is not a new concept, with work ranging from basic sun-studies, to overlaying data onto architecture (Wisneski et al., 1998), to data-based robotic-fabrication studies (Anders, 2001, Webb, 2015), through to physical data (Ishii et al., 2012, Parisi, 2012). This research considers data as a means of understanding people through an array of quantifiable traits that could be used within architectural workflows to help designers create authentic relationships between spaces and people. A range of scripts are developed to three-dimensionalize and rationalize data that has been collected from the author's life, social media and public datasets. The experiments presented here are examples of ways in which data can be collected and harnessed to allow architecture to embrace digital personalities.

\footnotetext{
$\overline{\text { Figure_2 }}$

Design experiment depicting flow of data from web

browsing, researching for this thesis for 30 minutes.

Developed through Lightbeam browser plugin.

Circles are visited sites, triangles are third party

sites that are sent data. $\nearrow$
} 


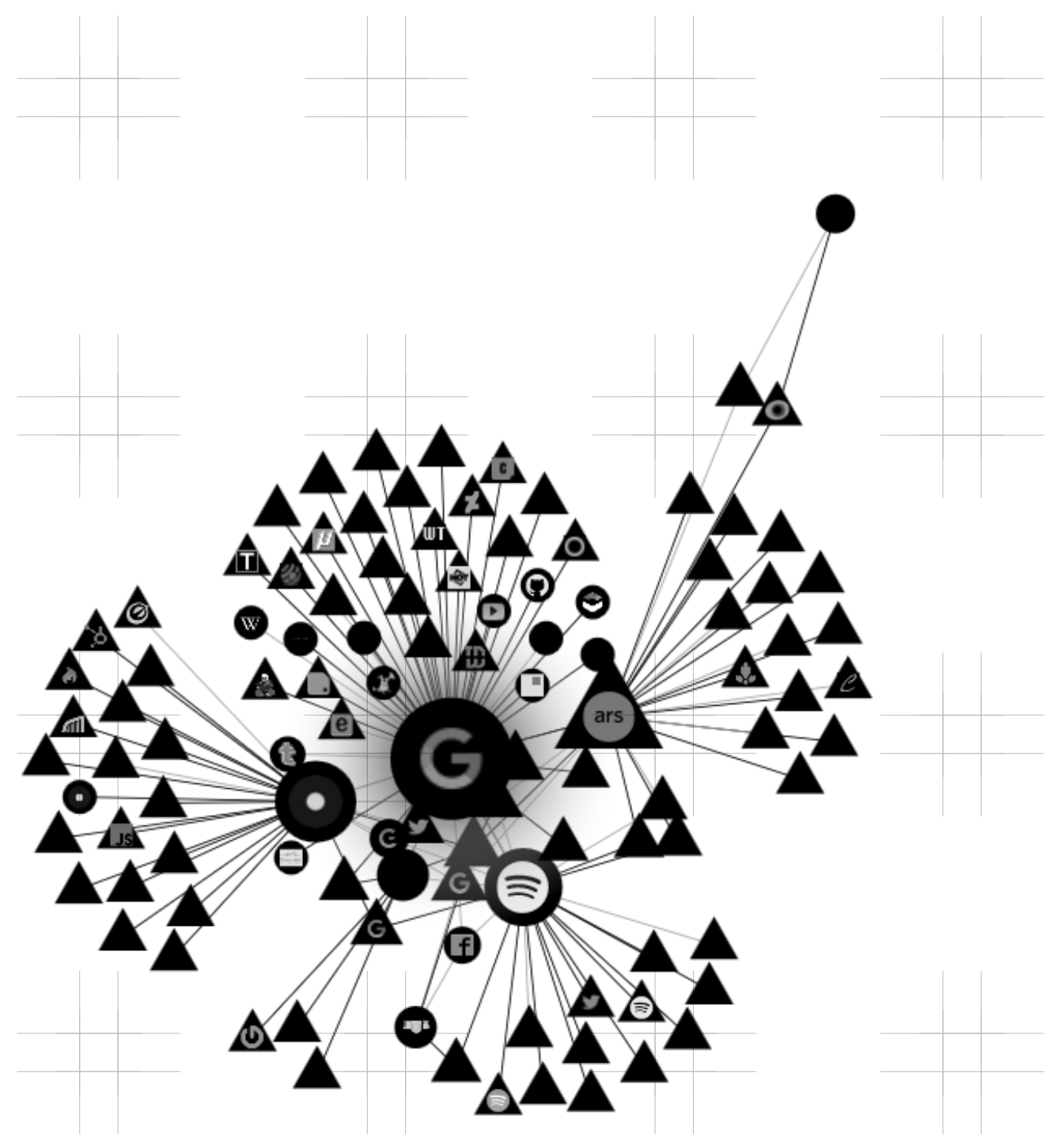




\subsection{OBJECTIVES + STRUCTURE}

The key aim of this thesis is the conversion of data into space that reflects individuals via their digital identity and provides a more efficient typology for personalised architecture. A range of experiments are done to test the validity of this idea. The experiments begin by collecting data and testing which methods of collection are currently feasible or are likely to become feasible for architects in the foreseeable future. This has been done by collecting data about the author through a range of mediums. Following this, experiments are conducted to test the relationship of data with a range of key architectural elements: organizing spaces, identifying sites, creating atmosphere, adapting to client feedback, creating forms and aesthetics, developing material composition and finally combining these into architectural outcomes. Each experiment is evaluated and learnings are carried into subsequent tests.

$\overline{\text { Figure_3 }}$

Thesis Structure. $\rightarrow$ 


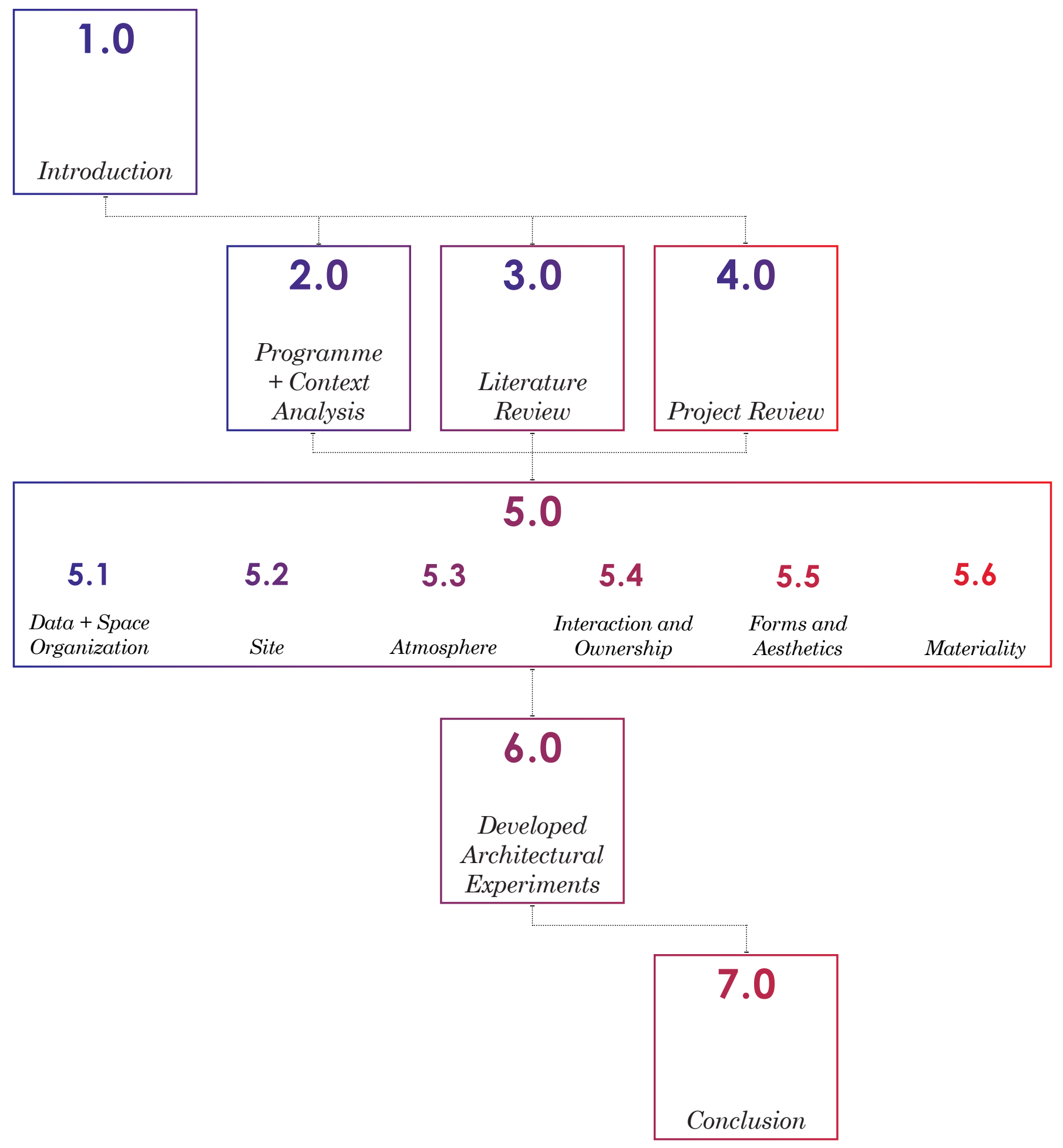




\subsection{SCOPE}

The main method of design research used in this thesis is writing scripts. This allows data to be manipulated comprehensively and provides the potential for novel outcomes as demonstrated through these introductory images.

It is recognized that both the influence of data and architecture are broad topics. To limit the scope of the project no machine learning scripts have been developed due to complexity and the requirement for data-centric skillsets. Other than this, the research has attempted to be inclusive of the broad and varied aspects of both data and architectural design with a focus on varied experimental architecture over pragmatic outcomes.

There are almost limitless methods for mixing data with architectural design and understanding this broad potential requires comparison of many results. To this end a developed design is not the goal, instead the focus is on generating the initial expressions of form from an abstract and original basis to develop novel architecture, which is one of the most important steps when using original sources of design inspiration (Christensen and Schnabel, 2008).

\footnotetext{
$\overline{\text { Figure_4 }}$

Design experiment depicting clothes worn on days that this thesis was worked on. Data collected in Reporter App and visualized using RAW software. Thicker connections denote more commonly worn combinations. $\lambda$
} 


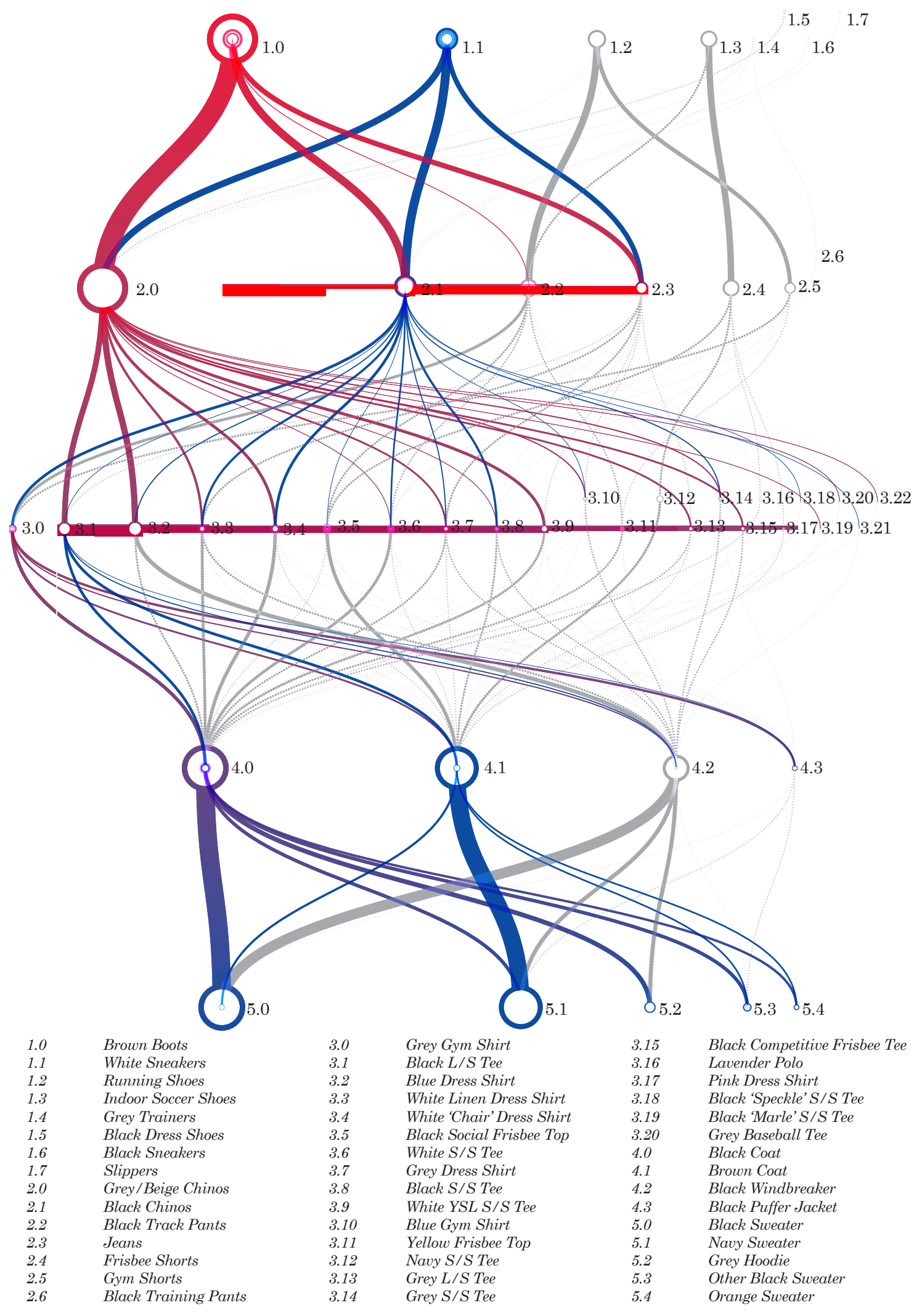



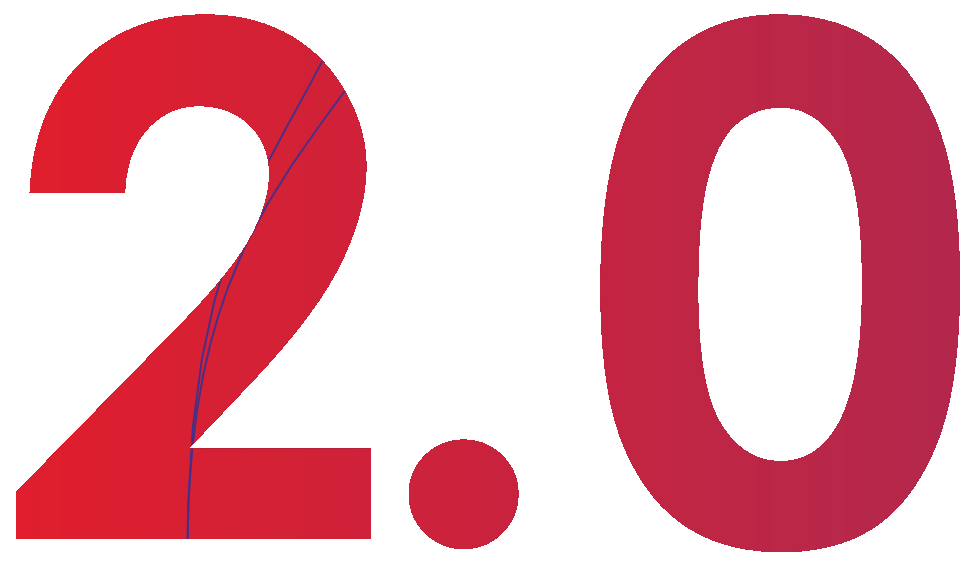

\section{PROGRAMME + CONTEXT ANALYSIS}


${ }^{6}$ The wisdom of the crowd can potentially be integrated to inform processes of digital design generation, adaptation and change in the various phases of design in order to improve design."

-Rivka Oxman

Computational Schema as a Facilitator for Crowdsourcing in a "Social-Motive" Model of Design 
In his book Cognitive Surplus: Creativity and Generosity in a Connected Age, Clay Shirky discusses the problem industries have of assuming too much about their product, a problem that data may help us solve in architecture (2010). Shirky coins the term 'milkshake mistake' to describe this phenomenon which arises from his observations of a McDonald's product review. In this review McDonalds commissions a range of people to investigate how to popularize milkshakes. These investigators test new formulas for milkshakes, making them thicker, colder, sweeter and so on. Architectural design research typically has this same focus - how can the product be improved? What combination of building elements works best to create 'good' architecture based on pre-defined ideas about successful architectural design? The reality is that architects design and administer the contract in a dwindling percentage of new constructions (Cohen et al., 2005). Even when in architecturally designed buildings, people are increasingly "not really experiencing that space. Rather, they're off meeting people in environments designed by Facebook and OkCupid" (Davis, 2014). All the while architecture aims to improve the product - bigger houses, cheaper materials, better construction methods and so on.

In the McDonalds study all of these tested product improvements produce no improvements in sales or customer satisfaction. The declining influence of architects on the built environment indicates a similar result. The breakthrough in the investigation of milkshakes came when one researcher ignored the product and focussed on the people, discovering that there was one predominant group of people who bought the milkshakes: commuter's buying breakfast. They didn't care about the product itself, they cared that they could hold it in one hand while they drove to work. Shirky explains

"The first [mistake] was to concentrate mainly on the product and assume that everything important about it was somehow implicit in its attributes, without regard to what role the customers wanted it to play [...] The second mistake was to adopt a narrow view of the type of food people have always eaten in the morning, as if 
all habits were deeply rooted traditions instead of accumulated accidents."

It can be argued architecture requires a similarly focus on the user instead of the product. It is hypothesised here that the big data phenomenon may help us find a more objective window into people and the aspects of architecture that they benefit from.

To this end there is no proposed site for these architectural tests nor is there a proposed program. Instead of selecting a site and working to the constraints it provides, the data is asked where do people want to be and why? The ideas contained in this thesis are not fixed to a location although the final speculative concept is depicted in Wellington. Programme is considered similarly. This attempts to develop a new perspective on architectural design.

Because the data defines these aspects of this thesis, the data itself can be seen as the programme and context. This makes the gathering of data very important. A difficulty with gathering relevant data is the rapid momentum of the big-data phenomenon. More of our lives are quantified than ever before and every day over seventy times the amount of data stored in the Library of Congress is added to the internet (Neef, 2014). Essentially the limits of data today will not be the limits of data tomorrow and the datascape in 10 years is unimaginable. To combat this the types of data collected are not available to industries but might be in the foreseeable future. The majority of this data and the resulting digital identity is the product of my day to day life. Data within this thesis that is focussed on an individual is focussed on myself allowing me to control the quality, avoid privacy issues with collecting others data and have a better understanding of the identity behind the data. Despite this it is intended that this is data that could be collected about anybody in the future. Supplementing this data is some publicly available data such as New Zealand Census data, data scraped from randomly generated public Facebook profiles and so on. 


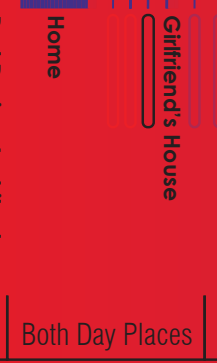


When am I home and awake?

Times I am Home

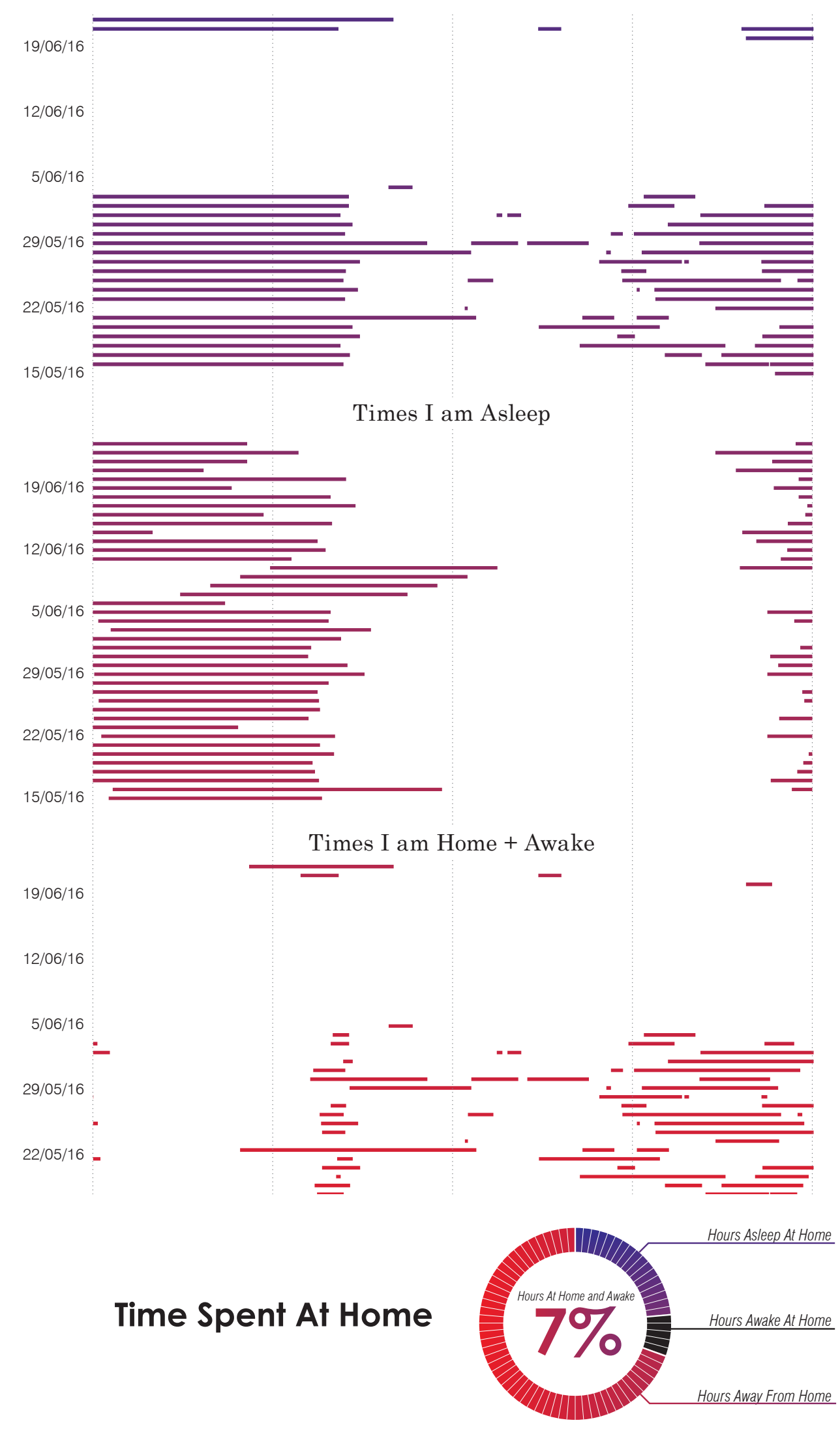




\subsection{DATA GATHERING}

The first step to using data to inform design processes is data collection. It is common in many industries to collect as much data as possible without considering its use, then selling it to whoever has a use for it; this data is often difficult for non-specialist data users such as architects as it is "unstructured" (Neef, 2014). Machine learning, algorithms can be developed to unlock previously unseen connections within unstructured data, however, this is too complex for architects to embed into their workflow. It has the added drawback of being difficult to edit or correct (Neef, 2014). A good example of unstructured data is communications such as email, Facebook posts, one conversations and so on (George et al., 2014).

Unlike unstructured data, structured data has a legibility that makes it more readily usable for archtects, however it is more difficult to collect. Expanding on the earlier example of communications, structured data could be a record of communication such as a call log. From the call log we can see between thom communication has occurred but this is significantly less data than existed in the words exchanged between the two callers ofignally 

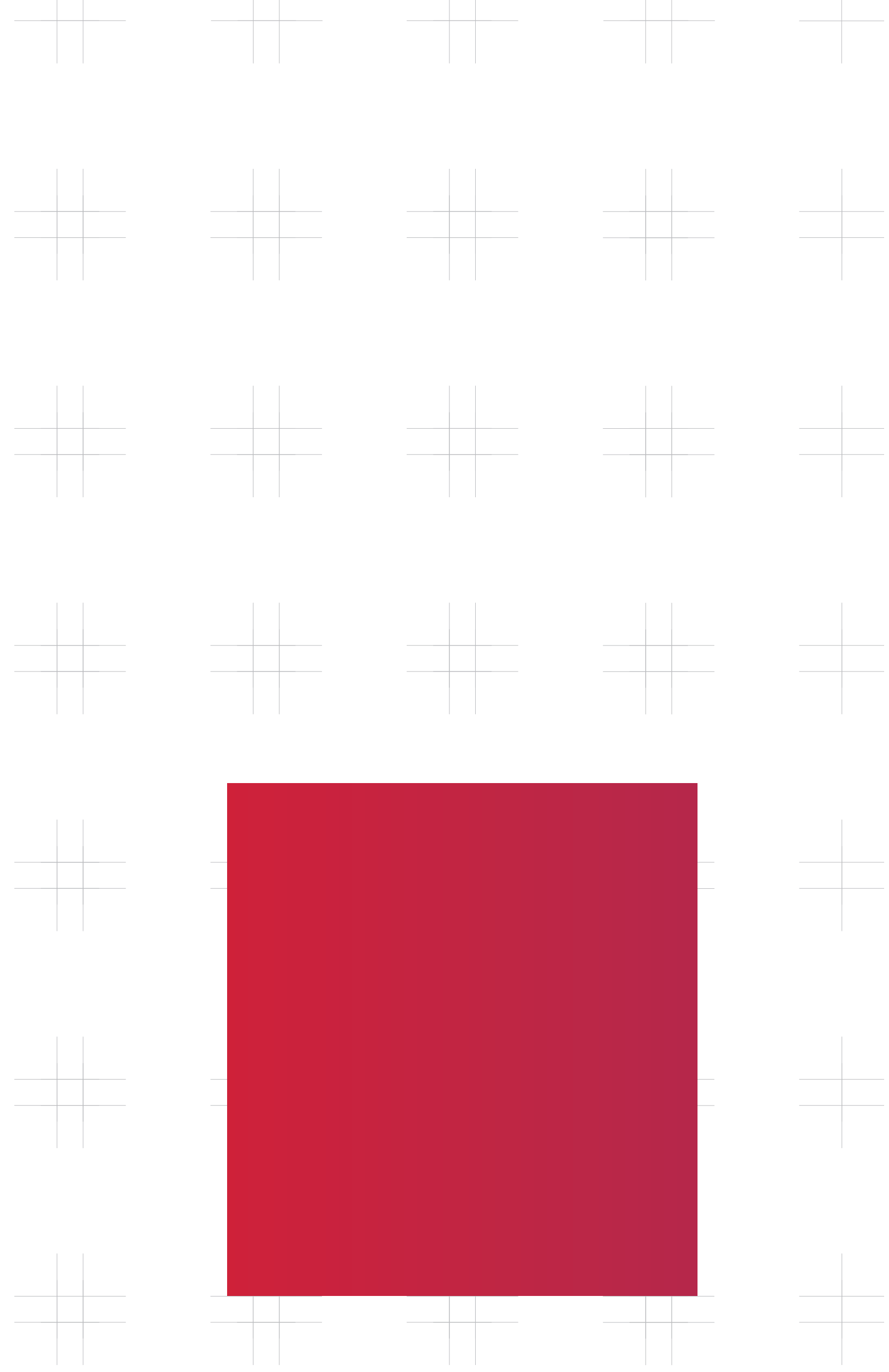

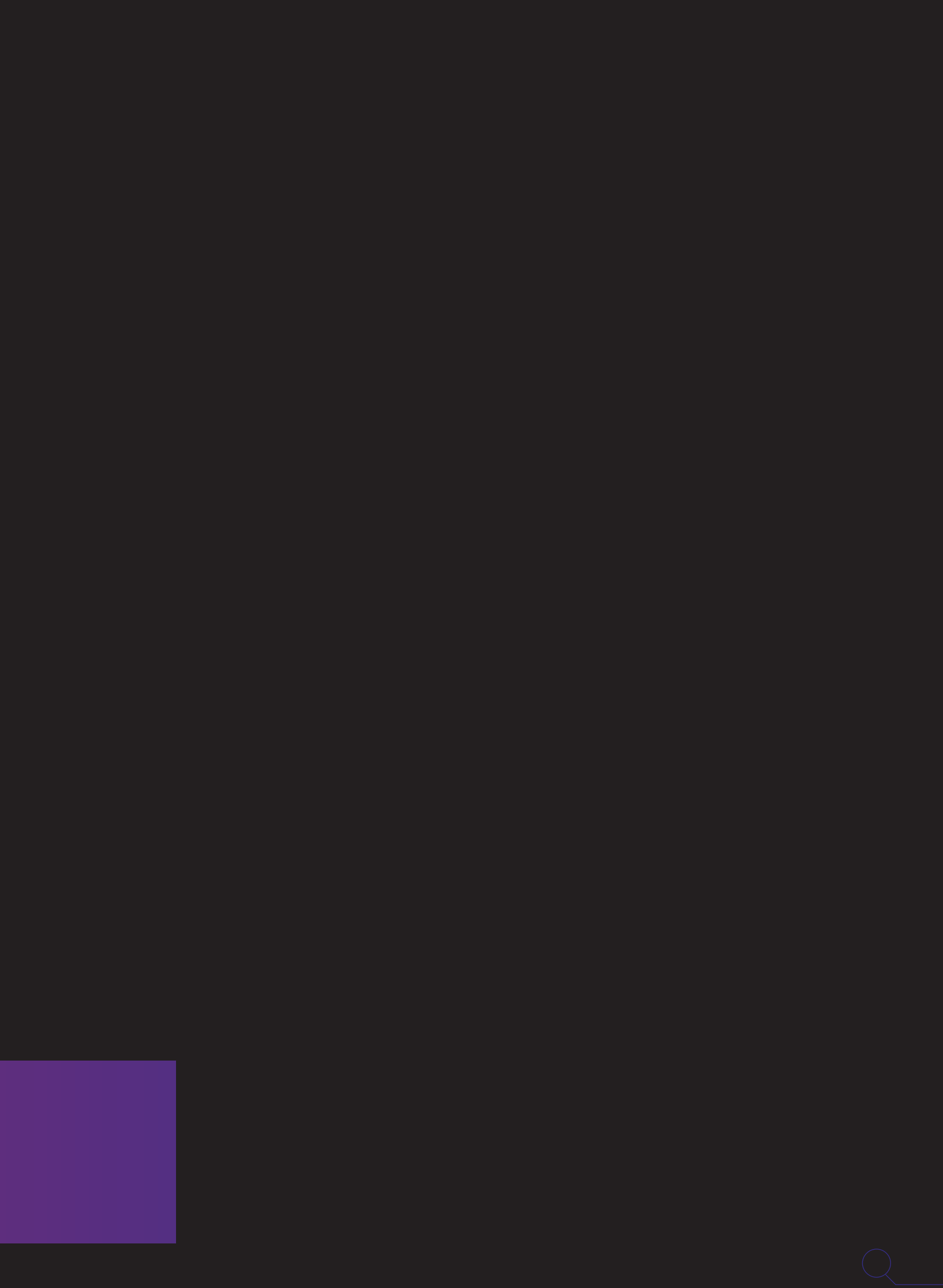
Data collected about my daily life comes from a range of categories. Because of the year long duration and unpredictable outcome of this research I have adopted the attitude of commercial big data users who "collect everything they can incase they might later be able to extract information that could be useful" (Neef, 2014). Data that I have been able to collect passively about myself includes:

- Steps Taken

- Time I begin sleeping

- Time I wake up

- Time I am in light sleep

- Time I am in deep sleep

- Location by general area (i.e suburb)

- Weather and temperature of my location

- Elevation above sea level

- Local Noise Level

- Latitude/Longitude

- GPS location tracking at all times

- Transport methods used

Actively I have collected some additional data sets that were either of interest or that I felt may have useful synergies with the other data I had available. Actively collected data required me to fill in a form, at random times throughout the day. The random timing ensures that with enough data points the results represent a

$\overline{\text { Figure_9 }}$

Visualisation experiment using Microsft Excel to manipulate personal Fitbit data showing time spent being transported and step count for work and leisure days. $\downarrow$ 
statistically relevant dataset about myself at any given point in the day. The time and date is recorded allowing data to be referenced against specific times or dates. Actively collected data includes:

- Exact places visited (i.e café names)

- How happy I am

- What shoes, pants, shirts, sweatshirts and coats I wore that day

- If I am working

- Who I am with

- If I am in front of a screen

- Noise level of my daily commute to and from university

- Another set of data I never intended to collect was photograph metadata which is recorded with every photo I took. 


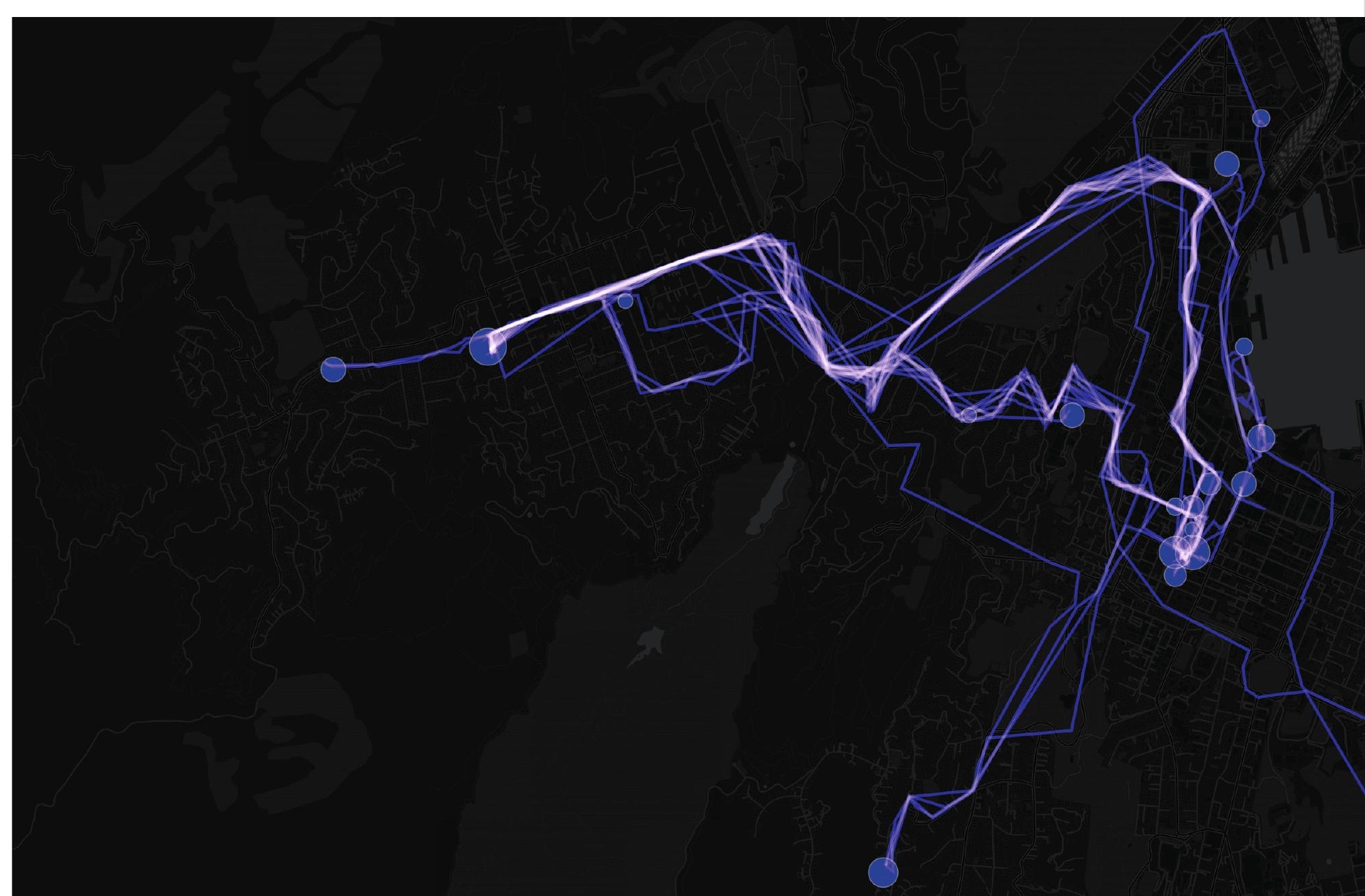

\section{$\overline{\text { Figure_10 }}$}

Design experiment using CartoCSS scripting to map 15 days of movement

recorded in Moves App for my supervisor, Marc Aurel Schnabel, demonstrating

the ability for personality to show through even small sets of data. $\uparrow$ 


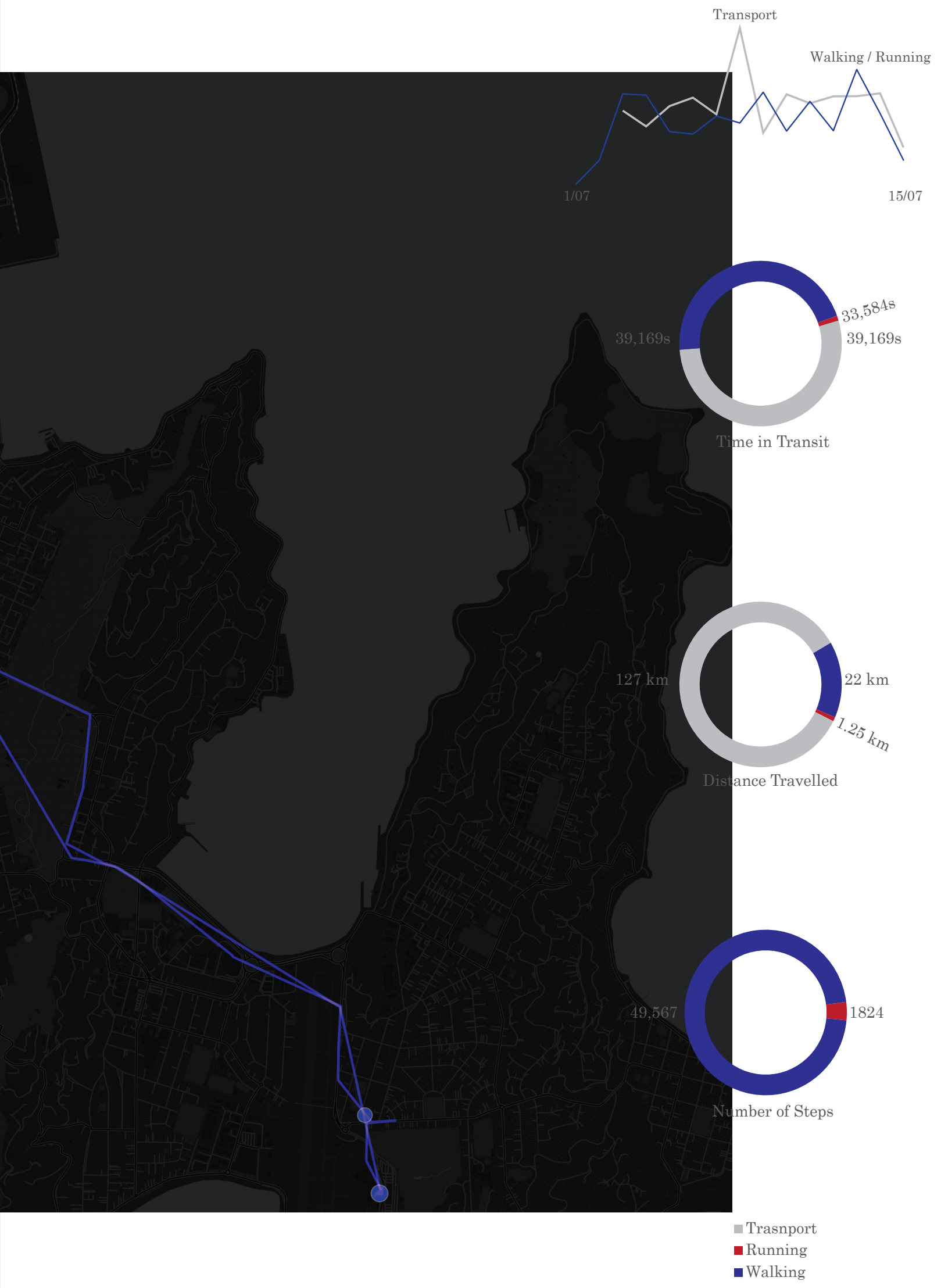




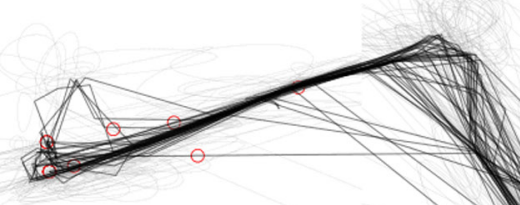




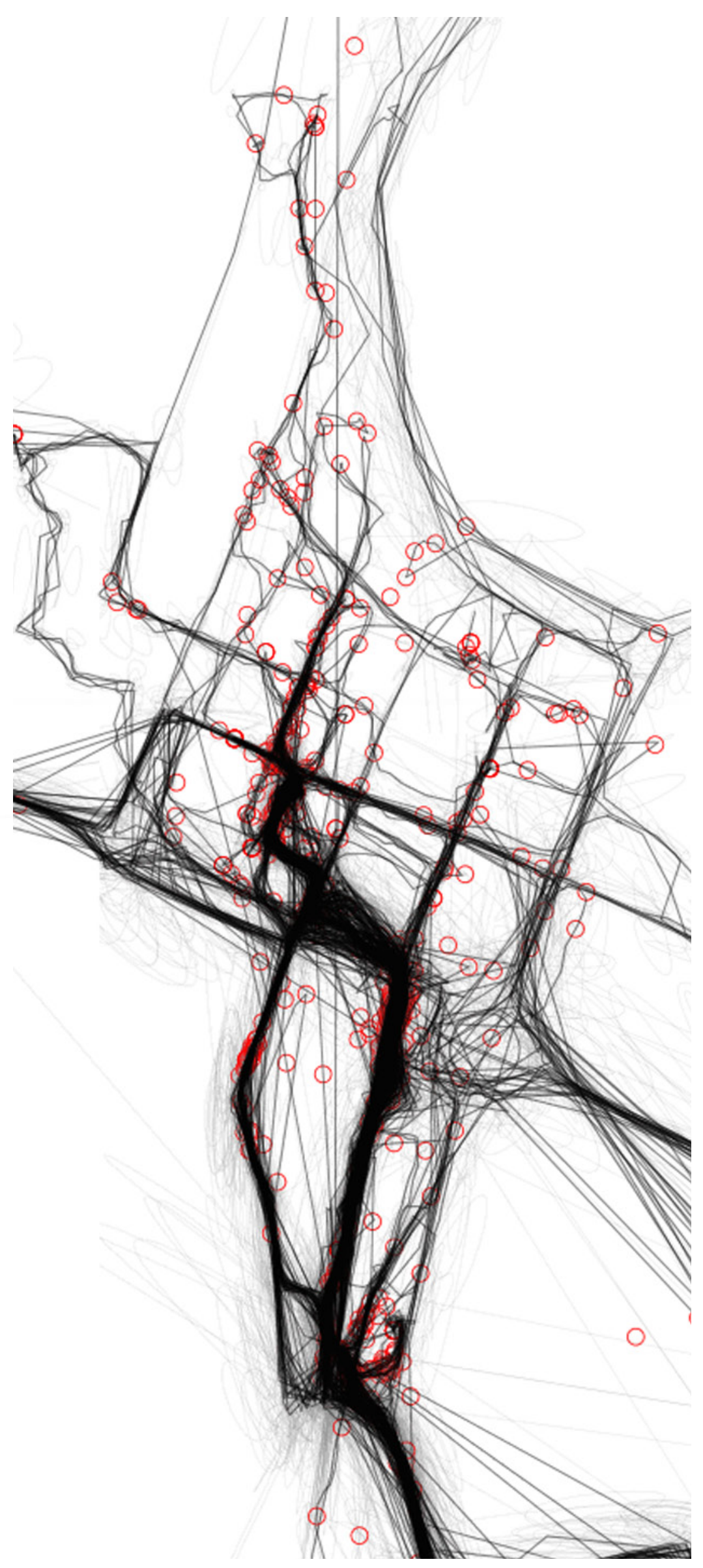

$\overline{\text { Figure_11 }}$

Design research depicting movement around

Wellington via GPS tracking for 178 Days

(123 Weekdays + 55 Weekend Days). Lines are movement with GPS errors left in, red points are places I have paused or stopped. $\leftarrow \uparrow$

$\overline{\text { Video_1 }}$

Animated GPS Tracking based on Time and Date 
Gathering data for architecture is about finding differences. This is different to most fields that use big data - generally removing outliers and finding averages allows for informed decisions that are not so precise as to remove the applicableness of the outputs. Architecture deals with individuality however, and it is these outliers and differing data points that are most interesting. To provide a unique experience that aligns with a digital identity we first need to know what aspects of this identity are different and require focus.

To start looking at differences in data and develop an idea of how a digital identity might take shape an experiment was done by applying sentiment analysis to randomly generated public Facebook profiles. This "sentiment analysis intends to comprehend these [Facebook profiles] and distribute them into the categories like positive, negative, neutral" (Kumar and Sebastian, 2012). To group text into these categories, each word is checked against a dictionary - in this case the AFINN-111 from Finn Årup Nielsen (2011). In this dictionary each word has a value between -5 (negative) and 5 (positive). By averaging the values of words used a positivity value for each person was found. These Facebook profiles, representing a simple digital identity, and by extension the people behind these digital identities were grouped on two axes, the overall positivity or negativity of the profile and the 'confidence' based on how many words the algorithm understood.

\section{$\overline{\text { Figure_12 }}$}

Sentiment data design experiment based on randomly sourced public Facebook profiles and graphed through the use of a sentiment analysis algorithm using recursive C\# scripting loops. $\rightarrow$ 



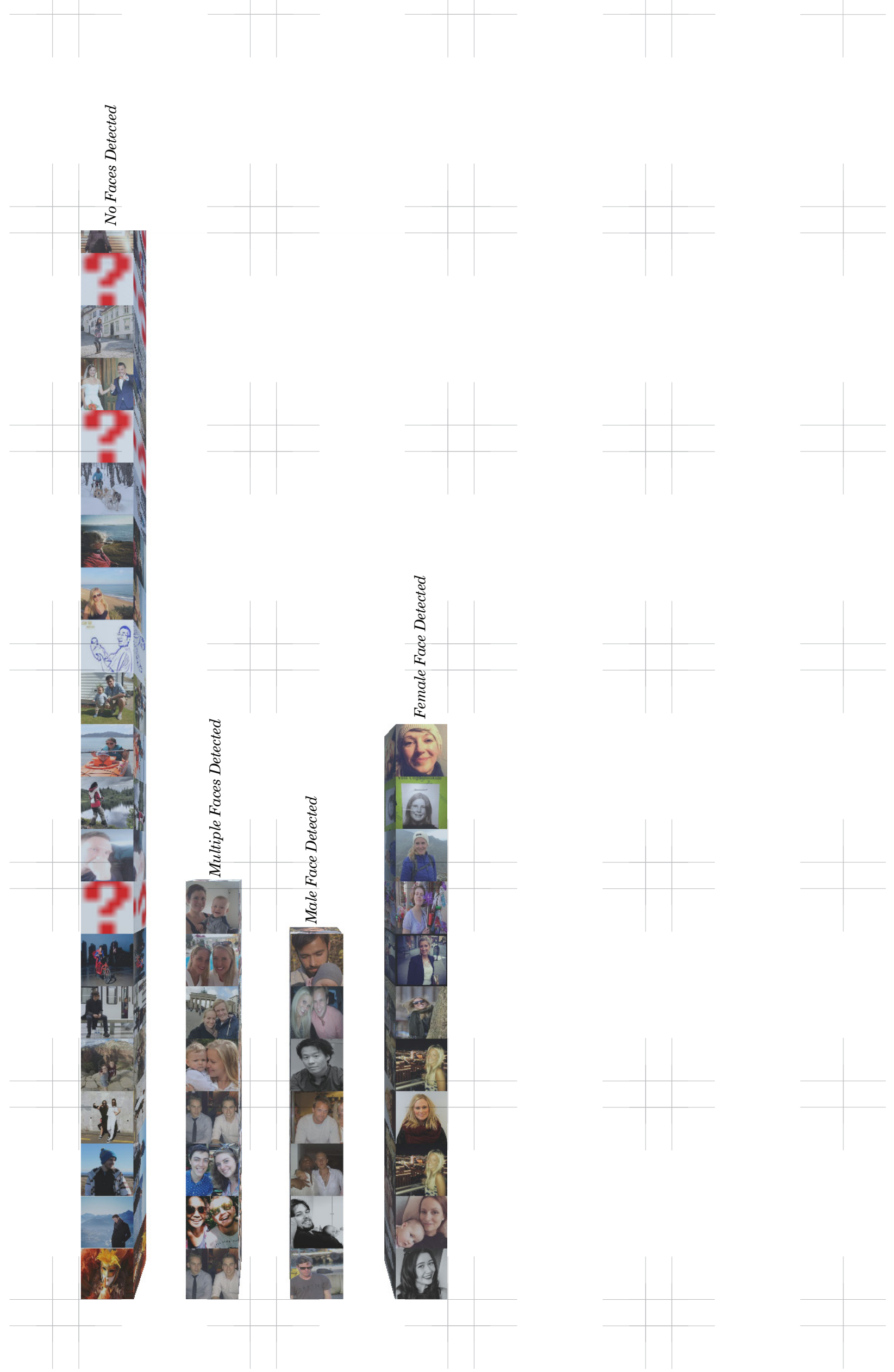


Gathering data from text was a useful starting point, however data can be collected in many formats. Social media often focuses on imagery making it an important consideration when gathering social media data. Converting the unstructured data of pixels into structured data can again be done with a motive. For example we may want to know the gender of a series of people on Facebook - to do this profile photos can be analysed. A script was developed that prepared the photos before using a tool called Face from Microsoft's Cognitive Services suite to automatically identify faces and estimate their age, gender and 'smile value'. Tools like these provide endless possibilities for non-specialists to gather and structure data.

There are weaknesses to this automated method of gathering datasets. Architects typically assess and tweak throughout the design process, however, the automated nature of gathering data removes this ability from this stage. There are many inherent limitations to how data is collected and manipulated; using the earlier example of sentiment analysis we can see that the simplicity of the tool could lead to inaccurate results. The profile photo example has similar inaccuracies when guessing ages and not being able to recognize faces in some scenarios. Limitations in tools is not new to architectural processes, although when any process is automated these limitations have more potential to go unnoticed than in conventional tools.

\footnotetext{
$\overline{\text { Figure_13 }}$

Experiment grouping randomly generated Facebook profile pictures by gender using $\mathrm{C \#}$ script and Microsoft Face API calls. $\leftarrow$
} 

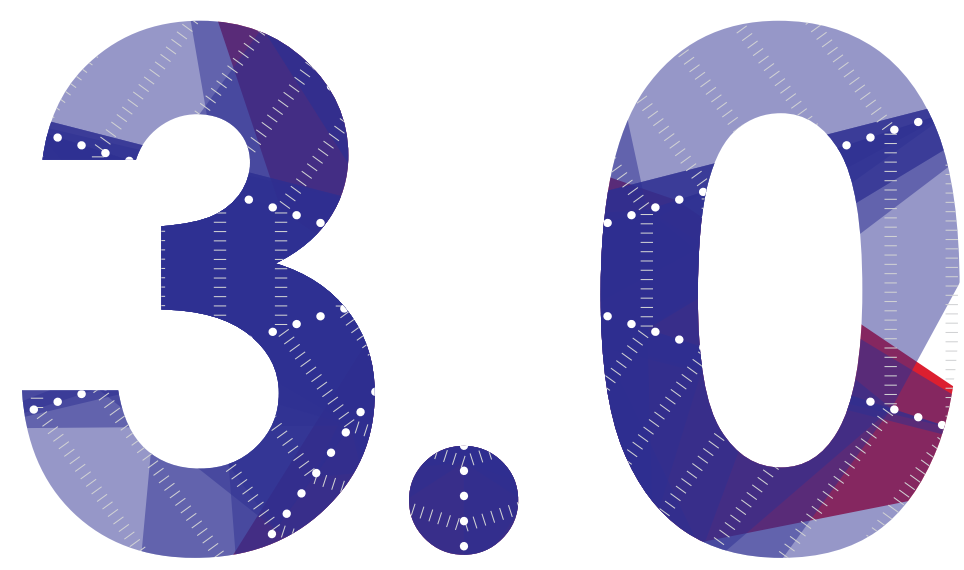

LITERATURE REVIEW 
Ambient displays: Turning architectural space into an interface between people and

digital information

Craig Wisneski, Hiroshi Ishii, Andrew Dahley,

Matt Gorbet, Scott Brave, Brygg Ullmer, Paul

Y
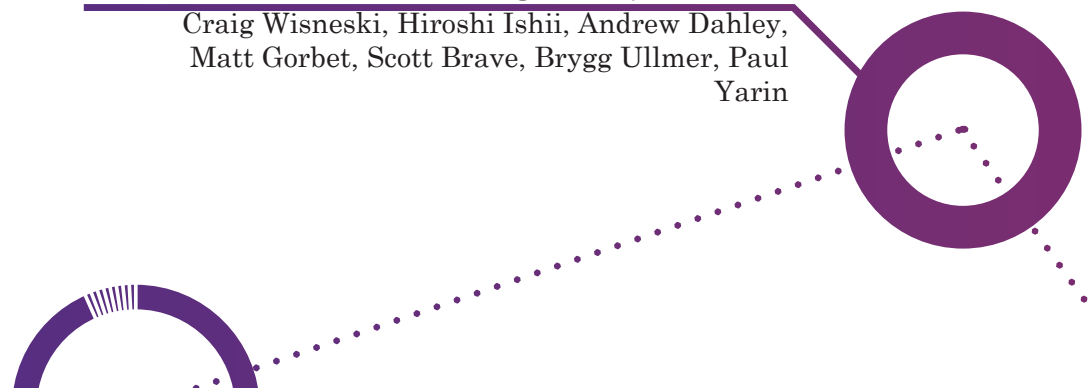

Life On Screen: Identity
in the Age of the Internet

in the Age of the Internet

A taxonomy for and analysis $\because$.
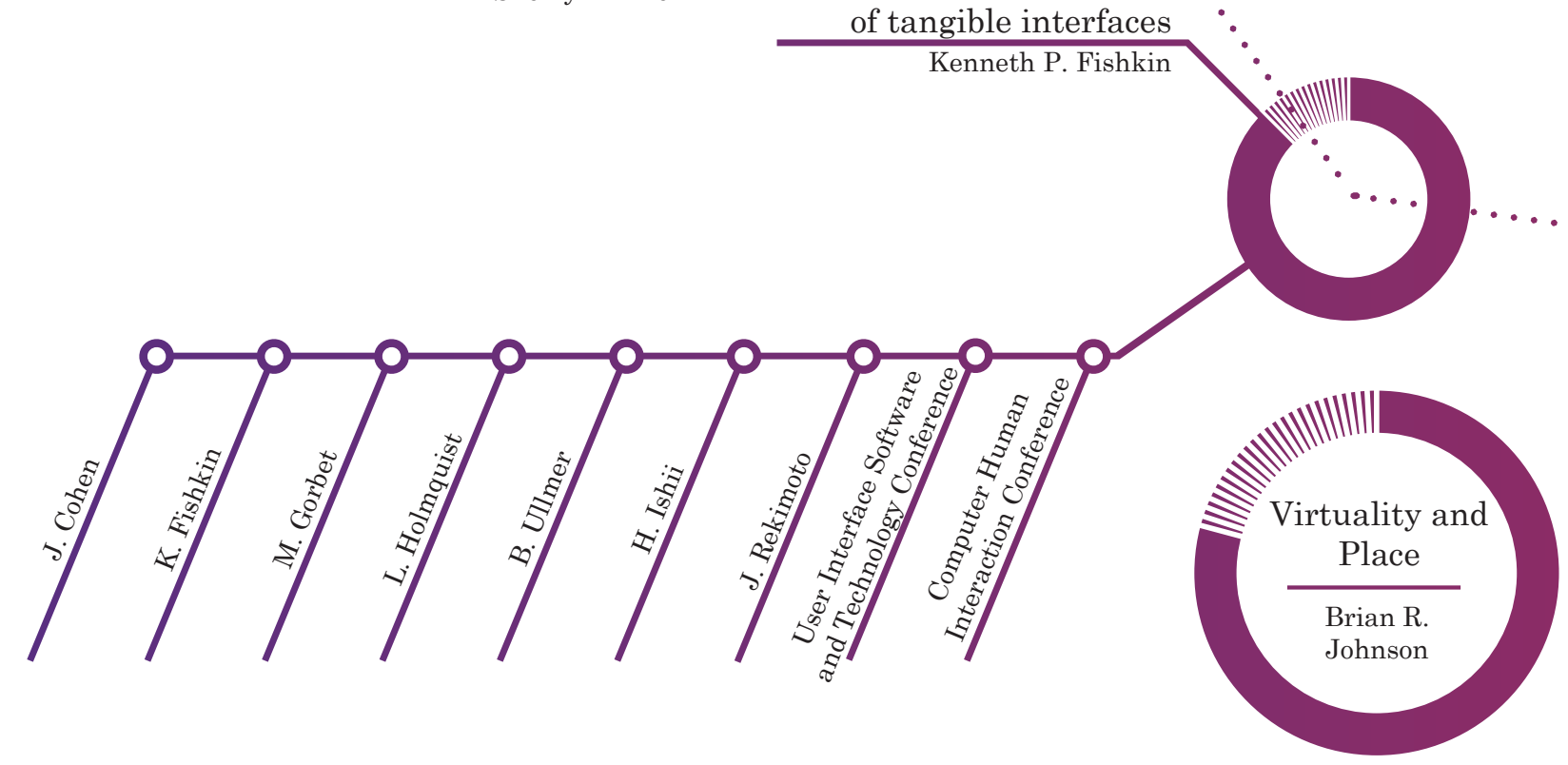

Anthropic Cyberspace: Defining

Electronic Space from First Principles

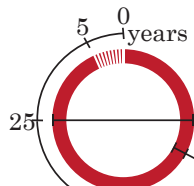

Circle Diameter: Importance of text to field Border Thickness: Importance of text to thesis Border Notches: Future Timeframe considered Key not applied to Datatecture Node
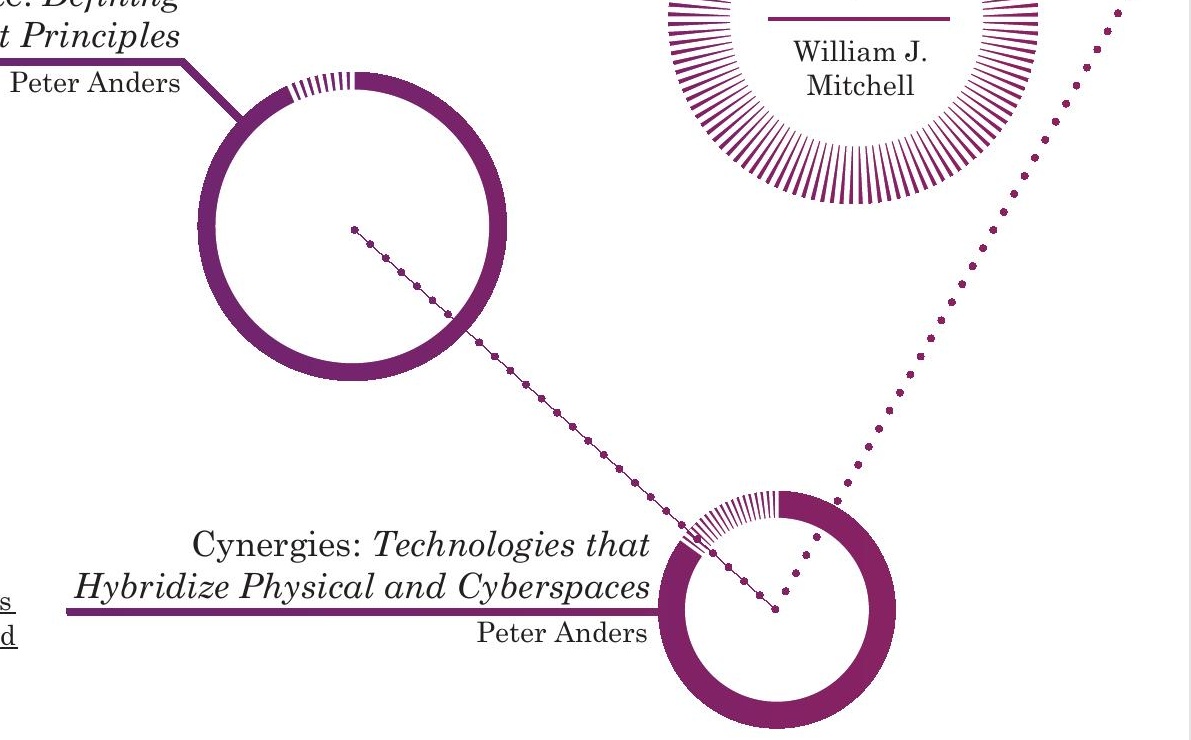
This research lies at the intersection of fields such as big data, social intelligence, dynamic architecture and data visualization. Because of the broad nature of the fields from which this research draws, this literature review only includes sources that consider at least two of three topics: data gathering, using data three dimensionally and architecture. Overall this research sits between the large scale of big data and the small scale of personal interaction. Supplementary concepts are those of dynamic and reactive architecture through the use of programmable buildings, which has been drawn from research on ambient data usage and nano-architecture.

Sherry Turkle's Life On Screen: Identity in the Age of the Internet (1995) is a useful publication that contains interviews with scientists of the time, showing how divided they are between embracing and shunning digital tools, with one physicist even labelling computer simulations the "enemy". The interviews, despite being outdated, draw close similarities with current architecture practice. Many architects are wary of digital tools, similar to the physicist saying he prefers subject matter that he can "touch, smell, bite into" (Turkle, 1995). In architecture the argument is made that digital design processes are only useful as a complement to conventional workflows, with an assertiveness similar to the physicist's - less than ten years after Life on Screen was published, however, the ability to use digital tools in physics is "part of the essential repertoire" (Gould et al., 2005).

If we accept digital processes will evolve to become central to architecture, the question is what will they be? This research

\footnotetext{
$\overline{\text { Figure_14 }}$

Experimental visual overview of literature reviewed and key research areas and connections discovered. Based on data collection shown in Appendix $1.0 \curvearrowleft$

Figure_15

Key comparisons of areas that have been thoroughly covered and areas that have less of a focus in the literature studied. Based on data shown in Appendix $1.0 \rightarrow$
} 
focuses on the potential for data to become part of this future toolset. There are three predominant related research areas: Collective and Social Intelligence, Physical Data and the Supplementation of Conventional Architecture. Some key research aspects that were considered when reviewing the texts are shown in figure 15 , layering the results of each text to show overall trends. Each text reviewed was rated from one to ten on how much weight it gave to ten key aspects to better understand the complex context of this research.

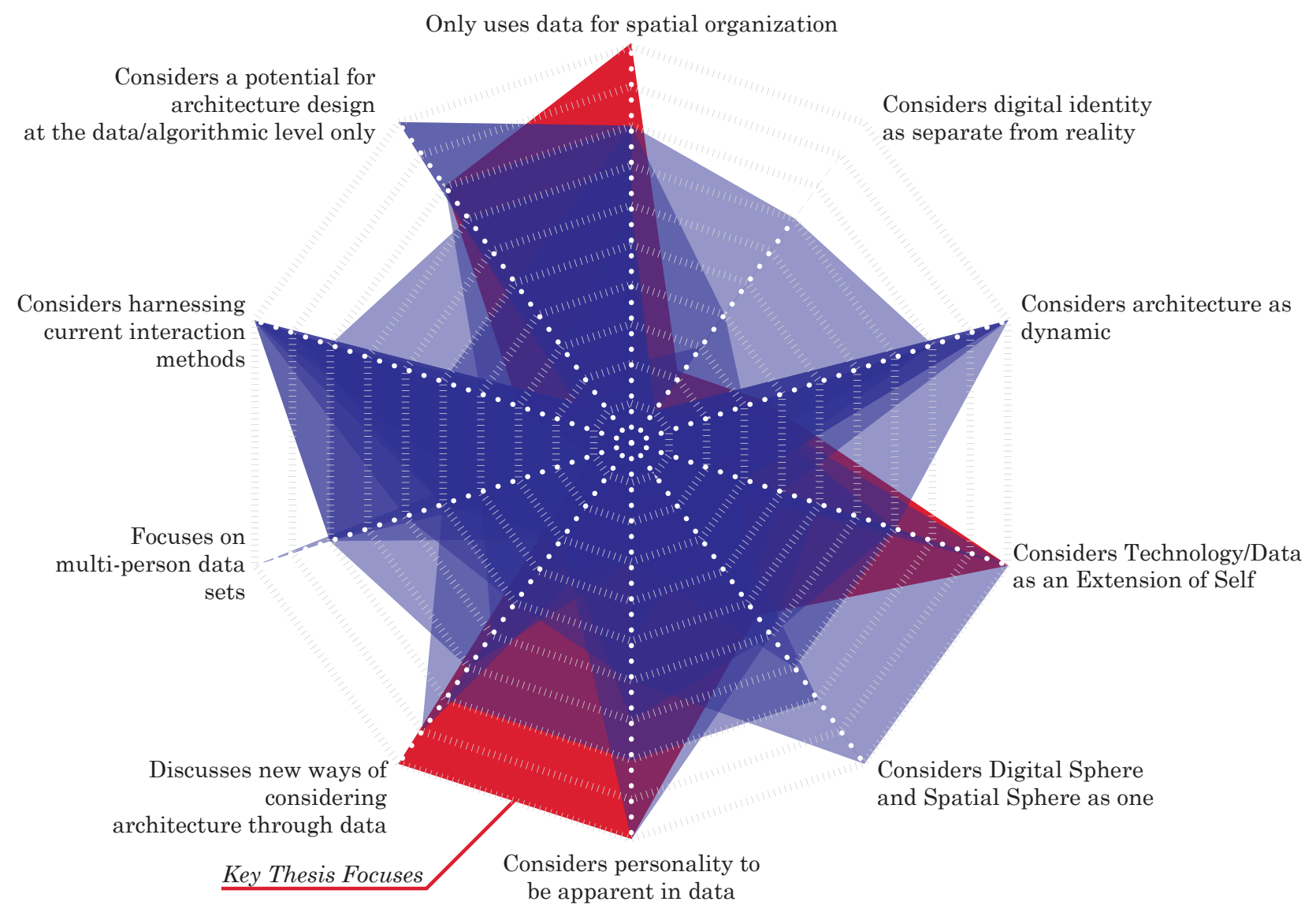




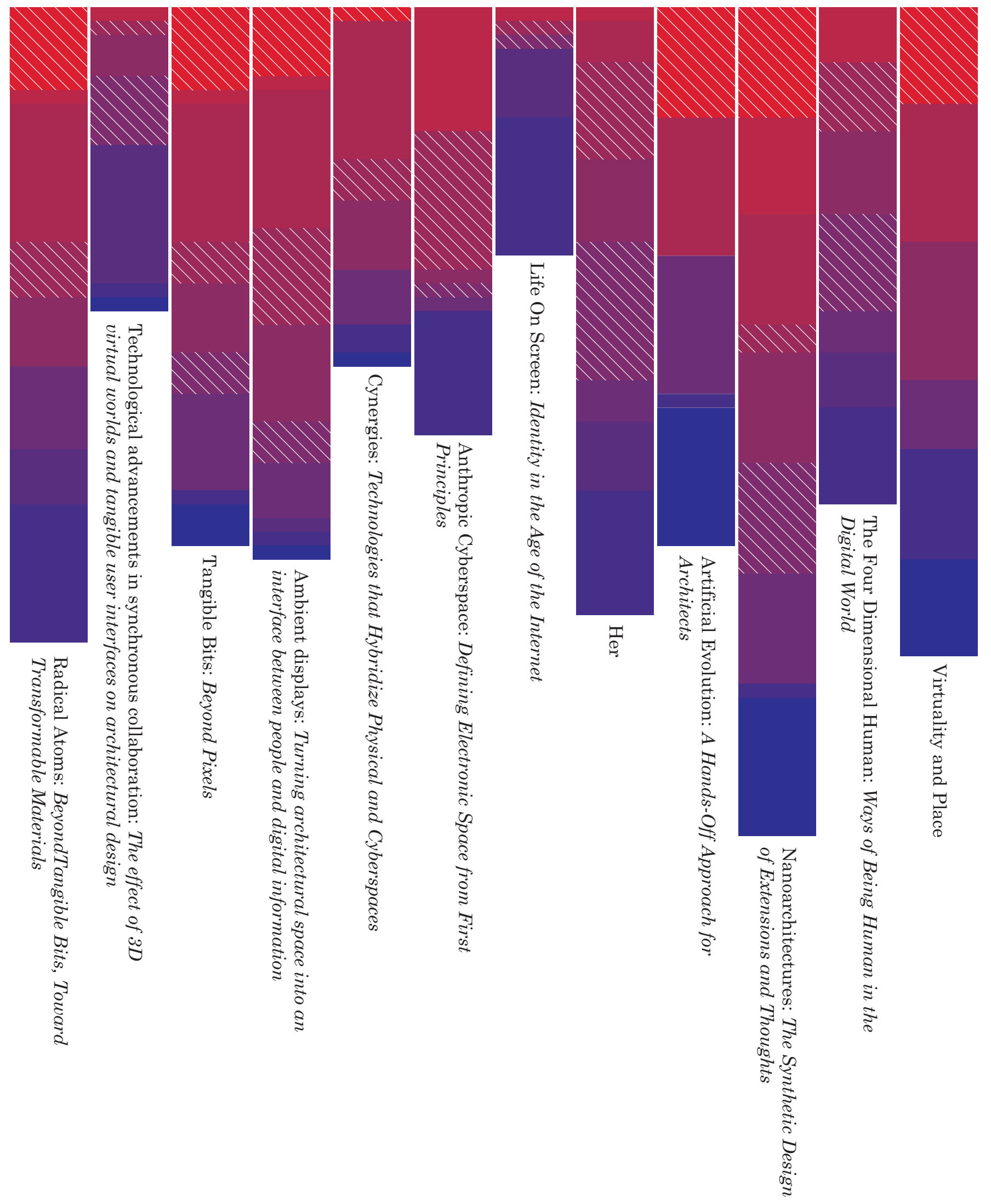




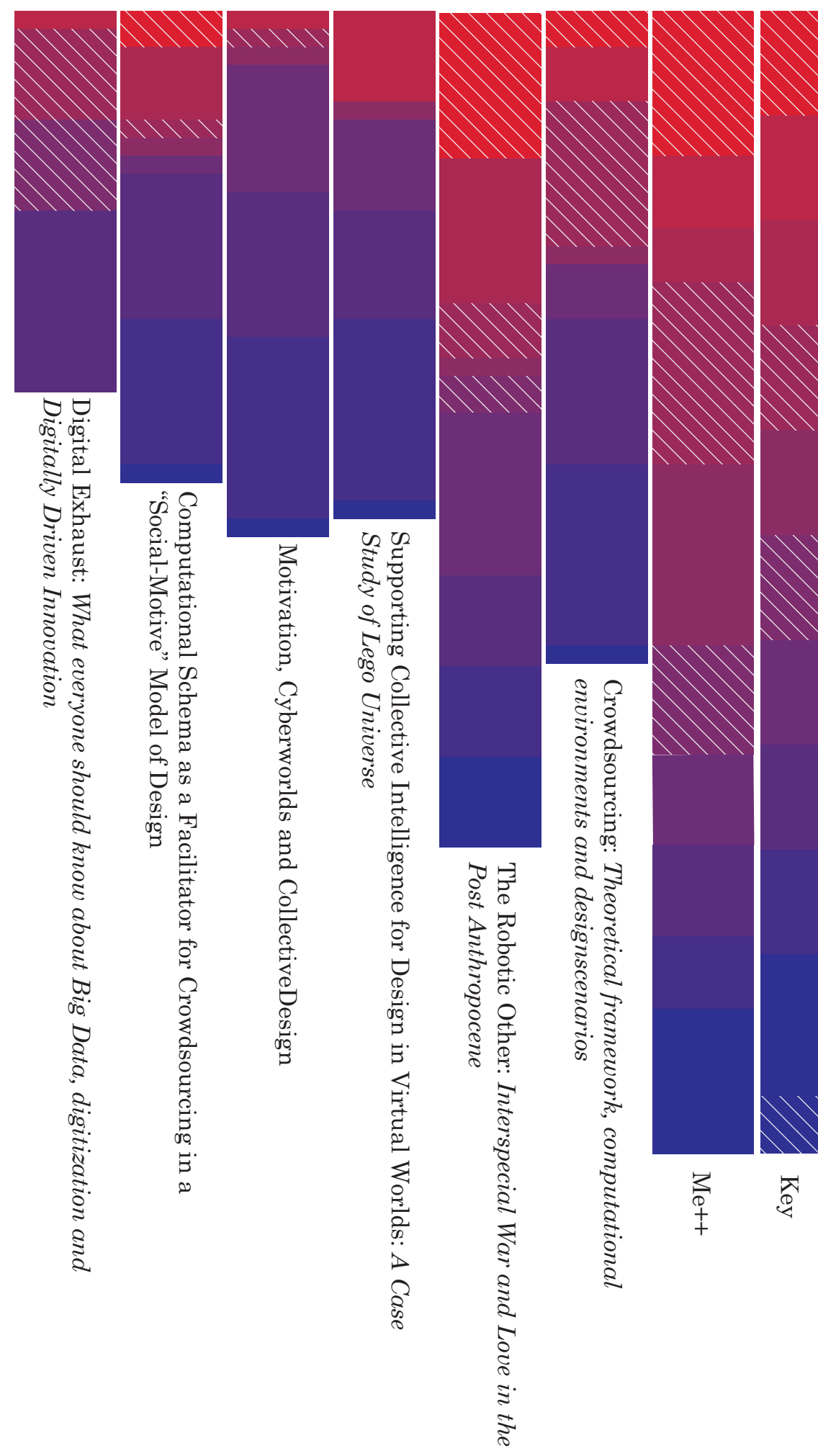

Focuses on using data for spatial organization

Considers digital identity as separate from traditional identity

Considers architecture as dynamic

Considers technology or data as an extension of self

Considers digital sphere and spatial sphere as one

Considers personality to be apparent in data

Discusses new architectures through data use

Focuses on multi-person data sets

Considers harnessing interaction via current technology methods

Considers a potential for architecture design at the data/algorithmic level only

Key Thesis Considerations

Figure_16

Focuses of key texts studied with regard to key focuses of thesis. Based on data collection shown in Appendix $1.0 \uparrow$ 


\subsection{COLLECTIVE AND SOCIAL INTELLIGENCE}

Collective and social intelligence exists at multiple scales. Digitally it ranges from collaborative design to the big data phenomenon which is currently coming to the fore (Neef, 2014). At the smaller scale collective intelligence resembles conventional architecture practice in which a small group digitally collaborates, it is can be useful for digital design processes due to cost, speed and efficiency (Merrick and Gu, 2011, Merrick et al., 2011, Gu et al., 2011, Oxman, 2015, Oxman and $\mathrm{Gu}, 2012$ ). Often in digital collaboration people are simplified into data and become points in space or notes of text, etc. At this scale each participant retains a noteable input into the final product and the resulting solution has elements that are directly attributable to each participant. Social media plays less of a role at this scale although Motivation, Cyberworlds and Collective Design discusses social media platforms as a precedent for developing collaborative tools (Merrick et al., 2011). At the other end of the scale big data uses the collective intelligence of many individuals who each make small contributions. This digital process is common to industries such as economics and operations research (Manyika et al., 2011). This is a process which architectural design has yet to embrace, within the architectural sphere industrial engineers and research analysts are the only notable users of big data (Manyika et al., 2011). A potential weakness of big data in architectural design processes is that it minimizes individuality and personality is often considered the crux of good architecture (Stamps, 2013).

Ham and Schnabel argue that collective intelligence in architectural design allows anyone to contribute to a design process through 
crowdsourcing even if each design process is individual (2012). This is especially true in big data environments where many contribute to these processes. As Paulini et al. state, developing successful collective design starts by understanding how individual and collaborative design are supported within digital processes and then go beyond collaborative design by increasing the value of the final design (2011). By harnessing digital networks of people, the ability to connect ideas and information increases beyond that of a conventional setting. It also differs from a conventional problem-based design process due to the difference in how the problem is framed (Schnabel and Howe, 2012). Big data not only frames the problem differently, but also engages designers through social knowledge, resulting in a collective social intelligence that can inform architectural design processes (Kvan and Gao, 2004). 

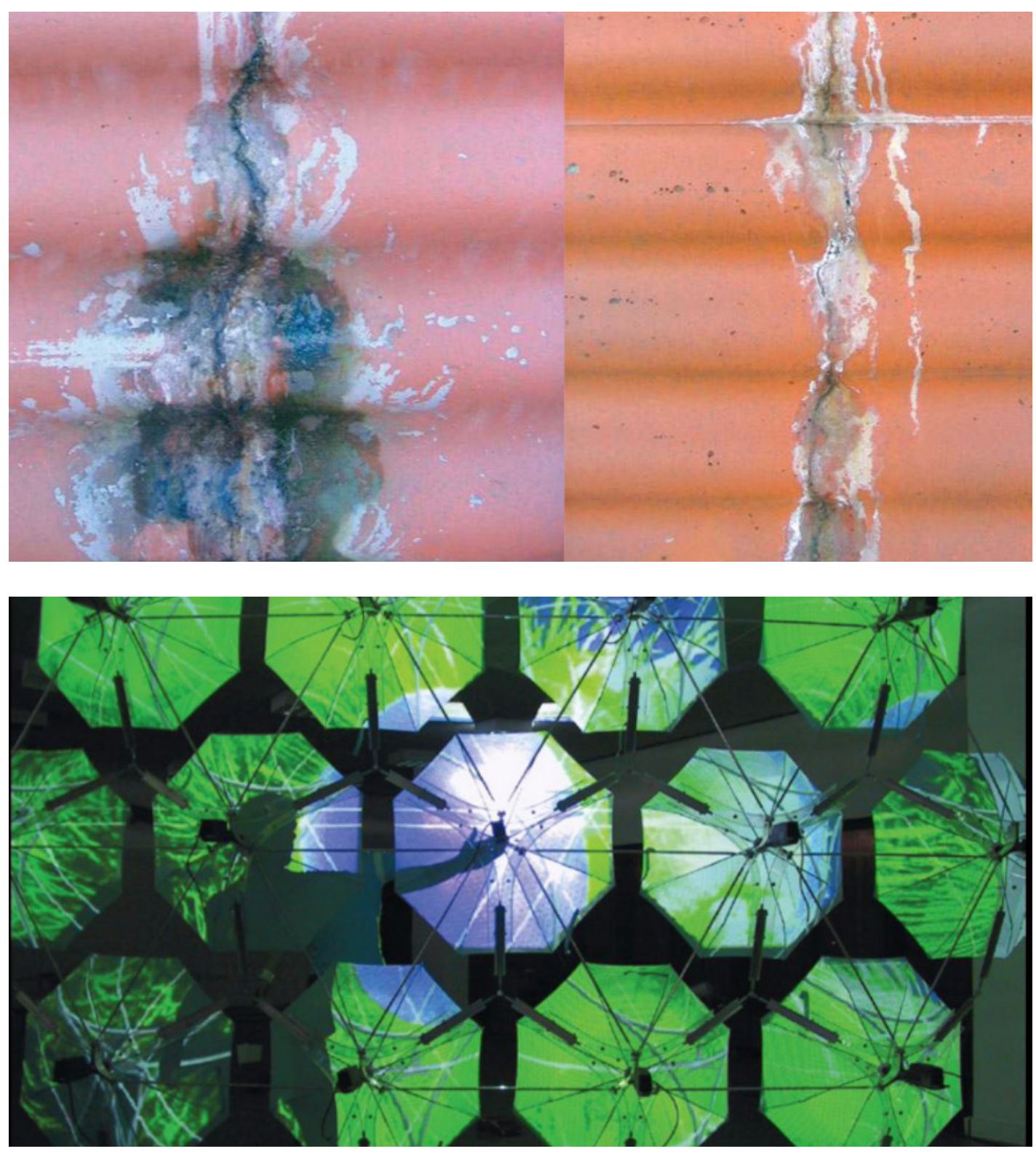


\subsection{PHYSICAL DATA}

Physical data is a small, theoretical area of research within architecture. At its heart lies the concept of micro-programming such as changing atoms through the shuffling of electrons to create different material properties material (Armstrong, 2008, Parisi, 2012). By programming data directly into physical materials, structures could be built from the data itself, allowing architecture to be "responsive to its surroundings and adjust according to the demands and needs of its inhabitants" (Armstrong, 2008). It is worth noting that although this use of data may sound fantastical it has grounds in reality, best shown through bacteria-infused concrete with self-healing properties being developed at Delft University (Schlangen et al., 2010).

Physical data research is a useful method of bridging the gap between data (likely in algorithmic form) and architectural application. The implications of this for architectural design processes may not be realised for some time, however, the concept of responsive architecture has been applied with current technology - such as 'Project WideShut' which reacts to changing light that is projected onto it (Rieger, 2008).

$\overline{\text { Figure_17 }}$

Self-healing concrete tests by HM Jonkers of TU

Delft in 2007. $\nwarrow$

$\overline{\text { Figure_18 }}$

Detail of Project WideShut Installation, by Uwe

Riger, Helle Schroeder, Martin Janekovic, 2008. 
Ripples on the roof indicate movement in the hallway

Light projections communicate the number of people in the atrium

Phycon (physical-icon) represents the lab's hamster by vibrating to indicate

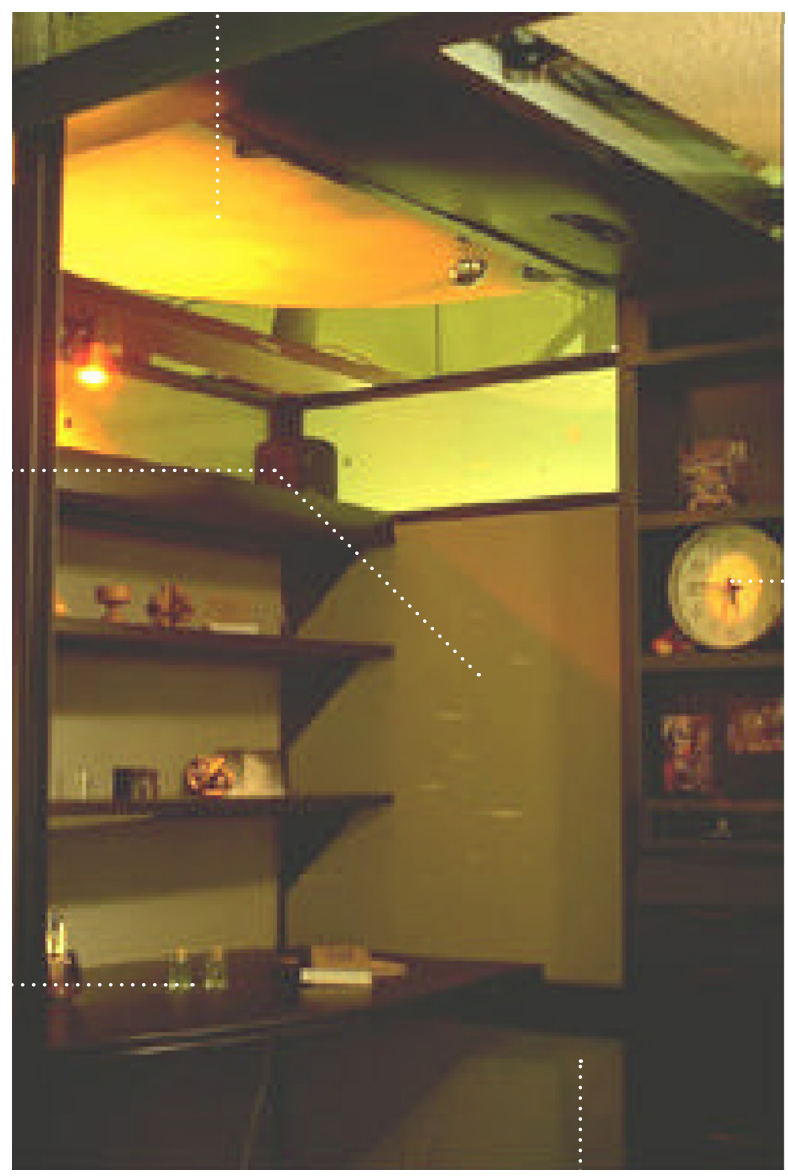

Clock acts as a tangible interface and can transition the time of the simulated sunlight

Ambient weather sounds communicate the number of unread emails 


\subsection{SUPPLEMENTATION OF CONVENTIONAL ARCHITECTURE}

Supplementing conventional, non-responsive architecture with data was the initial movement towards integrating architecture with data and has become a common typology with data being used particularly in green building initiatives. Early experimental data usage in buildings can be attributed to the MIT Tangible Media Group's ambient room; this was a subtle introduction of simple data, such as whether it was raining outside, into a small test space through a range of methods such as projection, movement and sound (Wisneski et al., 1998). A great deal of work was done in this area in the early 2000's resulting in a myriad of 'tangible interfaces' between data and people via architecture (Fishkin, 2004).

The impact of this research on the architectural design process is primarily in the additional design opportunities it provides. Architecture can be seen as a hybrid of shelter and operating system with the ability to be programmed and responsive. The data interaction is also important in this area of research and is in contrast to the weaknesses of the big data phenomenon which appears to divorce data and people (Ishii, 2008).

$\overline{\text { Figure_19 }}$

MIT Media Lab Ambient Room project introduces data visualisation to architecture in a way that it occurs subtly around the user. $\leftarrow$ 

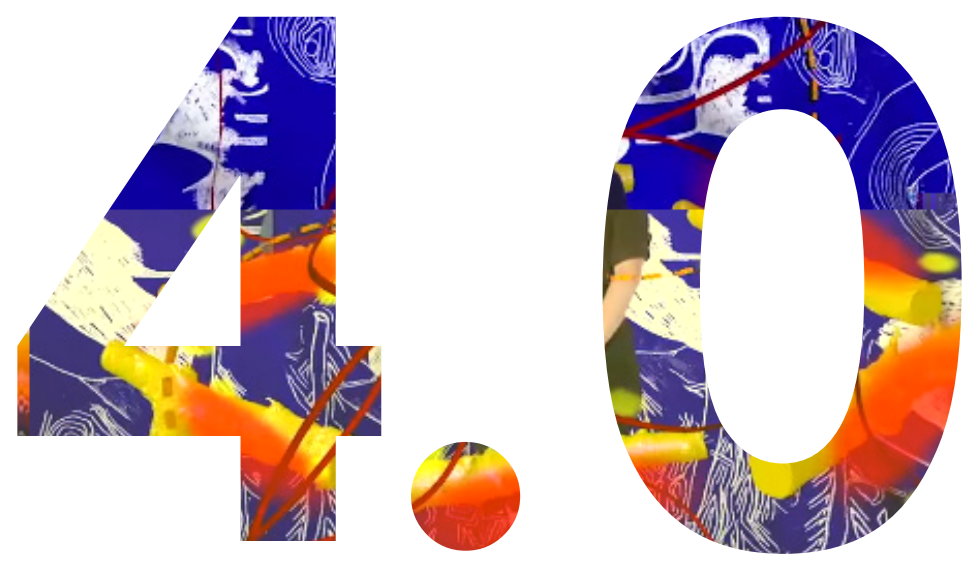

PROJECT REVIEW 


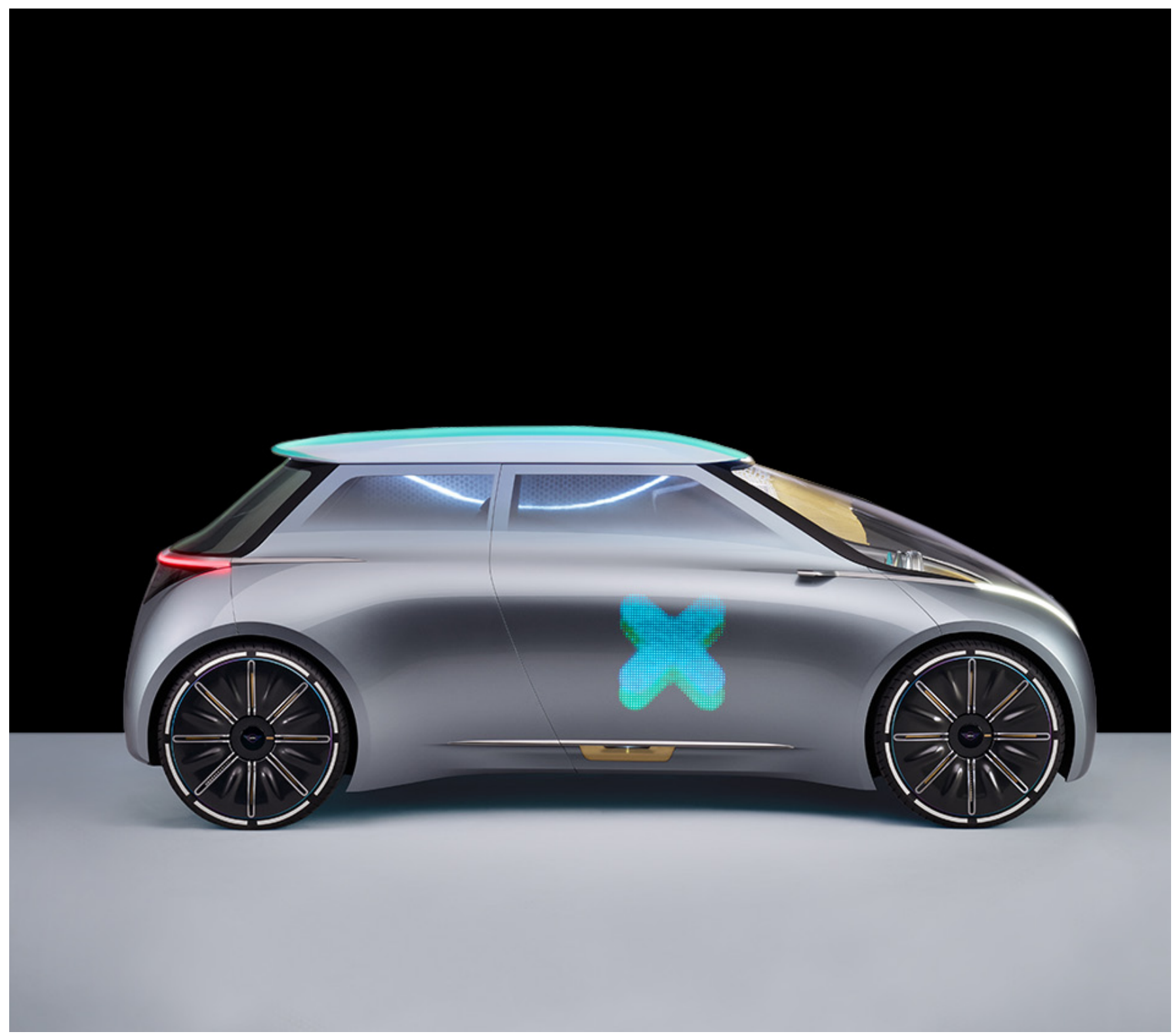

$\overline{\text { Figure_20 }}$

MINI Vision Next 100 concept car using data to

maintain personalization despite shared ownership.

$\uparrow$ 
Currently the integration of architecture and data is considered largely from a Building Information Modelling perspective and as a tool to prove the additional value architects can bring to a project. It is well accepted that it can help "reduce risk", "provide certainty and confidence" and "make better decisions" (Deutsch, 2015). It is seldom discussed as a tool for adding personalisation to architecture however. Concepts of data and identity have been explored more thoroughly in fields outside architecture, from correlating smart-phone data and personality traits (Chittaranjan et al., 2013) to identifying people by typing speed (Joyce and Gupta, 1990). Examples that correlate with the built environment are rare, however some interesting examples do exist.

\subsection{MINI VISION NEXT 100}

The MINI Vision Next 100 program was devised by MINI to predict the direction of their car design over the next 100 years. The resulting concept car tackles some similar issues to those posed by this thesis. The design was released under the heading "digitally mine" and has at its heart the ability to detect inhabitant identity and customise visual aspects of the design to reflect them (MINI Next 100, 2016).

The design considers the provision of customization as key in a future where a self-driving car typology means vehicles are shared rather than individually owned. There are parallels with these ownership issues in contemporary architecture with apartment buildings that are inhabited by non-owners and have no architectural personalisation. It is proposed this will become of increasing importance in the future as architecture is increasingly shared due to current inefficiencies in space use and residential shortages. 

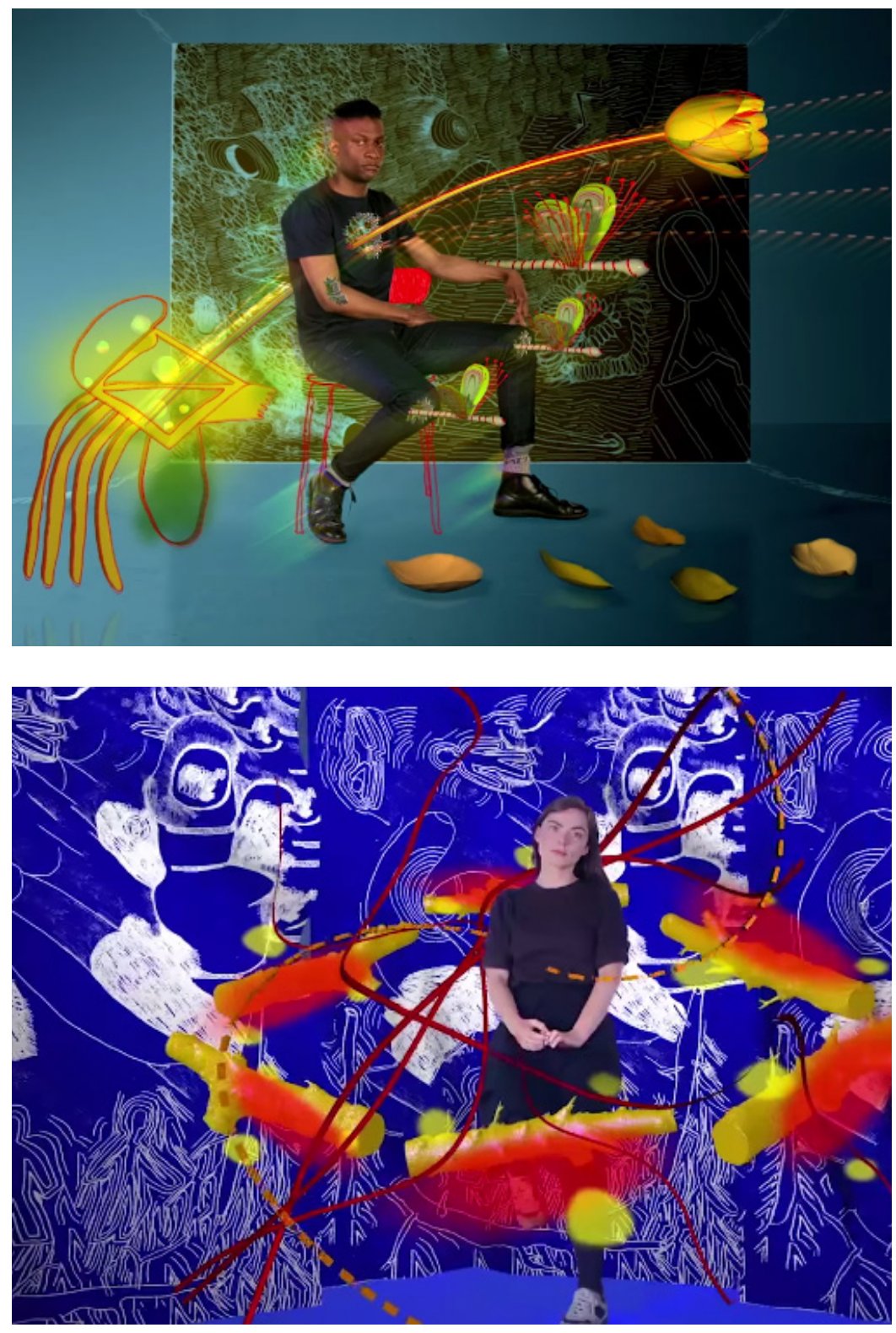

$\overline{\text { Figure_21 } a, b}$

Work for MINI Vision Next 100 by Margot Bowman,

collage portraits of people overlaid with visual

representations of their data. $\uparrow \uparrow$ 
While the concept contains useful parallels with the aims of this thesis, the process is less robust than required. One key aspect is the translation of data into visual or formal personalisation. MINI collaborated with Margot Bowman, a "digital data artist" and the process she used is more artisanal than this thesis requires - she has created a series of "data-inspired portraits" by looking at data about people and manually layering her understanding of it onto portrait photographs as shown in figure 21 (MINI Next 100, 2016). From these portraits MINI pulled personality cues and visual ideas to be projected onto the car's interior and exterior. While interesting this process is common in conventional architecturethe architects extract what they consider relevant from the client and create a customized architectural outcome. Where this process fails is the expense and exclusivity of the architect, for this to be available to a wider user-base more automation is required.

66In a future where a single MINI can be shared amongst everyone, a new generation of technology enables the car to always look and feel like your own. Parts of the exterior surfaces transform to suit your personal preferences and beam a personalised greeting as you approach it. ${ }^{\text {'9 }}$

- Mini Next 100 


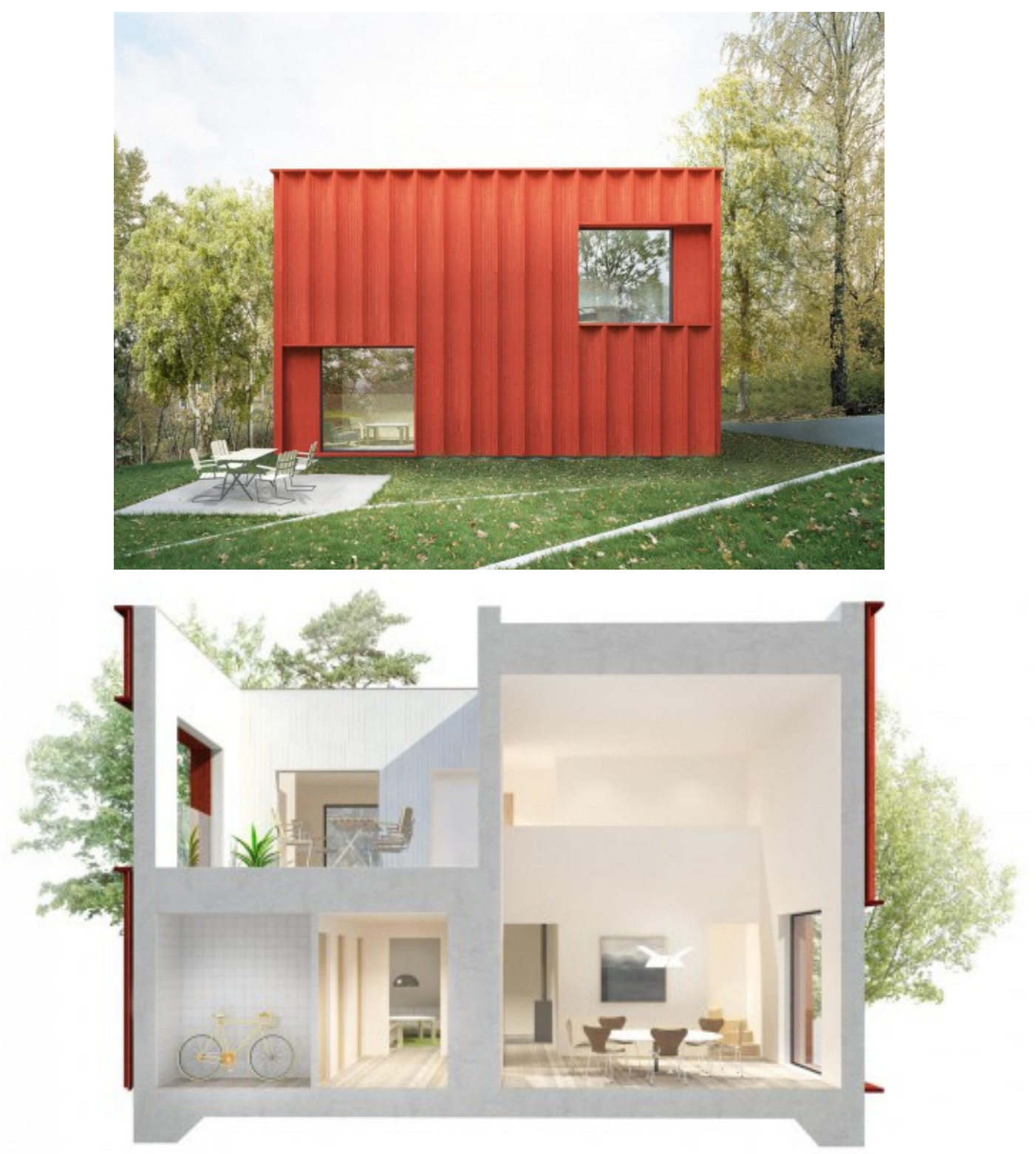

$\overline{\text { Figure_22 } a, b}$

Hemnet Home by Tham \& Videgård Arkitekter is

based on data gathered from Hemnet, Swedens most

popular property site. $\uparrow \uparrow$ 


\subsection{HEMNET HOME}

The Hemnet Home is a project completed by Tham \& Videgård Arkitekten in 2015. The Hemnet Home is an example of data being translated into built architecture - in this case the data came from "200 million clicks on Hemnet", Sweden's most popular property website (Tham \& Videgård Arkitekter, 2015). By averaging the most viewed properties they have extrapolated the 'ideal' floor sizes, number of rooms and so on. More interestingly they have also noted some data on taste, for example: the most popular wall colour is white and most popular sofa colour is grey. This is essentially the beginning of a digital identity for a country rather than an individual. The weakness of this design is the lack of personalisation; the resulting house is effectively an average of people's needs and tastes in architecture reducing the personalisation of the outcome. There is always the risk that averaging data to simplify the results will remove the personality the data showcased originally. 

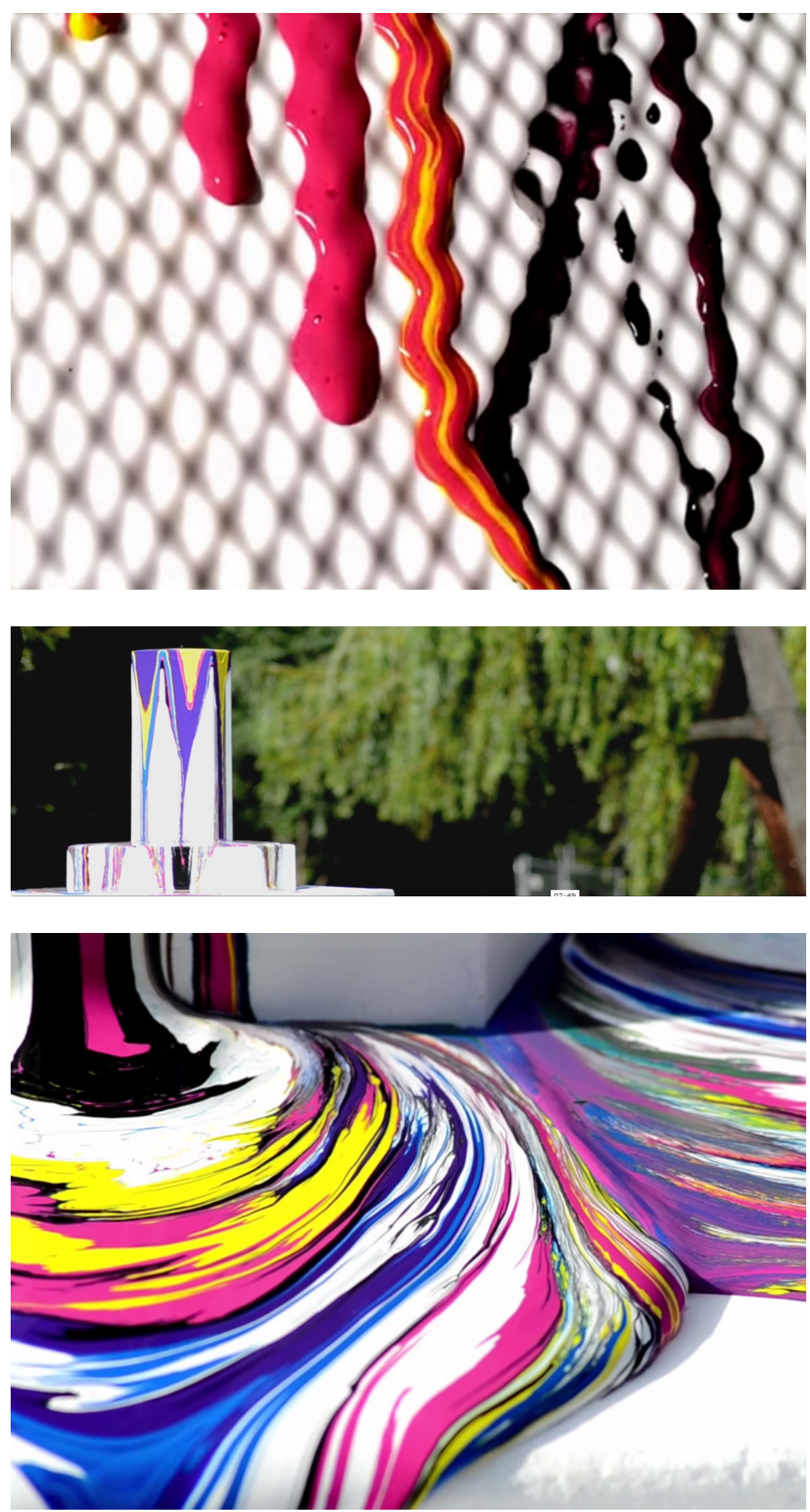

$\overline{\text { Figure_23 } a, b, c}$

MONOLITT is a sculpture by Syver Lauritzsen that

oozes paint to reflect moods expressed by people

on twitter, black for instance represents anger or

annoyance. $\uparrow$ 


\subsection{MONOLITT}

MONOLITT is an interactive art project combining social media and digital identity with physical artwork by Syver Lauritzsen. This typology is becoming increasingly common in art and design fields as small computing devices such as the Rasberry Pi and Arduino make it increasingly easy for non-specialists to convert social media prompts into real world actions as exemplified by MONOLITT. The sculpture pushes a drop of paint out through the canvas at the top of the geometry in response to tweets on Twitter. The colour of the paint is determined by a sentiment analysis and runs down the sides of the sculpture, creating a flow of layered colours cataloguing the emotions expressed in recent tweets. This is digital identity being transferred into three dimensions and architectural elements at its most basic. While an architectural element, colour has limitations in what it can portray and eliminates the ability for a digital identity to be displayed in a way that acknowledges individualism - every tweet that is angry is black for example meaning no individual can be differentiated in the colours flowing over the sculpture. This lack of individuality is unproblematic in an art piece that is created to be enjoyed by a many people as opposed to personalised architecture which should reflect individuals. 

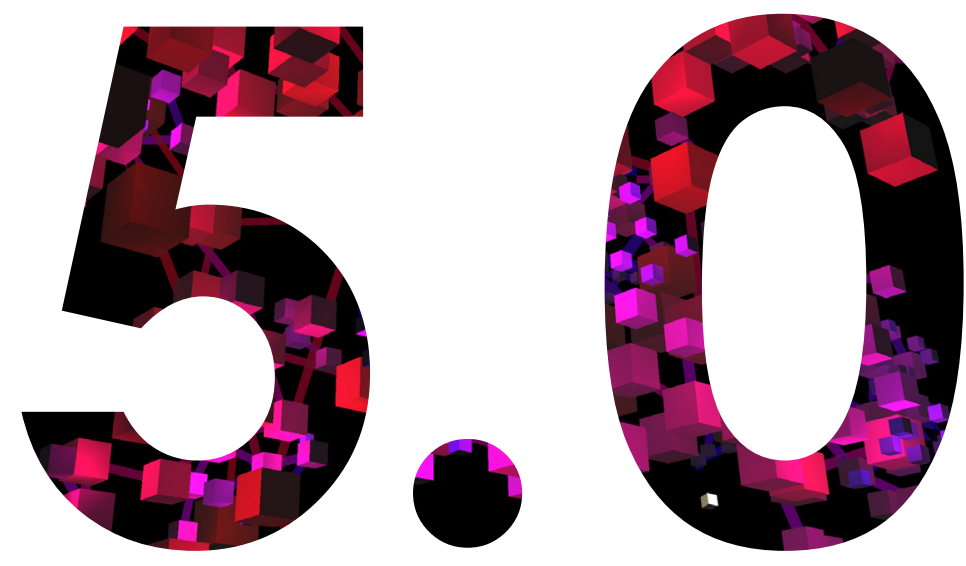

PRELIMINARY ARCHITECTURAL EXPERIMENTS 
Transferring datasets into architecture can be done in a multitude of ways. These experiments are the crux of this thesis and require a balance between authorship of the work and proving the ability for data to produce automated results. This automation must be tempered with authorship and demonstrate the ability for the designer to choreograph the results. To ensure these results are sufficiently architectural each focus on an architectural element; these elements are spatial organisation, site, atmosphere, interaction and ownership, forms and aesthetics and materiality. The act of designing and experimenting is completely interrelated with the overarching goals of this thesis and so these experiments morph to align with an increasingly robust understanding of digital identity, changing with each additional experiment (Darke, 1979).

\section{$\overline{\text { Figure_24 }}$}

Design experiment using moving nodes to represent and react to data, acting as a three dimensional

display. Using Unity physics engine and C\# scripting. $\rightarrow$ 


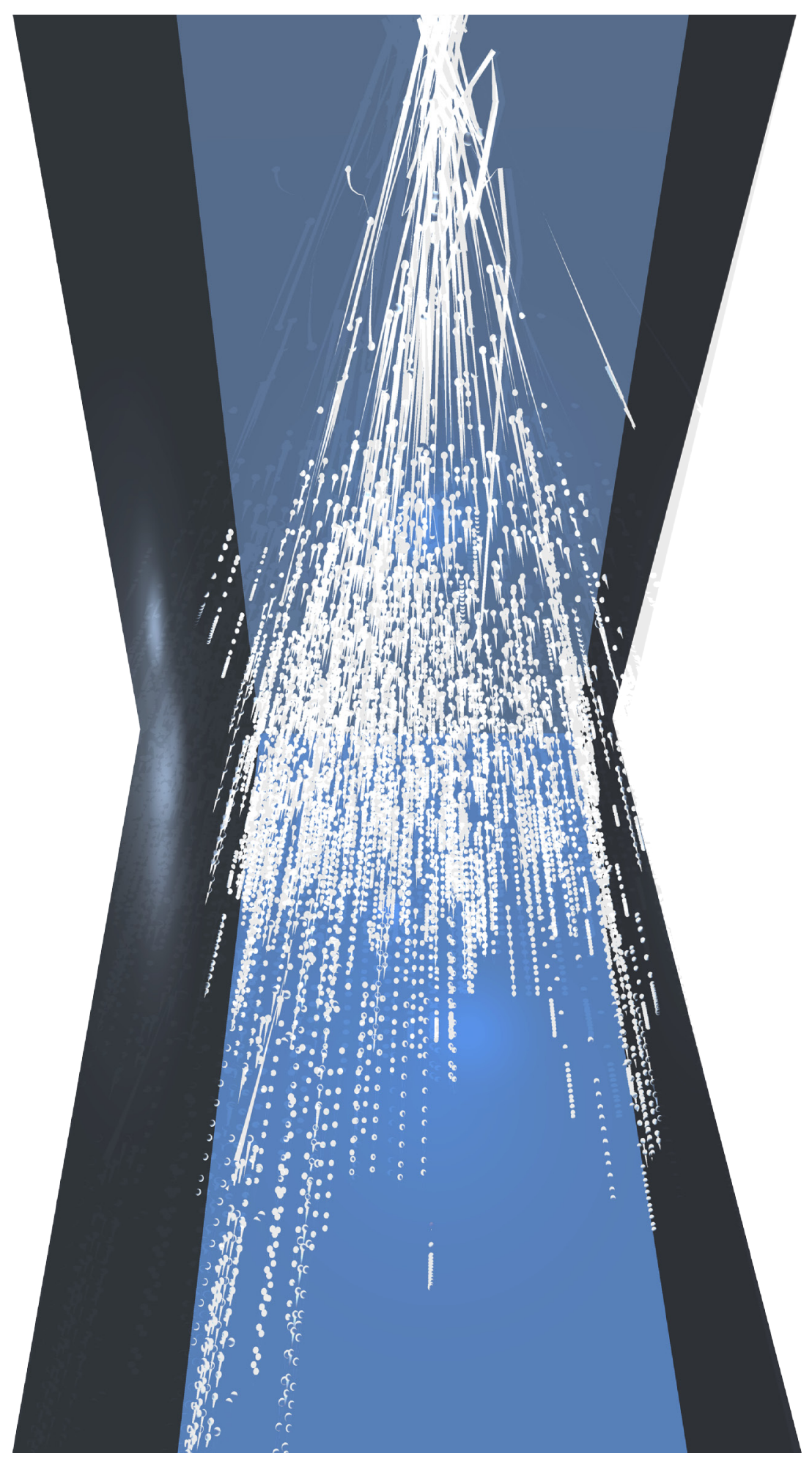




\subsection{DATA + SPACE ORGANIZATION}

The initial investigations into provoking digital identity to react to space involved practical tests for accessing and utilising data. This initial test involved a mock-up of a room within which glowing spheres represent and harness data. Shown in figure 25 a number of spheres is instantiated based on the number of events in my calendar.

The following test, shown in figure 26 , devised a visual countdown by determining the next event, time and location and projecting them onto a wall. A countdown until this event began was created and visualized by moving the glowing spheres into a line that rises up the wall.

The third test, shown in figure 27, extracted data from the Student Architecture Network New Zealand Facebook page by taking the latest post (updating in real time) and projecting this onto a wall. The post was visualized by creating patterns based on the GUID, a unique identifier given to all Facebook posts.

$\overline{\text { Video_2 }}$

Initial Investigations into organising points to present and reflect data. 

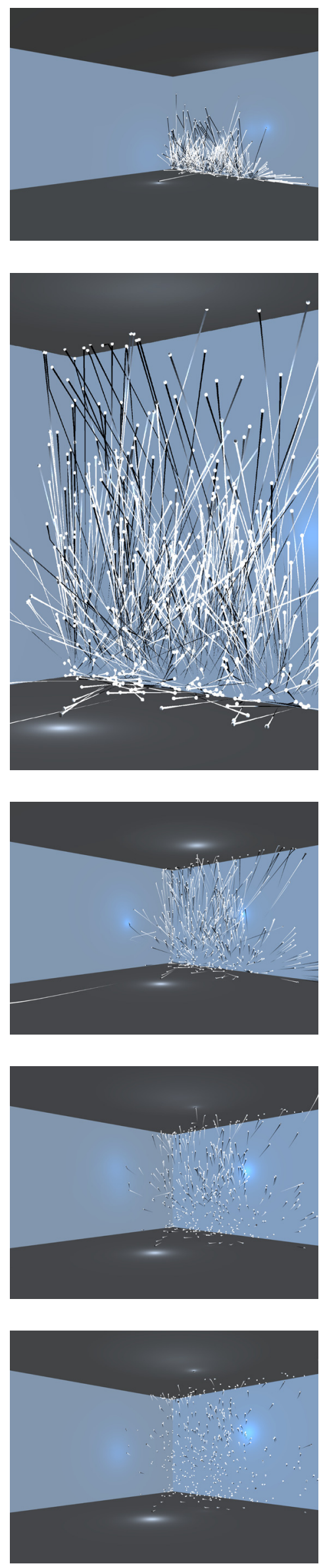

\section{Figure_25}

Nodes spreading out prior to creating a formation due to Javascript based repulsion forces. $\uparrow$
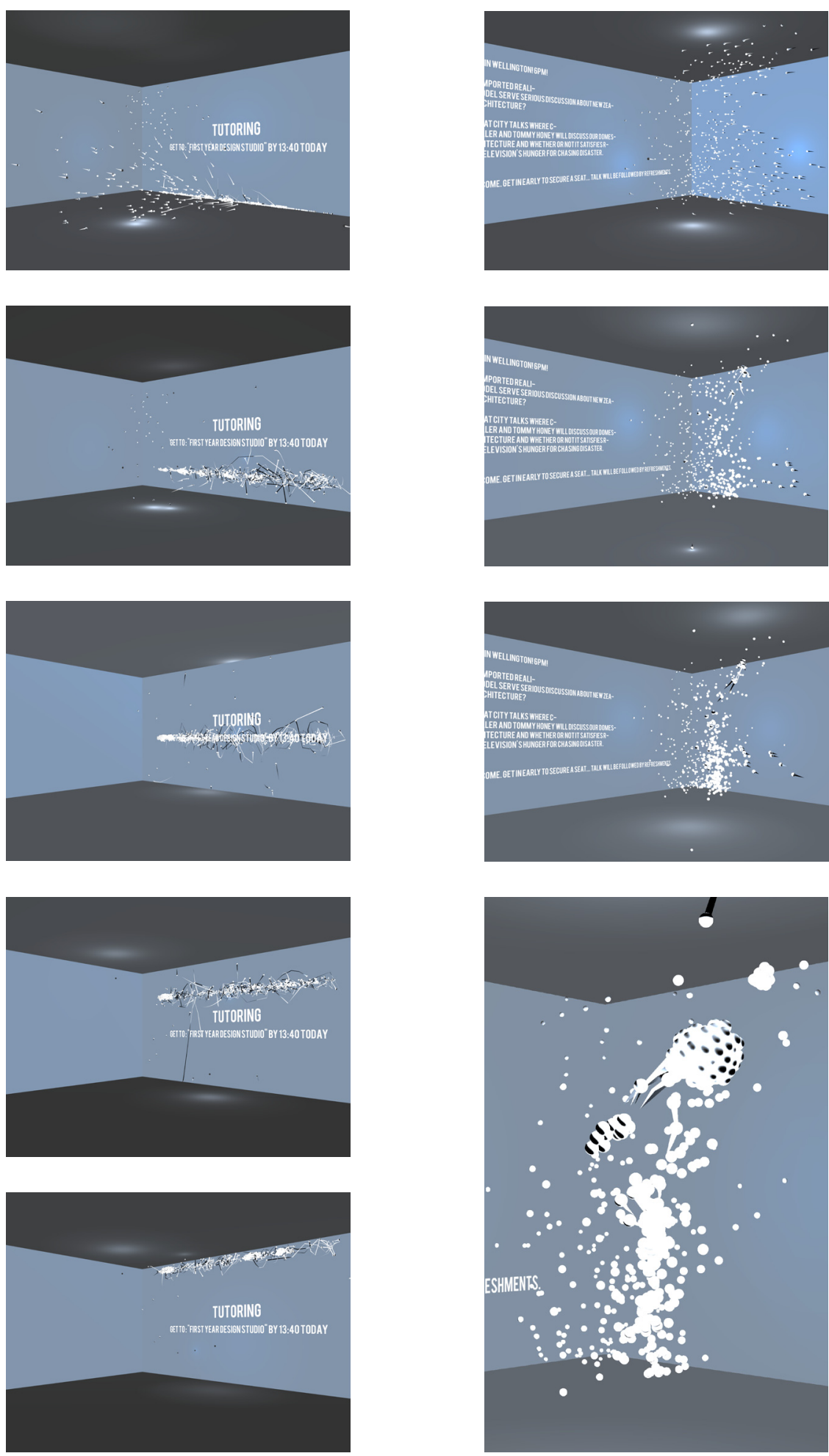

\section{Figure_26}

Nodes reacting to calendar data to assemble a line that counts down the time until the calendar entry is due to begin. Using Javascript based attraction forces. $\uparrow$
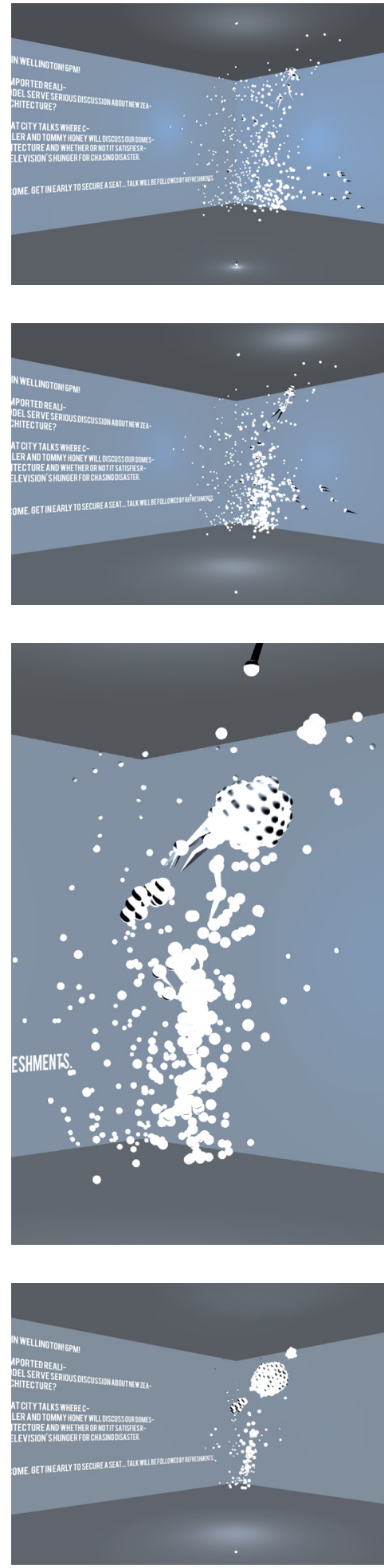

\section{Figure_27}

Nodes reacting to Facebook post data and creating a sculpture that is unique to the Facebook posts GUID. Using Javascript based attraction forces. $\uparrow$ 
From the earlier sentiment analysis shown in figure 12, the difficulty of translating 'sorted' data into 'organised' architecture became apparent.

From the sentiment analysis graph a tongue in cheek concept neighbourhood was developed based on a literal translation of the sentiment graph, demonstrating the problem simple ordering of data could bring to architecture. The problem with ordered data is that the sorting leaves little room for design authorship of how the digital identities and people are related.

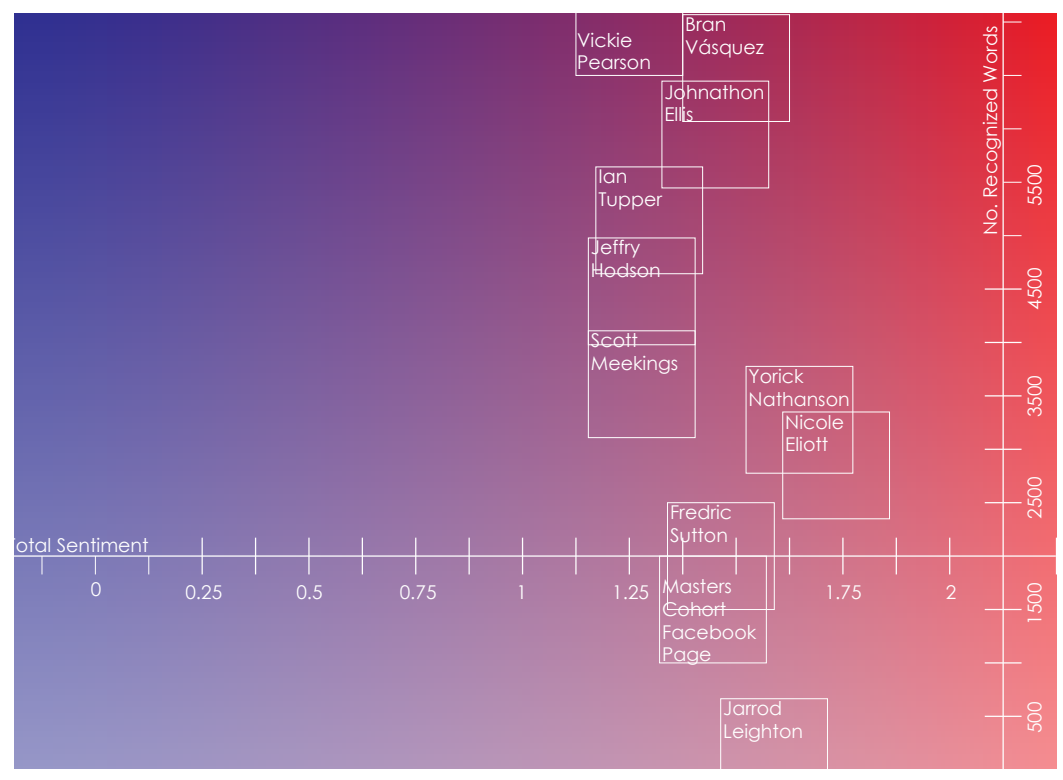

$\overline{\text { Figure } 12}$ shown earlier on page $28 . \uparrow$ 


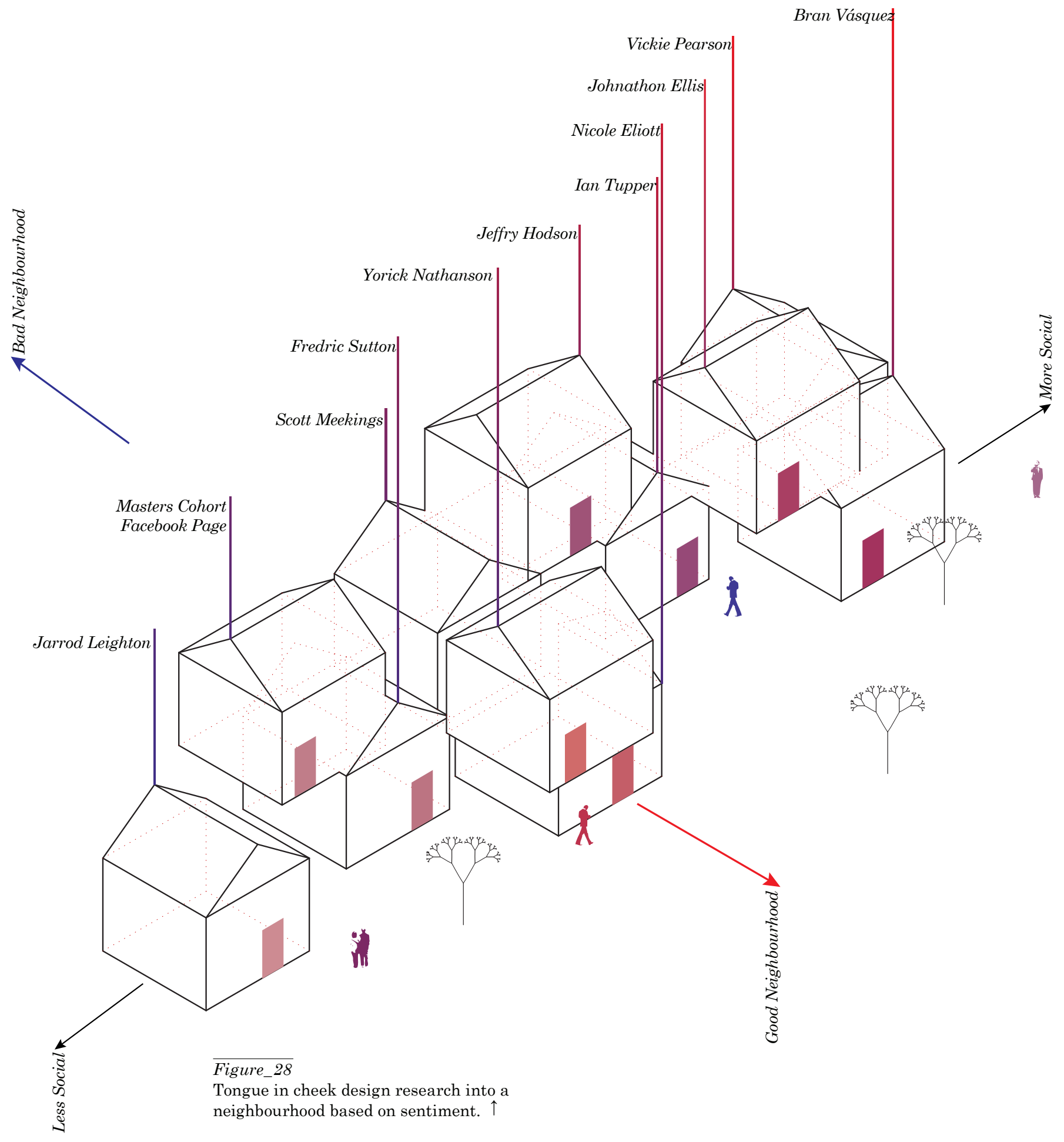




\subsubsection{DIFFUSION \\ LIMITED AGGREGATION ALGORITHM}

A solution to organizing data rather than sorting it was tested through the use of a diffusion-limited aggregation algorithm (DLAA). DLAA's come from a physics background and provide a method for assembling many pieces to create a form, the "model has been found to describe a remarkably large number of interesting physical systems" (Pietronero, 2013). The DLAA was chosen for its ability to create connections between data points (nodes) and work in three dimensions. To test this method a C\# script was developed which was flexible enough to be modified quickly and easily, allowing creative license to be applied. This model was used to organize data into many forms with criterias based on similarity or disparity and a range of datasets. This criteria develops a three-dimensional form where clusters of similar nodes occur while nodes remain interspersed overall, this avoids a linear sorting which would, for example, group all negative people together away from the positive people. This algorithm creates connections that are controlled and organized but not ordered.

\footnotetext{
$\overline{\text { Figure_29 }}$

A DLA algorithm based on Sentiment (node colour) and Age (node size) of a series of randomly generated Facebook profiles using C\# scripting and Unity

Physics. $\rightarrow$
} 


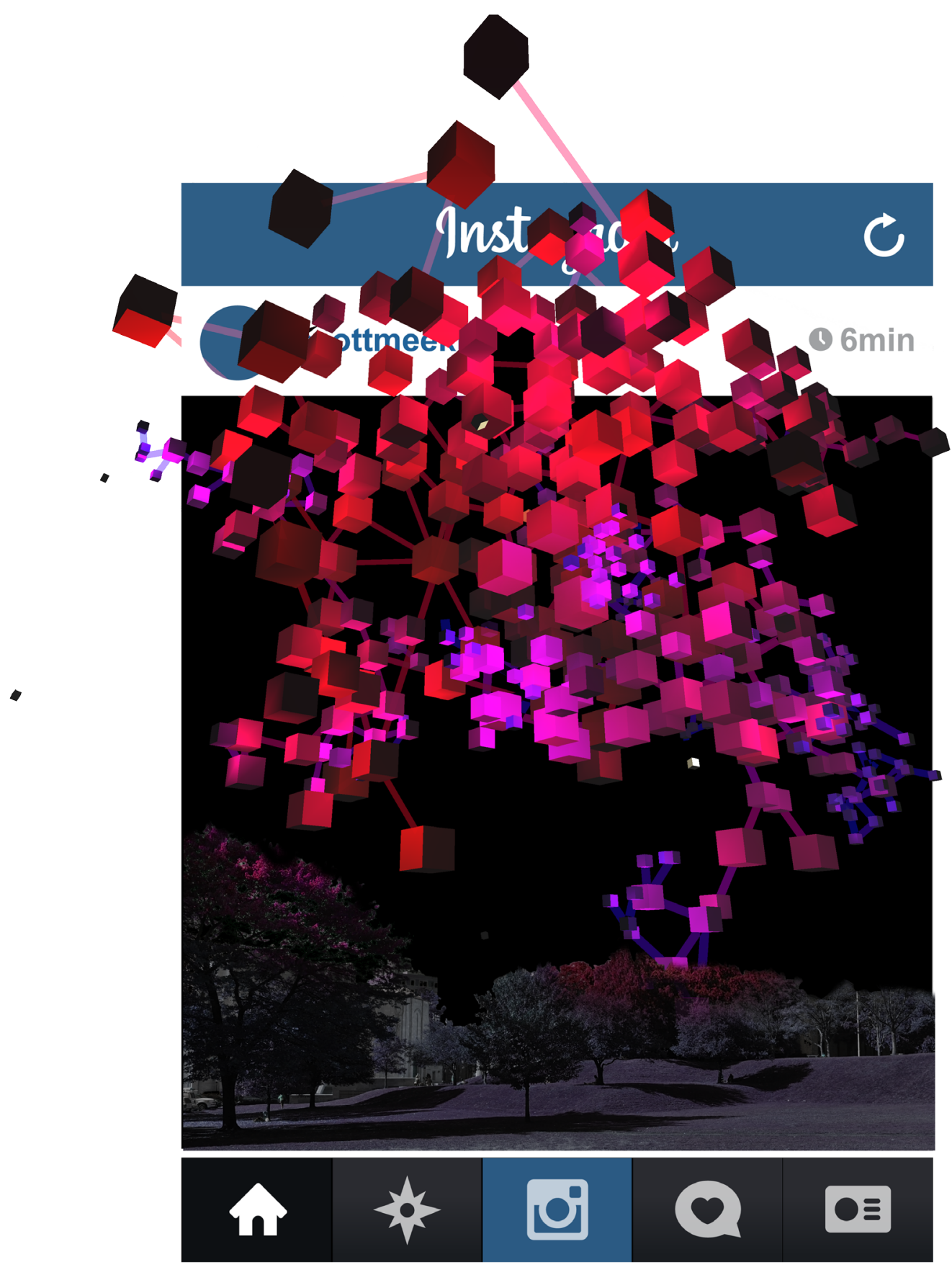



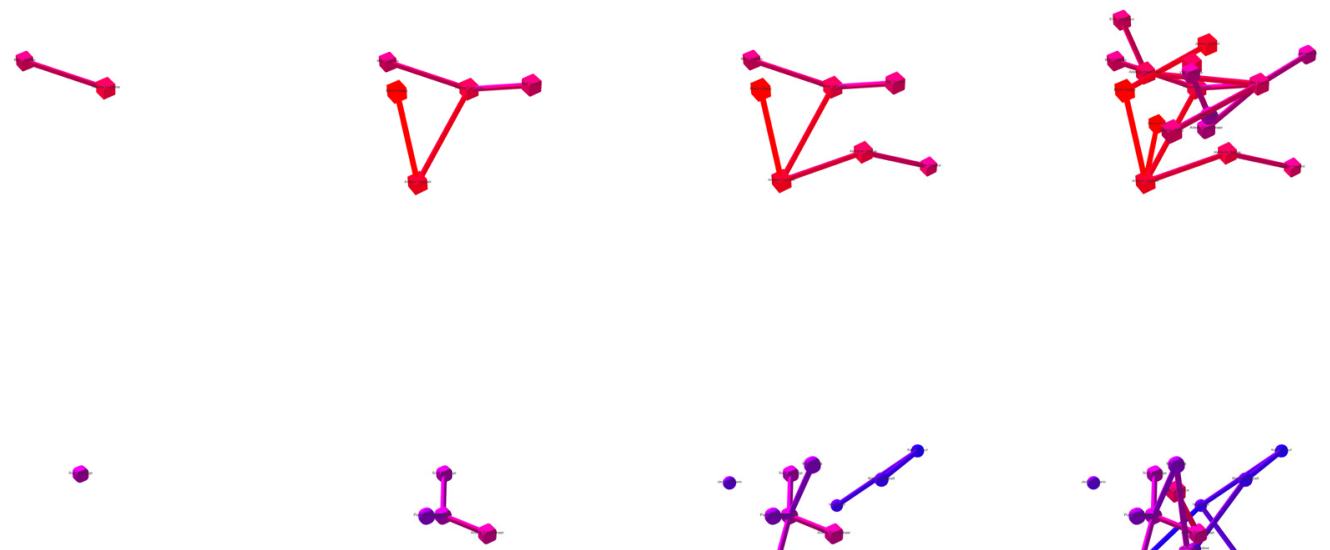

2

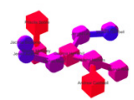

Figure_30 $a, b, c$

A DLA algorithm based on sentiment (red cubes $=$ high, blue spheres $=$ low). For this series only nodes that are within 2 sentiment values (scale 1 - 10) will connect.

$a$ Favours high scores - making them more likely to join earlier in the process altering the outcome to be more 'high-sentiment' based. $\uparrow$ Top Row

$b$ Favours low scores - making them more likely to join earlier in the process altering the outcome to be more 'high-sentiment' based. $\uparrow$ Centre Row

$c$ No bias - all nodes have an equal chance of being connected and creating a consistent spread while retaining grouping of similar nodes. $\uparrow$ Bottom Row
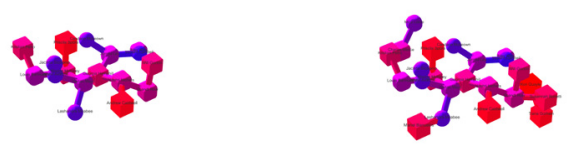

$\overline{\text { Figure_31 }}$

A DLA algorithm based on sentiment (red cubes = high, blue spheres $=$ low). For this series only nodes that are within 2 sentiment values (scale 1 - 10) will connect. An additional very complex $\mathrm{CH}$ script has been designed to add connections to nodes with only a single join - creating a significantly more connected outcome with no 'dead ends'. $\rightarrow$
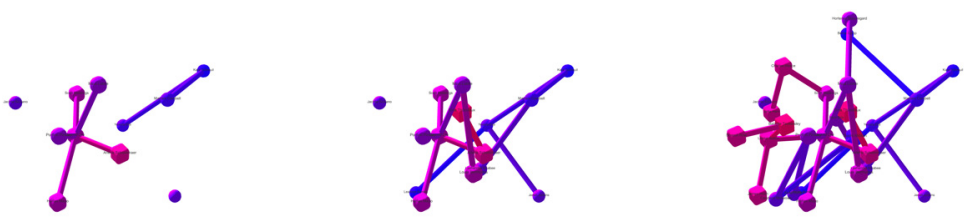
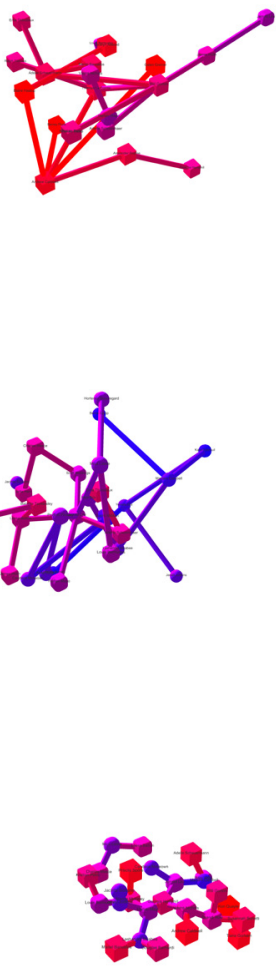

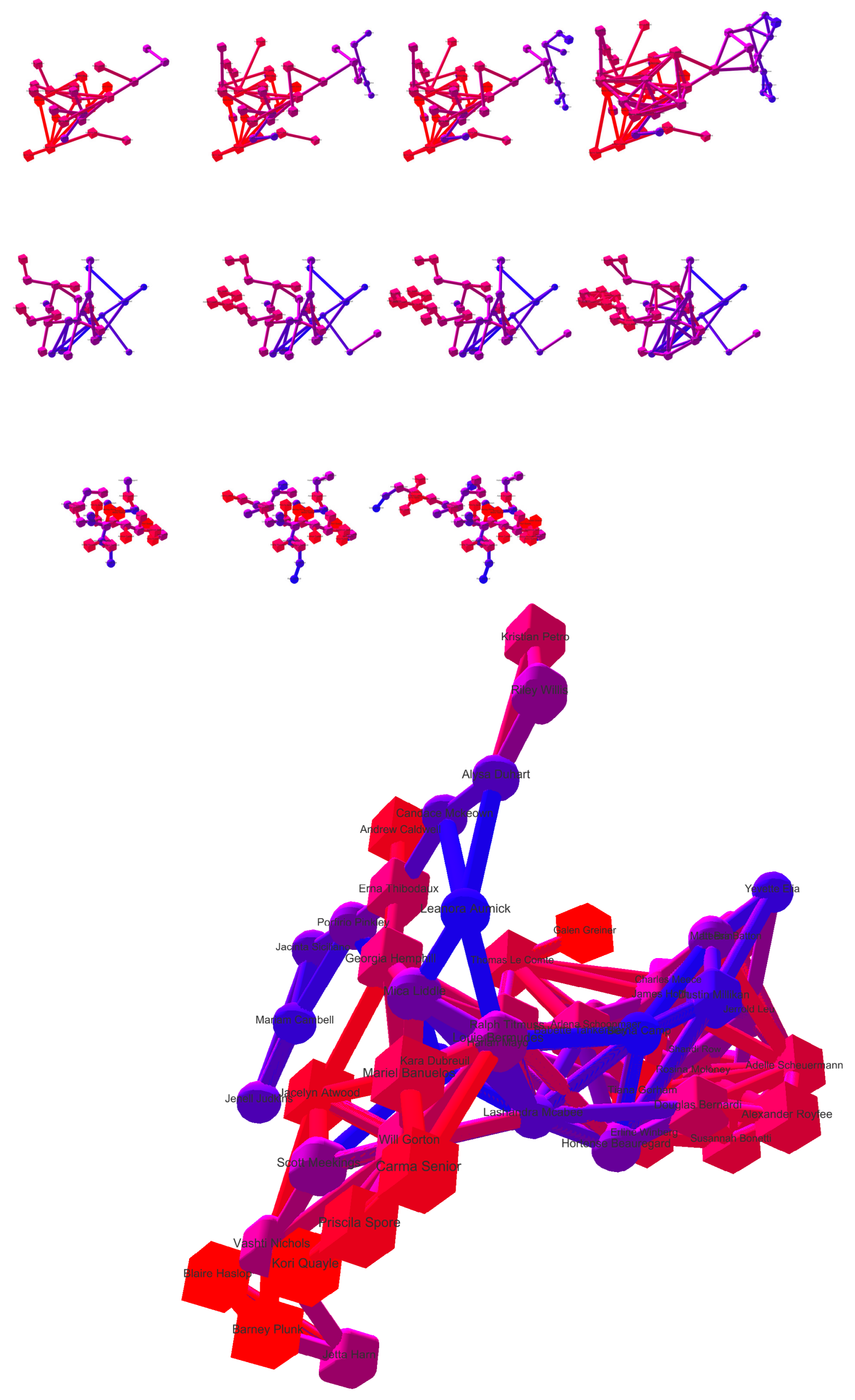


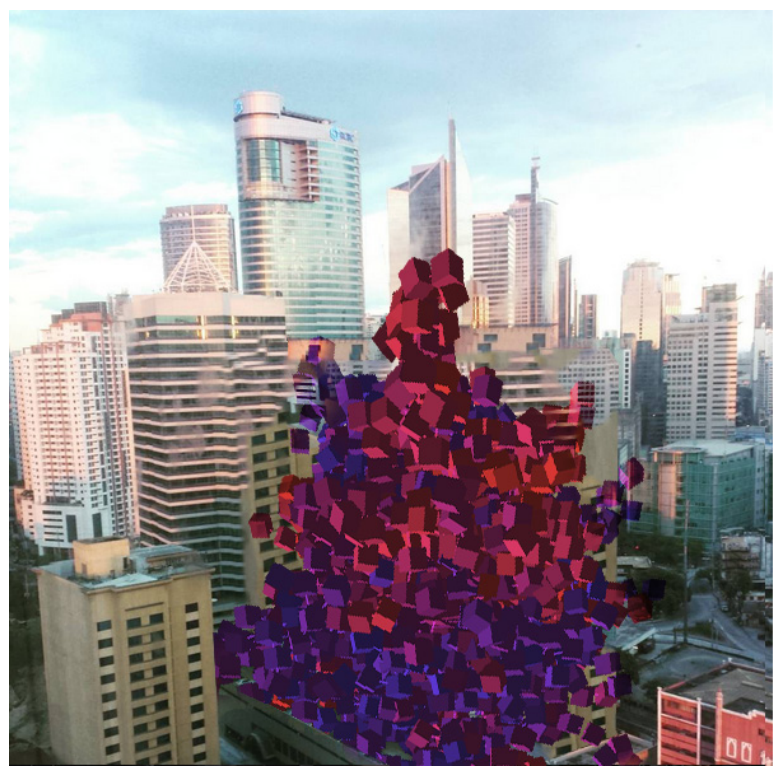

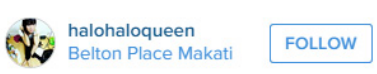

joseph_gonzales86, karan_0910, going gonzales w, karancosh, bipitri, mrdigitalnomad, philihappy, travelpostsdaily and

cocaine_cowboys_manila like this

scott meekings diffusion-limited

aggregation. each node only joins to other

nodes of the same sentiment-analysis

value

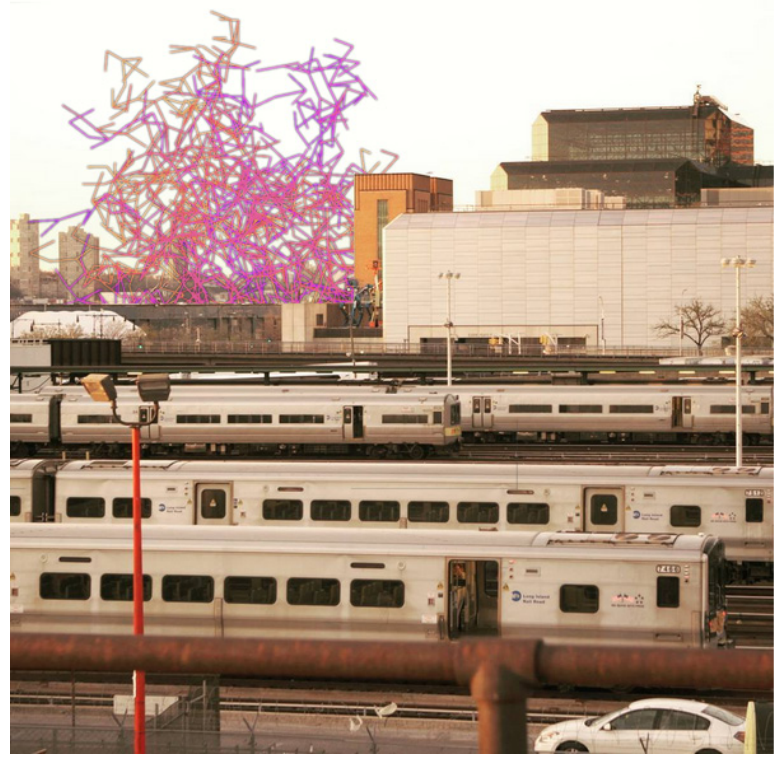

\#skycraper \#Makaticity \#Makati \#Manila

Add a comment.

Q

thanatham.t

Highline.

FOLLOW

vpfitness, tomisinnewyork

theathletestable,

highline_custom_jewelry and

emantadros like this

scott meekings diffusion-limited

aggregation. each node only joins to other

nodes of the same sentiment-analysis

value. connections only.

thanatham.t สดสายที่ปลายทา

\#endoftheline \#highline \#chelseamarket

\#manhattan \#newyork \#subwaynewyork

Add a comment.

\section{Figure_32 $a, b, c, d$}

Design research into DLA algorithms with varying value

set-ups composed onto social media photos at varying

scales in order to extrapolate potential architectural

narratives that could be assigned to the outputs.

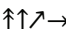




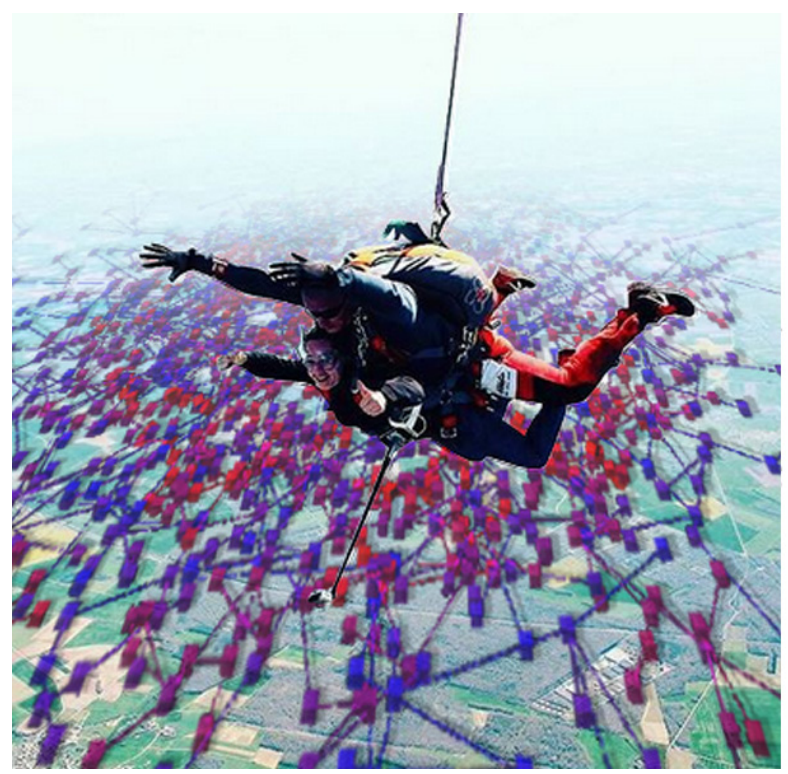

6 aiirah92 2 Paris Jump -aerodr... FOLLow

elissa_sahli, almacartney.

adrenaline.junkies, fabian.m.arnold,

grantkaspo and aiirah92 like this

aiirah92 En grande amatrice de

sensations fortes, j'ai enfin réalisé un de

mes kiffes !!! \#sky \#skydive \#skydiving

\#tandem \#paradise \#parachute

\#airplane \#crazy \#instagood \#instalike

\#instamood \#instadaily \#fly \#flying

\#landscape \#nature \#nofear \#France

\#wild \#follow4follow \#picture

\#pictureoftheday \#picoftheday \#model

Add a comment.

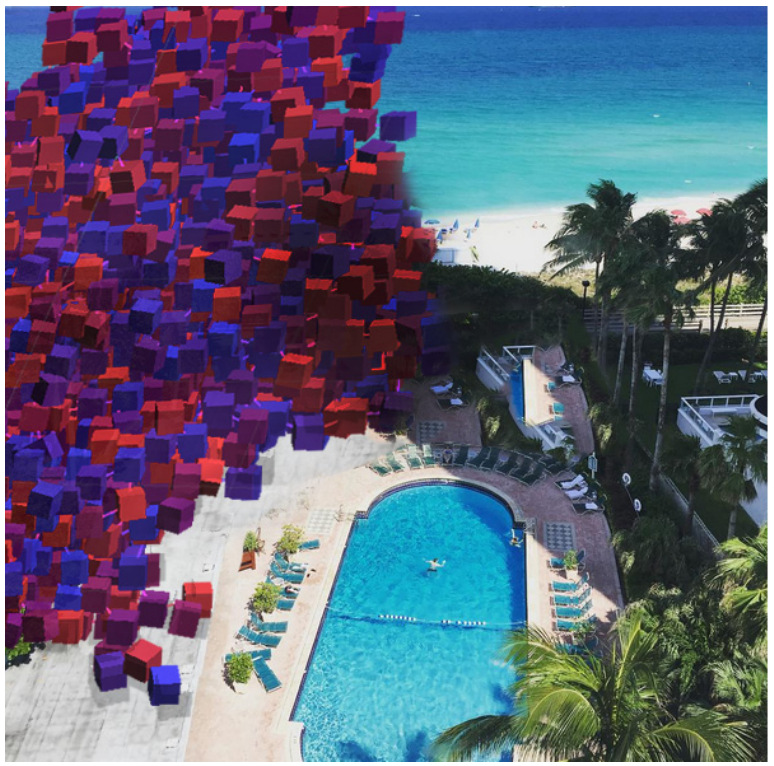

$\begin{array}{ll}\because \text { Datelparthj } & \text { Days Inn Oceansid... } \\ & \text { FOLLOW }\end{array}$

16 likes

scott meekings diffusion-limited

aggregation. each node joins any other

nodes.

patelparthj \#lifeisabeach but make sure

beach is \#Miami []

Add a comment. 

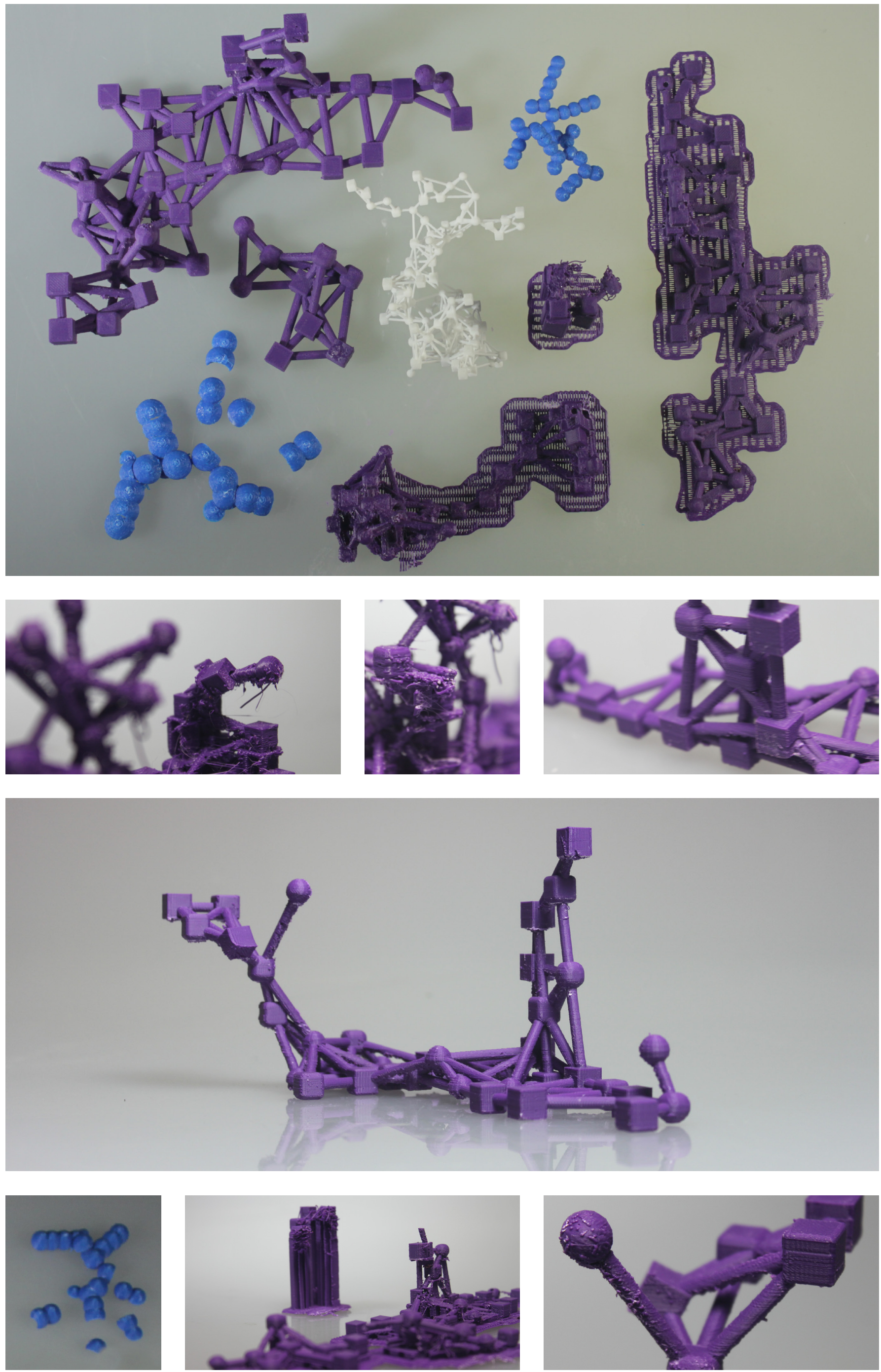


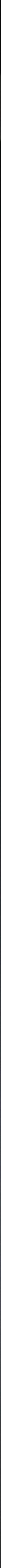




\section{Figure_33 $a-i$}

DLA models 3D printed. Purple models are the

original algorithms, blue models are simplified

(as discussed on page 73), white model is SLS 3D

printed DLA with additional nodes added to reduce

'dead ends'. $\curvearrowleft$

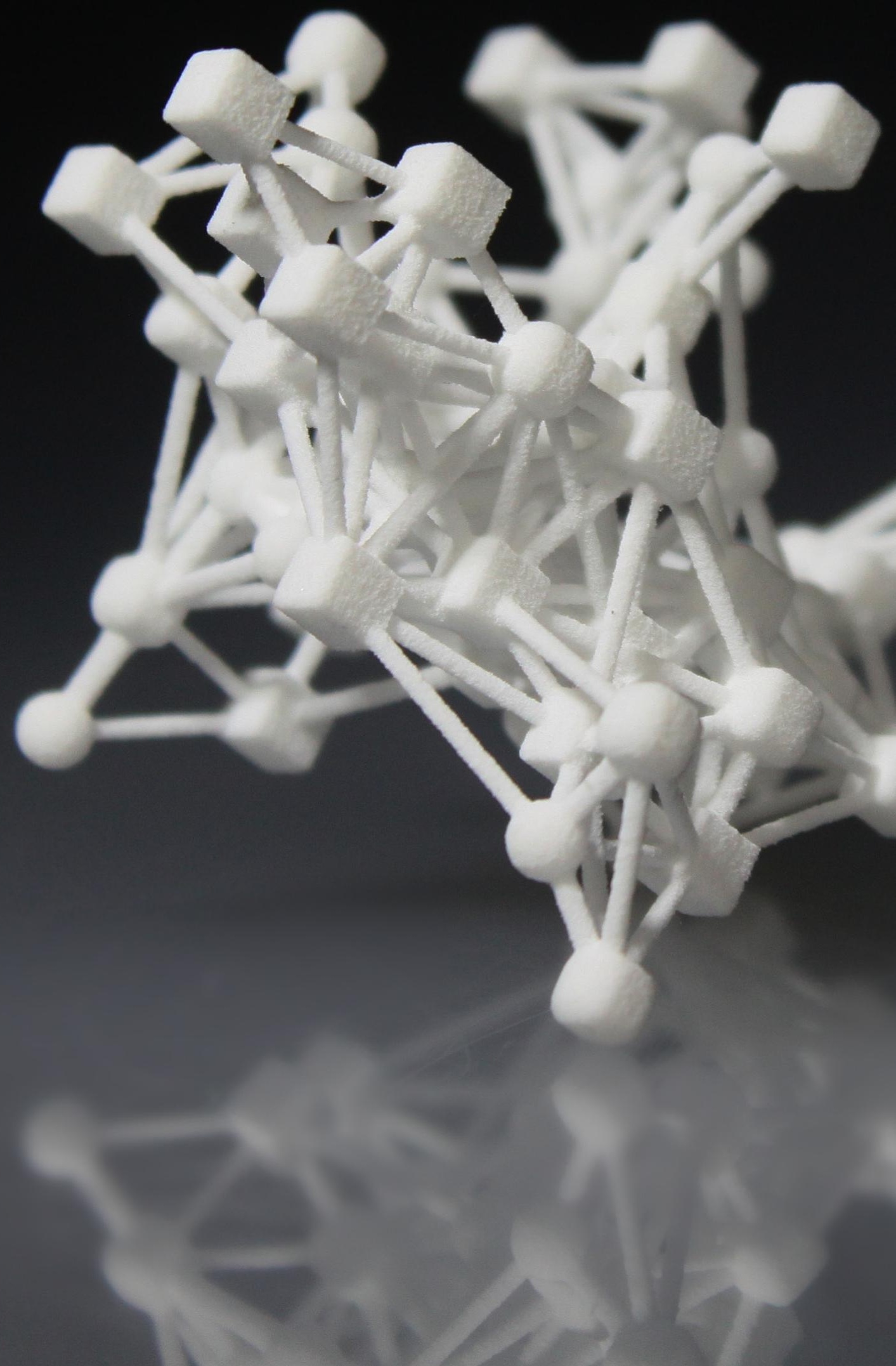


Figure_34

SLS 3D printed DLA with additional connections added

to reduce 'dead ends'. $\downarrow$

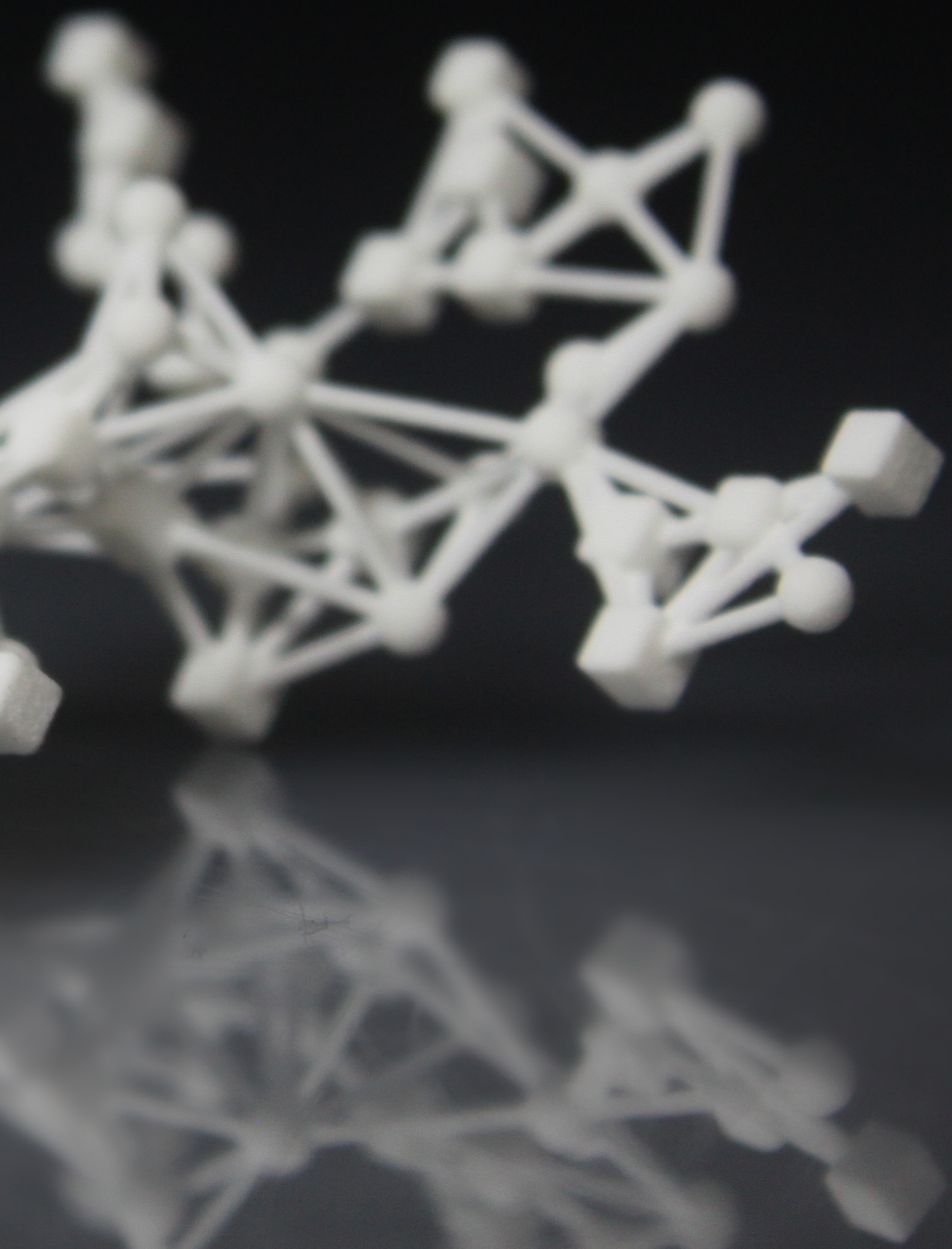



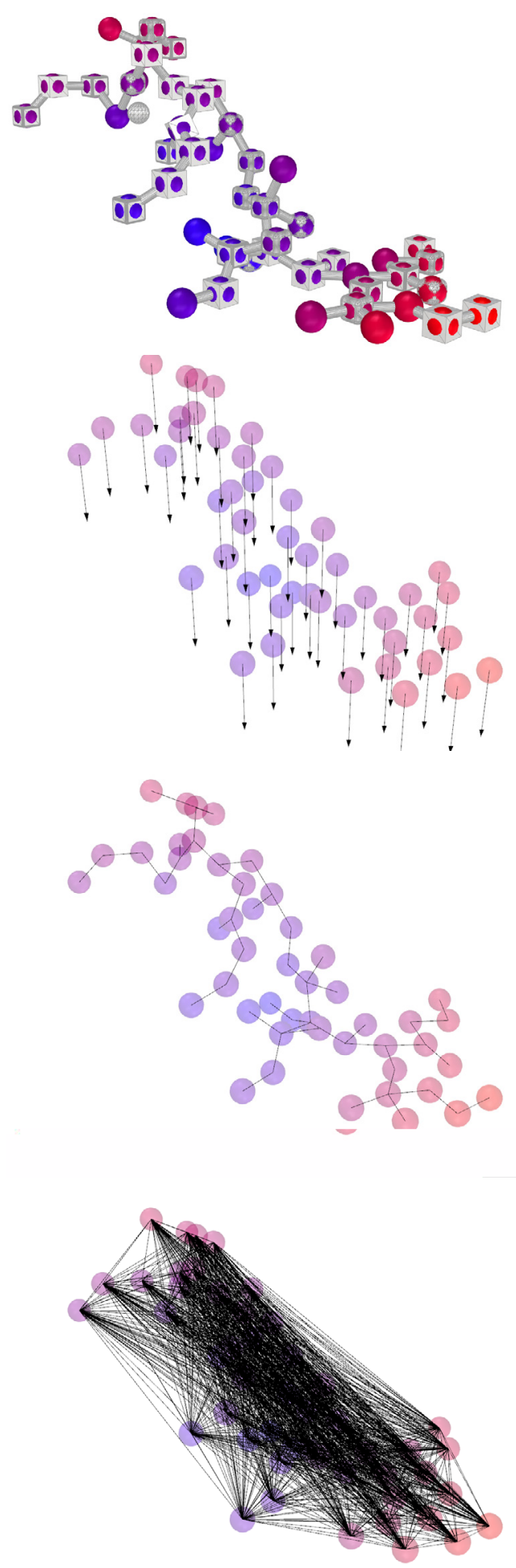

The weakness of the DLAA used to separate space earlier was that non-connected nodes could inhabit close proximity. There was no ability to ensure that non-connected nodes were not located directly beside unrelated (and unconnected) nodes which reduces its usefulness in architecture - for example locating two people who are not connected in rooms right next to each but without connection means that hallway space must be constructed so that the neighbors are not linked resulting in a awkward hallway space. Using physics simulations in the Kangaroo plugin for Grasshopper this problem was reduced by creating forces which repel all non-related nodes while drawing all related nodes together. This creates a layout that has additional potential for real world application. Figure 35 shows the forces in black where the downwards arrows are an approximation for gravity, the connecting lines are approximations of springs which pull together the connected nodes and the complex web of black lines show the repellant forces acting between all non-connected nodes as inverse springs to push them apart. While more pragmatic this method reduces the aesthetic qualities of the output and is not built upon further in this thesis.

$\overline{\text { Figure_35 } a, b, c, d}$

$a$ DLA with connections of varying lengths $\bar{\kappa}$

$b$ Gravity Force Applied. $\nwarrow$ Top Middle

c Spring connections to which elasticity force is applied. $\nwarrow$ Bottom Middle

$d$ Repulsion Connections used to repel unconnected nodes. $\leftarrow$

\section{$\overline{\text { Video_4 }}$}

Demonstration of the algorithm using

a physics engine for manipulation of a

DLA algorithm. 

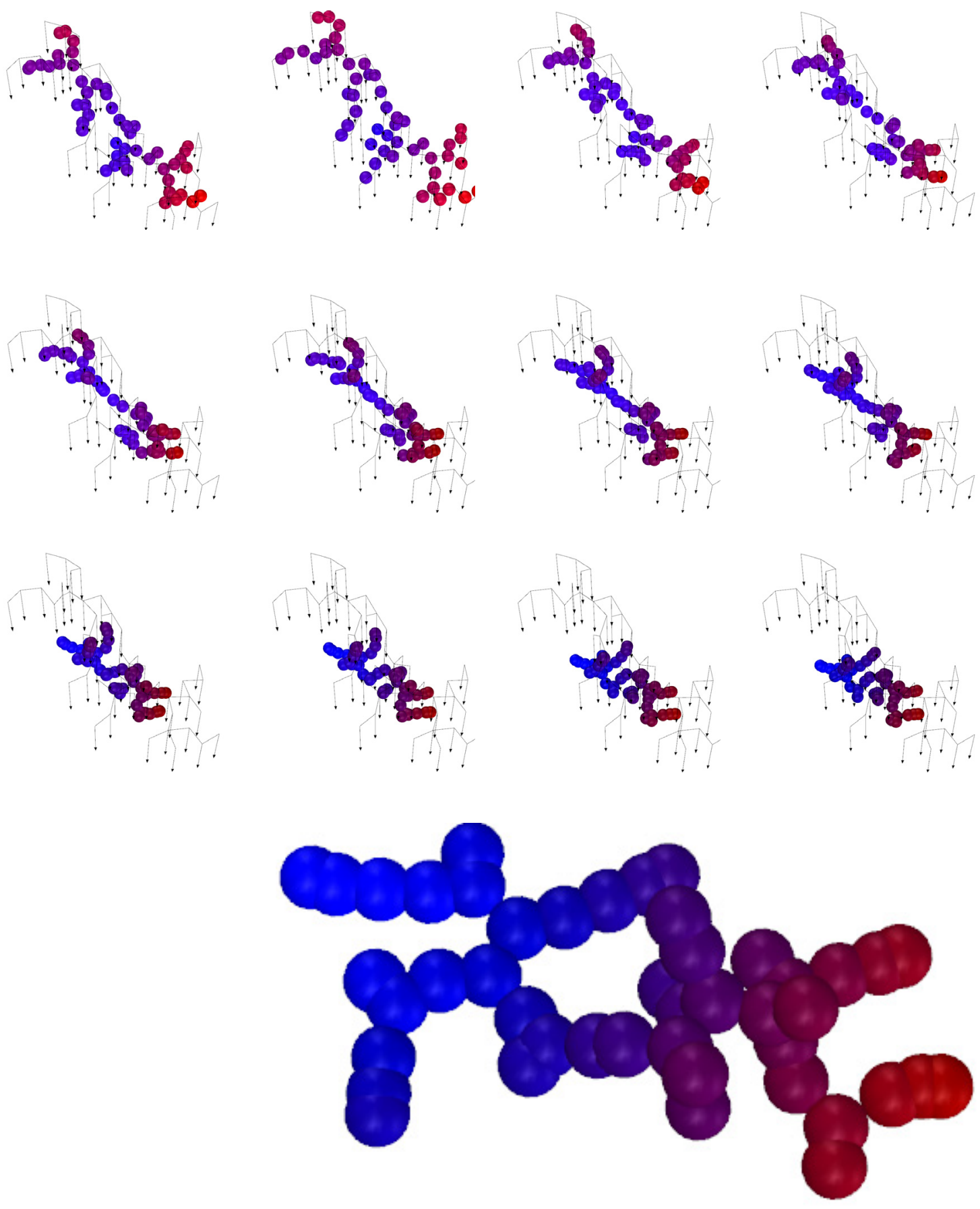

$\overline{\text { Figure_36 } a, b}$

$a$ Physics based simplification of DLA algorithm in

action using Kangaroo plugin for Grasshopper.

$b$ Resulting simplified DLA algorithm. $\uparrow \uparrow$ 

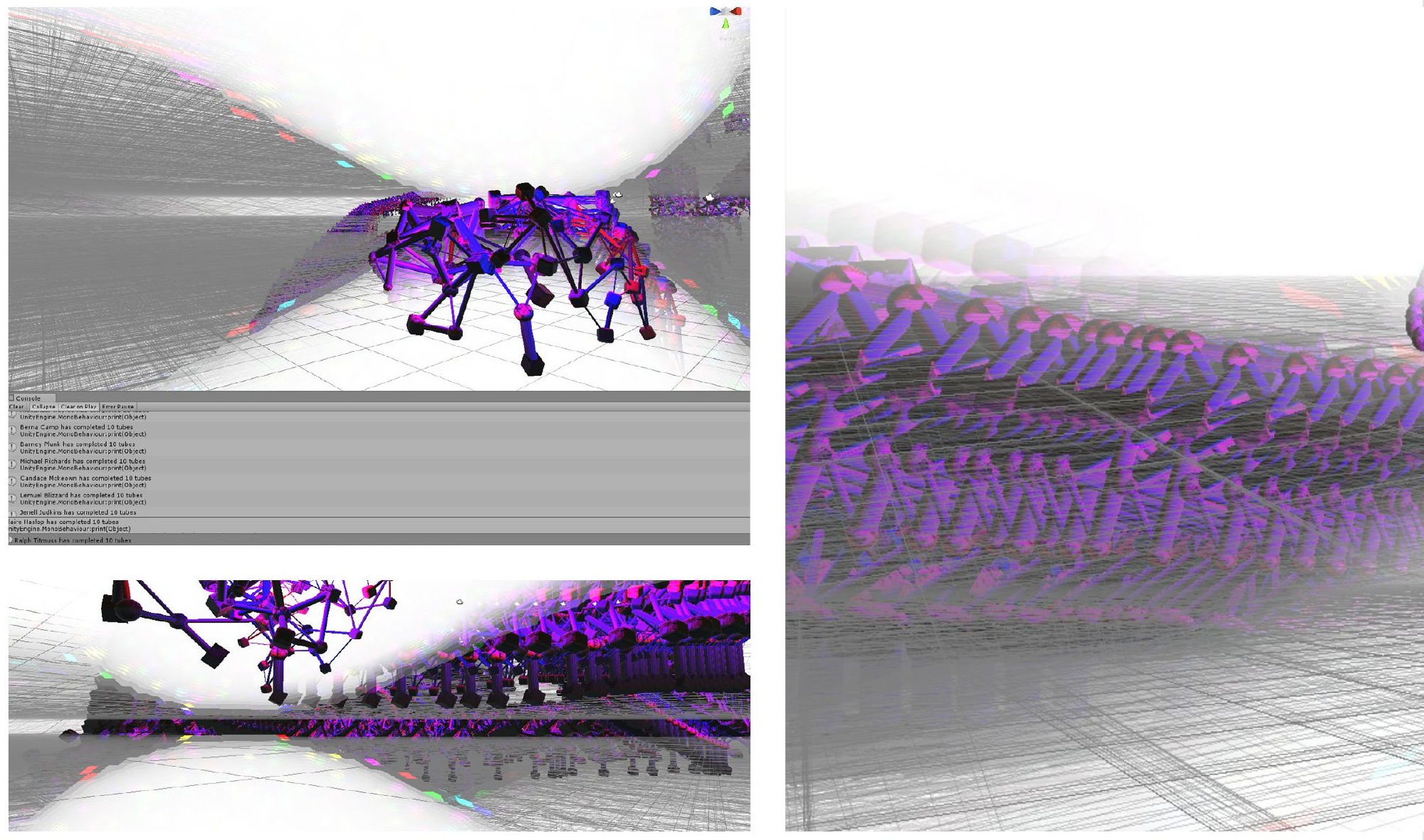

Figure_37a-e

Explorations of aesthetics and form derived from the digital algorithm process. Focussing on repetition, order within disorder and authorship symbols from software inputs. ↔ $\leftrightarrows$ All

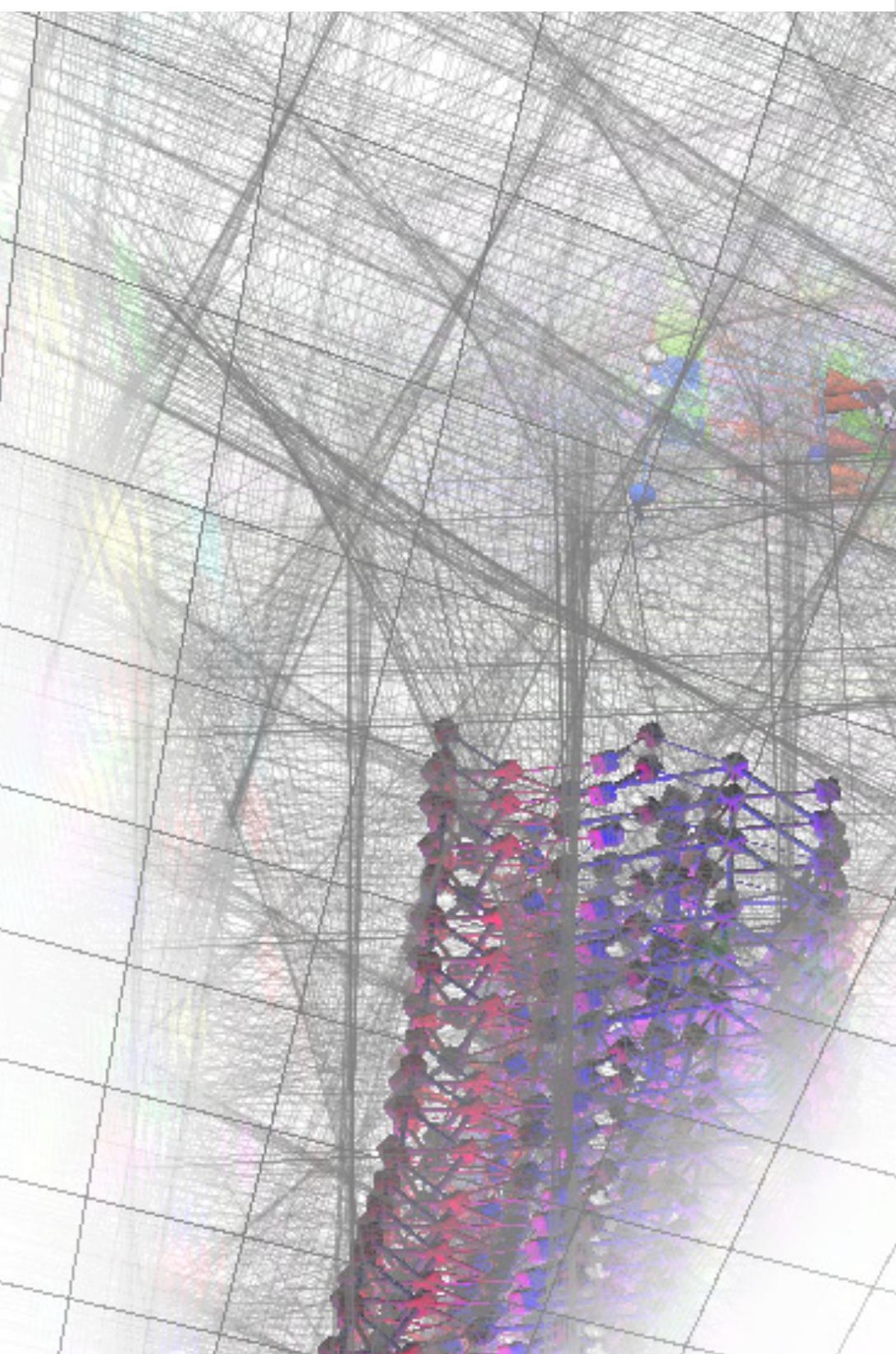



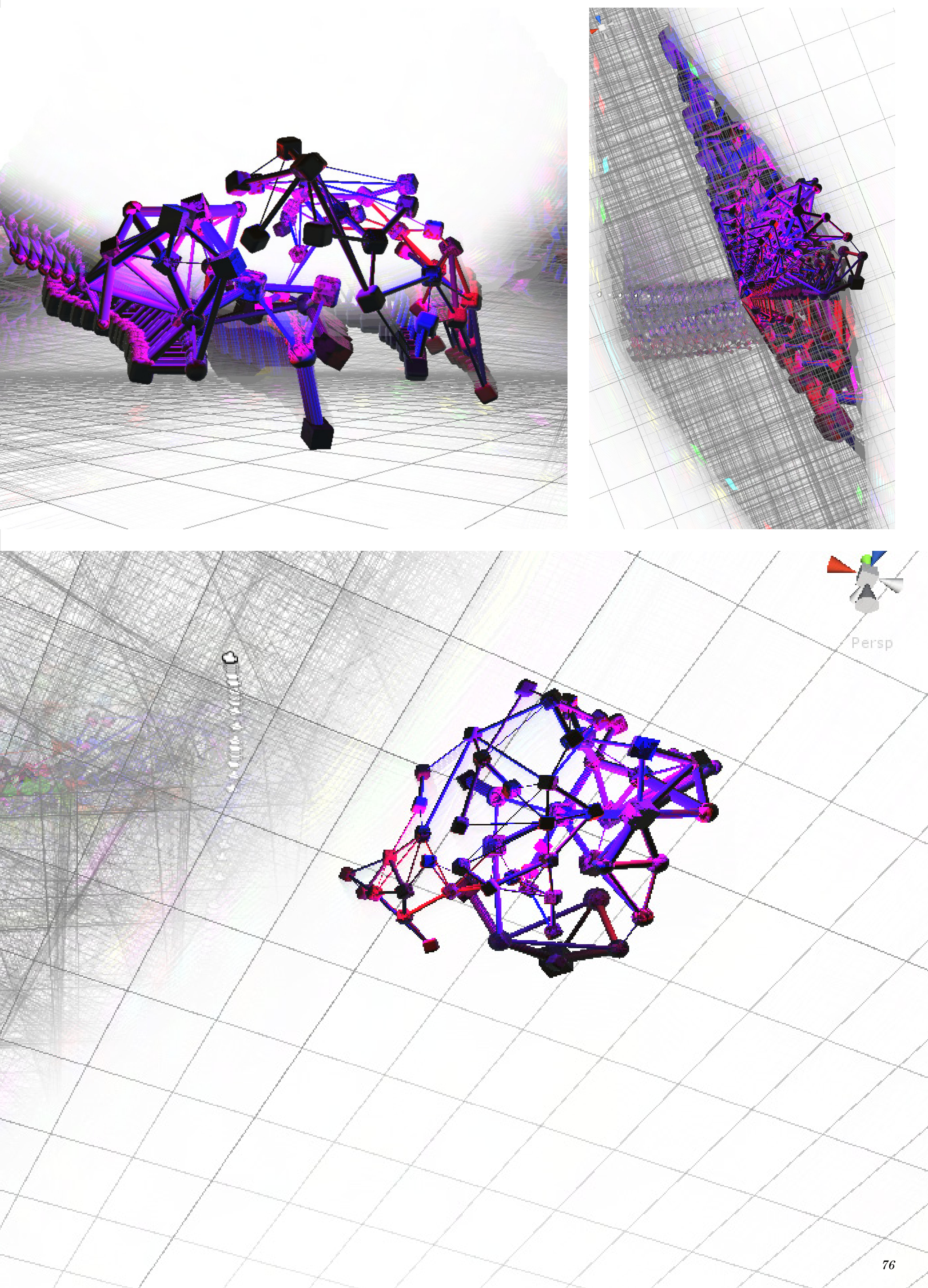


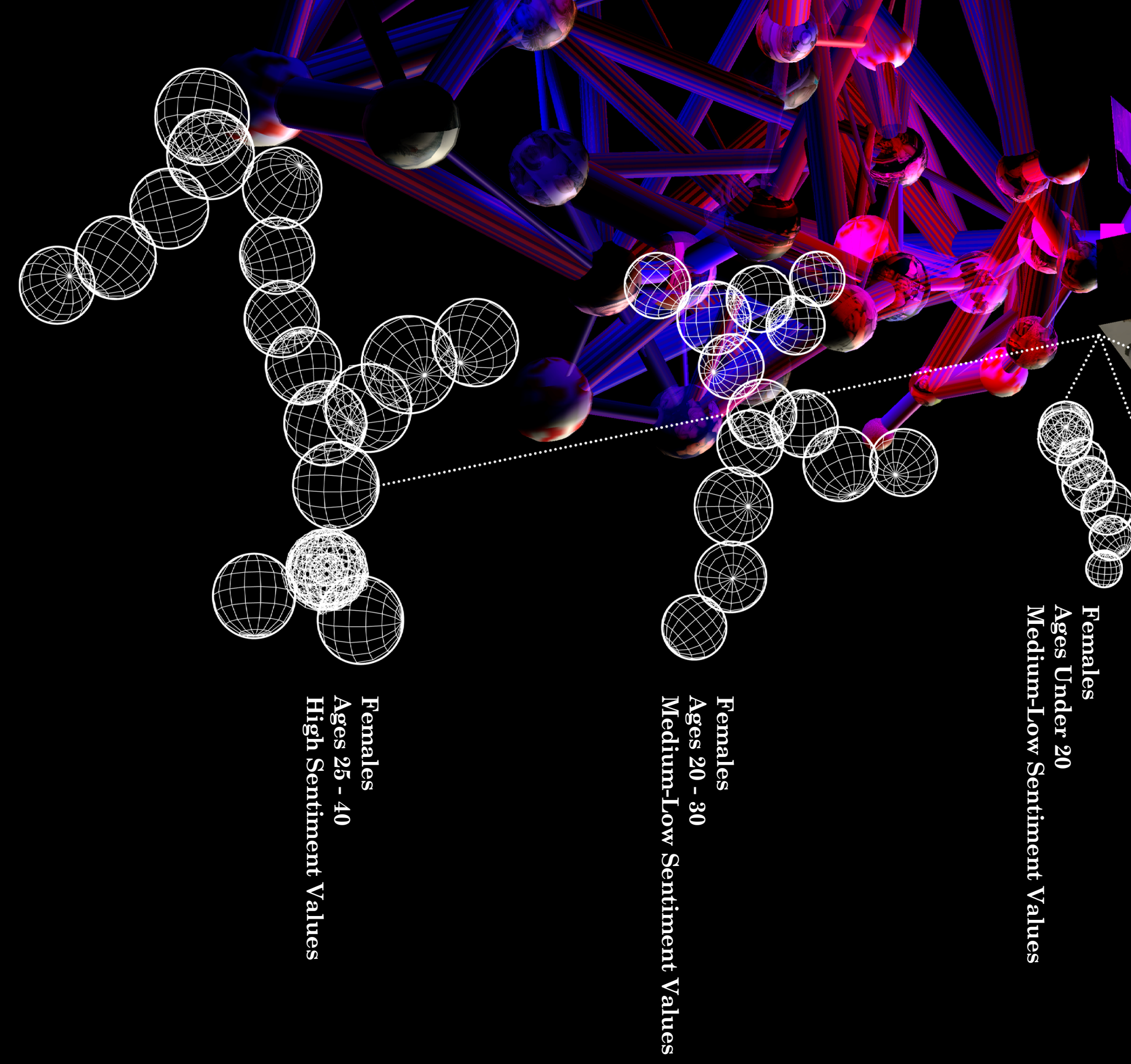

$\overline{\text { Figure_38 }}$

DLA algorithm dividing a range of randomly

generated Facebook profiles (and by extension, real

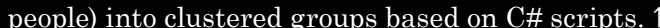




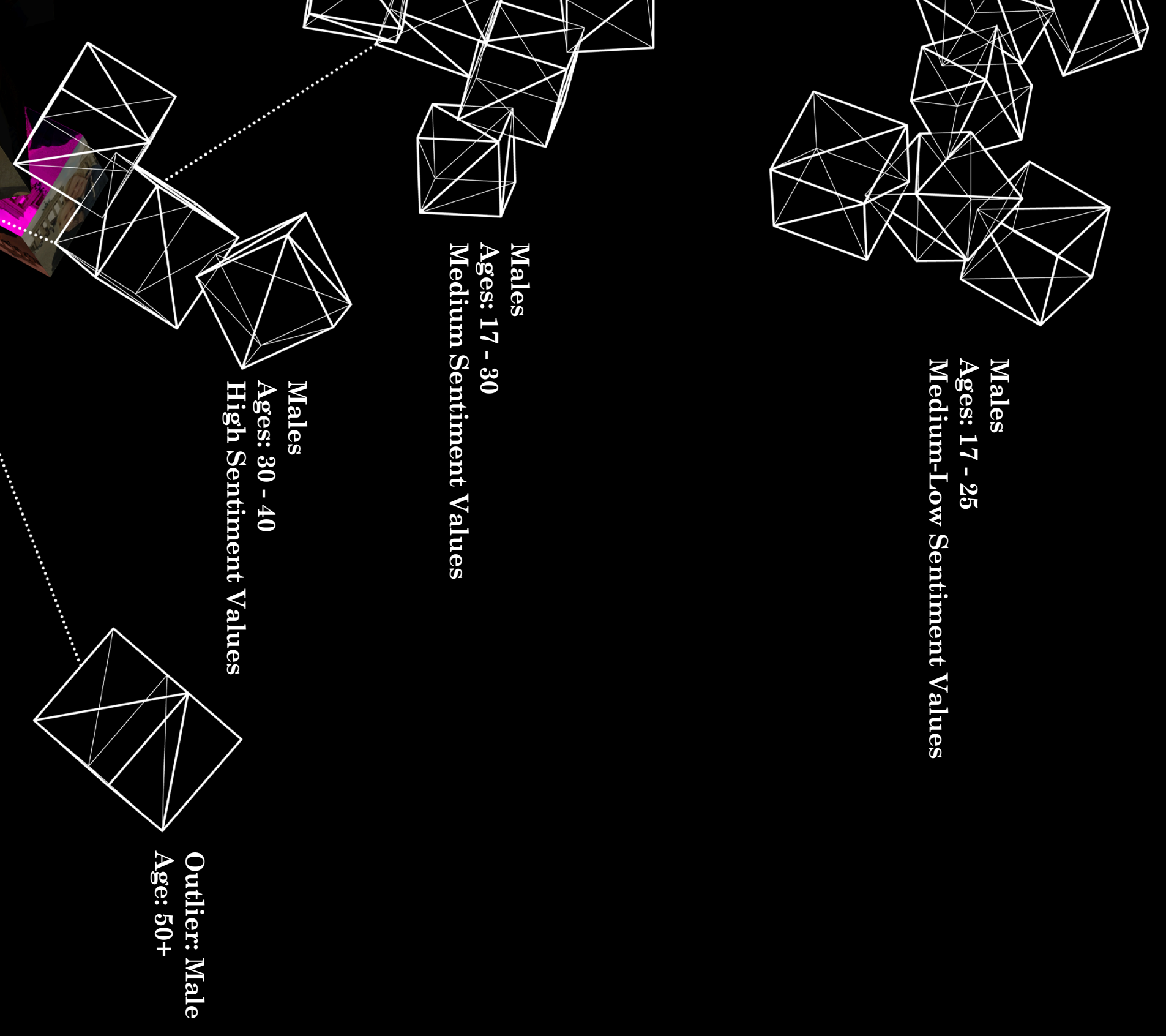




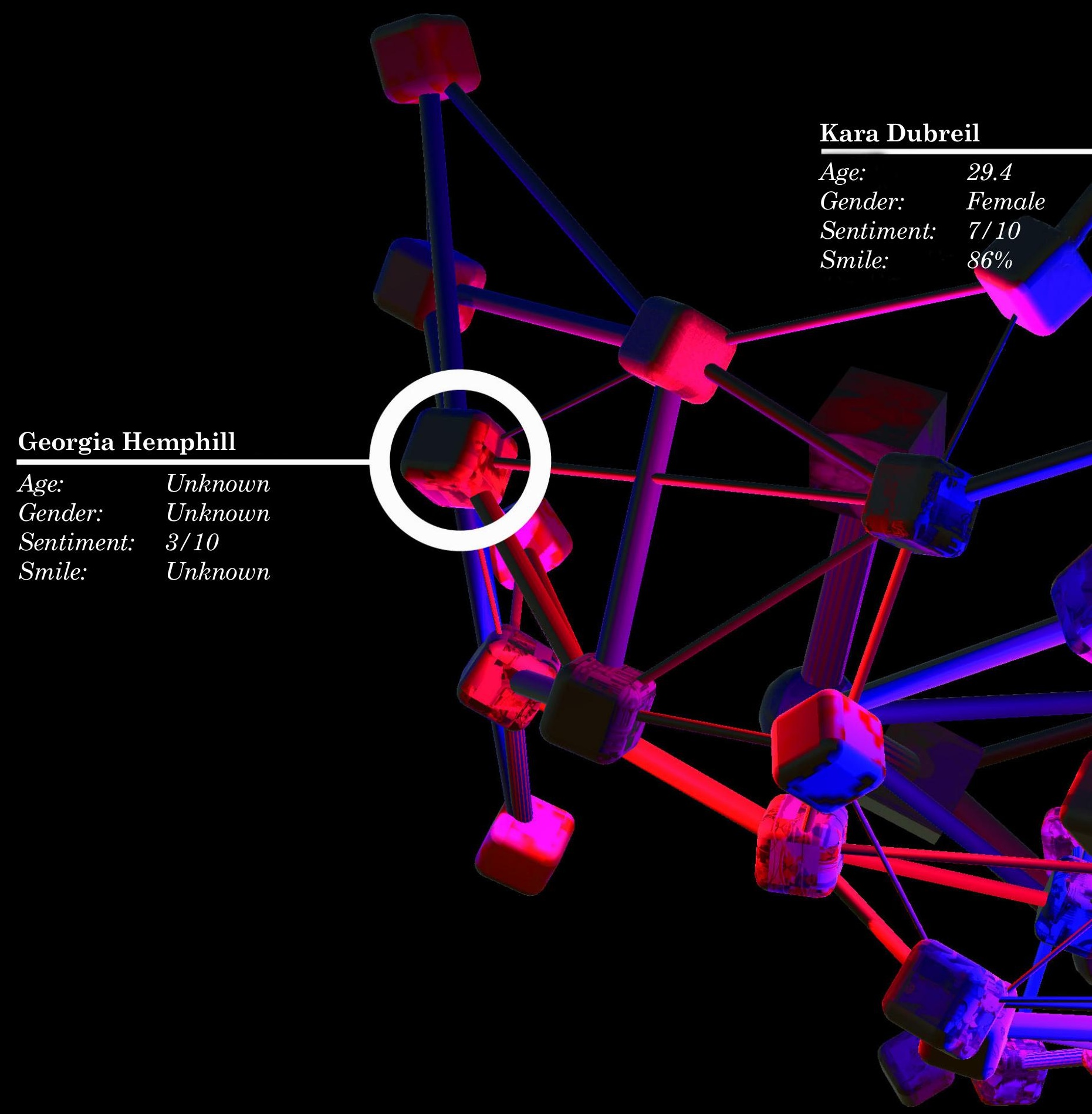




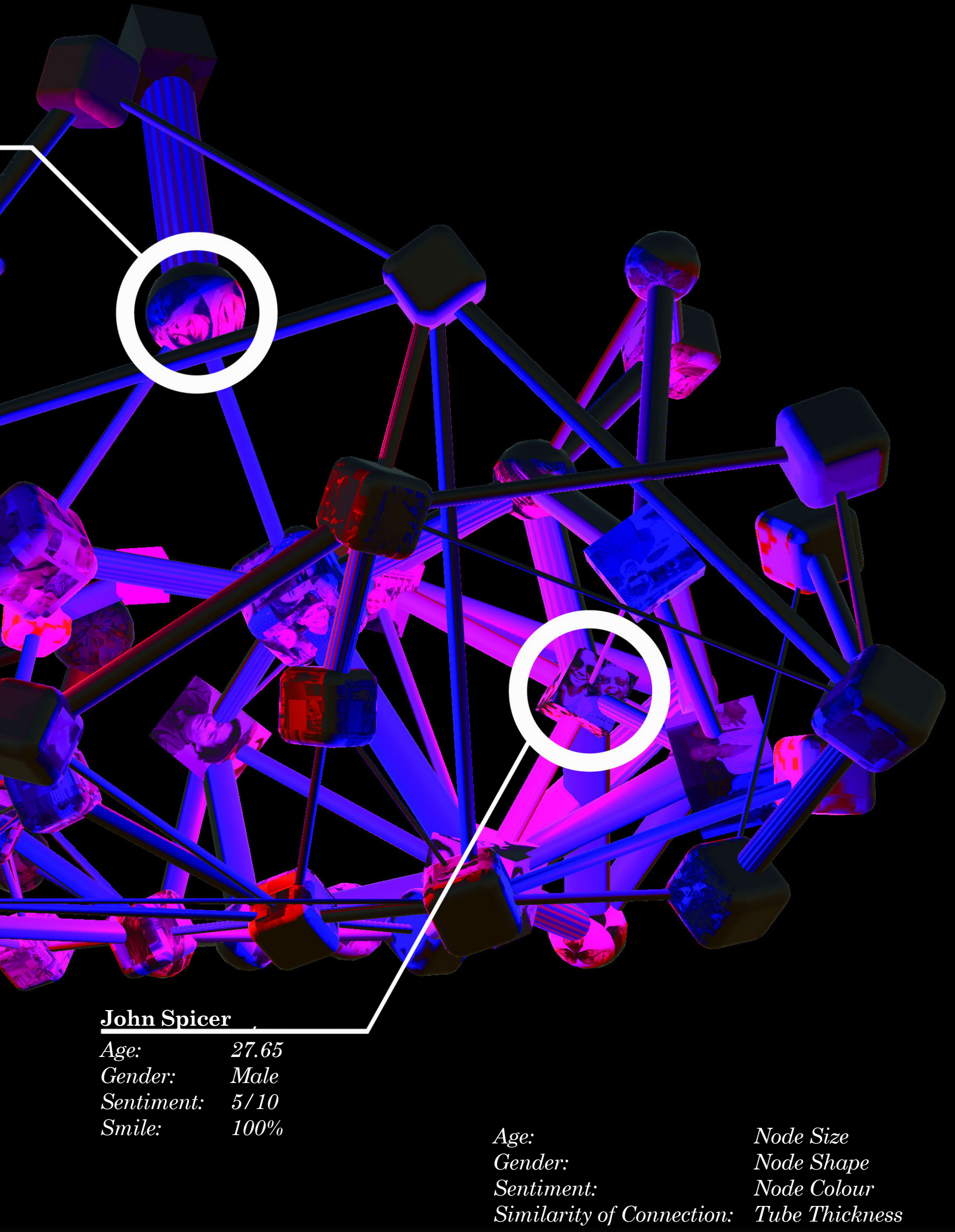




\title{
5.2 [WEB]SITE
}

\begin{abstract}
Site in architecture is a complex topic, more so when the relation to site is that of a digital identity rather than a conventional identity. The idea that "memory and place are inseparable" becomes questionable with a digital identity (Hornstein, 2011). Place and site exist as data and be a part of a digital identity while memory itself cannot exist in data. Metrics such as place names, coordinates, time spent there and data collected at a particular location all contribute to understandings of site, however, digitally space is not linked with a singular place. One of the significant advantages digital identities have provided people is the ability to converse with anybody or visually inhabit anywhere with almost no limit. Effectively translating this into physical space requires the ability to manipulate geographic data to provide equivalent locations for inequivalent geographies.
\end{abstract}

\section{$\overline{\text { Figure_40 }}$}

Moves App GPS tracking of my location in Wellington, the data collected also includes all visited locations and how long I spend at each place. 7 


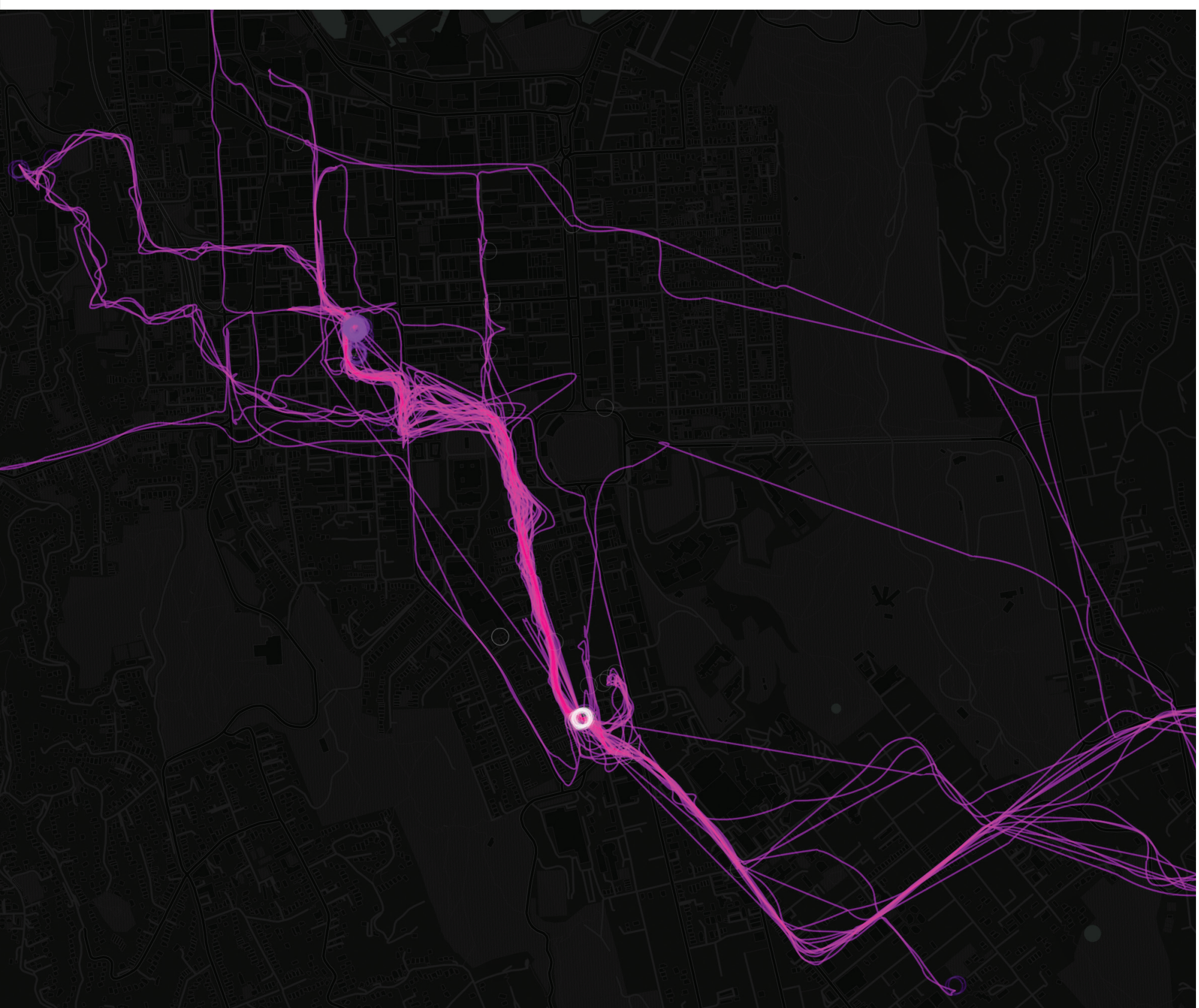

Working Location $\bigcirc$

Non-Working Locations $\bigcirc$ 

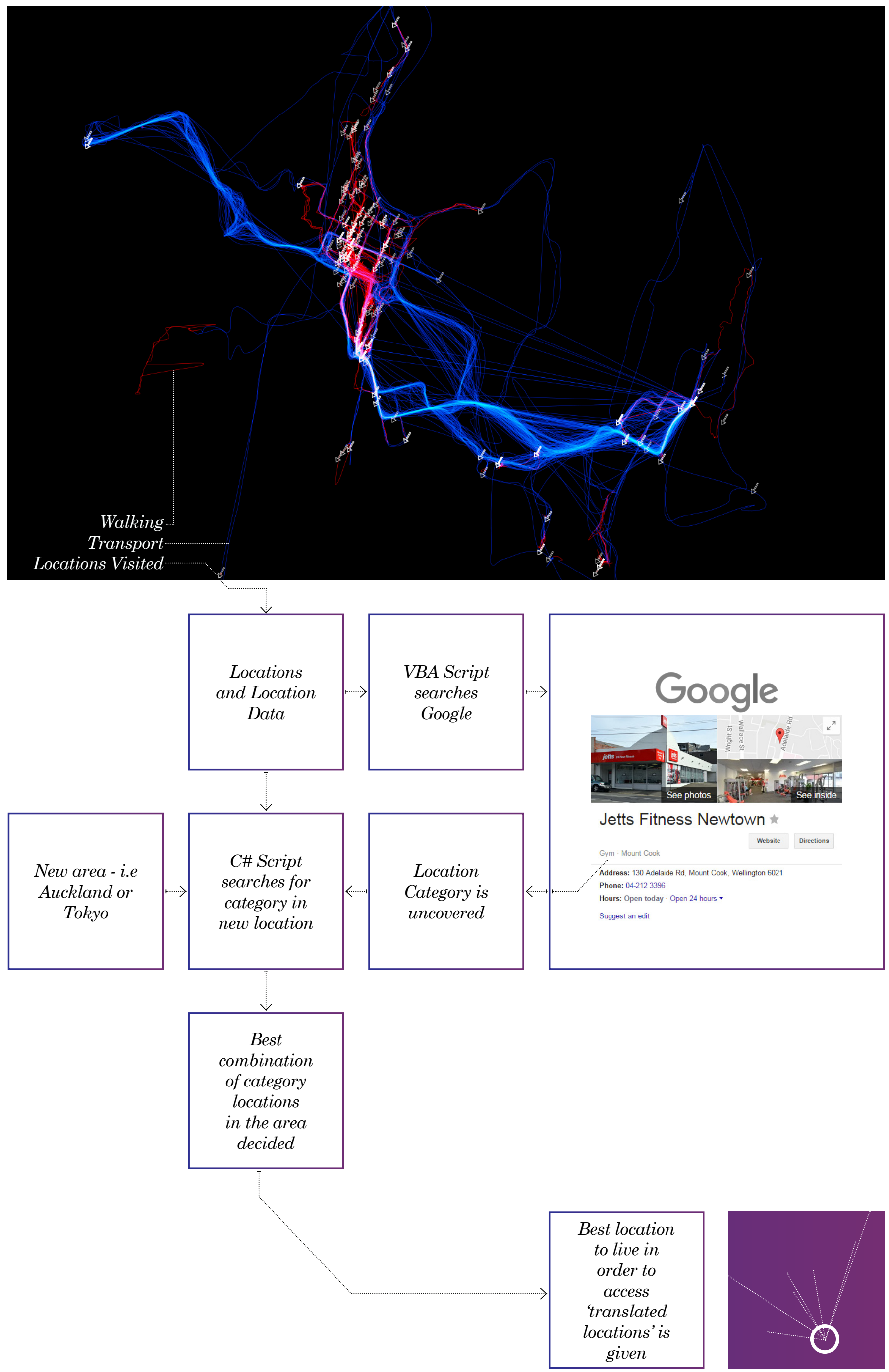
The idea that architecture could accommodate a person's digital existence requires autonomous ability of buildings to understand how aspects of architecture should be dictated by data - including site. For example, for a home in a foreign country that was intended to reflect a home left behind in a person's home country, site would be just as important as the architecture itself. To this end I have created a method for translating 'place' from one city to another:

Firstly tracking where I go gives visited locations, how long and how often I visited them.

From this a spreadsheet is created showing locations and number of visits. Key locations are translated into categories through the use of Google - for this a VBA script for excel takes the place name (e.g. Jetts Fitness Newtown) and searches Google for it. The google results tell the script which category the place belongs to (e.g. Gym). A generic address is then created, reflecting the area to translate the data to (e.g Gym, Ota, Tokyo, Japan). This address can be added to Google Maps and each place of each category plotted. By using the number of visits and time spent at each location, the best cluster of potential results is selected and an 'equivalent' house location is given.

$\overline{\text { Figure_41 }}$

Flowchart showing the range of complex steps used to produce the geographic translation algorithm. $\leftarrow$ 


\section{5}

17

11

While successful this system still contains some errors: some GPS locations were originally recorded while I was in Bali, resulting in the algorithm assuming Iwill visit 'resorts' or 'boutique hotels' while in Auckland. Other potential issues are places with generic category labels such as 'store'.

\section{$\overline{\text { Figure_42 }}$}

Experimenting with the geographic translation algorithm. Places I visit, translated to Auckland, grouping locations of close proximity. $\uparrow$ 
Boutique Hotel

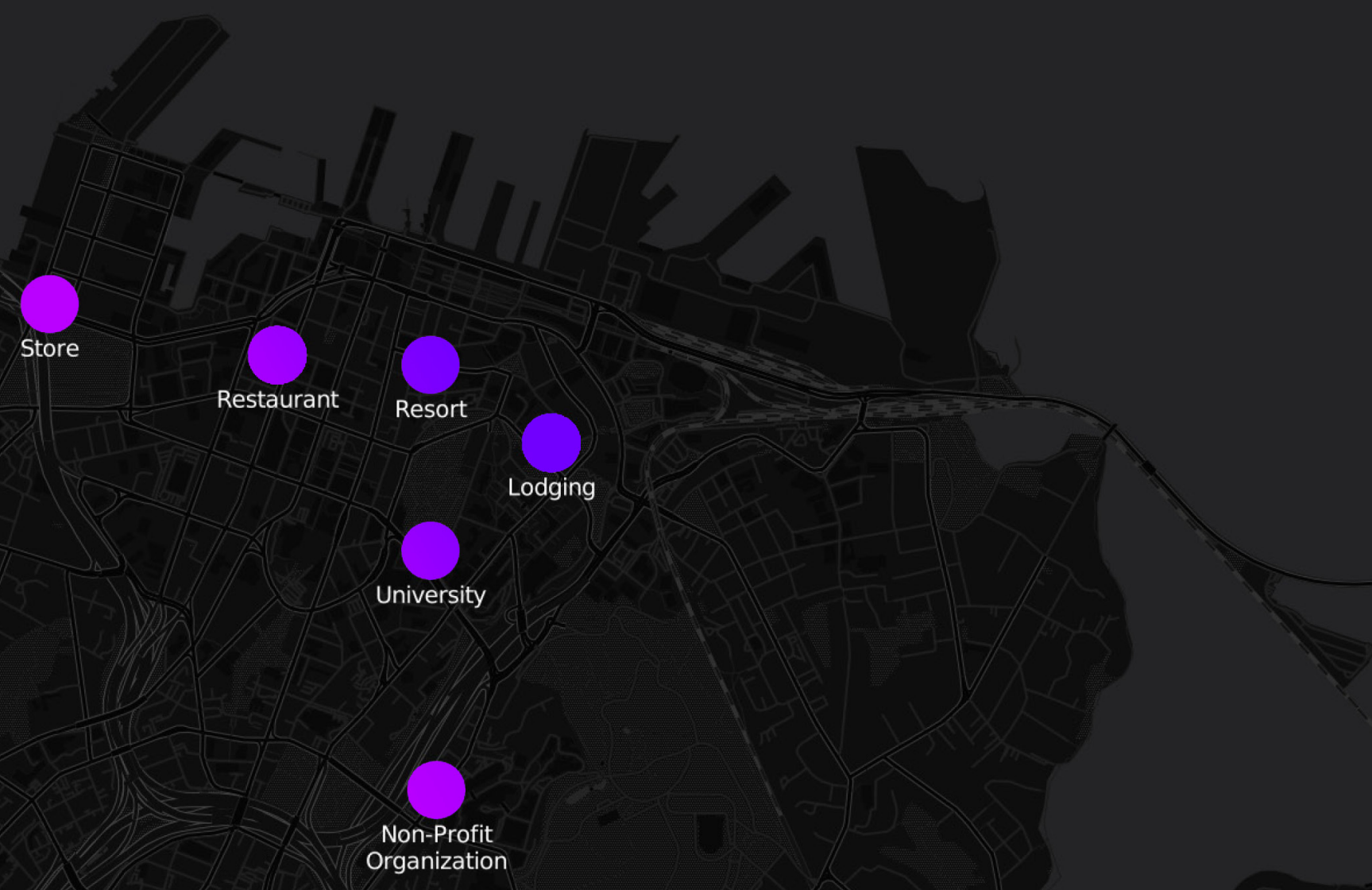




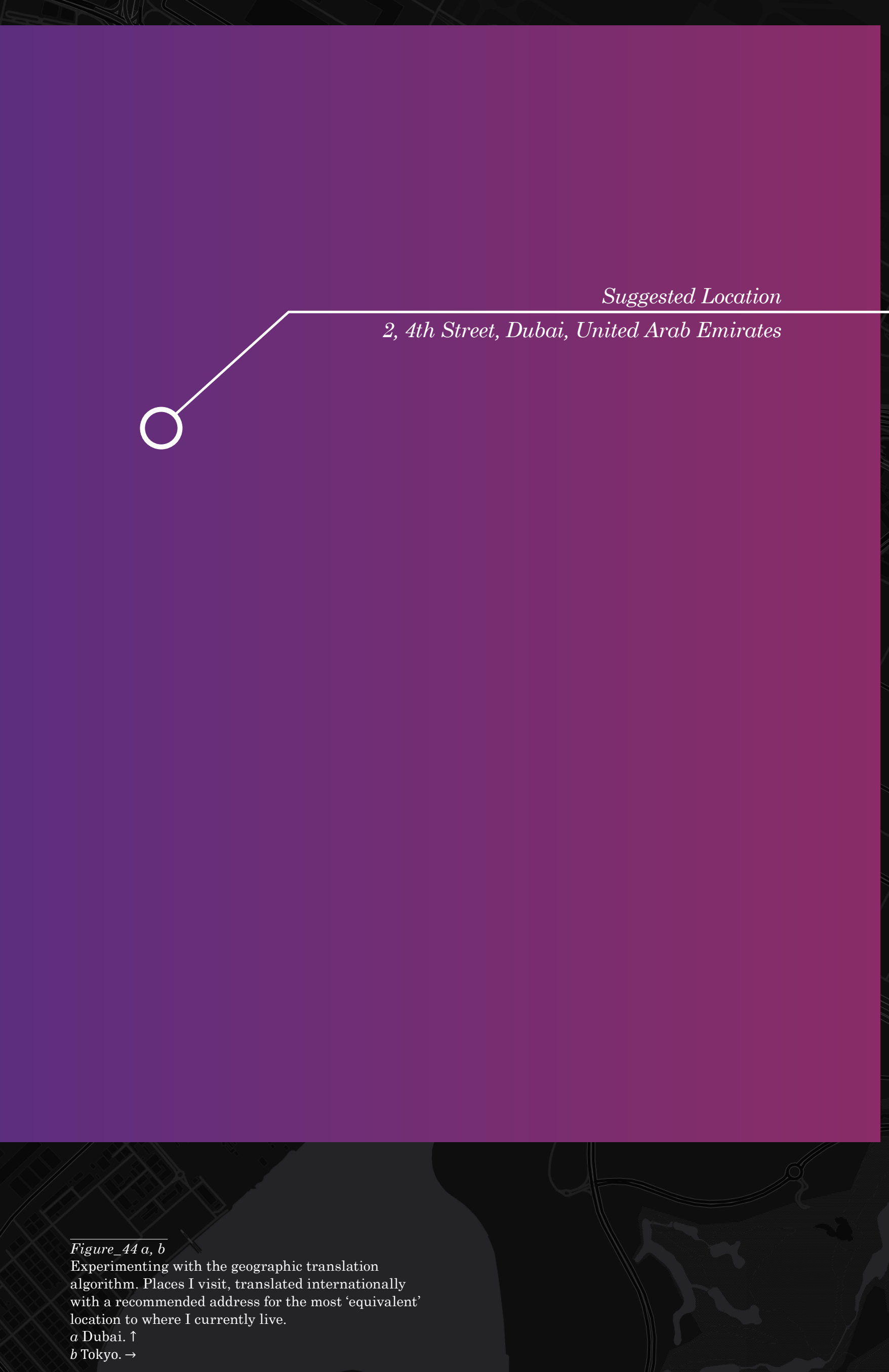




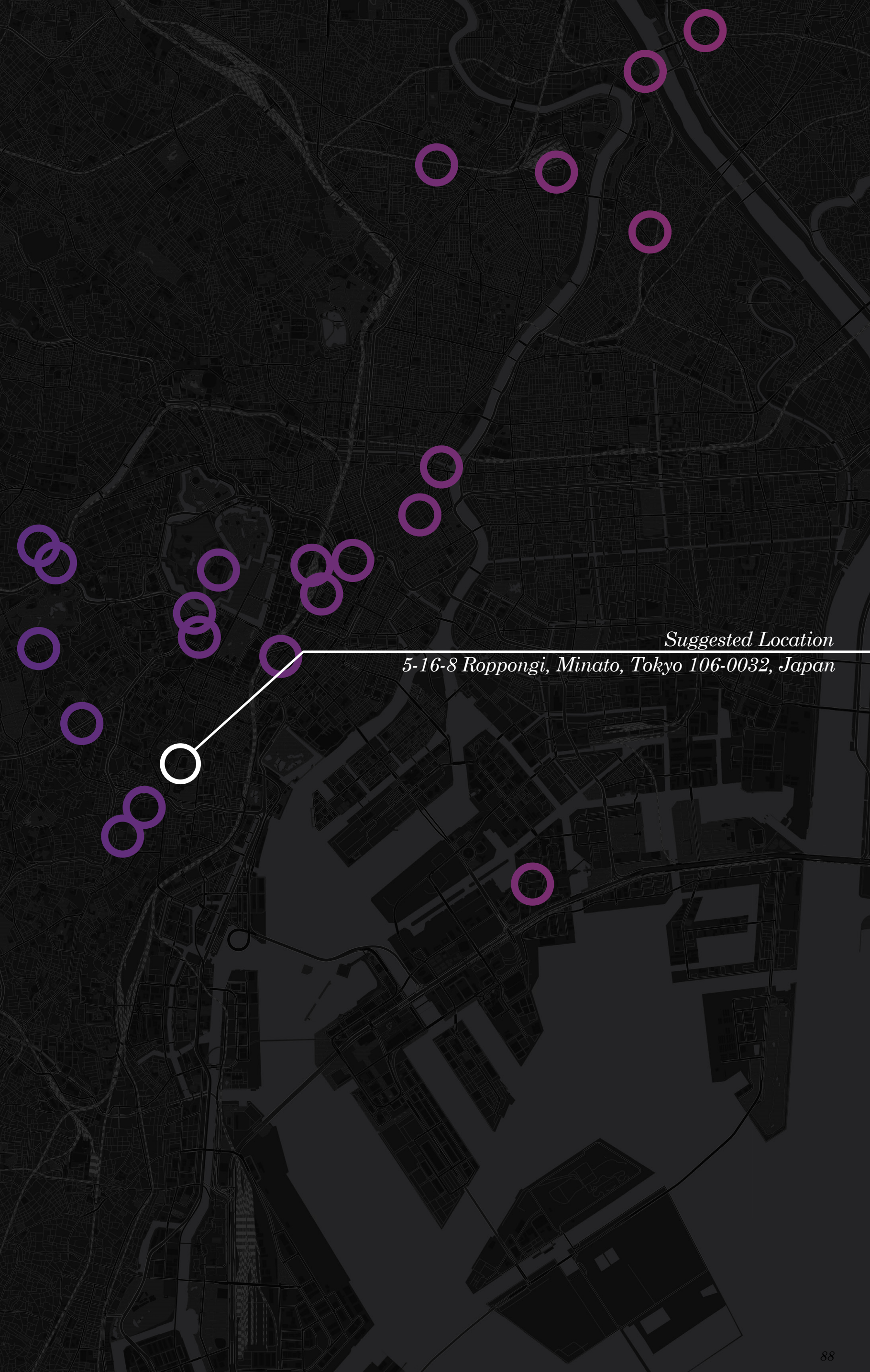


Kuta Squae

International Departure Terminal Denpasar, Bal

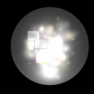

Maha Ungasan Villa

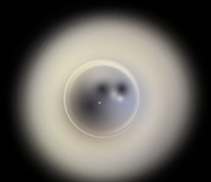

Kawan Mini Market, Nakula

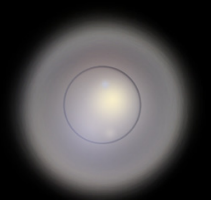

Home

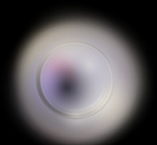

Gunung Kawi Tample Tampak Siring

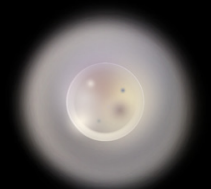

Karma Kandara Private Beach, Namos

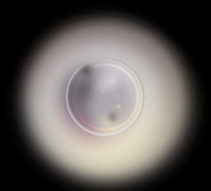

Generic Shop 4

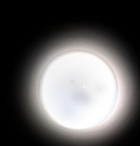

ASB Sports Centre

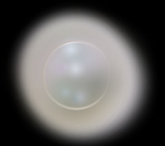

Gordon Harris

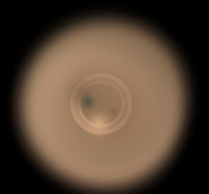

Jl. Legian, Kuta

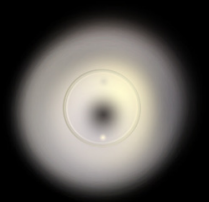

Generic Shop 2

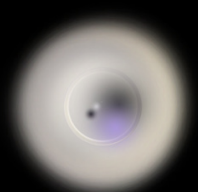

Circe K, Petitenget Line, Kuta,

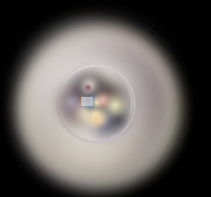

Local Soccer Field

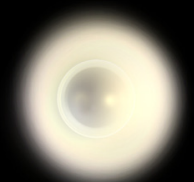

Karma Kandara Beach Club

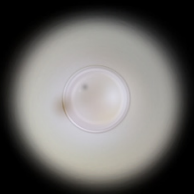

Harvey Norman

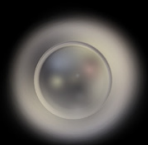

Goa Gajah Temple

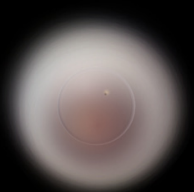

Gunung Kawi

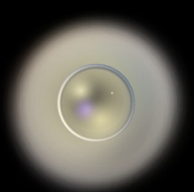

Generic Shop 3

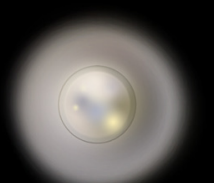

Bar and Cafe, Bali
Lembongan Dream Beach Resort

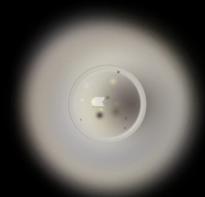

Kendi Kuning Bar and Restaurant

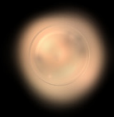

Jetts Fitness, Newtown

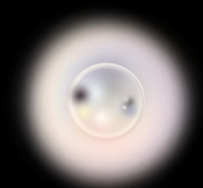

Hai Tide Bar and Grill

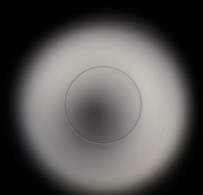

Glory Express

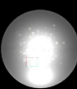

Georgia's House

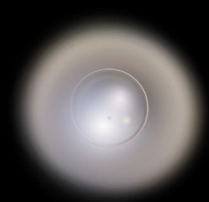

Generic Shop 1

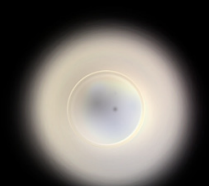

Batur Volcano, Bali, Indonesia 


\subsection{ATMOSPHERE}

To further explore potential outcomes of the data I created atmospheric scenes in Unity using $\mathrm{C \#}$ scripts to harness data collected in Reporter App, Moves App from locations along with photo metadata.The data translations focus on familiarity.

The number of visits define the fog particles size, fewer visits equate to less familiarity and therefore more fog. The transparency of the fog is similarly defined by the total amount of time spent at the location. The particles change less often the more work is done at a location - locations where work is done are likely more focussed and less diverse meaning the fog remains more consistent. Small glitching screens appear within the sphere based on the amount of time spent in front of a screen at the place. The lightness of the overall scene is based on happiness data recorded at that location. The size of the orb is determined by the light values recorded in location-matched photographs. The colours of the fog particles are determined by colours in these photographs.

\footnotetext{
Figure_45 $a, b, c$

Atmospheres developed using C\# scripting and Unity particle arrays based on place data collected in Moves App. Each changes and pulses in a unique way depending on data about the place. Should be watched as a video (linked above). $\leftarrow \curvearrowright$ Next pages
} 


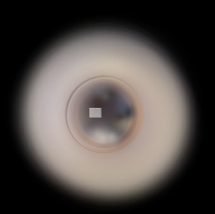

Legian Street, Kuta, Bali

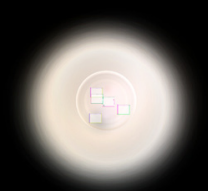

Sydney Airport International Terminal

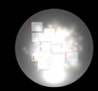

Villa Pajar, Ubud

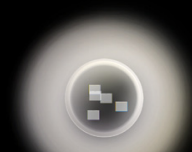

Shop Generic 3

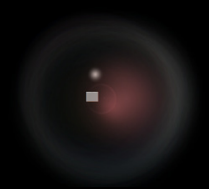

Wasabi Sushi

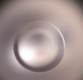

Victoria University of Wellington

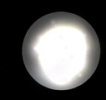

The Royal Purnama Villas

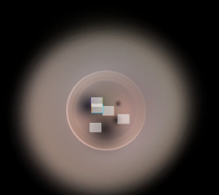

Rotheram Terrace

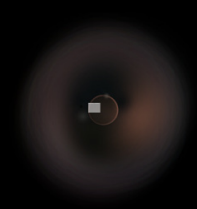

Wellington City Council

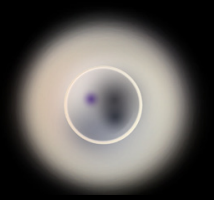

Toro Sushi Ubud

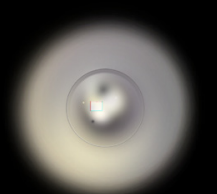

Yan Yan Silver Jelewery Hand Made Factory [sic]
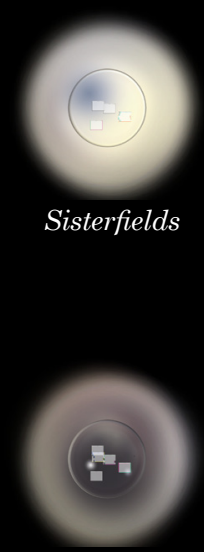

Taksu Spa

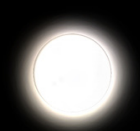

Tigerlillys Boutique Hotel

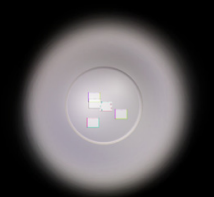

Sacred Monkey Forest Sanctuary, Ubud

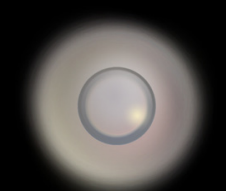

Pick up Location

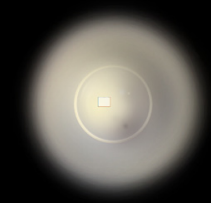

Wood Carving Workshop

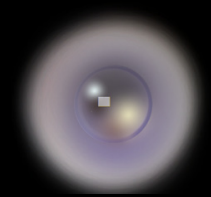

Warung De Koi Tampaksiring

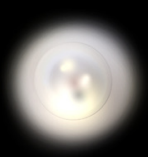

Three Monkeys

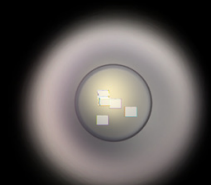

Sunrise Huts Lembongan

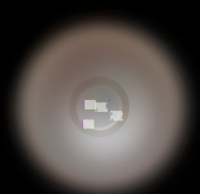

Sydney International Airport Gate 36

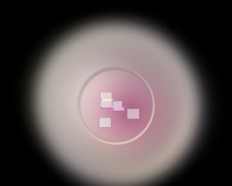

Taranaki Street, Wellington

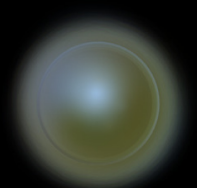

Por Pors House

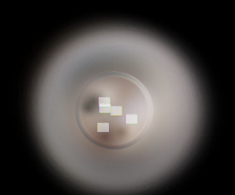

Rouge Sushi and Lounge Bar
Place in New Zealand Contiguous Zone

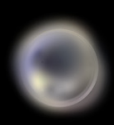

Ubud Palace Puri Saren Agung

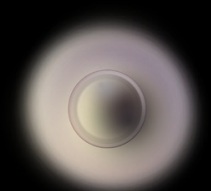

Tegallalang Rice Field Terrace

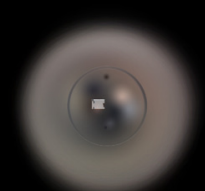

Wellington Domestic Terminal

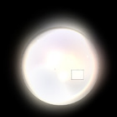

Standing Stones Restaurant and Beach Lounge

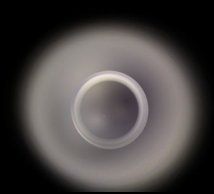

The Flea Market Seminyak Bali

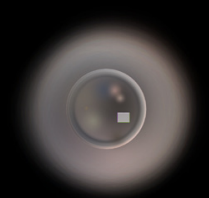

Red Architects

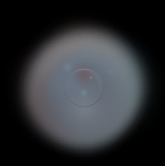

Place in Auckland International [sic] 


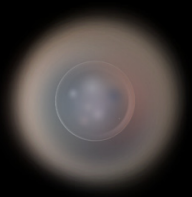

Shop Generic 1

\section{Shop Generic 2}

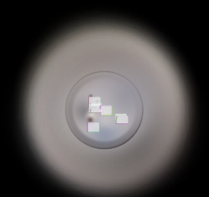

Sacred Monkey Forest

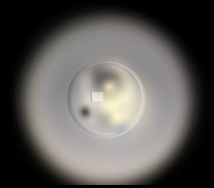

Mini Mart, Oberoi

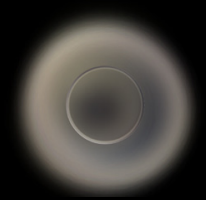

Mount Batur

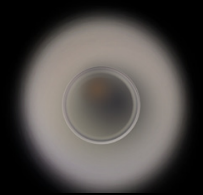

Fidels Cafe

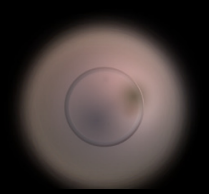

Devils Point, Nusa Lembongan, Bali

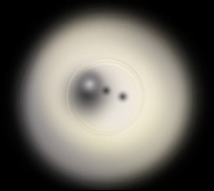

Bambu Restaurant, Bali

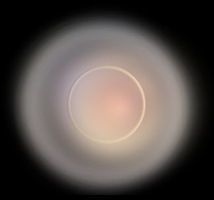

Gelato Secrets

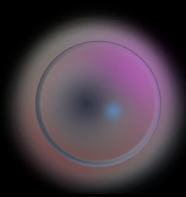

Noel Leeming

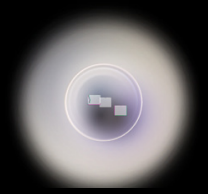

Sea Circus, Bali

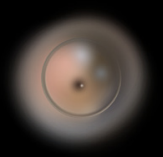

Pura Tirtha Empul Tampaksiring

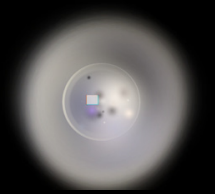

Mini Market $K$

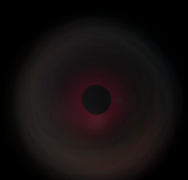

Cafe Instanbul

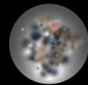

Countdown Newtown

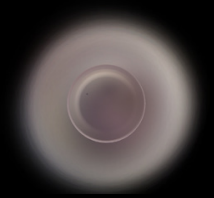

Gelato Factory, Bali
Pak'n'save Kilbirnie

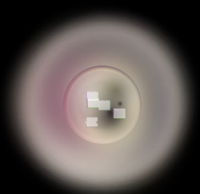

Seminyak Village

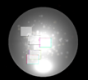

Victoria University of Wellington, Architecture and Design School

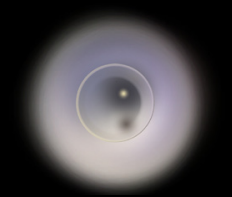

Nimala Mini Market

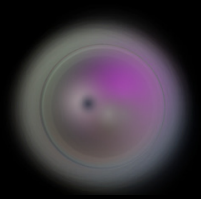

Noel Leeming

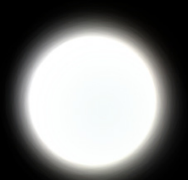

First Year Studio

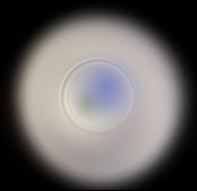

Body Works Spa at Seminak, Bali [sic]

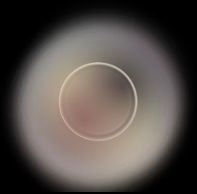

Co-operative Bank
Pantai Melasti, Ungasan

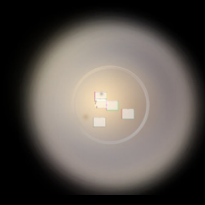

Sanur Beach

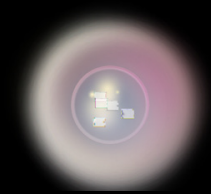

Satria Luwak Coffee

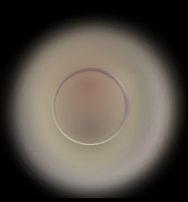

Palm Lagoon

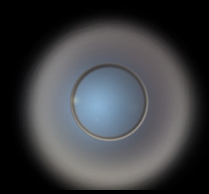

Dream Beach, Lembongan

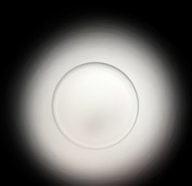

Finn's Beach Club, Canggu

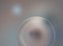

Bali International Airport Denpasar, Bali, Indonesia

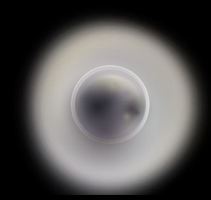

Black Canyon Corner, Petitenget 


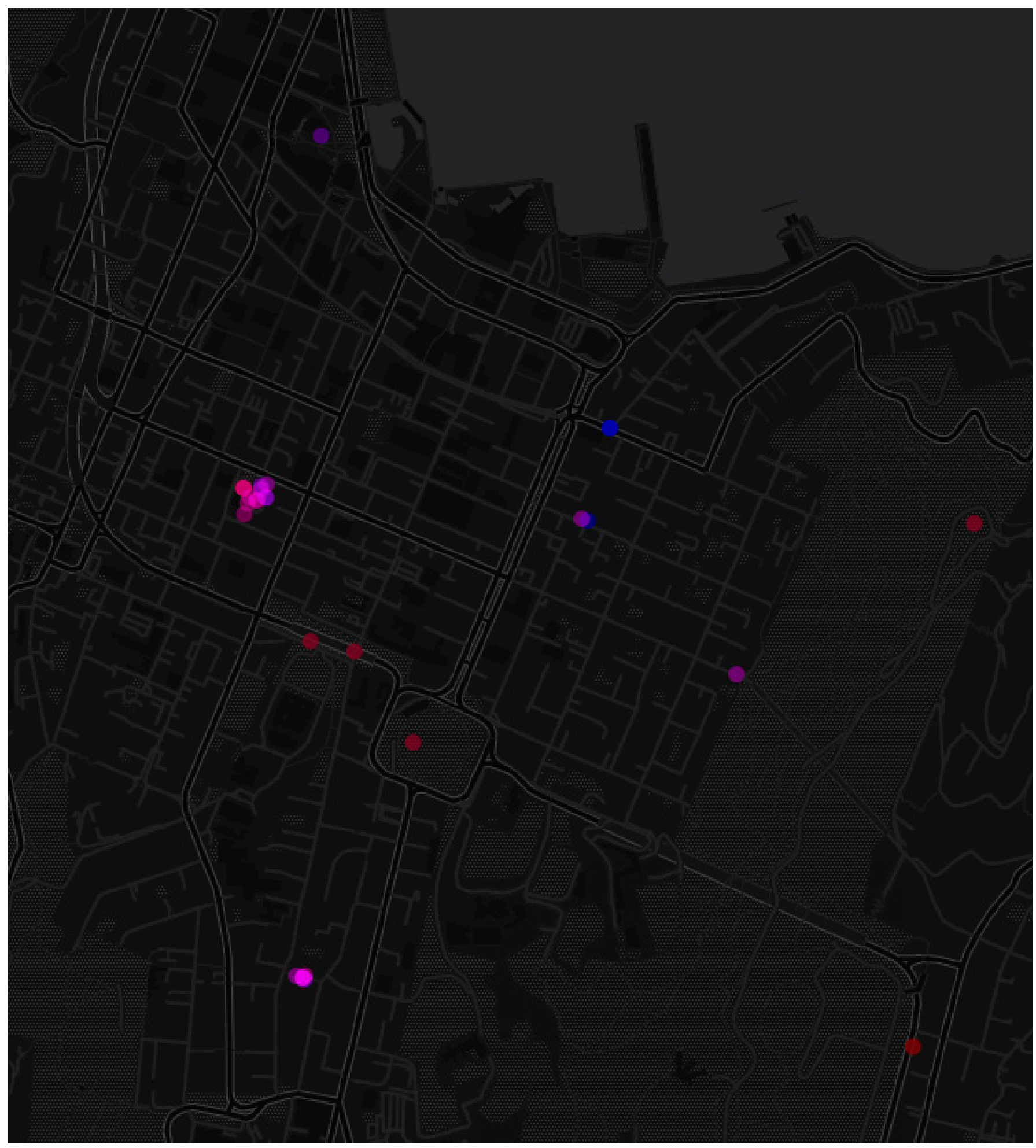

$\overline{\text { Figure } 46}$

Brightness Value

Extracting atmospheric elements of 'place' from

photo metadata. Each dot represents a photo I

took and the brightness of that location, allowing

us to assume to a degree something about the

atmospheric conditions of those locations. $\uparrow$

$\overline{\text { Figure_47 } a, b, c, d}$

Extracting atmospheric elements of 'place' from noise levels.

$a$ Commute to University $\rightarrow$

$b$ University $\nearrow$ Top Opposite

$c$ Home $\nearrow$ Middle Opposite

$d$ Supermarket $\lambda$ Bottom Opposite 

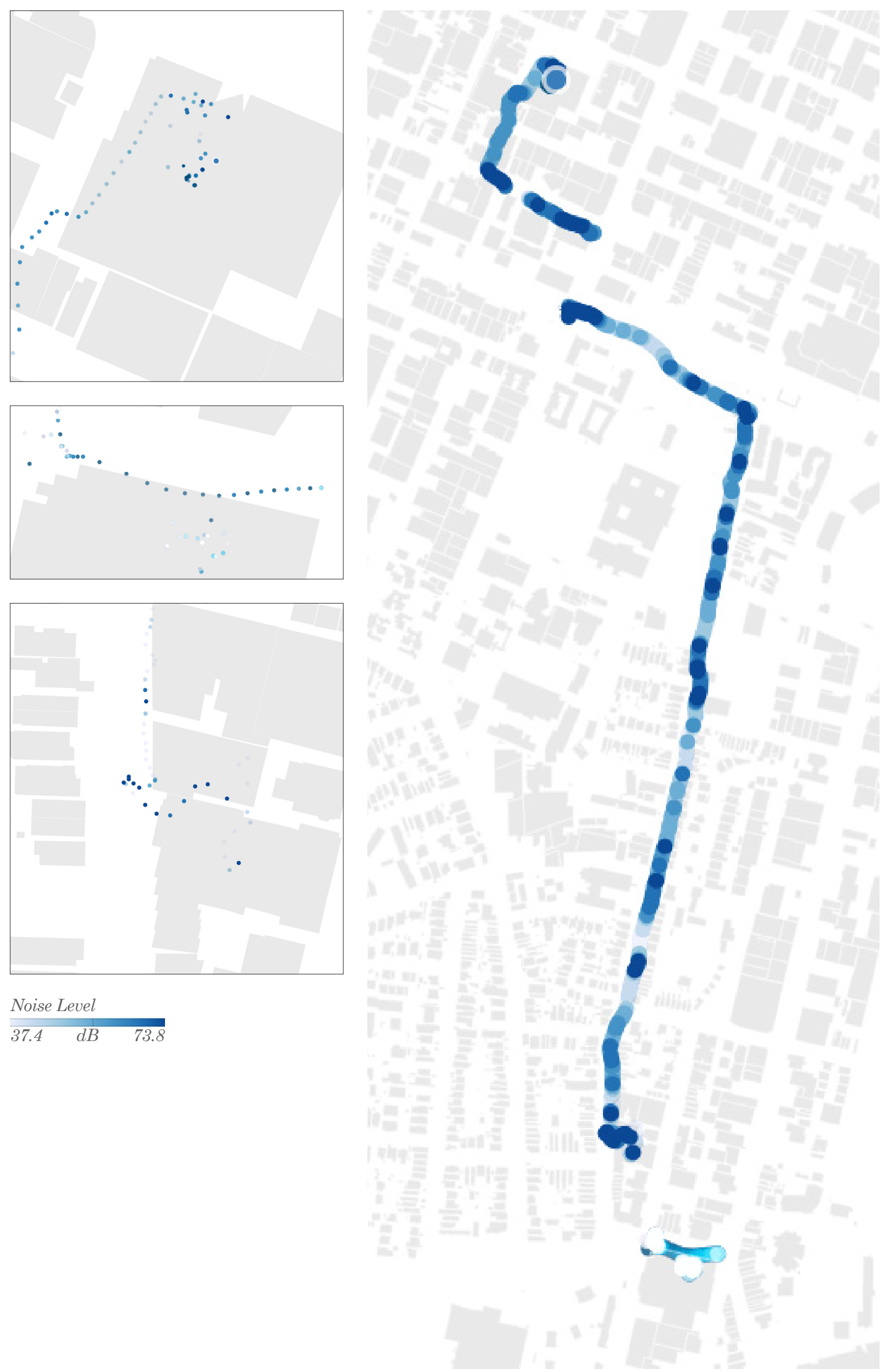


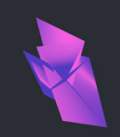

Crawford Green Park

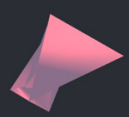

Victoria University Architecture and Design School

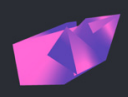

Georgia's House

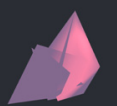

Victoria University Architecture and Design School

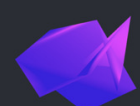

Georgia's House

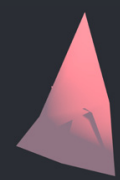

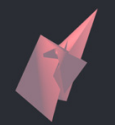

Cafe Polo

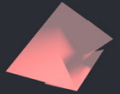

Victoria University Architecture and Design School

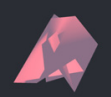

Victoria University Architecture and Design School

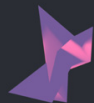

Victoria University Architecture and Design School
Countdown, Newtown

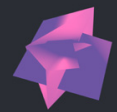

Georgia's House

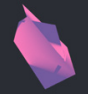

Victoria University Architecture and Design School

Georgia's House

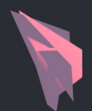

Victoria University Architecture and Design School
Gipsy Kitchen

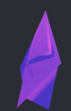

Georgia's House

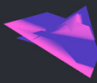

Jetts Newtown

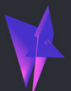

Georgia's House

\section{$\overline{\text { Figure_48 }}$}

A range of times and places scripted

to produce diagrams cataloguing weather, time and noise of places. $\uparrow$

\section{$\overline{\text { Figure_49 }}$}

A range of times, noise levels and

weather measurements taken at

home throughout a weekend. $>$

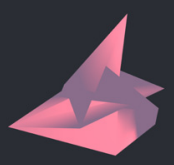

Victoria University Architecture and Design School 


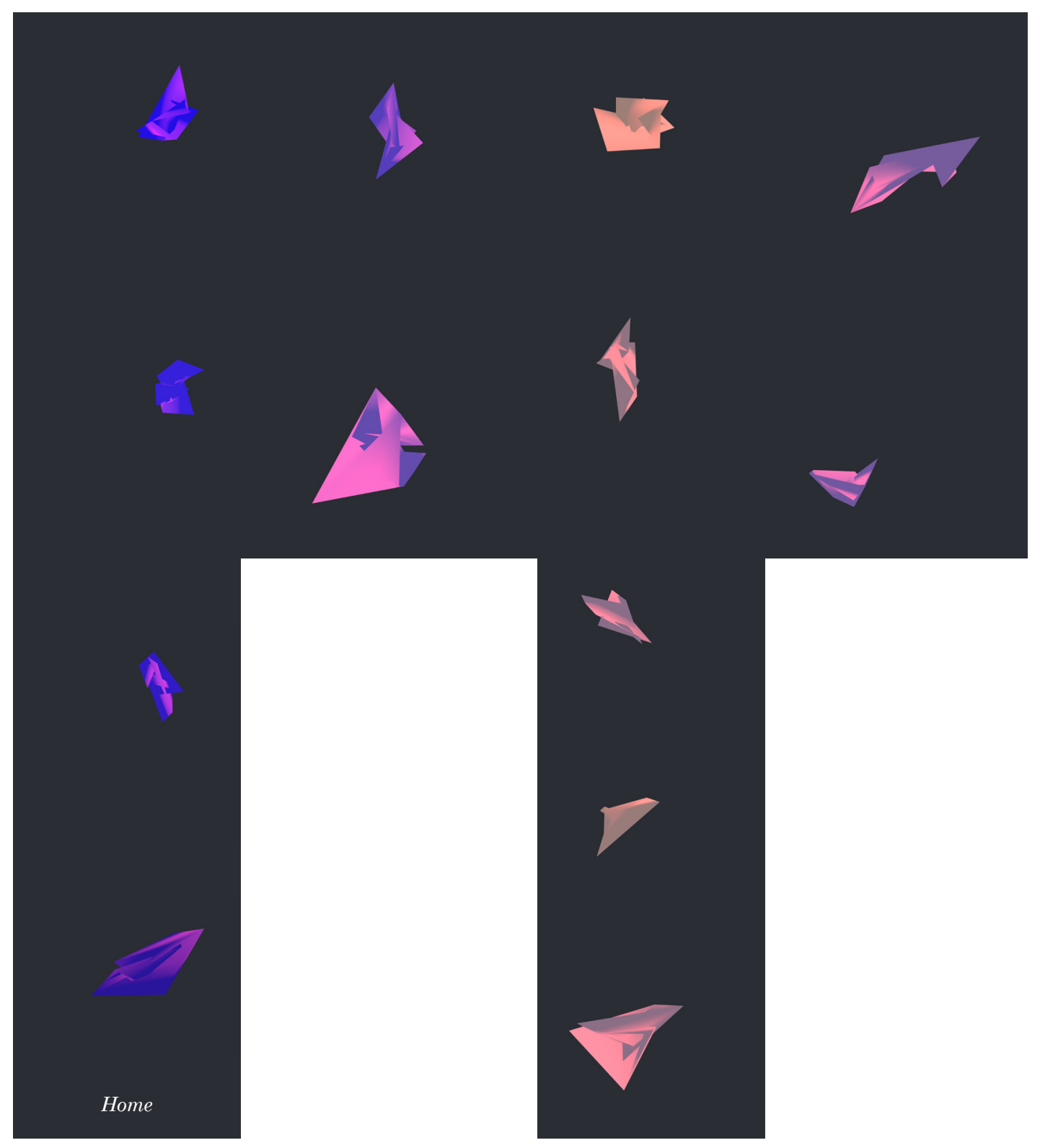

Data about conventional considerations of atmosphere such as lighting and noise data perceived by a person at different locations is also available. Through the use of time metadata, a cross reference with a weather API can return the state of the weather for a location. A phone's microphone can return noise levels. A combination of these traditional architectural factors was created by generating a jagged shape based on the noise at a locations. This was coloured by time of day and finally had a light projected onto it that was manipulated by the state of the weather. The outcome was illegible in terms of form although the soft light projections based on the weather were successful at unobtrusively conveying information.

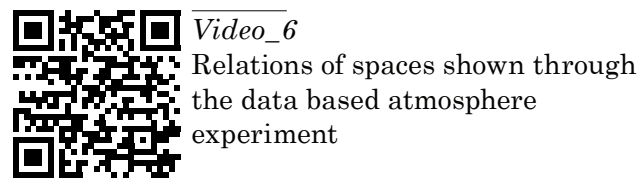




\subsection{DATA INTERACTION AND OWNERSHIP}

${ }^{6}$ The balance of power in the data ecosystem is weighted towards
the collectors and aggregators rather than to private individuals
and this needs to be redressed. - Mortier et al., The Emerging Science of Human Data Interaction

It has long been understood in architecture that the "enormous investment in capital, affords next to no room for variation without drastic and costly overhaul of the whole operation", leaving architecture to reflect the style of the time it was built or the whims of whomever commissioned it originally (Abel and Foster, 2012). Digital space is diametrically opposed to this with constant updates, the way content is sorted onto a Facebook wall alone has changed ten times in 2016 (Porter and Fekete, 2016). The ability for users to go beyond critique of architecture and exact change on their environments may allow quality-driven architectural design to reach many more people. As was discussed earlier, architects do not factor into the design of most buildings; an adaptable typology would allow architects to author a framework, within which architecture could be manipulated by inhabitants - giving architects authorship while also allowing personalised architecture to reach more people.

To test the concept of interaction a method for adapting the DLAA was devised. Using a Microsoft Kinect camera, depth and movement could be traced as human interaction. This contactless interaction method allows users to modify a DLAA by moving their hands while looking at a screen. The software designed allows users to 

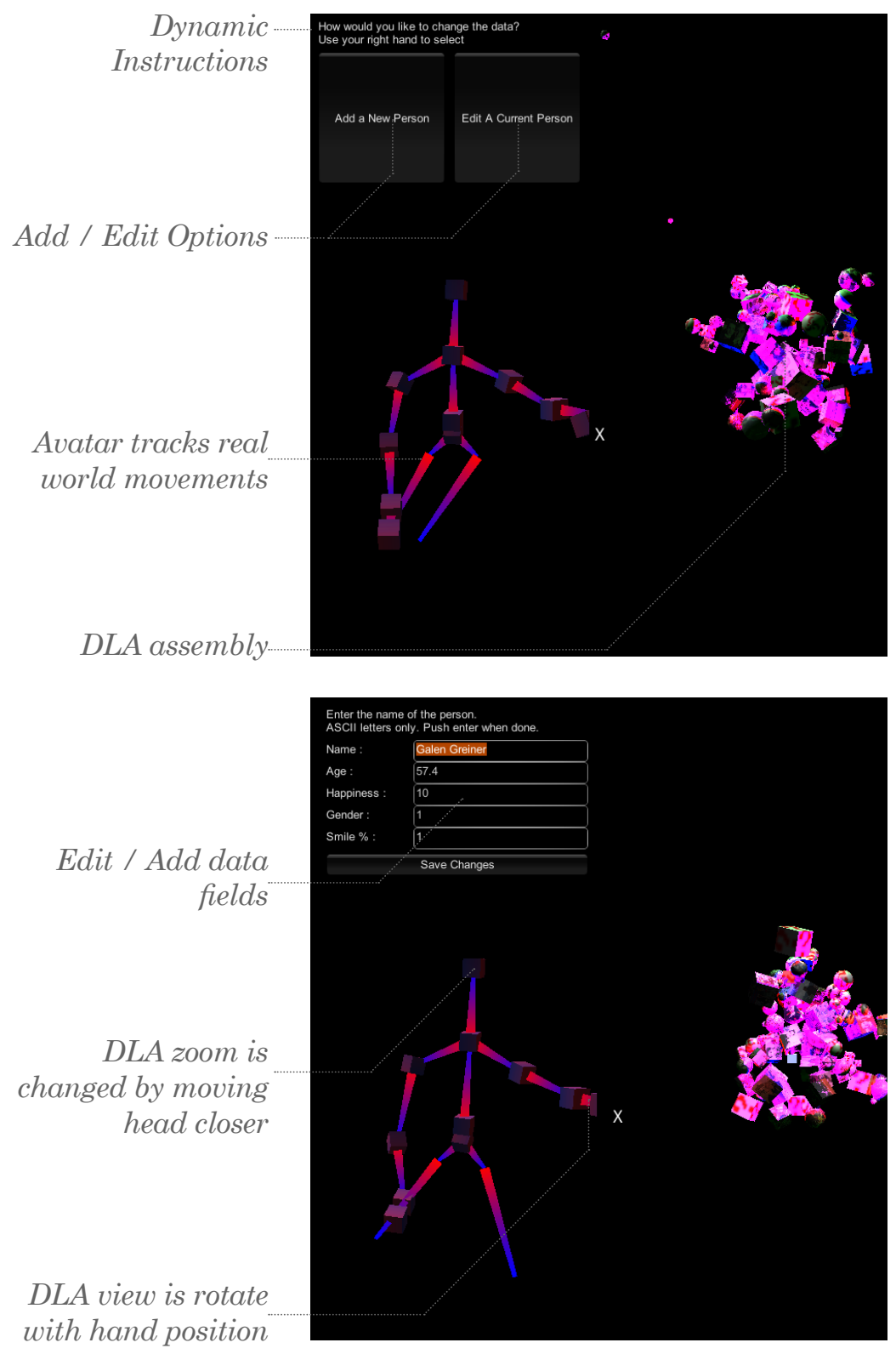

$\overline{\text { Figure_50 }} a, b$

Screenshots of the interactive software developed to explore DLA algorithms using real world gestures through a Microsoft Kinect camera and associated API, integrated with Unity C\# and Javascript coding. $\uparrow \uparrow$

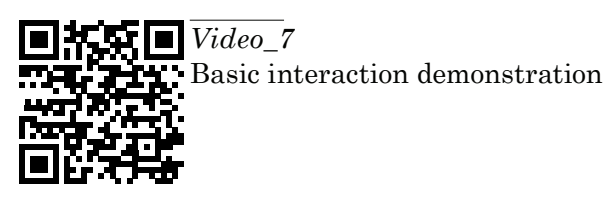



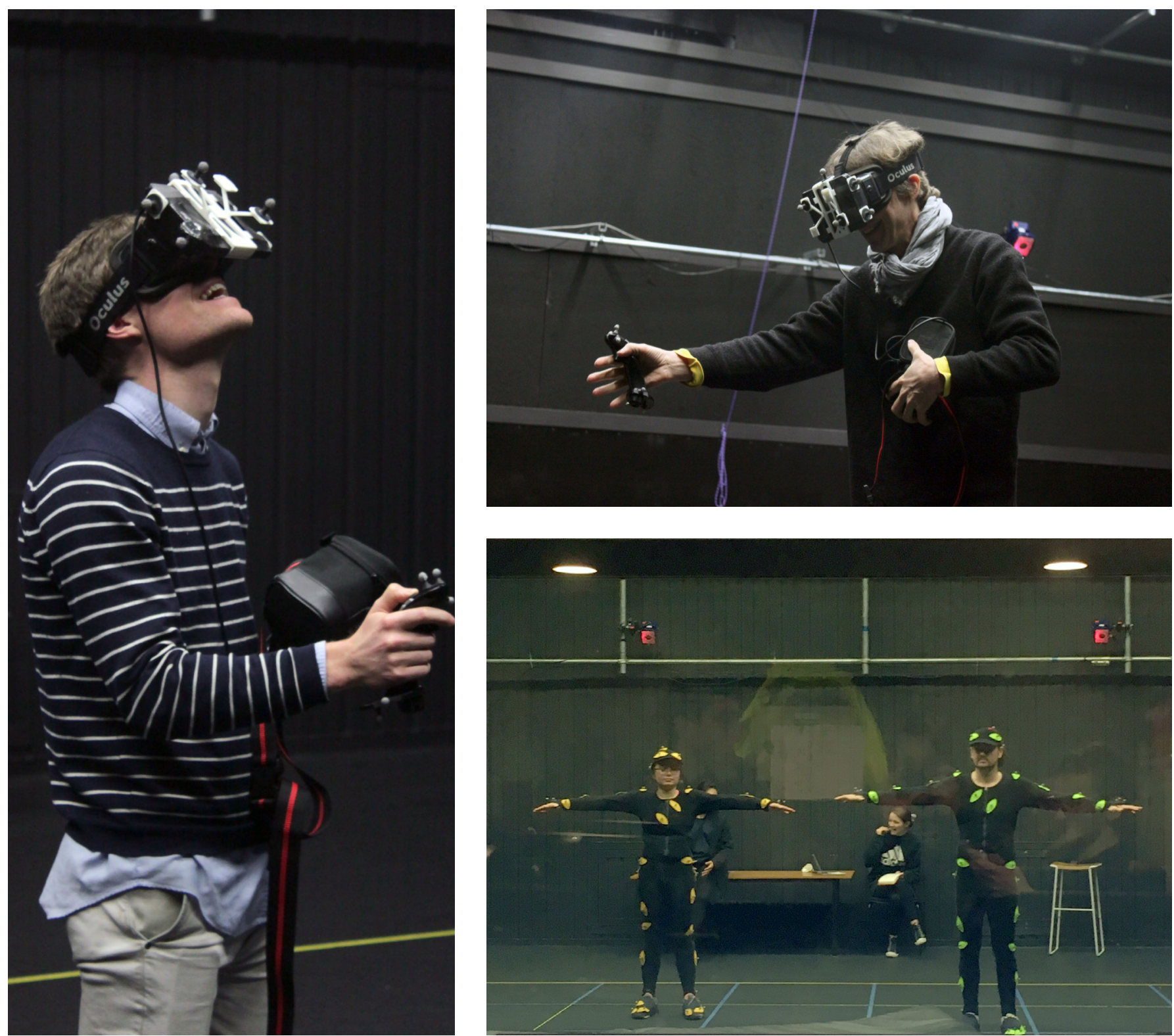

select a node, identify if they are changing themselves or somebody they know and update the data - allowing them to reformat the DLAA. User's can also break or add connections at will. Interaction is simultaneously used as a design tool. With software to enable user interaction, problems can be highlighted by non-designers. To further this interaction a range of experiments were done using tetherless Virtual Reality (VR). Using the Auckland University of Technology CoLab space for wireless VR allowed interaction with the virtual environment without being tethered by cables as shown in figures 51 to 57 - this permits walking anywhere within a large room. A range of experiments were converted to become VR compatible, the most useful included the DLAA which could be scaled and seen in three-dimensions at an architectural scale rather than the small scale allowed by $3 \mathrm{D}$ print prototyping. The atmospheric experiment was also converted and allowed people to transition through the data for a range of locations that I had visited by interacting with 'bubbles' placed on the ground. 

sina-violont

\section{Leesa Batton \\ Kristian Petro

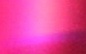

\section{shti Nichols}

Blaire Haslop

the Tankersley

Jetta Harn

Andrew Caldwellca Liddle

\section{Barney Plun}

\section{$\overline{\text { Figure_55 }}$}

Virtual reality view of a DLA algorithm assembling,

allowing interaction and changes to connections to be made. $\uparrow$

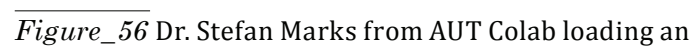

Atmopsheric experiment (explored on page 89) into the

VR software. $\rightarrow$

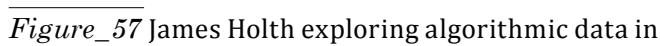
real-world space. $\rightarrow$ 

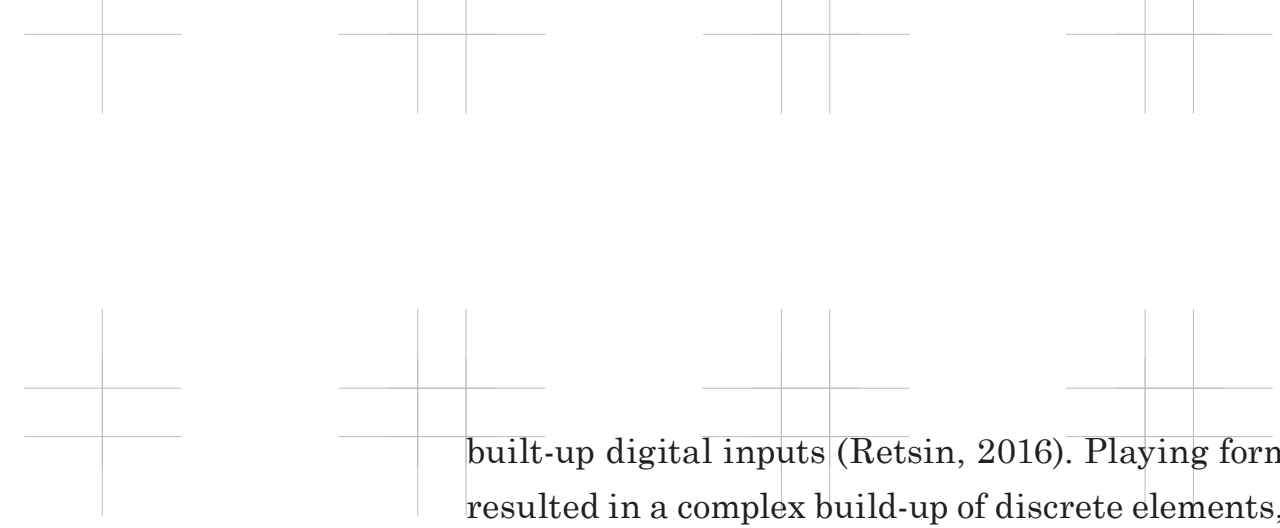

built-up digital inputs (Retsin, 2016). Playing form against data resulted in a complex build-up of discrete elements, each of which aims to portray a data node, a data set or some derivative of the data. The intention is for forms to be read at multiple scales, figure 58 for example was created from many small tubes, each of which was sized relative to data and configured around a data-derived form. While these individual, discrete elements act at one stage as a data visualization and habitation technique, at a larger scale the tubes are coloured by the atmosphere experiments, unifying the discrete elements into a single space. This dichotomy of disparate and homogenous is experimented with throughout. It is important that traditional data visualization is not overbearing. Data visualization does have strong theoretical links with the aesthetics of this research but cannot be a substitute due to the multidimensional nature of architecture when compared with traditional data visualizations. A related importance that clarity is not the focus, instead the focus was on space being derived from data, meaning the data may not be clearly legible from the architecture.
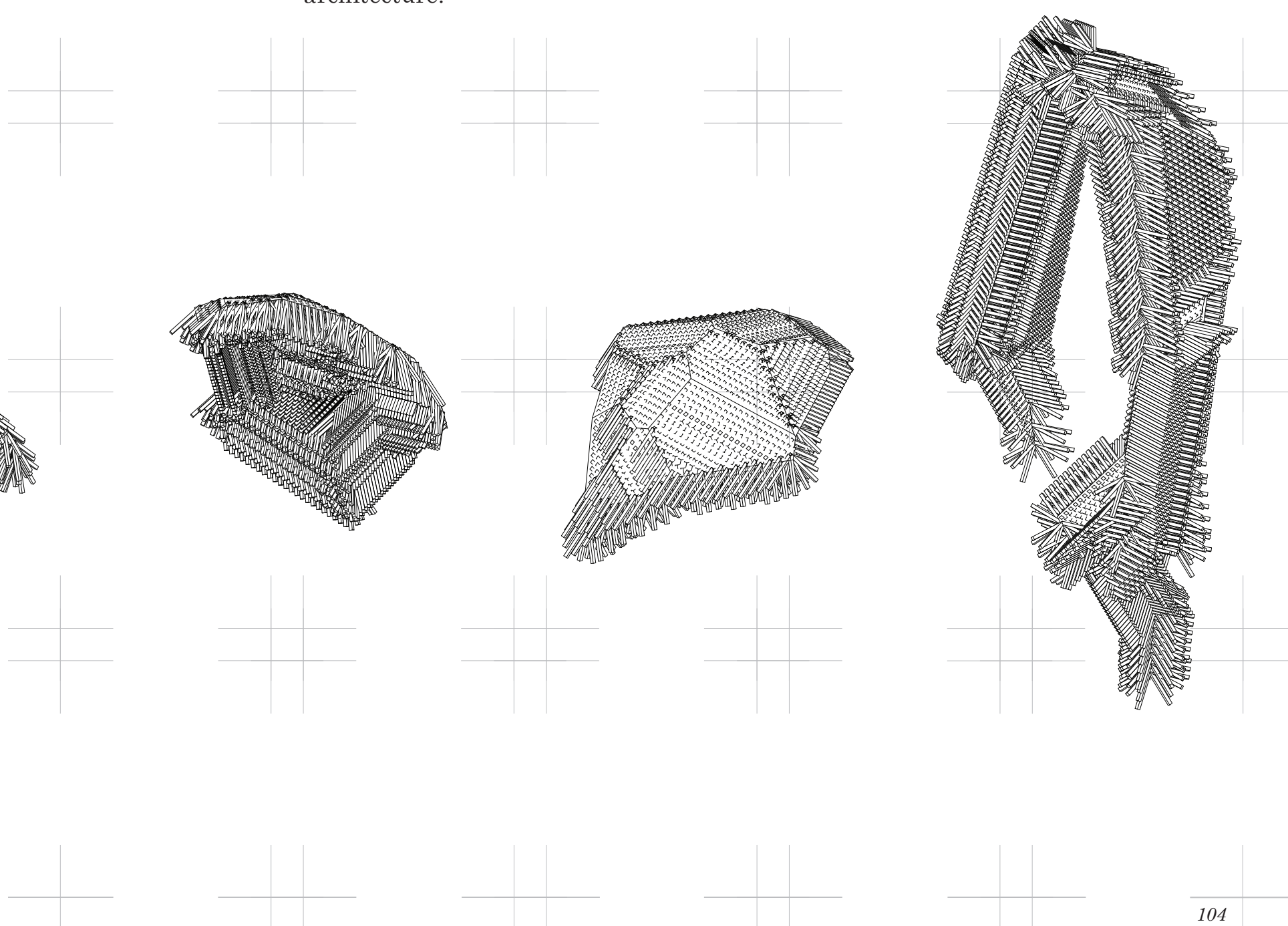

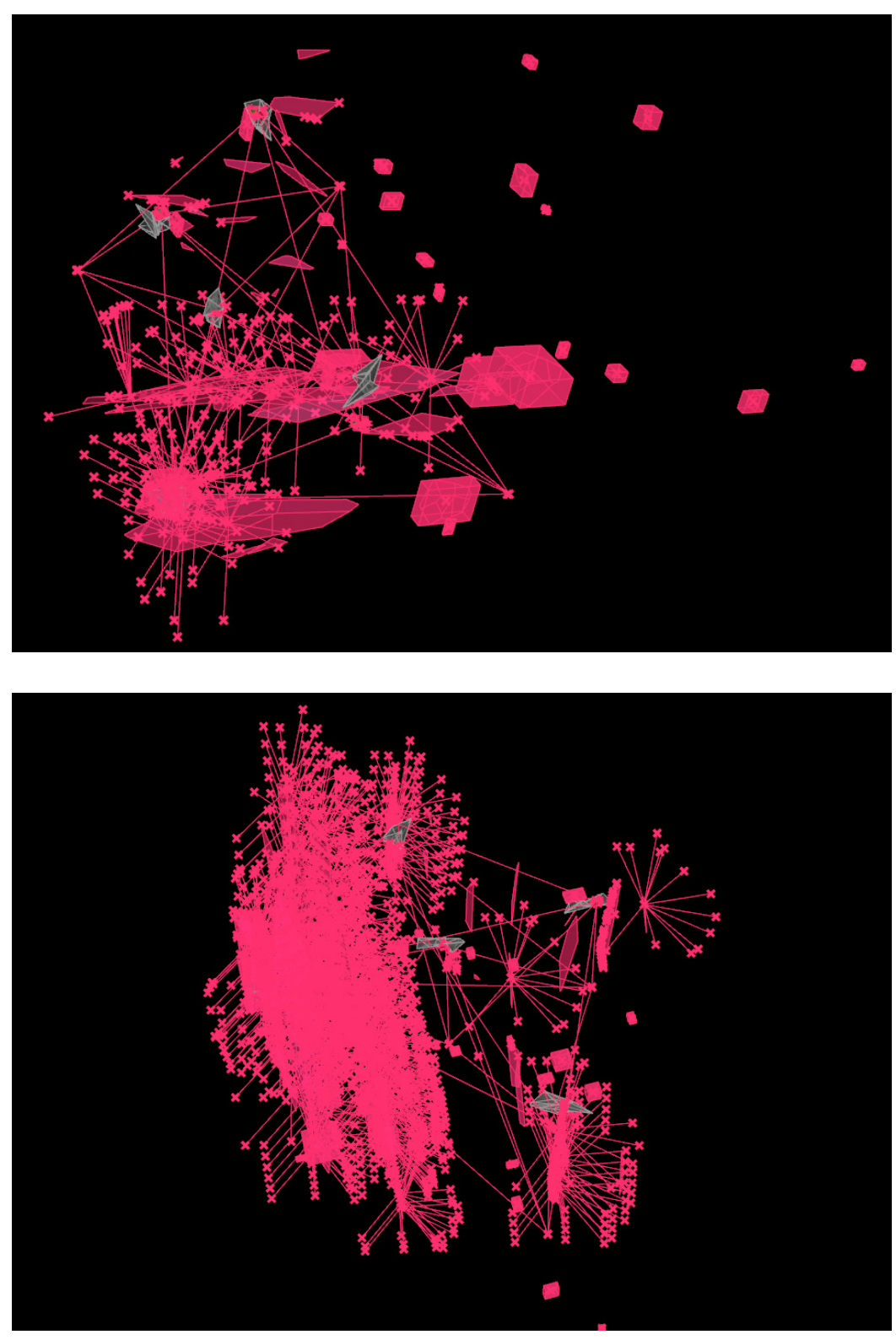

$\overline{\text { Figure_59 } a, b, c, d}$

Explorations assembling individual forms

created from data with a wider network, based on

connections from the DLA experiments and forms

from the atmosphere noise generation experiments.

$\uparrow \uparrow \rightarrow \curvearrowright$ 


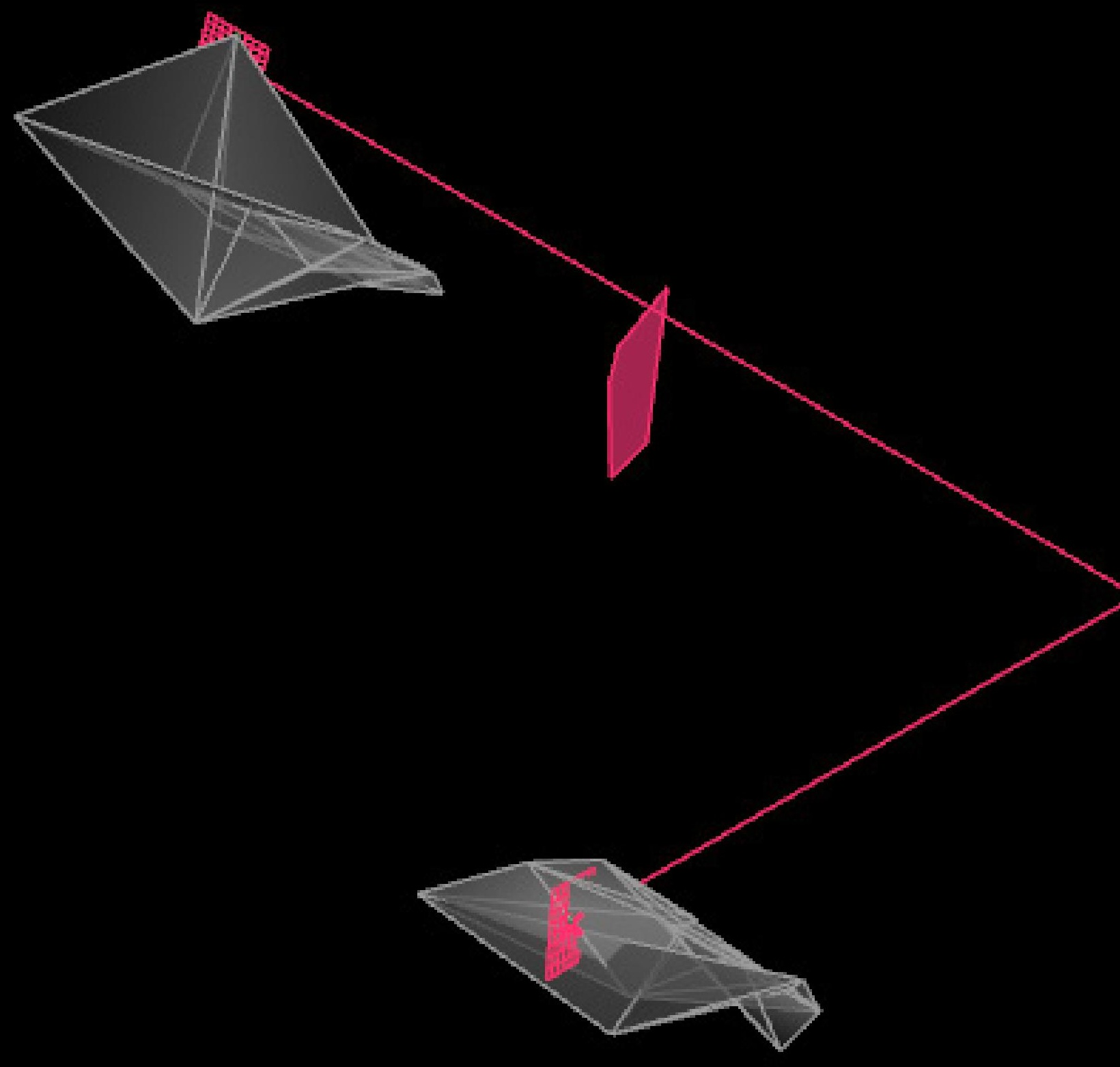




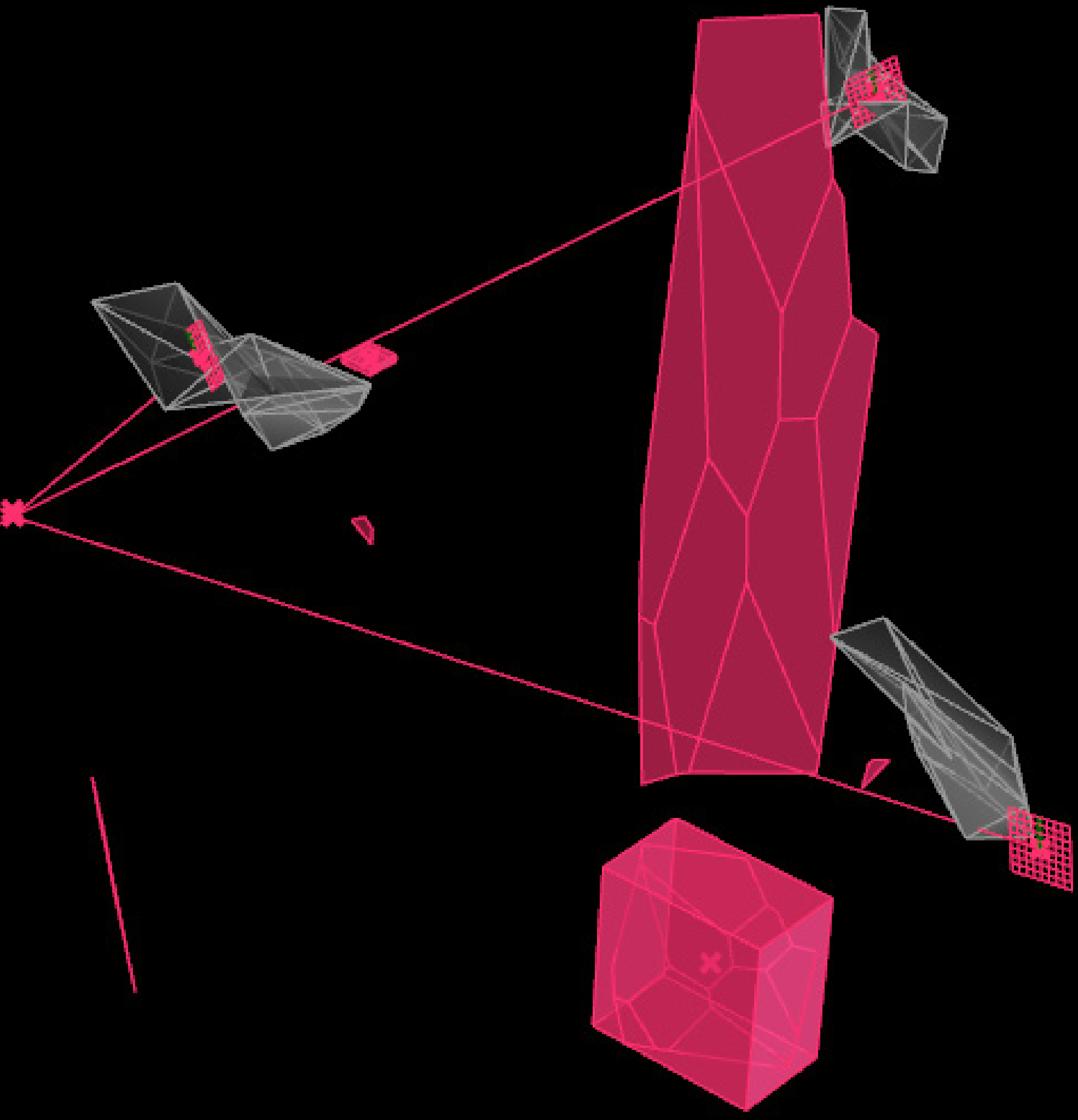


$\overline{\text { Figure } 60 a, b}$

Explorations assembling space (a) and form (b)

through procedural generation and data reading

scripts. $\downarrow \rightarrow$

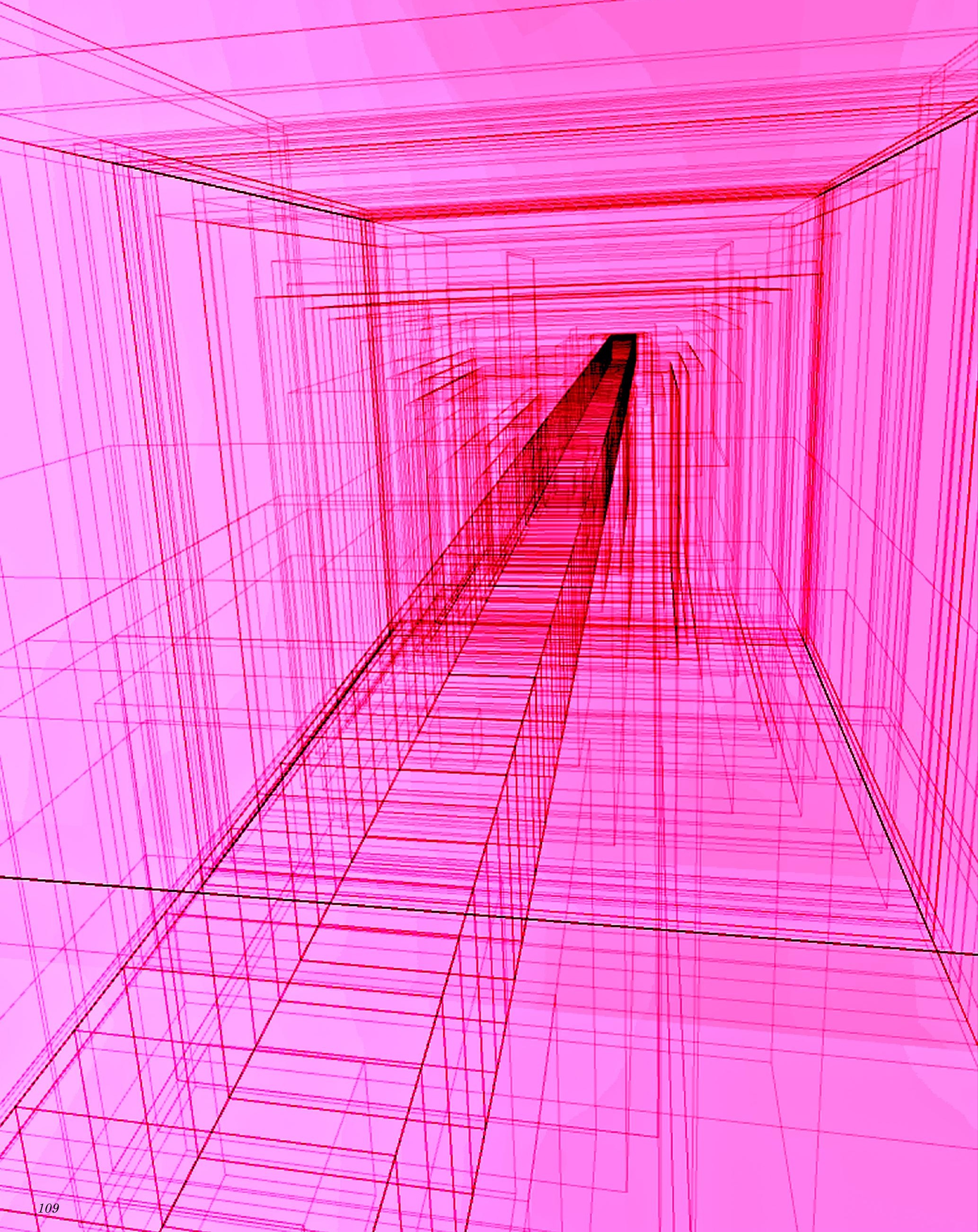




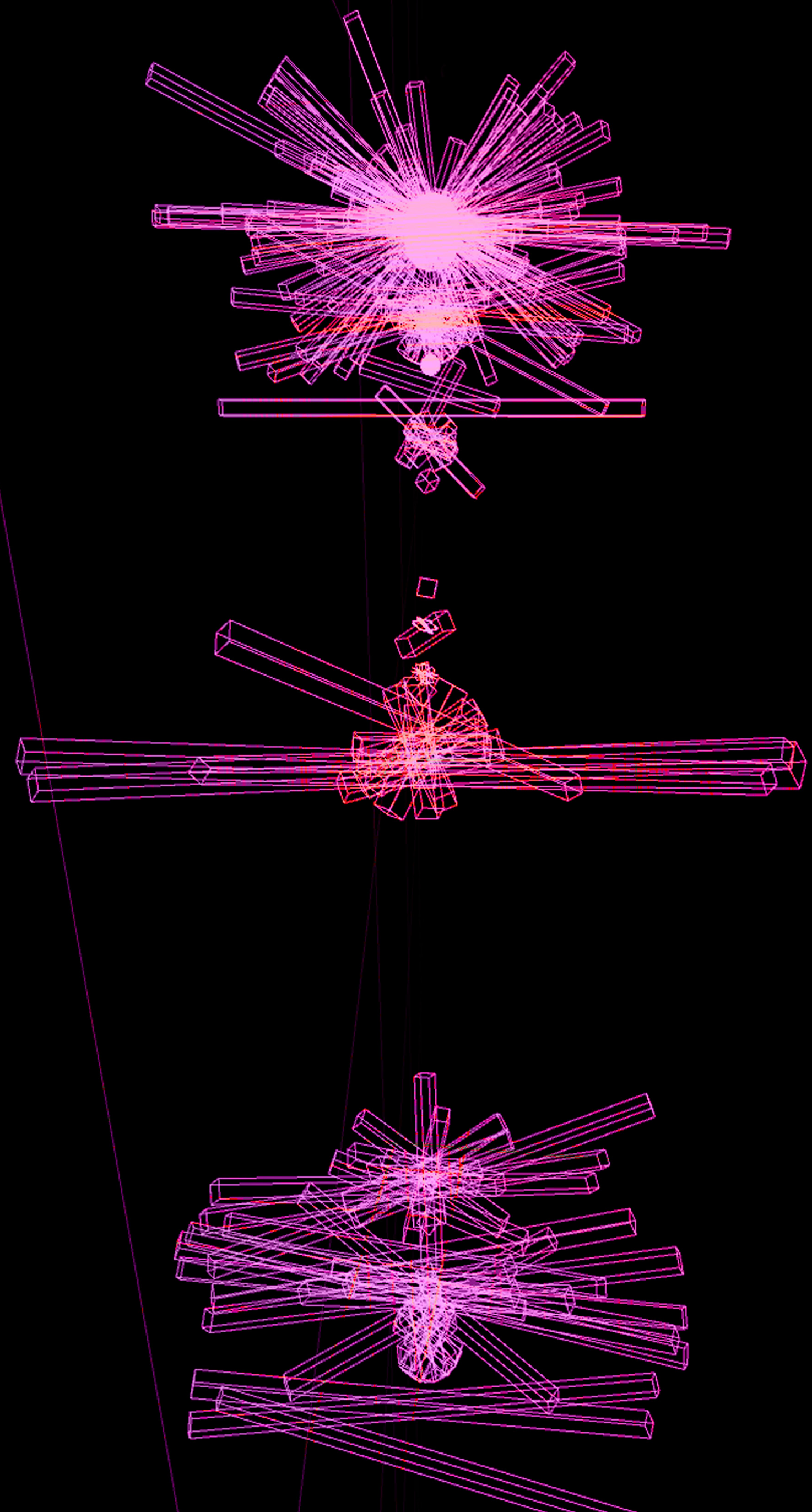



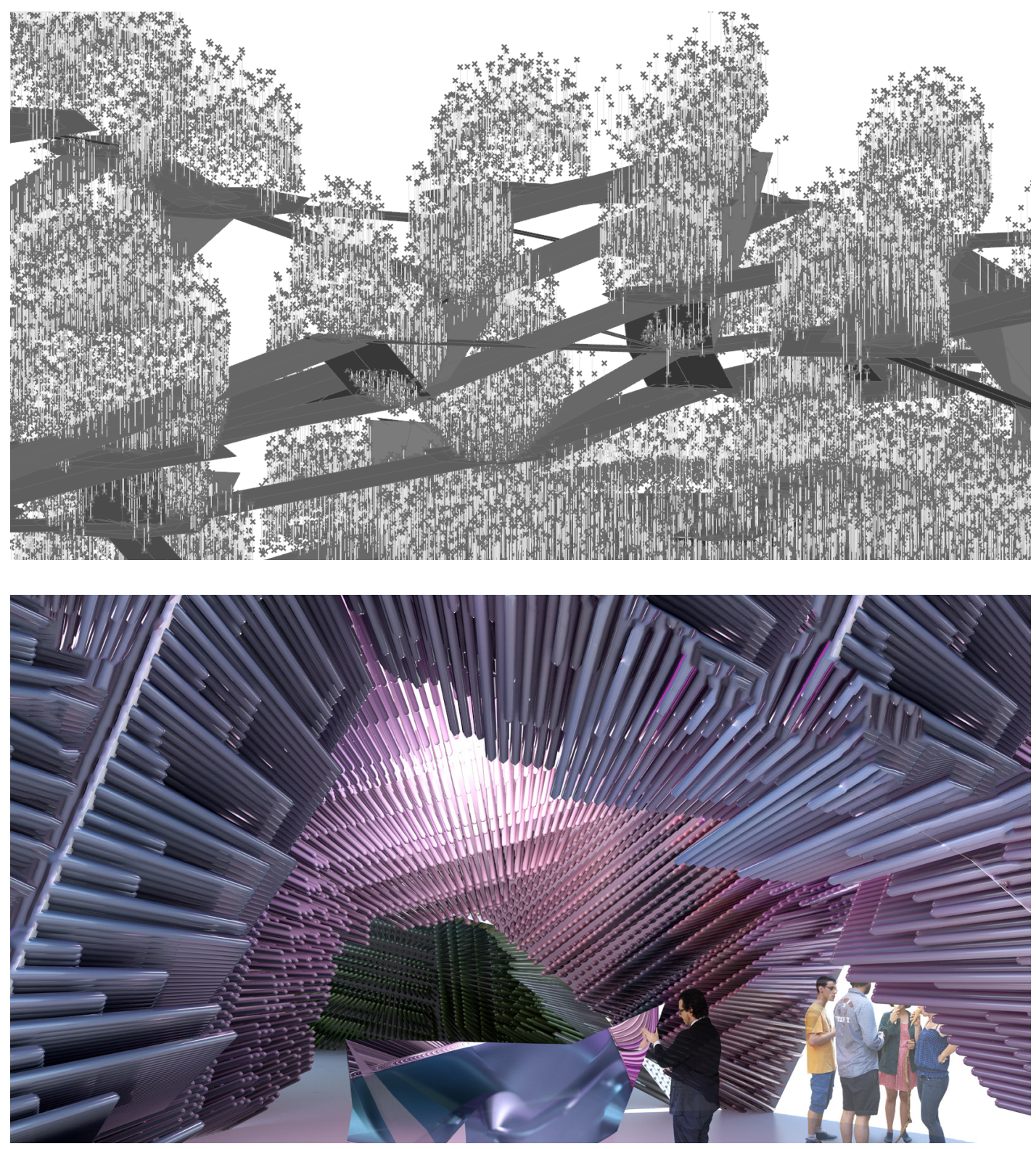

\section{Figure 61}

Exploration of larger data sets using the 2013 New Zealand census data, groupings are derived by similarity of housing stock, while individual lines are represent individuals as estimated off averages. There is the loose concept of an art installation summing up New Zealand from a democratic point of view. $\uparrow$

\section{Figure_63}

Abstract formalisation of multiple data sets created by creating randomised sets based on data collected about myself. Formalisation includes metrics such as daily movement (distance from center), Floor area used (average/hour shown by radius of surface curvature), etc. $\rightarrow \curvearrowright$

\section{$\overline{\text { Figure } 62}$}

Alternate art installation concept of 2013 New Zealand census data. Data is live streamed and colour is generated from photo metadata as generated from photos posted on social media with geo-location in New Zealand. $\uparrow$ 


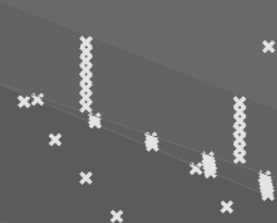

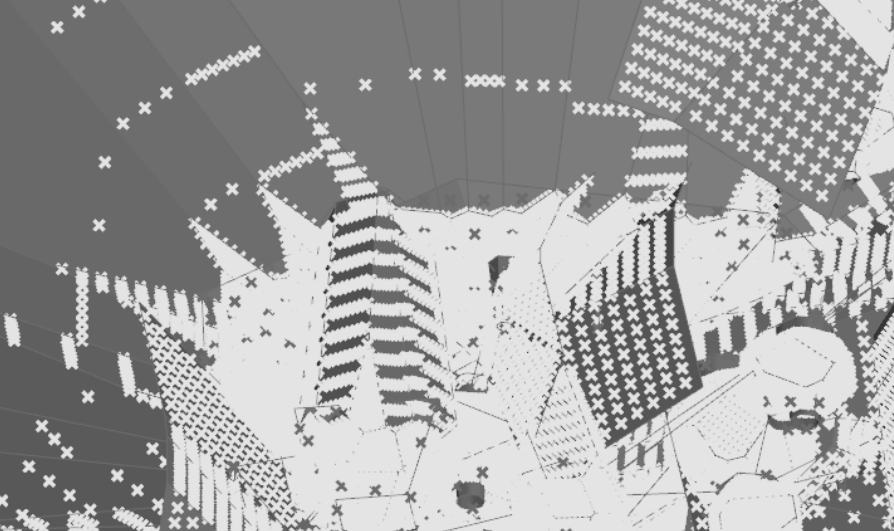

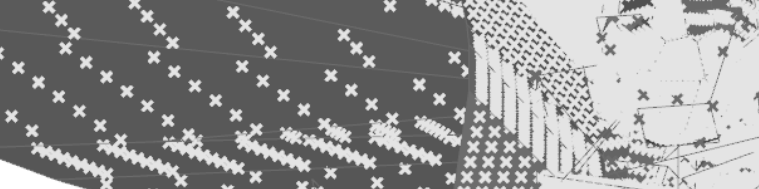
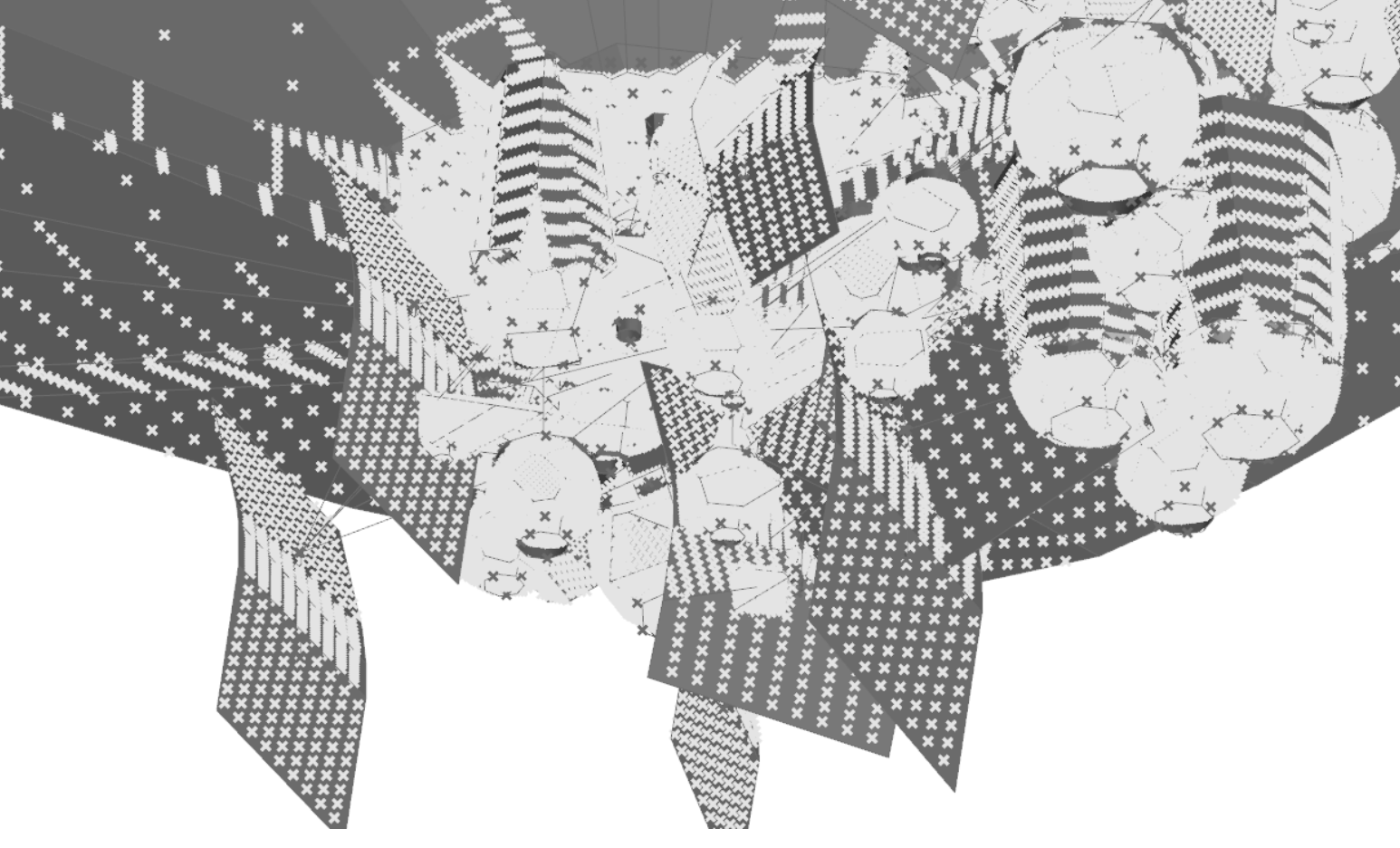

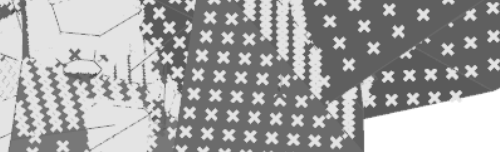

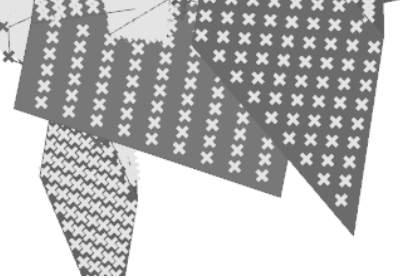

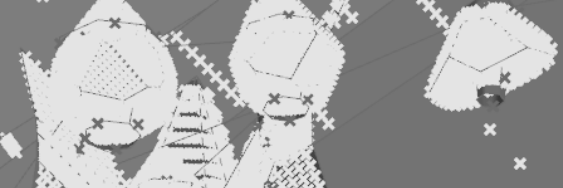




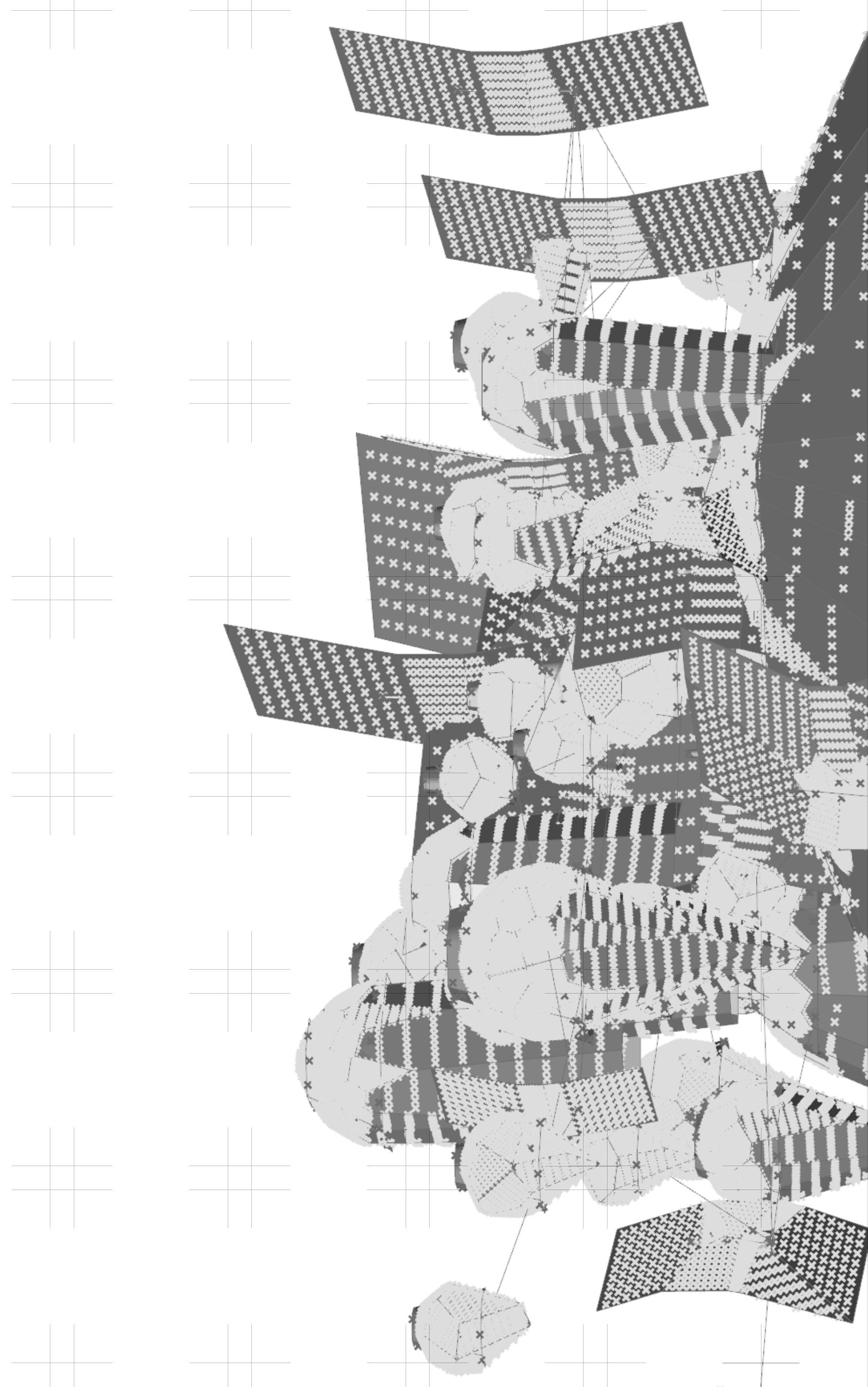




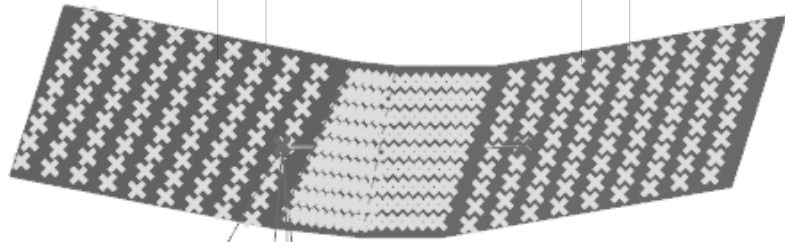

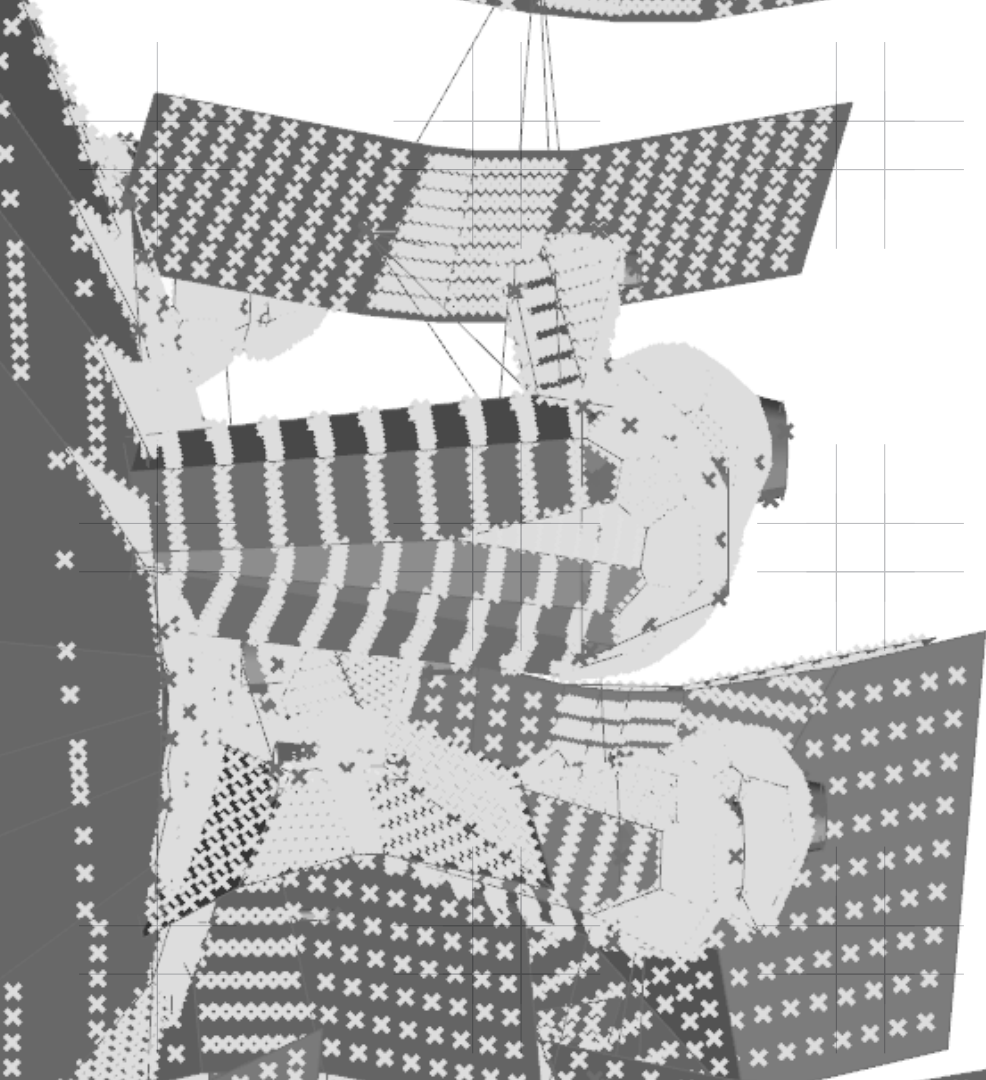

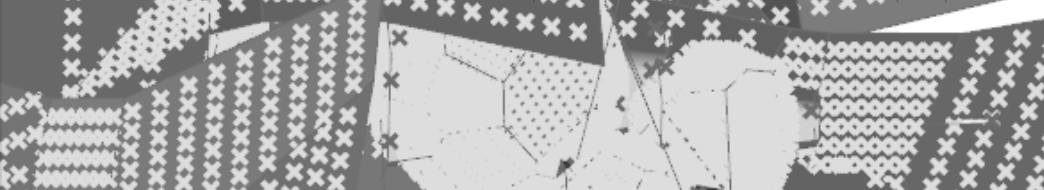
(x) $x \times x \times x \times x \times x$ if $x \times x \times x \times x=$

$+\infty$

$\times$

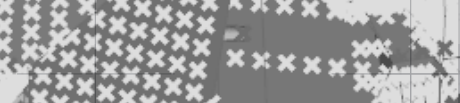

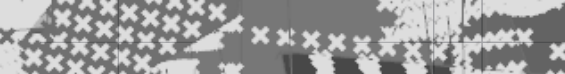

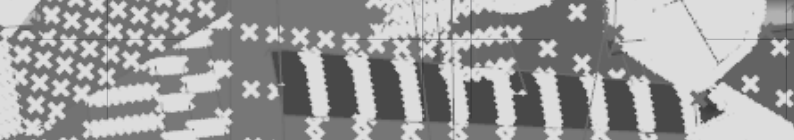
$x$

, 


\subsection{MATERIALITY WITHIN DIGITAL SPACE}

Extending on the experiments of forms and aesthetics, the materials most suited to data representation and manipulation appear to be a build up of many fine-grain elements that can be combined to create a complete material. Material considerations here exist within a digital vacuum, as there is no focus on the physical built environment but rather on digital, theoretical space. Similarly to the formal explorations, the data generates a material that is not necessarily able to be read or the data extracted from it. The focus is placed on personalization and manipulating materials to respond in a variety of ways to a range of data. These materials require competent parametric ability and a good understanding of the relationship between the data and how it will form part of the work to be carried out, which makes them unlikely to become central to traditional architecture. There is the potential advantage of this technique to allow continual, real-time processing of the data and automatic revision of the materials in digital space, however, conversion to physical space would be highly problematic, requiring either dynamic architecture or physical data.

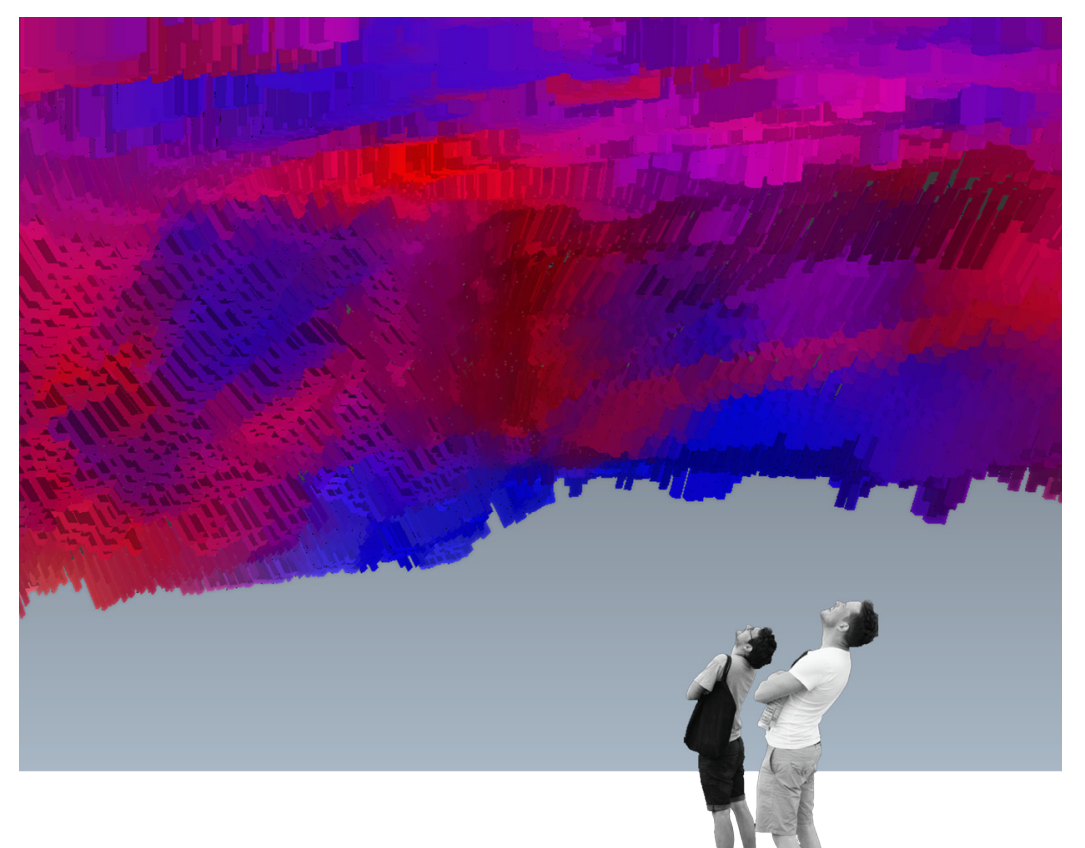



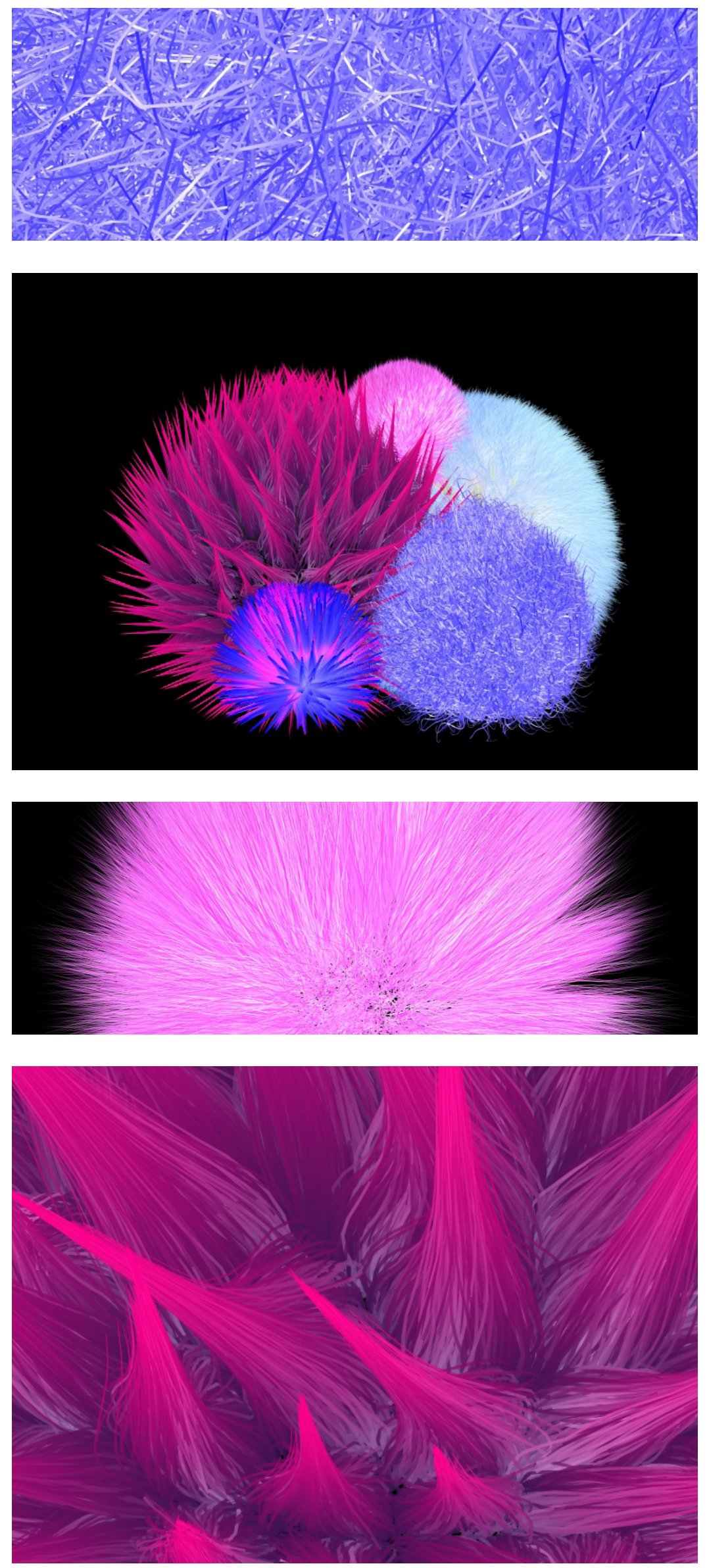

Figure_64 a,b, c, d from top

$a$ Walking distance (length) and weather (colour) ungrouped. $\uparrow$

$b$ A range of experiments using fur or hair as a medium. $\uparrow$

$c$ Steps by distance from home (length) and weather (colour). $\uparrow$

$d$ Walking grouped by weeks and length of journey (length). $\uparrow$

\section{$\overline{\text { Figure_65 }}$}

Building stock in New Zealand 2013 census grouped through DLA and defined by colour (floor area) and length (number of inhabitants). $\leftarrow$ 


\section{Figure_66}

Materials Installation Concept, allowing people to input their Facebook profile and have a 'tube' reflect their digital identity, they can also interact with other peoples tubes by taking them out and examining their data. $\rightarrow$
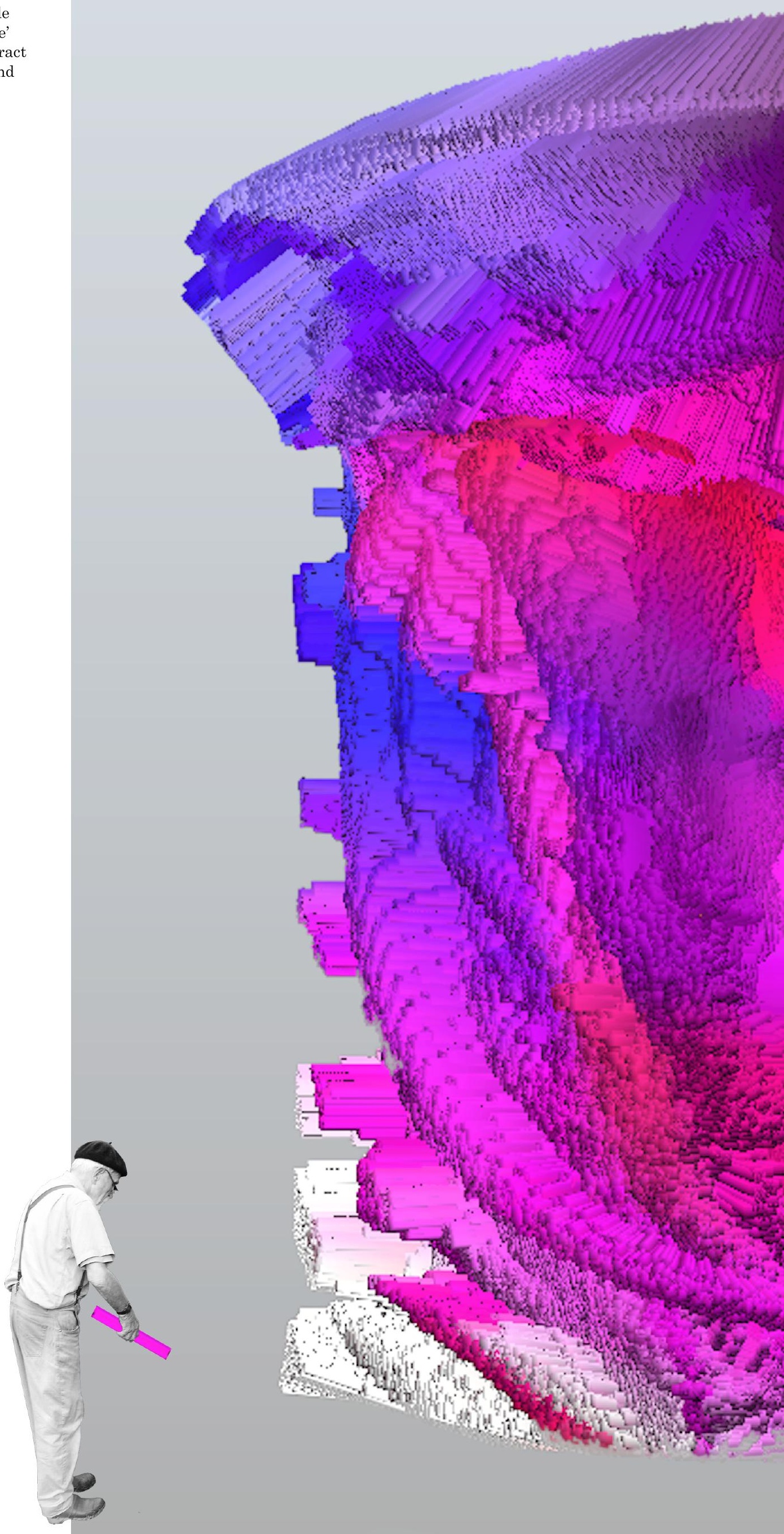


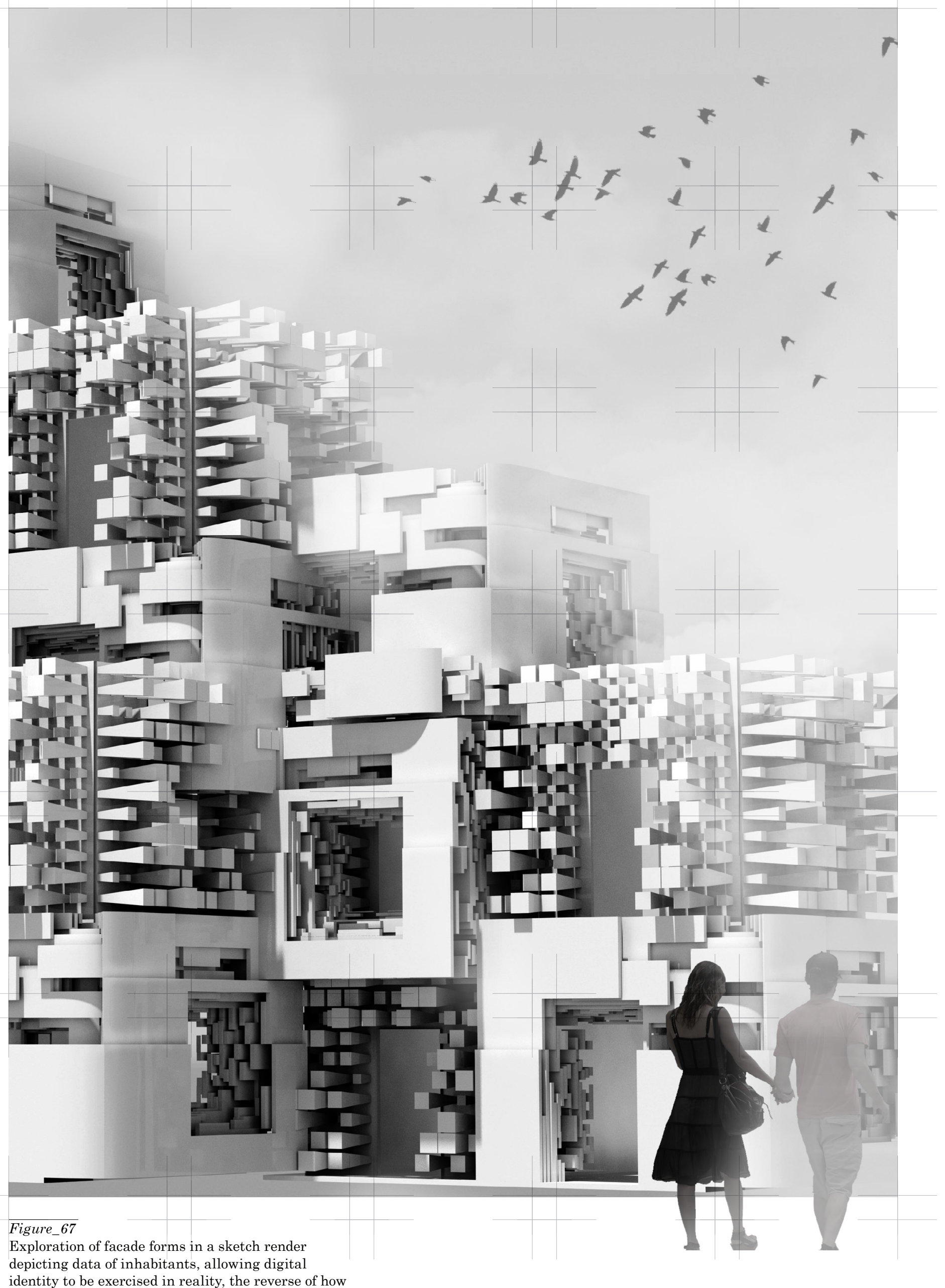

identity to be exercised in reality, the reverse of how social media projects into virtuality. $\uparrow$ 


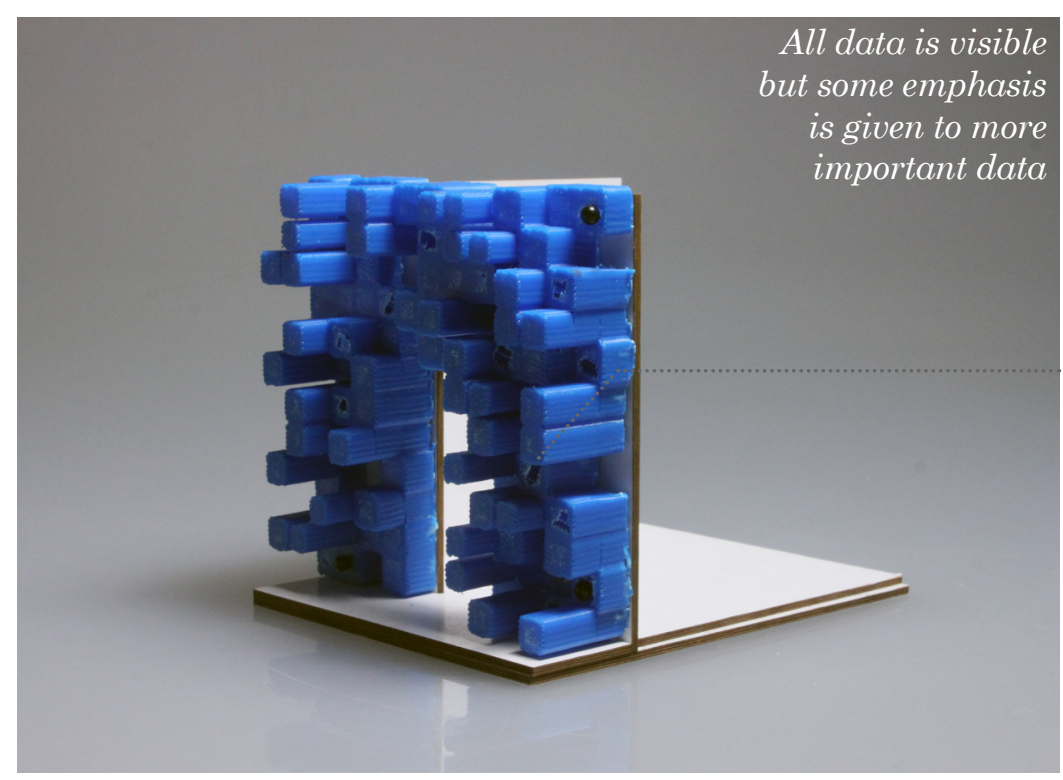

All data covers an even area

More important data is projected further out from the facade

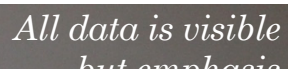
but emphasis

is given to more important data

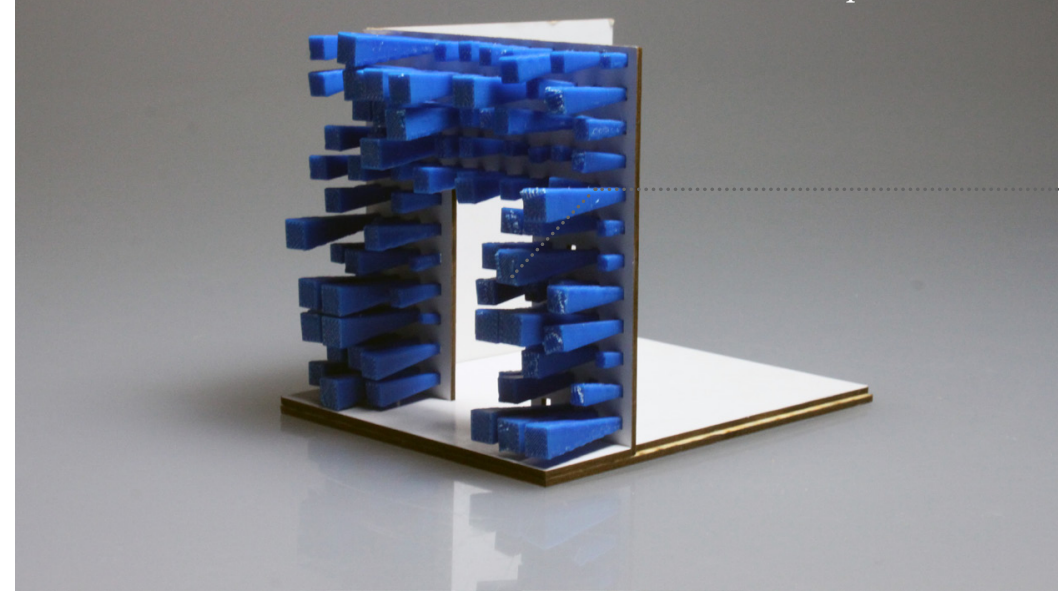

All data is

represented by a small area on the facade surface

More important data is projected outwards further and has larger volume the further from the facade it is

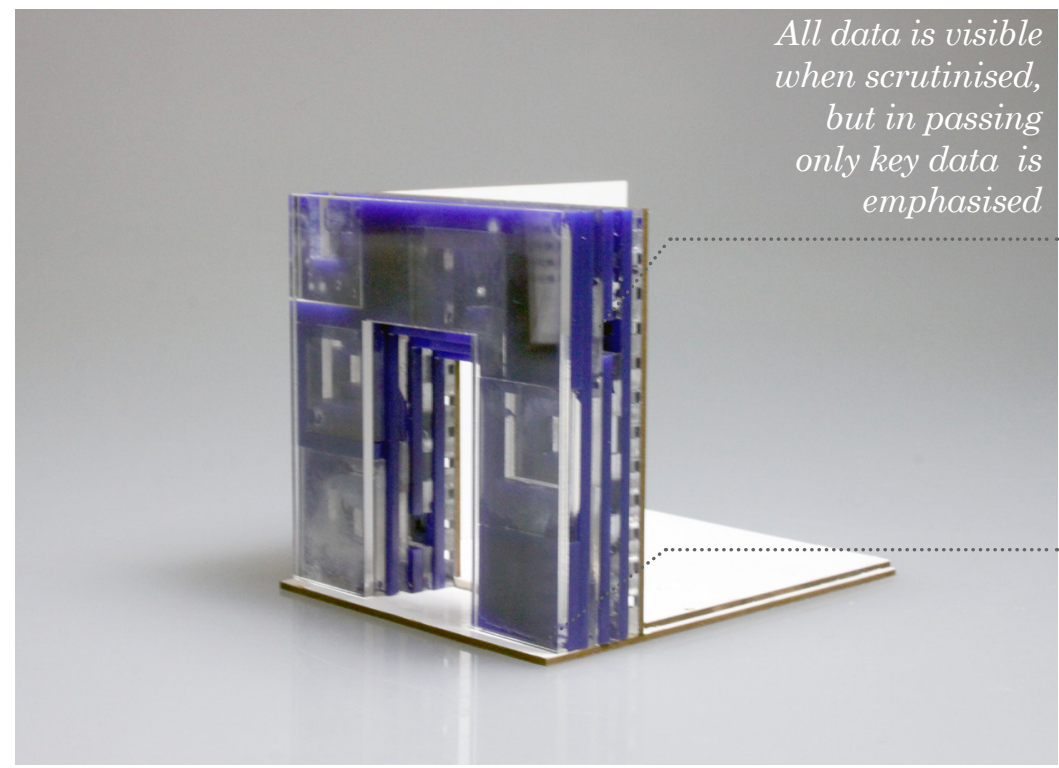

All data is shown at the base level

Increasingly the least important data is not represented at every subsequent level

Final level only emphasises the most important data

\section{$\overline{\text { Figure_68 }}$}

Exploration of facade forms through automated sketch modelling depicting data of inhabitants, allowing digital identity to be exercised in reality, the reverse of how social media projects into virtuality. $\uparrow$ 

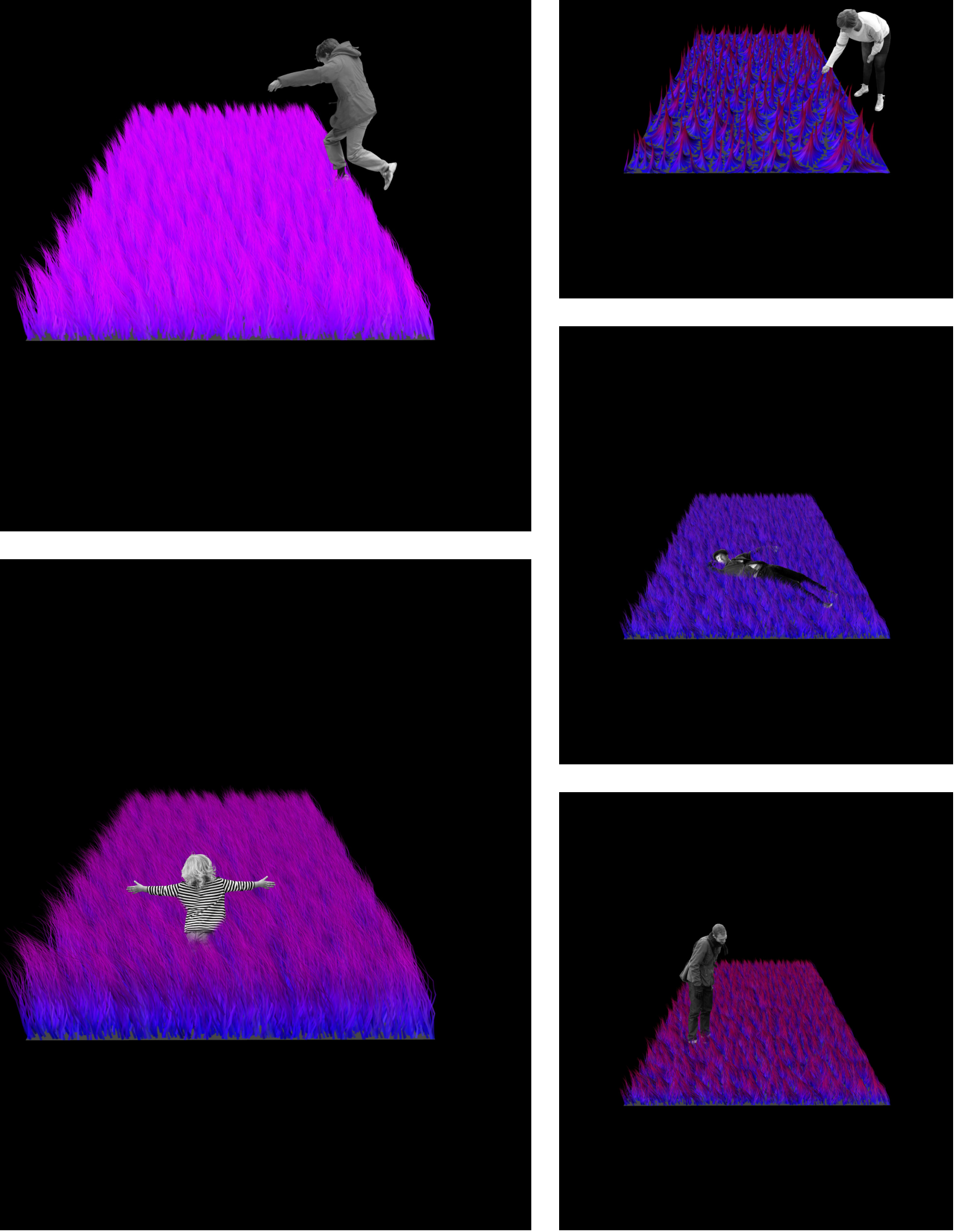

Figure_69 $a, b, c, d, e, f$

Concept for custom rugs that are woven from

strands of data. Each rug depicted is scripted to

present data about my social media posts in a range

of ways, using factors such as length, sway, twist,

clumping and straightness to portray words used in

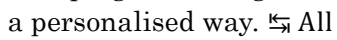




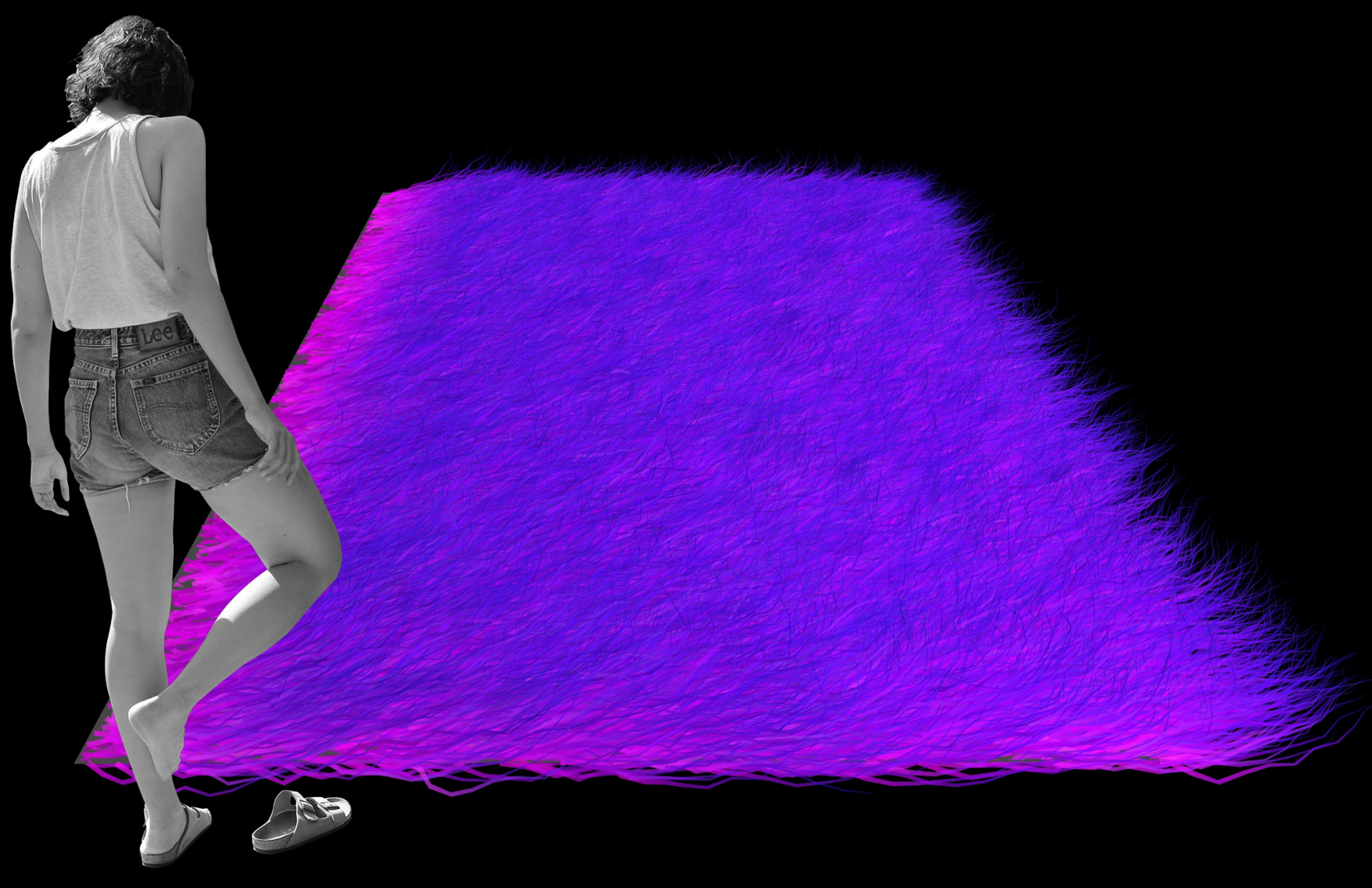




\section{Figure_70}

Plan of Pallazzo Bolani where the 2016 New Zealand Exhibition of the Venice Biennale was held.

$\leftarrow$
Figure_71

Concept for a tetherless VR installation at the

Venice Biennale at the Pollazzo Bolani. Integrating

traditional architecture with data based VR

materials to democratically represent architecture

in New Zealand showing places visited by time. $\downarrow$

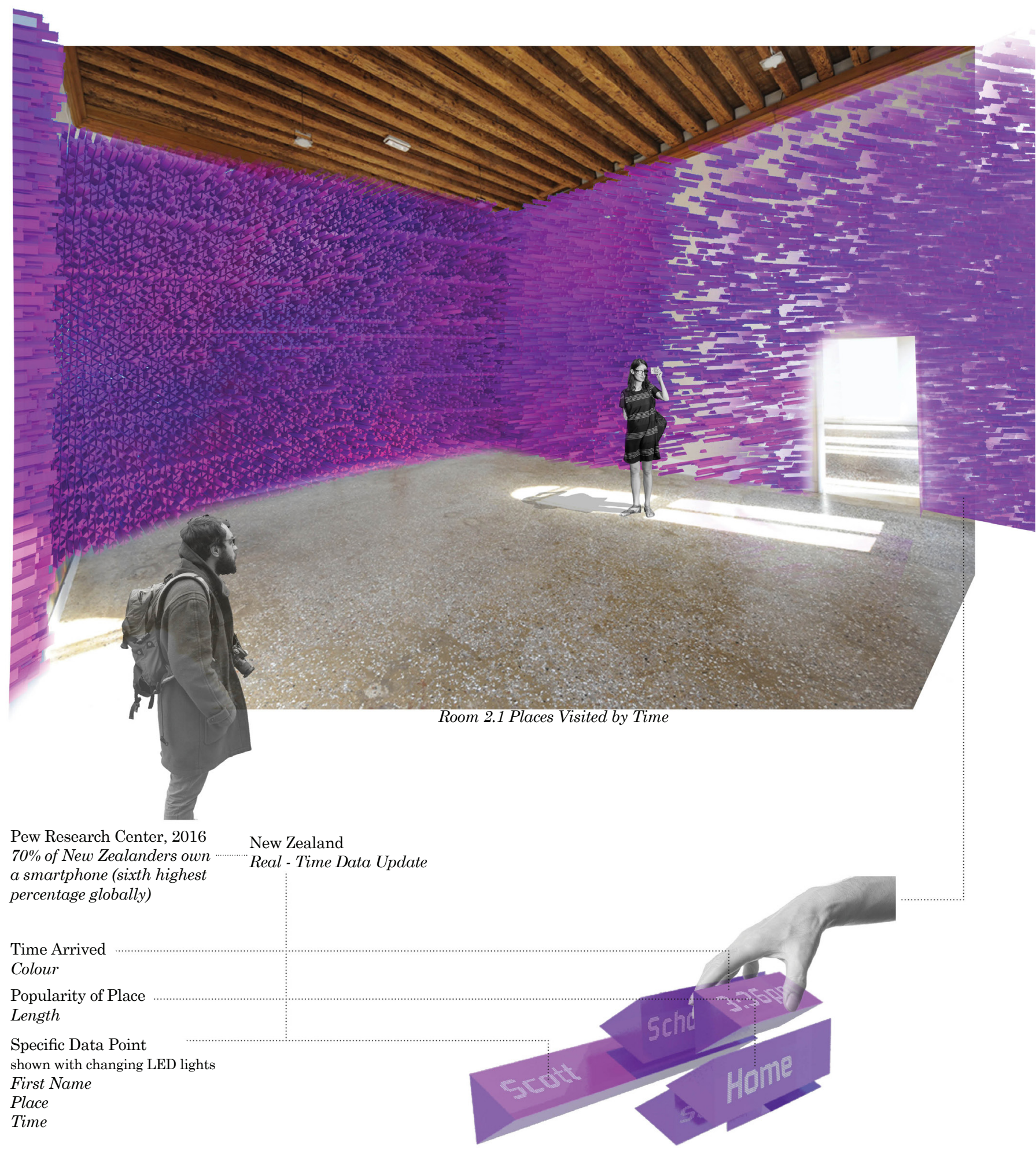

Exhibition Pieces 


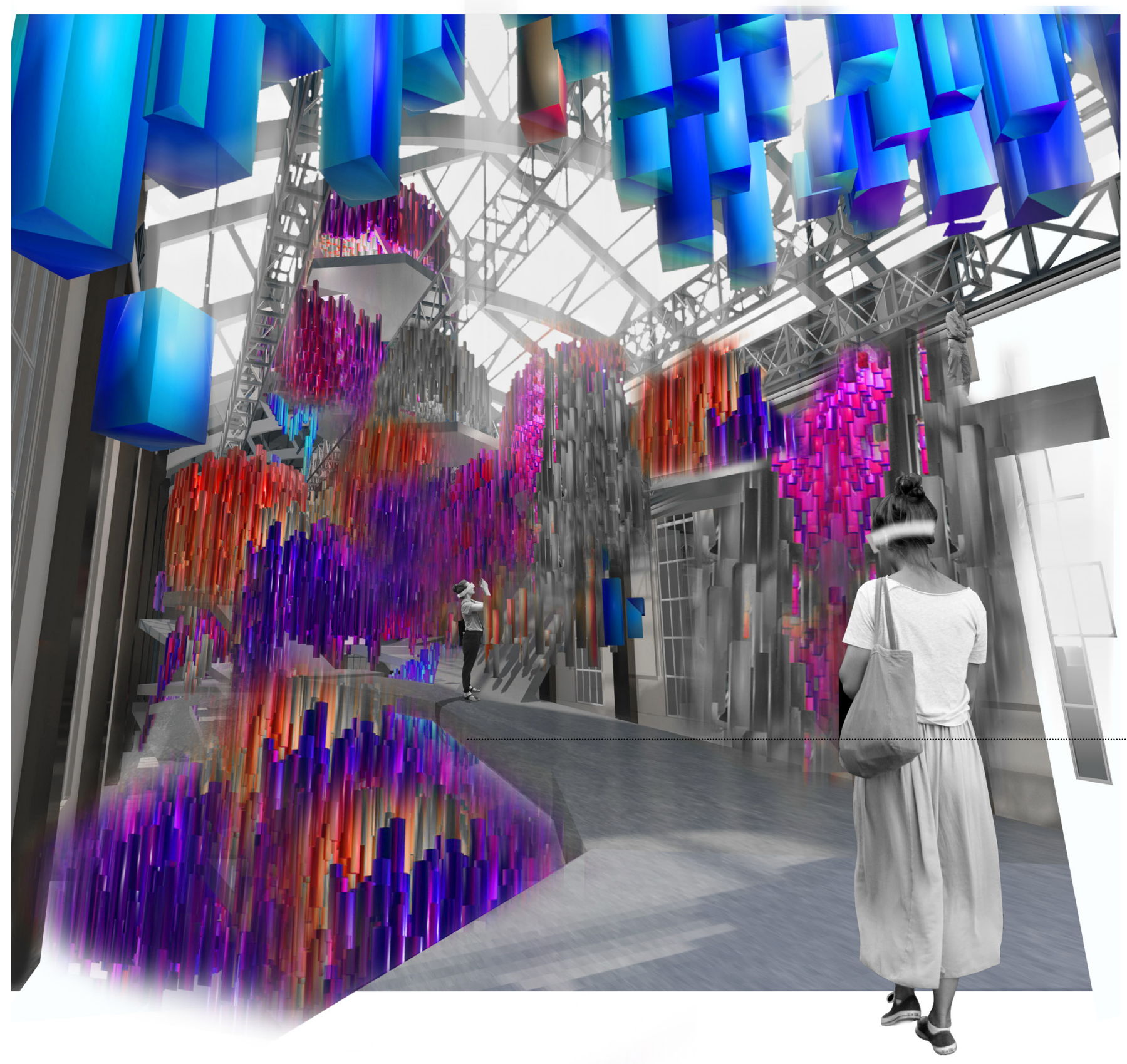

$\overline{\text { Figure_72 }}$

Perspective of a conceptual New Zealand VR pavilion installation concept at the Arsenale, Venice, as seen through virtual space. Data integration shown overleaf. $\uparrow$ $\overline{\text { Figure_73 }}$

Exploded construction diagram of Light tube groupings for the Venice Pavilion Installation concept at the Arsenale, Venice. As these exist only in virtual space they are designed although they have physical limitations to enhance the realism experienced by VR users. $\nearrow$ 
Fibre Optic Lighting

Rods

Electrical Layout

Fibre Optic

Lighting Rods

Structural Grid

Aluminium Tubing
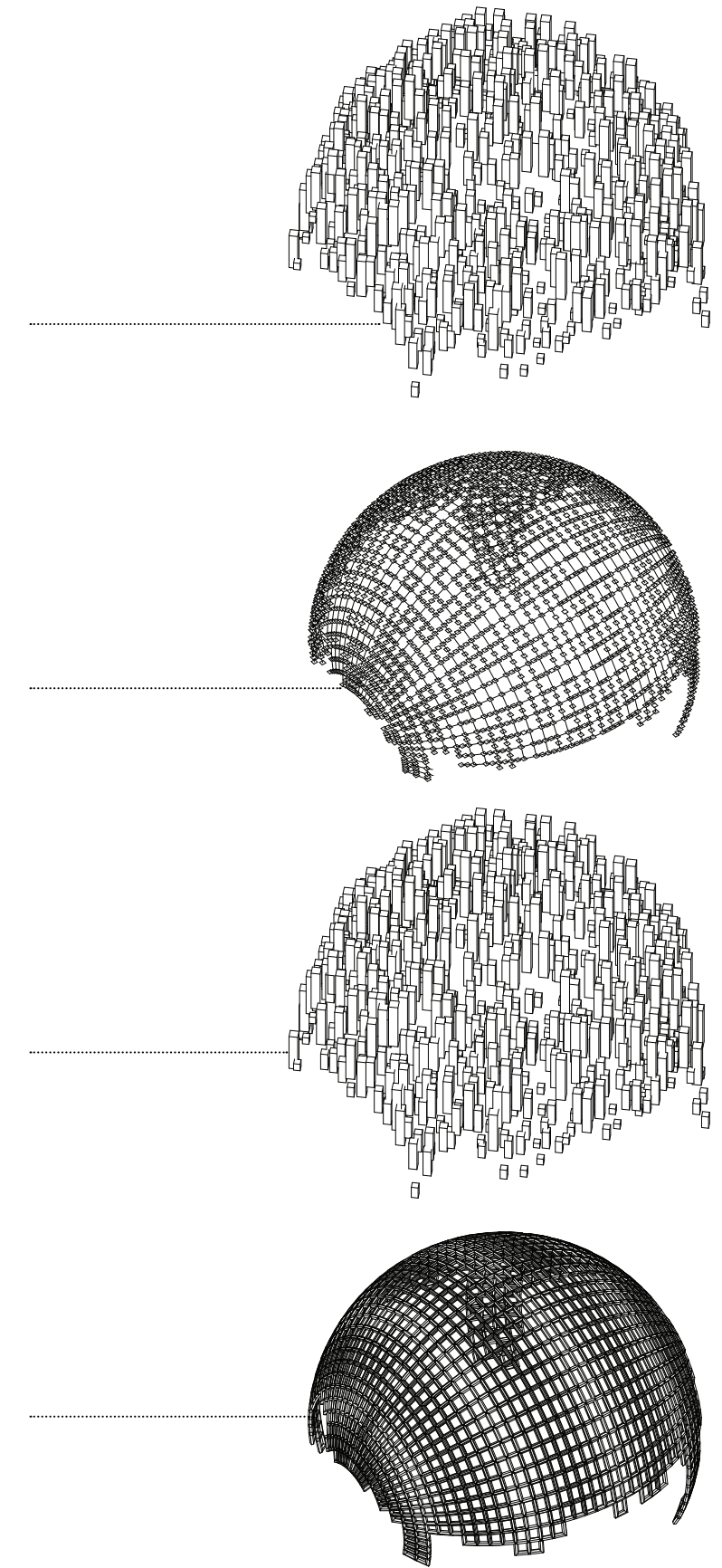


\section{Consent Data:}

Number of

Consents

Size + Value of

Consents

Trend of

Number of

Consents
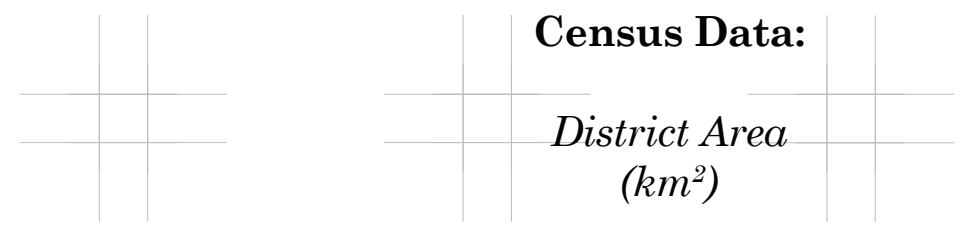

Average Number

of Bedrooms

\section{Average Weekly}

Rent Paid

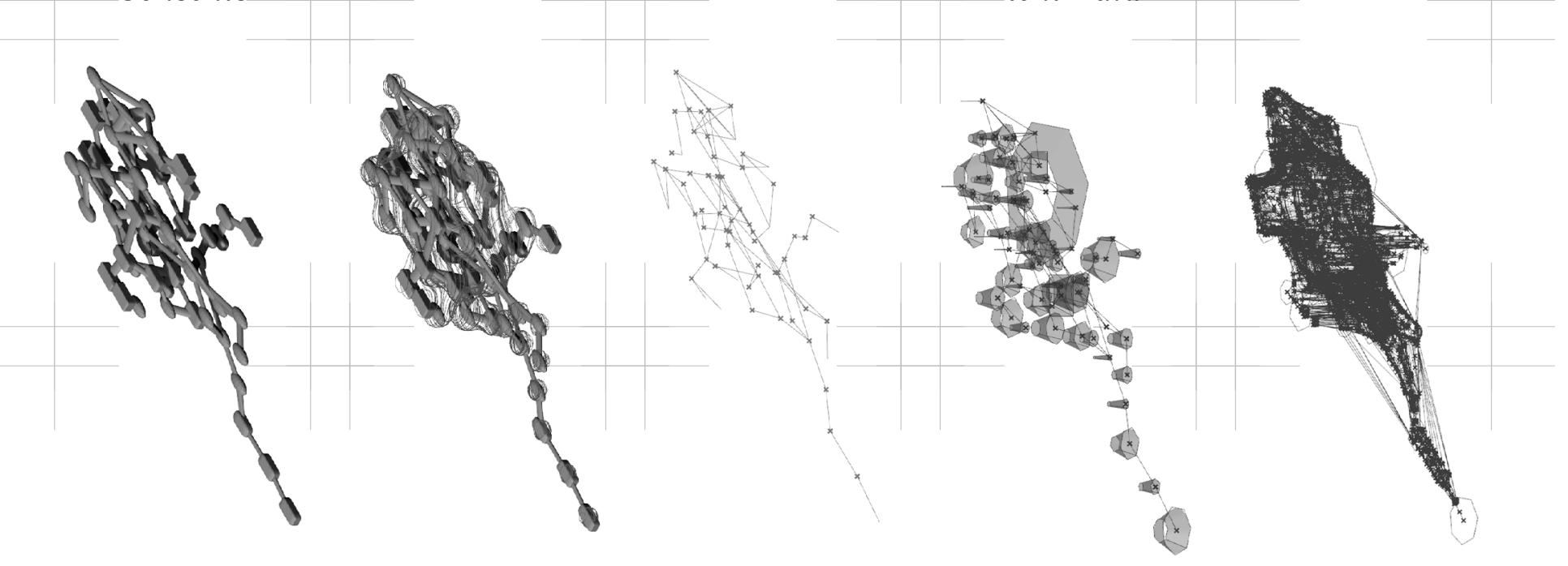

DLA Geometry is created through

the process described earlier as a mesh based on data from resource consents in different areas of New Zealand.

This connects similar areas of architecture within New Zealand.

\section{The geometry} is broken down into the 'nodes' which represent different districts. These nodes are turned into an overall form, combining areas that overlap and creating a fluid three-dimensional form which will be the basis for data layout.

\section{Connections} defined by the DLA algorithm are extracted through the use of averaging mesh points. Additional paths such as entrances, exits or accessibility ramps could be defined in this process.

\section{Data from the} resource consents are used to create volumes at each node. The shape is designed to be half-way between inhabitable space and object. The horizontal size of the area is based on the area of the district it represents, the number of edges is defined by the average number of bedrooms per dwelling while the height is defined by average weekly
A basic structural layout is designed using triangulated space frames. This framing aims to support the raised paths without cutting through paths that are below it. This structural layout is conceptual only. 

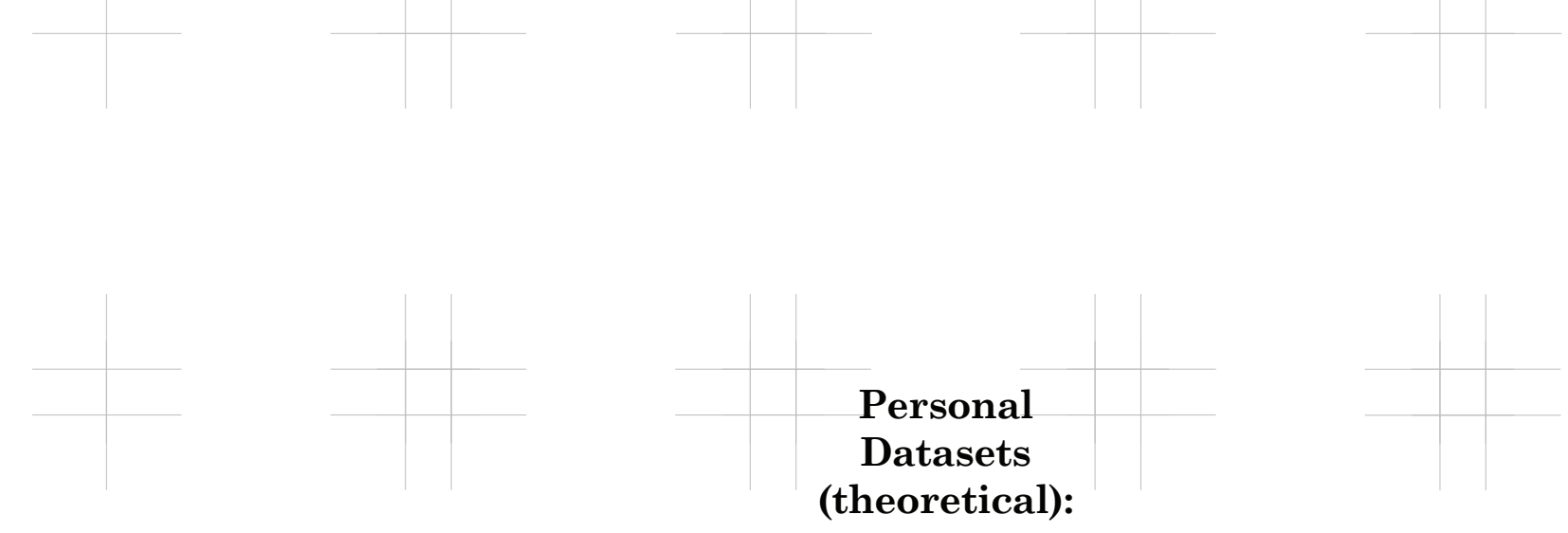
Photo Colour + Location

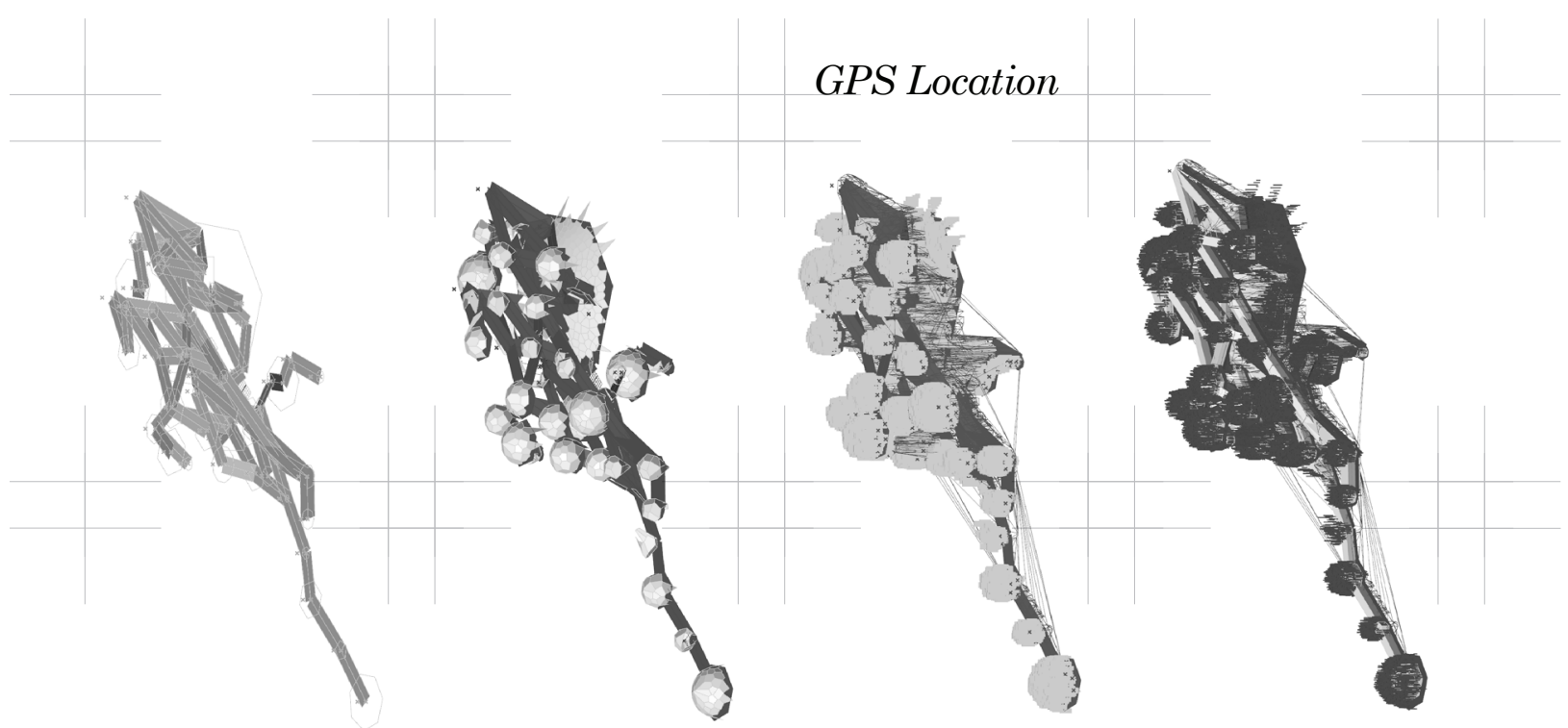

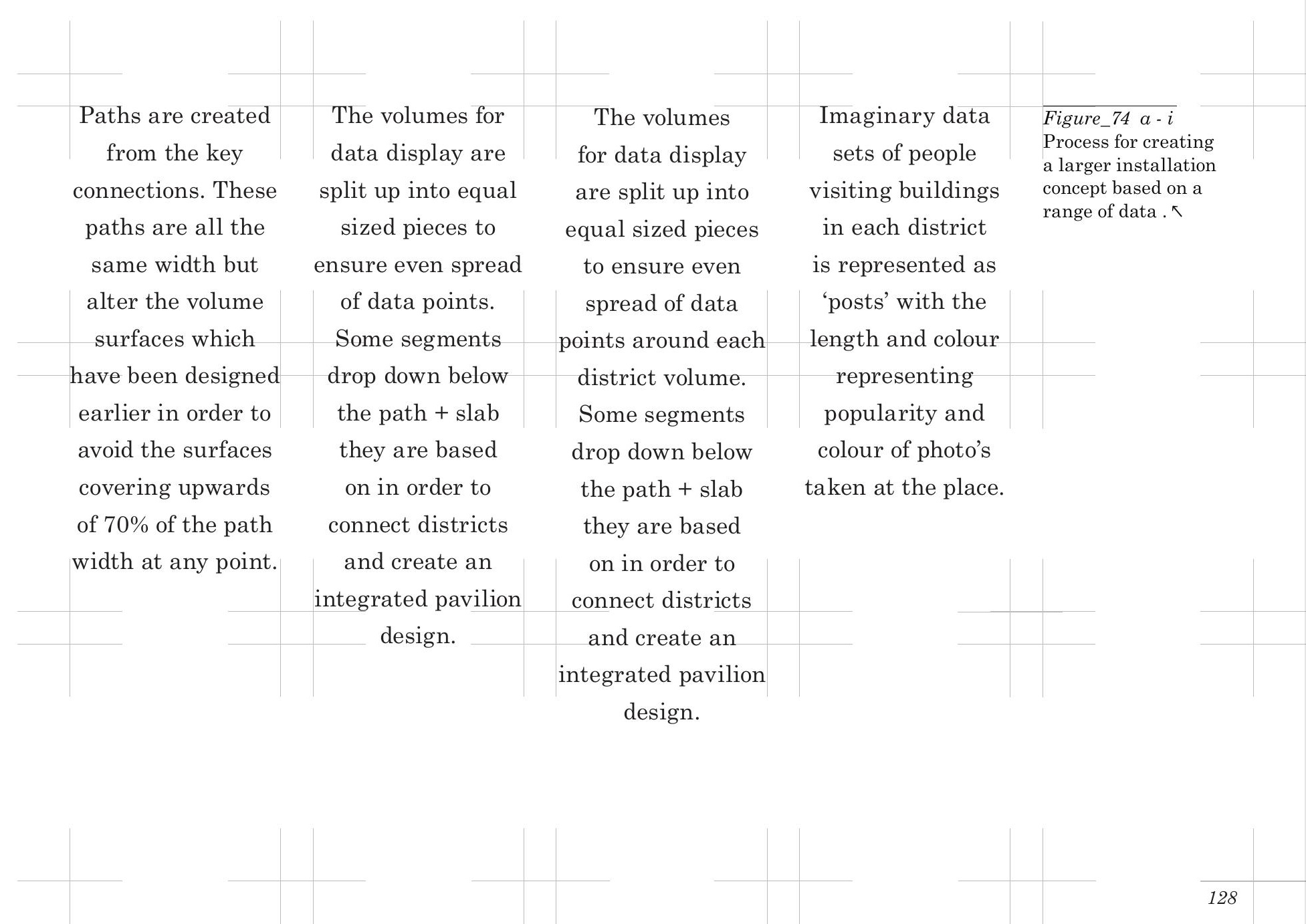




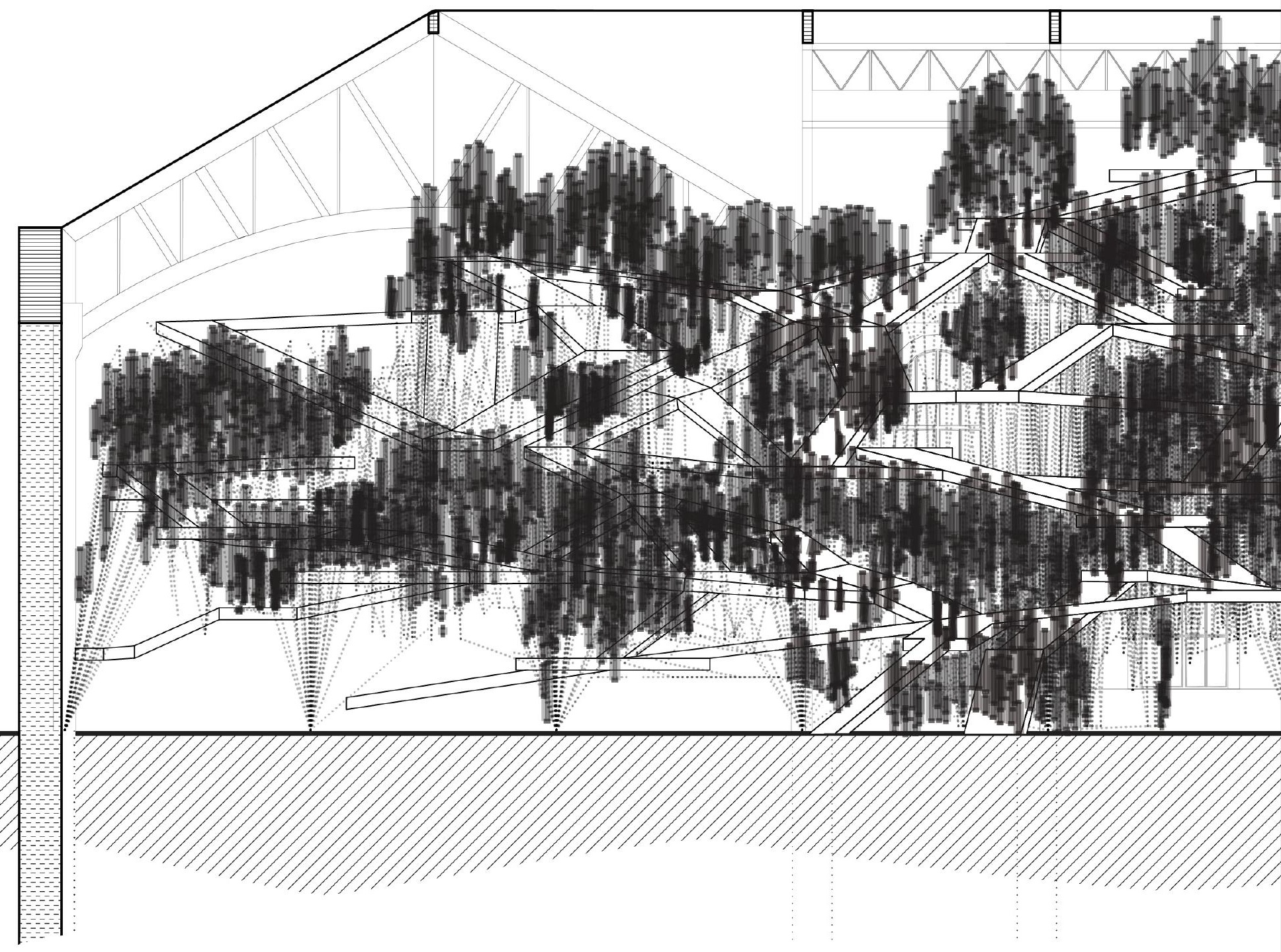

$\overline{\text { Figure_75 }}$

Section of Venice Pavilion Installation

concept at the Arsenale, Venice. This

sections includes the data rods even

though they exist only in the virtual

realm. $\uparrow$ 

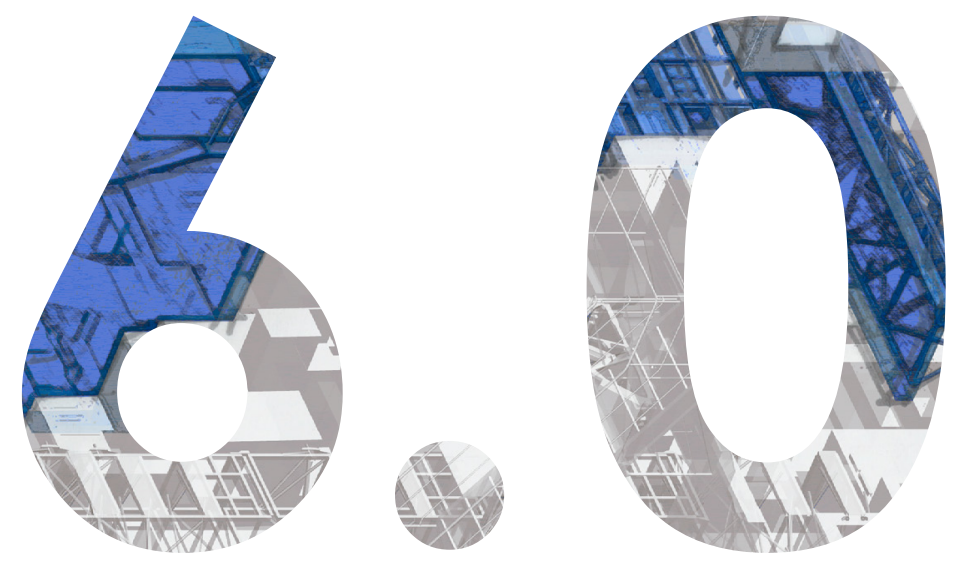

\section{DEVELOPED ARCHITECTURAL EXPERIMENTS}


${ }^{6}$ There is no logic that can be superimposed on the city; people make it, and it is to them, not buildings, that we must fit our plans. "'

- Jane Jacobs, The Death and Life of

Great American Cities 
Many of the earlier experiments were presented at the Parallelism in Architecture and Computing Techniques (PACT) conference in London and subsequently published (Meekings and Schnabel, 2016). Discussion chaired by Gilles Retsin and with input from Zaha Hadid Architecture's Patrik Schumacher, focused on developing the individual experiments into conceptual architecture. The discussion noted the value of novel design process and pushed for conceptual outcomes over design that was encumbered by 'real-world' issues. It was suggested privacy and ownership issues should be more important to this design research than 'real-world' feasibility problems.

Building on the preliminary architectural experiments, this chapter aims to incorporate this discussion to produce a conceptual architecture. This section also aims to step outside the traditional view of architecture and avoid Shirky's 'milkshake mistakes' as discussed earlier (2010). It is important to note that this architecture doesn't aim to draw a solid conclusion, the designs explored are speculative and build on both technical and philosophical concepts developed earlier. 

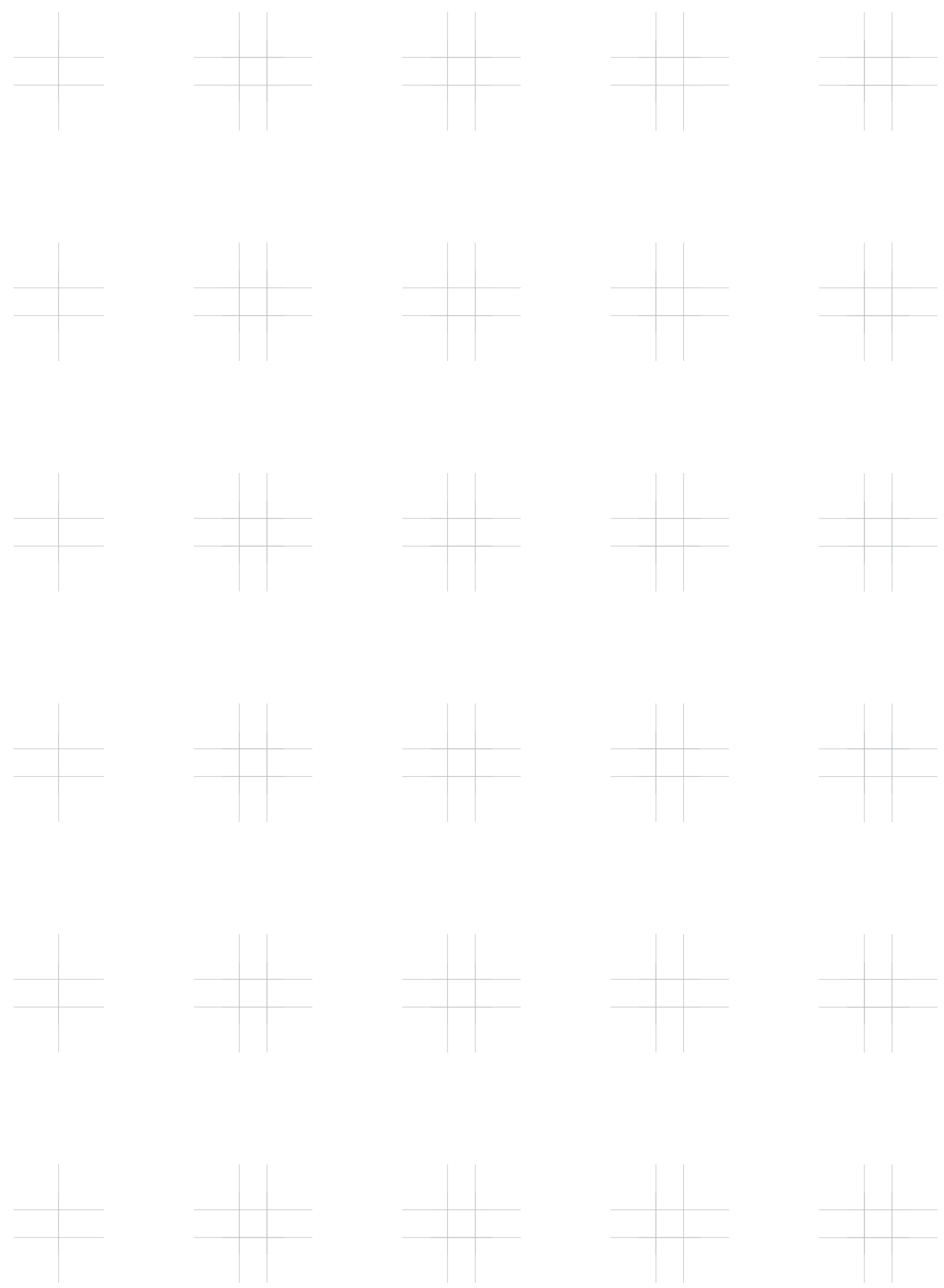


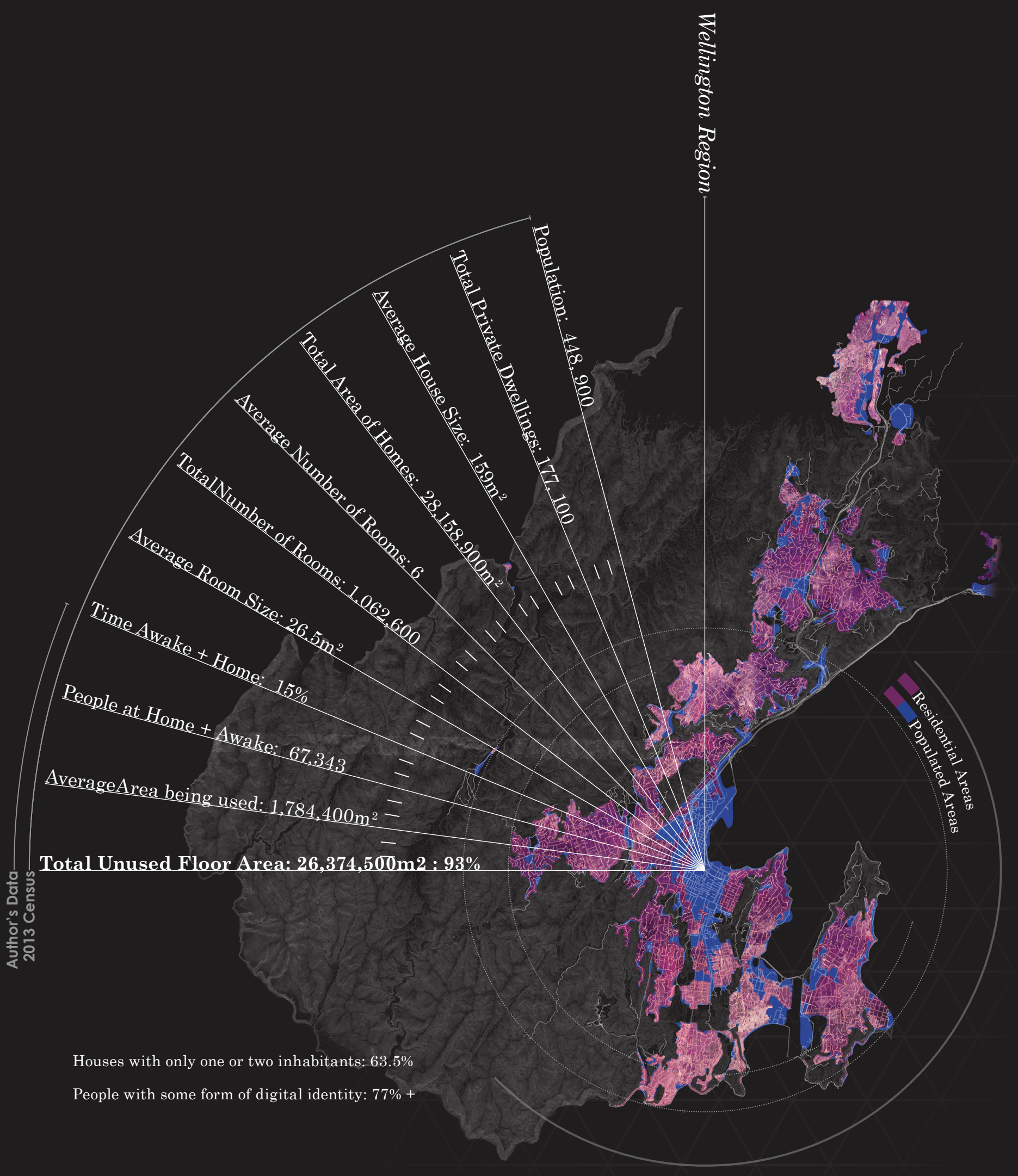

$\overline{\text { Figure_76 }}$

Unused floor area in Wellington as depicted by

author collected data and calculation, showing that

architecture is currently not reflecting the needs and uses of the inhabitants and owners. $\uparrow$ 


\subsection{DEVELOPING DATA- BASED CONCEPTUAL ARCHITECTURE}

The beginning point for this was an insight the data provided early on; it's rare that I use my apartment. While it is significantly my largest expense $(31.1 \%$ more expensive than my education per week), I use it for as little as $7 \%$ of the time. Most of the time I am either not in my apartment, or when I am, I'm sleeping. Using author-collected and census data, it is conservatively estimated that on average $93 \%$ of the floor area in Wellington is dedicated to rooms without an awake person using them. As you read this, it is likely there is nobody in your kitchen and yet it is considered a necessity that everybody always owns a kitchen. Initial reactions are generally that a kitchen cannot be shared because everybody will need it at the same times - however with time-location data this could be avoided by sharing kitchens between people who have empirically different routines. 
The system of architecture in which data-based sharing can occur requires a large scale adaptable design. The difficulty with adaptability is simultaneously providing enough variation that individuality can be expressed while allowing the designer to oversee possible outcomes and retain authorship over the design. Taking inspiration from big data and its effective buildup of information from smaller, repeated parts, a discrete element system has been designed. Discrete assembly provides both authorship to the designer and allows computational generation of a wide array of forms within set parameters. Difficulties arise in discrete construction from complex forms (generally requiring some form of digital fabrication technique) and less efficient material use.

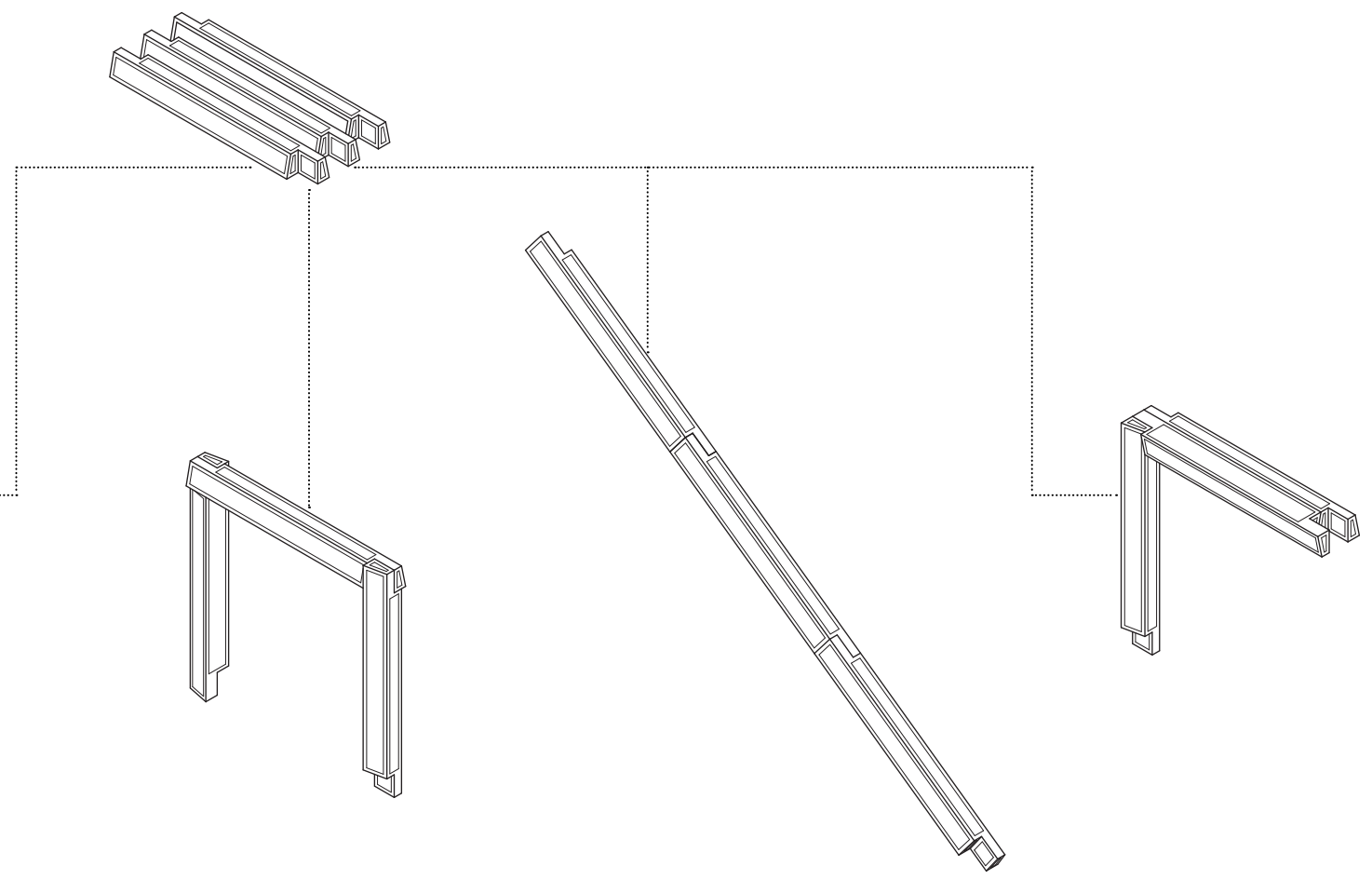

Conceptual research into singular discrete elements being used to construct a range of joins and spaces. $\uparrow$ 

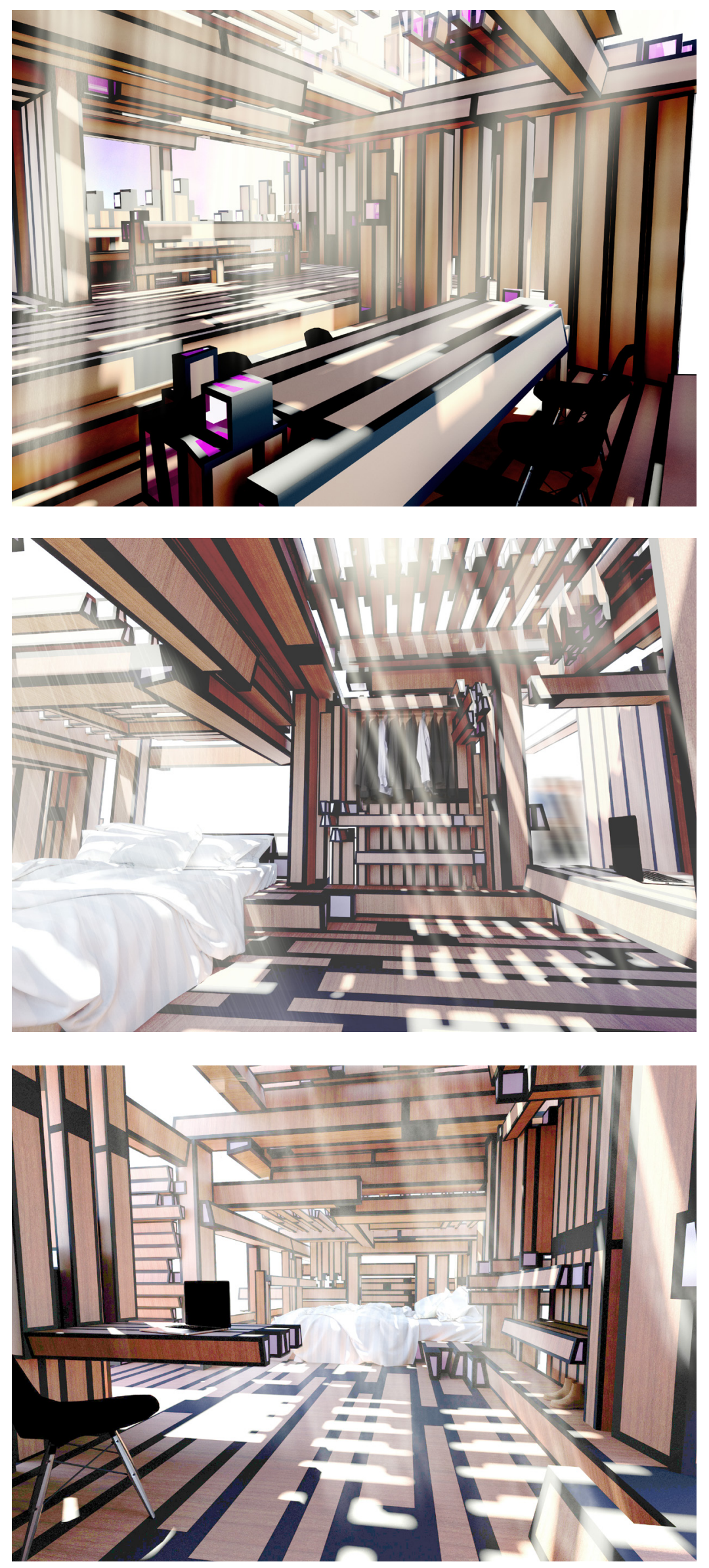

Figure_78 $a, b, c$

$a$ Conceptual kitchen and dining space constructed from discrete elements. $\uparrow$ Top $b, c$ Conceptual bedroom constructed from discrete elements. $\uparrow$ Middle, Bottom

$\overline{\text { Figure_79 }}$

Using data to formulate a basic bedroom concept from a range of data gathered about myself. ^ 
Average Time per Visit

3.83

Hours
Data For Location:

HOME
Average Time per Day

Hours

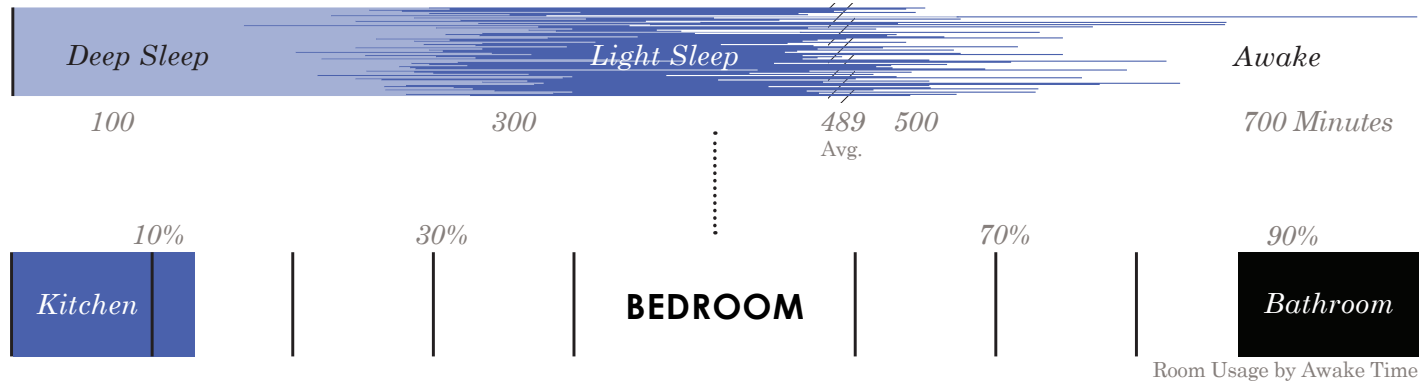

The first step for assembling space from discrete elements through data was to take all of the relevant data and organize it so that it could be used to organize space assembled from the discrete elements. The first project was a bedroom as this is a space that is not easily shared and has a great deal of useful data to inform its creation.

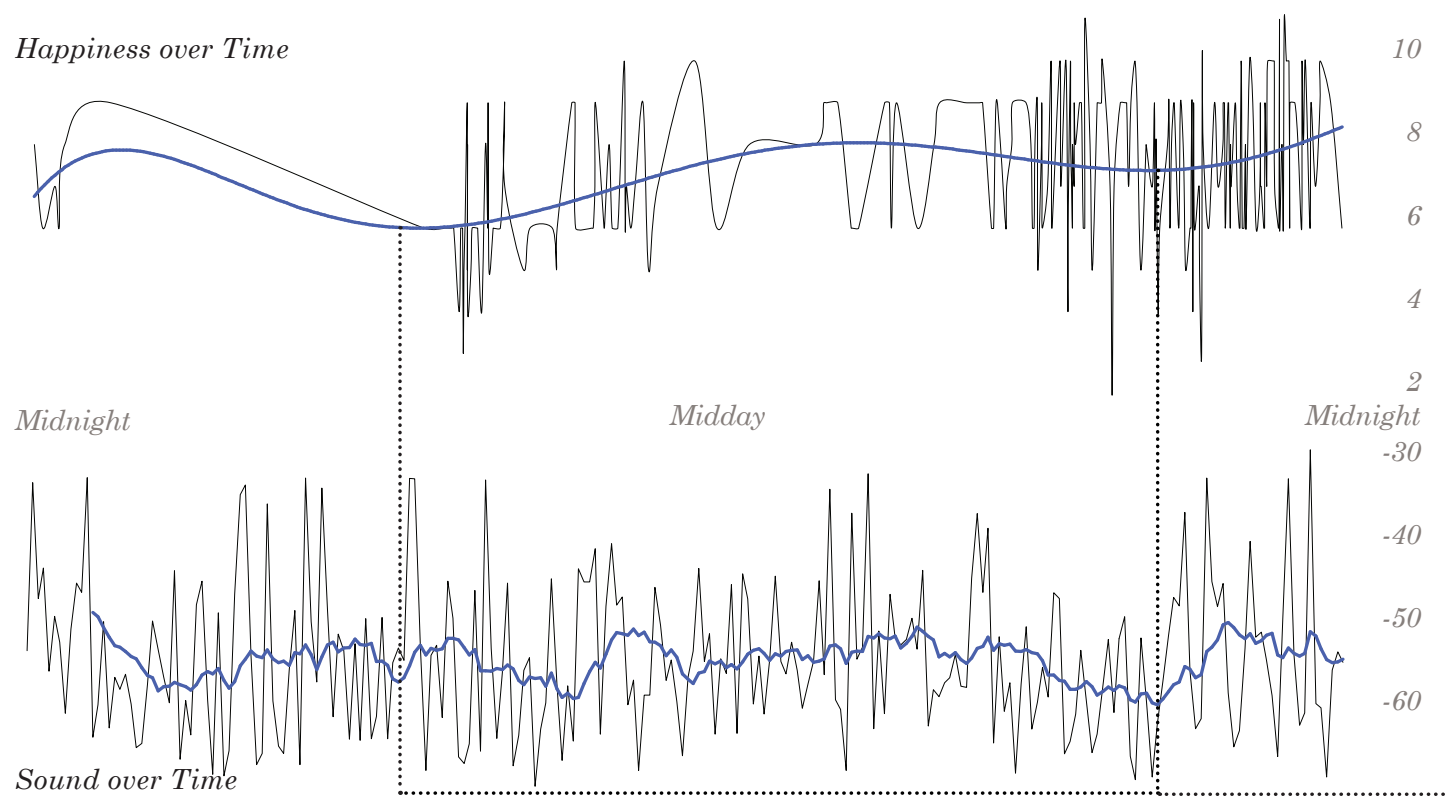



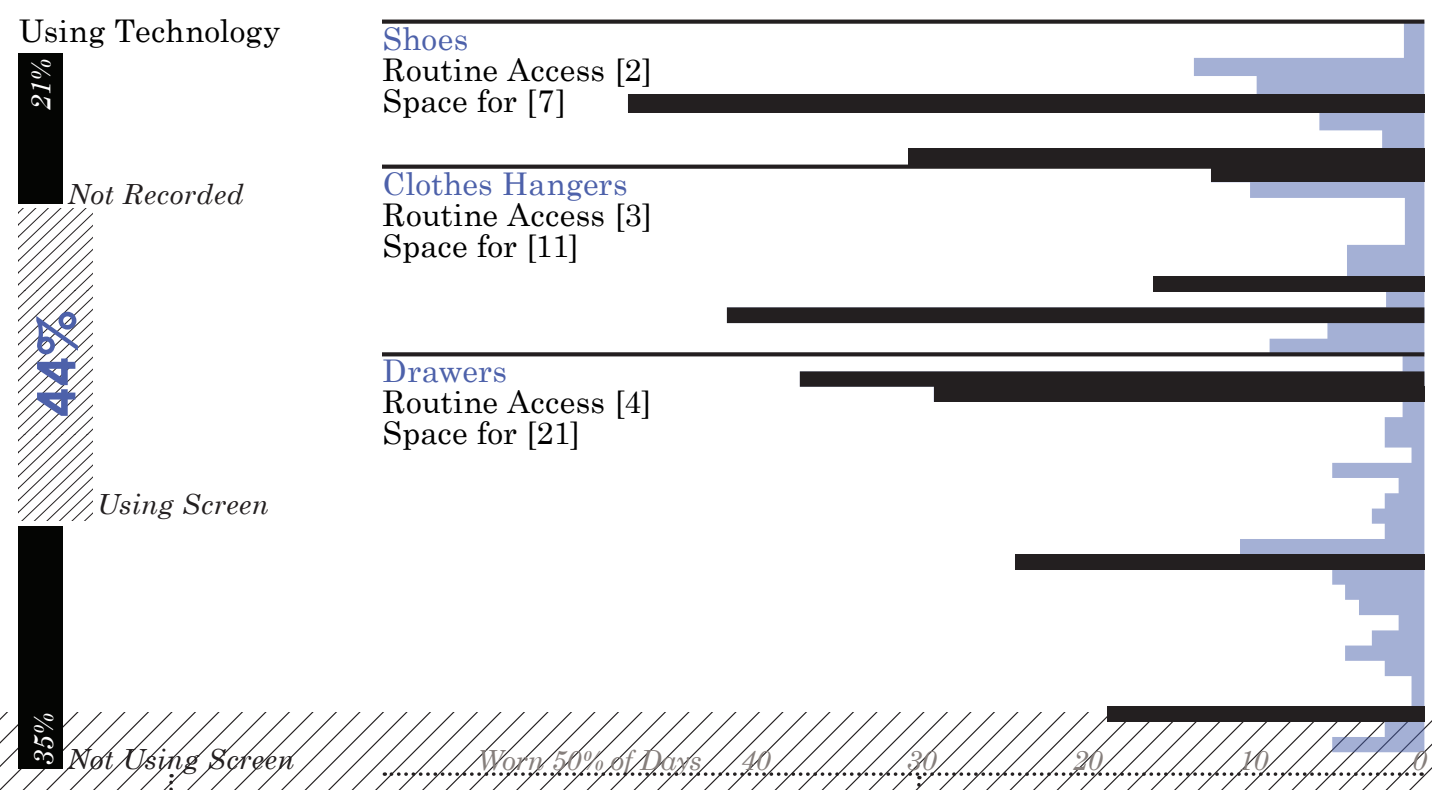

\section{Brown Boots \\ White Nikes}

Blue Shirt

Black Coat

Black Sweater
Navy Sweater

Routine Access [4]

Navy Sweater

Key Screen

...Requires:

Activities

Desk

Internet

Ability to Sit on Bed

Skype

Socializing

Working

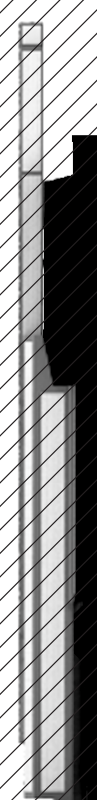




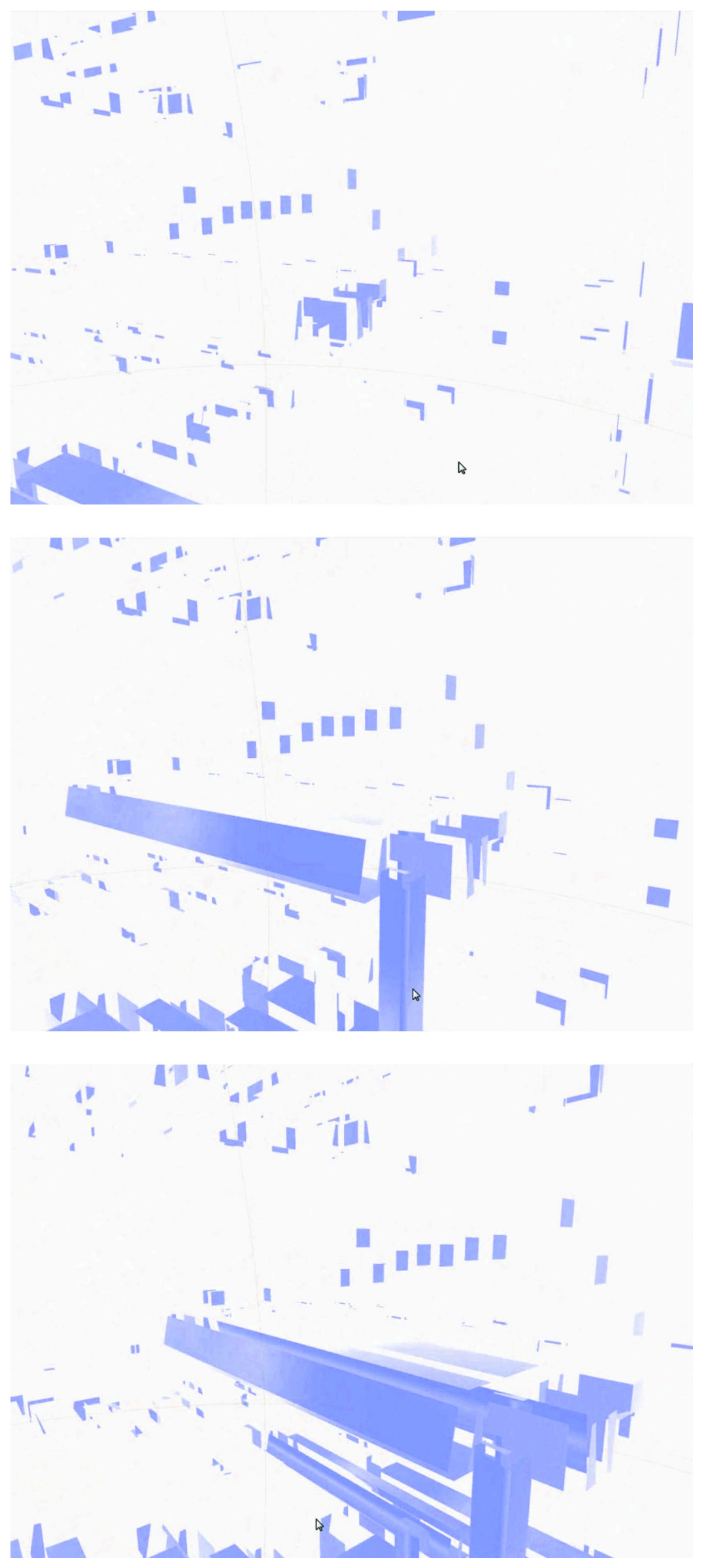




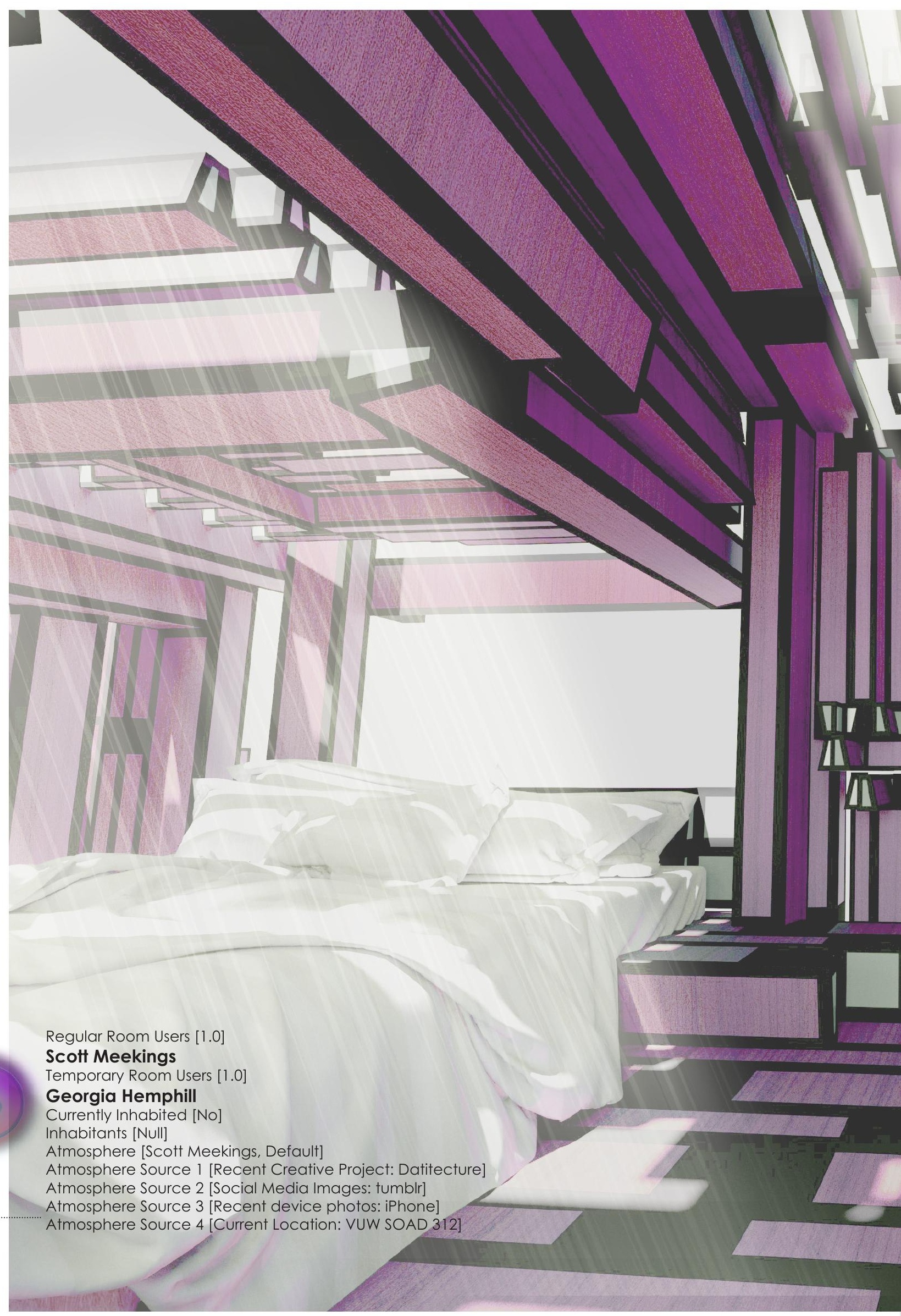




\section{Desk Sharing [On]}

\section{Expected Inhabitan}

Scott Meekings [91.4\%]

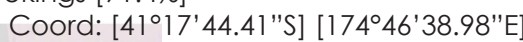
Georgia Hemphill $[8.2 \%]$

Coord: [ $41^{\circ} 17^{\prime} 5.40^{\prime \prime}$ ] [ [17444'11.20"E] Non Recorded User [0.4\%]

$$
\text { Coord: [Null] }
$$

\section{Arrival Time}

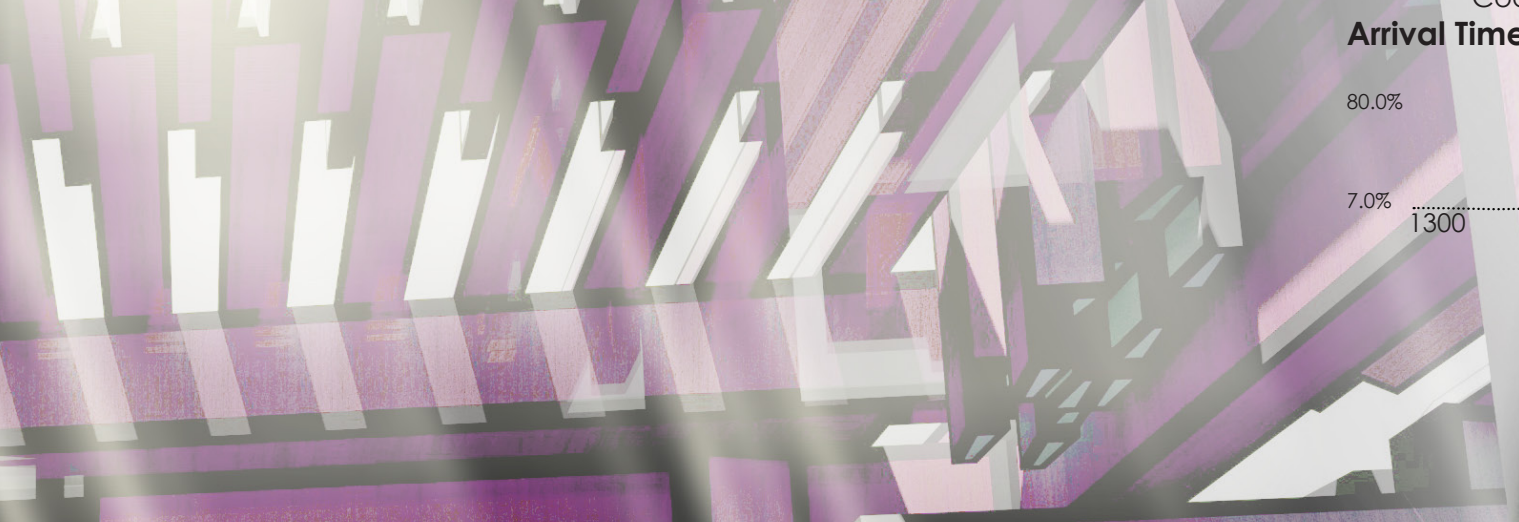

$+$
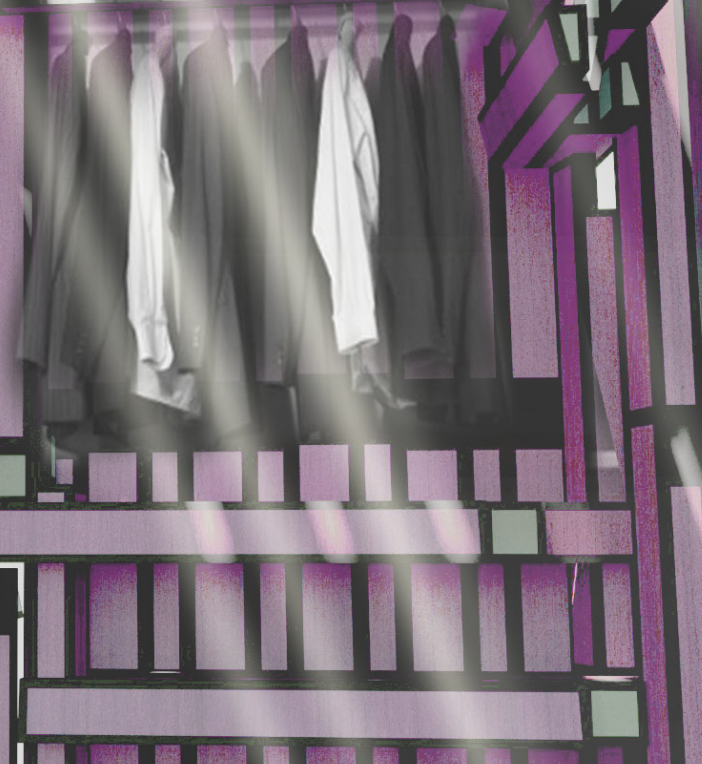

\section{1}

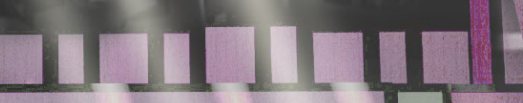
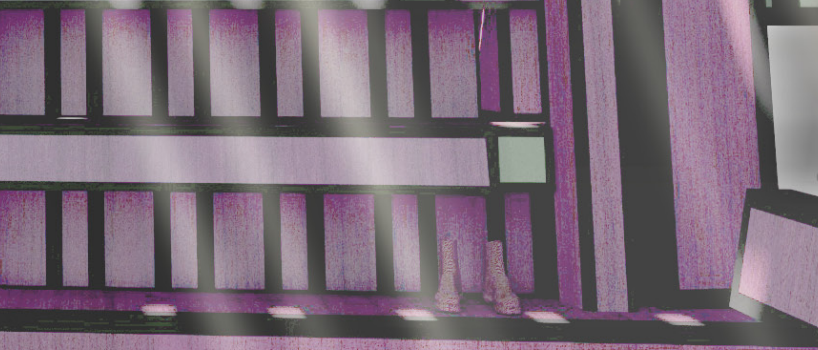


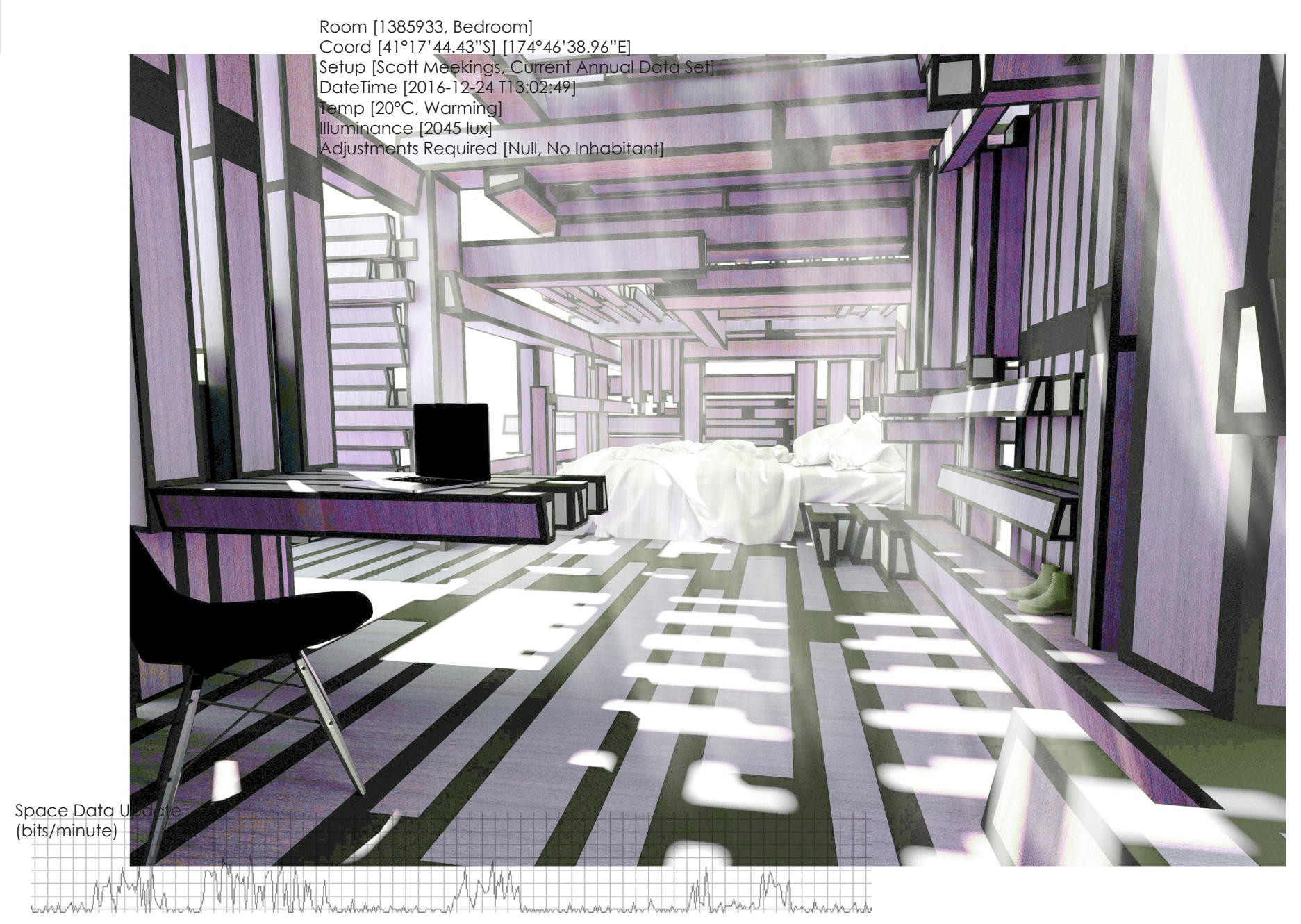

\section{$\overline{\text { Figure_81 }}$}

Uninhabited bedroom interior constructed from discrete elements and given colour and atmosphere from the earlier atmospheric experiments. $\uparrow$

\section{$\overline{\text { Figure_82 }}$}

Inhabited kitchen and dining space interior constructed from discrete elements and given colour and atmosphere from the earlier atmospheric experiments. $>$

Figure_83

Uninhabited bedroom interior constructed from discrete elements and given colour and atmosphere from the earlier atmospheric experiments. $\curvearrowleft$ 




Atmosphere [Sarah King, Eating Set]

Atmosphere Source 1 [Photos from most visited Cafe:Neo]

Using the atmospheric experiment to dictate the colours and moving patterns that make up spaces that are inhabited by a digital identity allows architecture to become an extension of that identity, as it is projected into the real world via architecture. This allows hyper-personalisation of space that is constantly reflective of it's inhabitants and provides a means of expression. Communication and expression is the typology for new media and people have always expressed themselves through their dwellings - the result of these is however not symbiotic. People personalize their dwellings and add photos of this personalization to websites such as Pinterest or Instagram but this social media is not reflected back into the architecture or space in any way as Michael Myers (2011) points out: "The ability to convey sentiment to our friends at the click of a (Like) button is now commonplace and social augmented reality offers some opportunities for sharing but it's not architectural." 


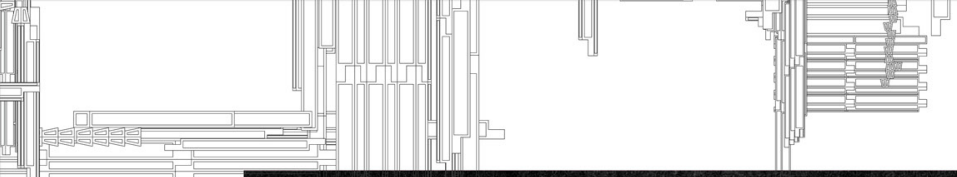

\section{Figure_84}

Plan for a small section of residential development

constructed from discrete parts based on data.

Published here at approximately 1:100. $\downarrow$
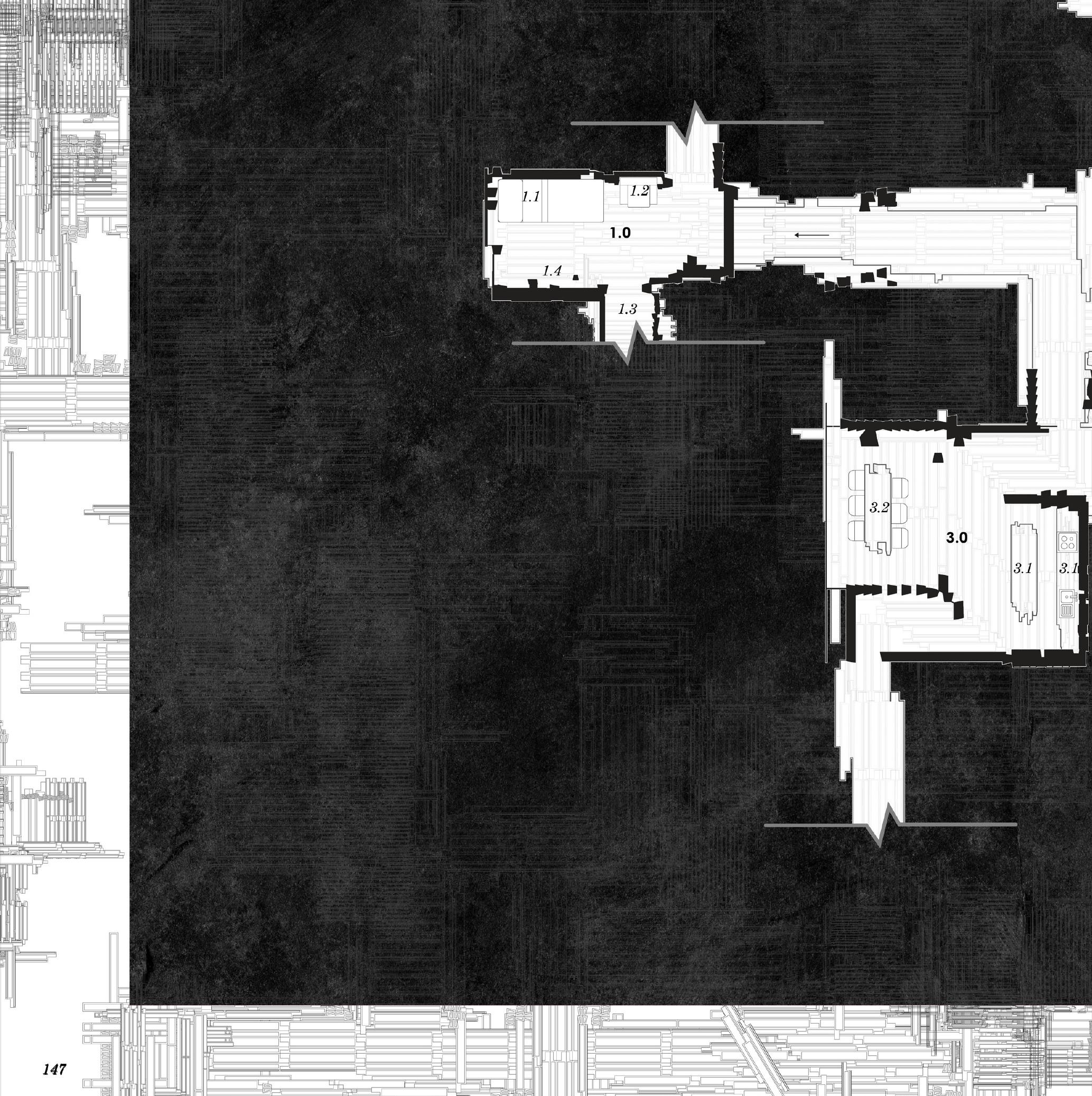

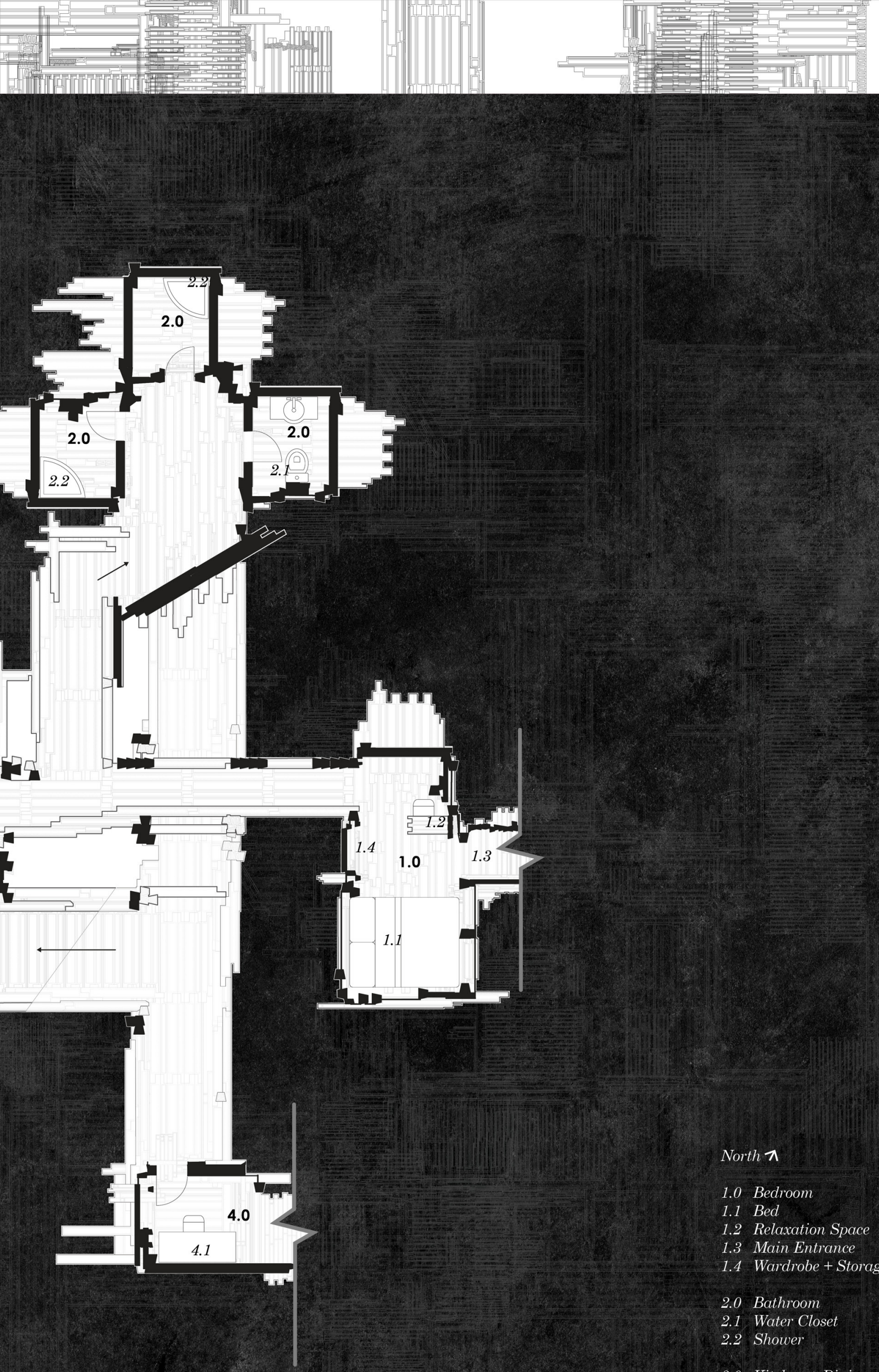

North $\pi$

1.0 Bedroom

$1.1 \mathrm{Bed}$

1.2 Relaxation Space

1.3 Main Entrance

1.4 Wardrobe + Storage

2.0 Bathroom

2.1. Water Closet

2.2 Shower

3.0 Kitchen + Dining

3.1 Bench

3.2 Dining Table

4.0 Study

4.1 Desk

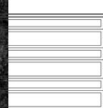

(1)

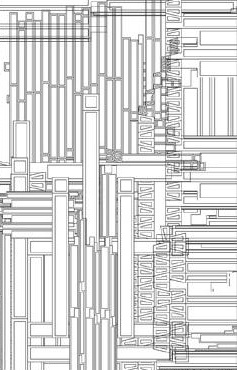

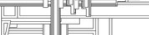
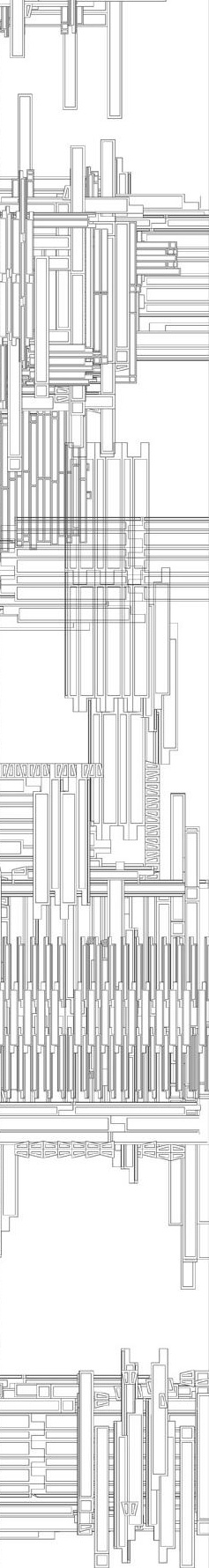


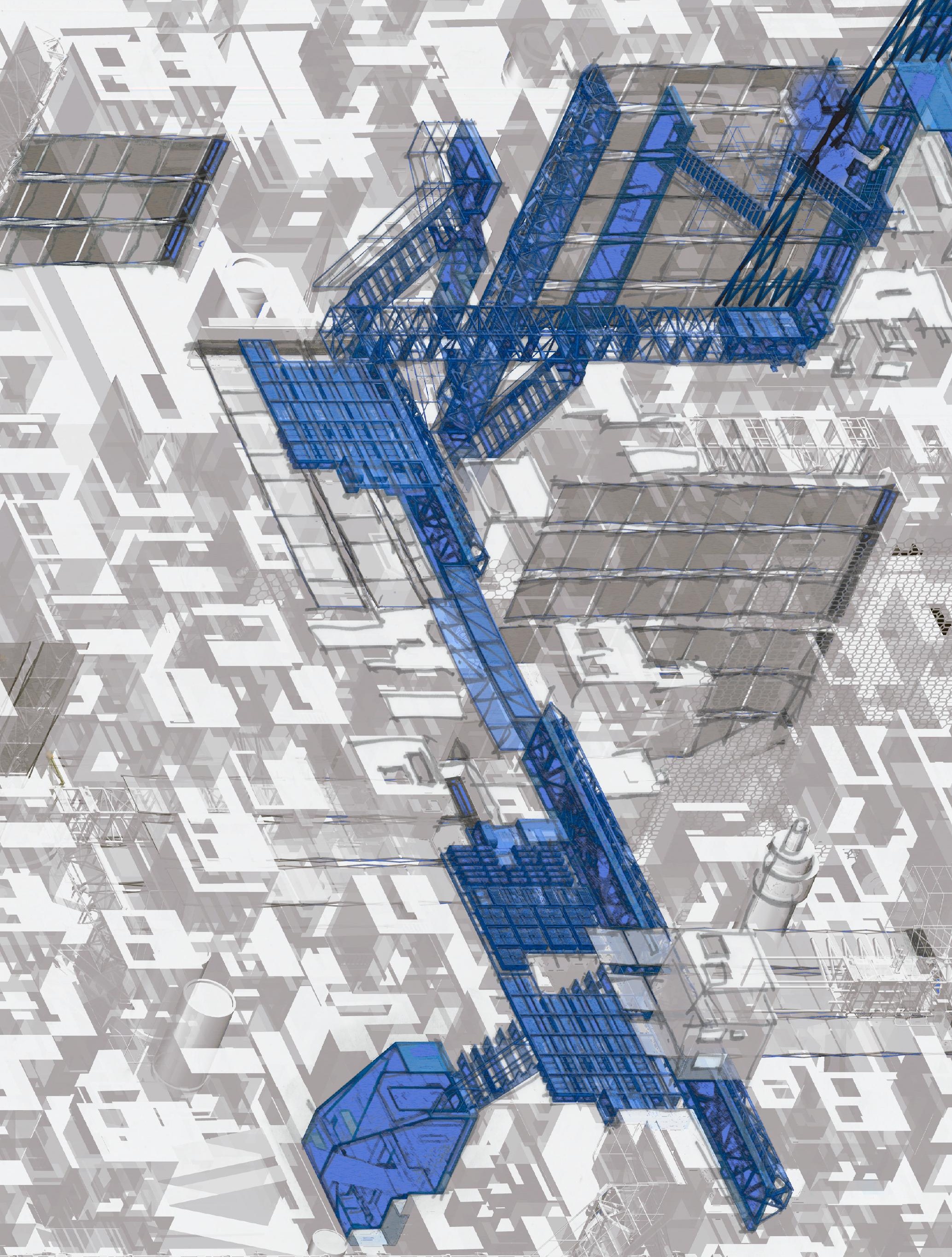




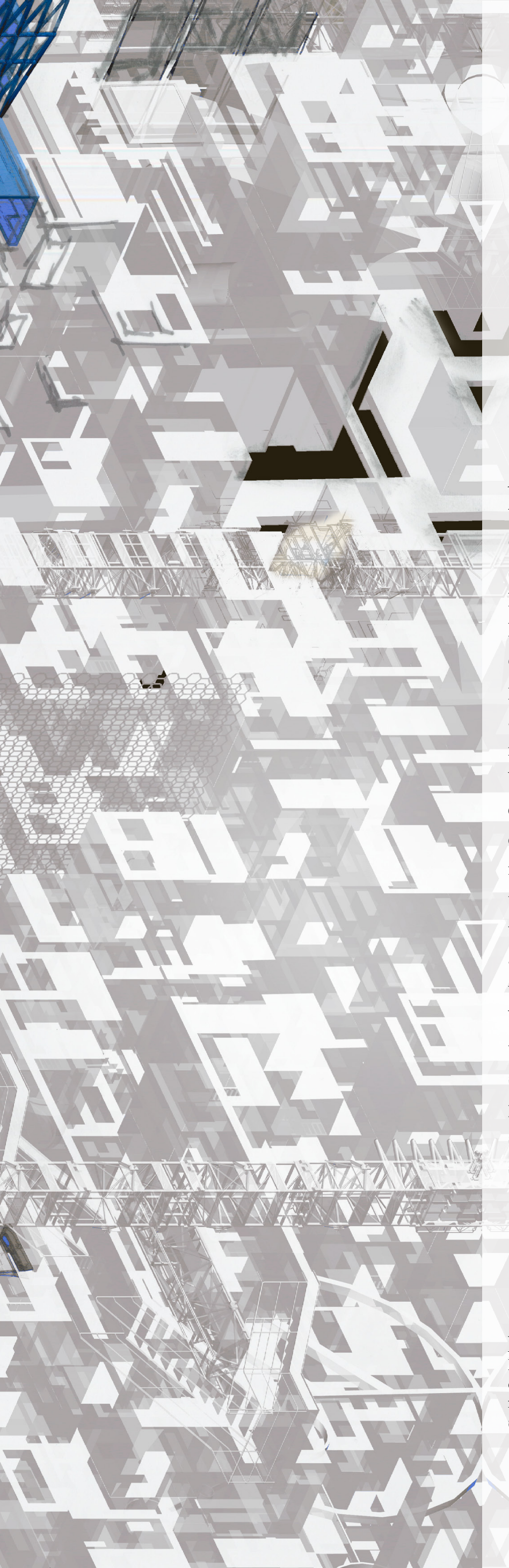

A problem that could arise over time is the homogeneity of architecture built from discrete elements. There is likely to be a small range of optimal layouts which is likely to encourage people to copy others layouts and constructions which are effective rather than solely to reflect their personality. While this crowd-sourced architectural wisdom is a perfect way to refine concepts it could also result in a more bland overall architectural experience. To counter this it is important that data from outside of the closed residential system is included. The paths that people walk will need to have data collected along the way, allowing input from places that are not limited to destinations chosen by the user but as a result of their transit between these locations. This introduces unintentional inhabitation of architectural space which, after correlation with how positive or negative the user found the space, can feed data into the residential system, minimizing homogeneity.

\section{$\overline{\text { Figure_85 }}$}

Is personal data and digital identity enough to ensure large-scale architectural interventions focussed on efficiency do not remove the variety of space that is encountered in day to day life? $\leftarrow$ 
Noise Level [dB] Low High

Movement Paths

Number of times stopped at a point

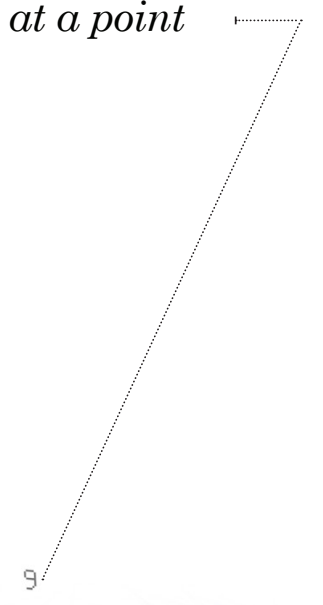

$\overline{\text { Figure_86 }}$

Real world data overlaid onto my daily walking

commute - representing the variety of spaces that I

naturally move through most days. In addition hand

drawn considerations of what I would change about

these spaces. This is reverse engineering of how a

crowd-sourced data-based communal area would be

defined. $\uparrow$ 
${ }^{66} \mathrm{My}$ boy, formulas are dangerous things. They are apt to prove the undoing of a genuine art, however helpful they may be, in the beginning, to the individual. The formula of an art remains and becomes more and more dry, rigid and shrivelled with time, while the spirit of that art escapes, and it vanishes forever."

-Louis Sullivan, 1918, Psychology and the Aesthetics of the Built Environment by Arthur Stamps.

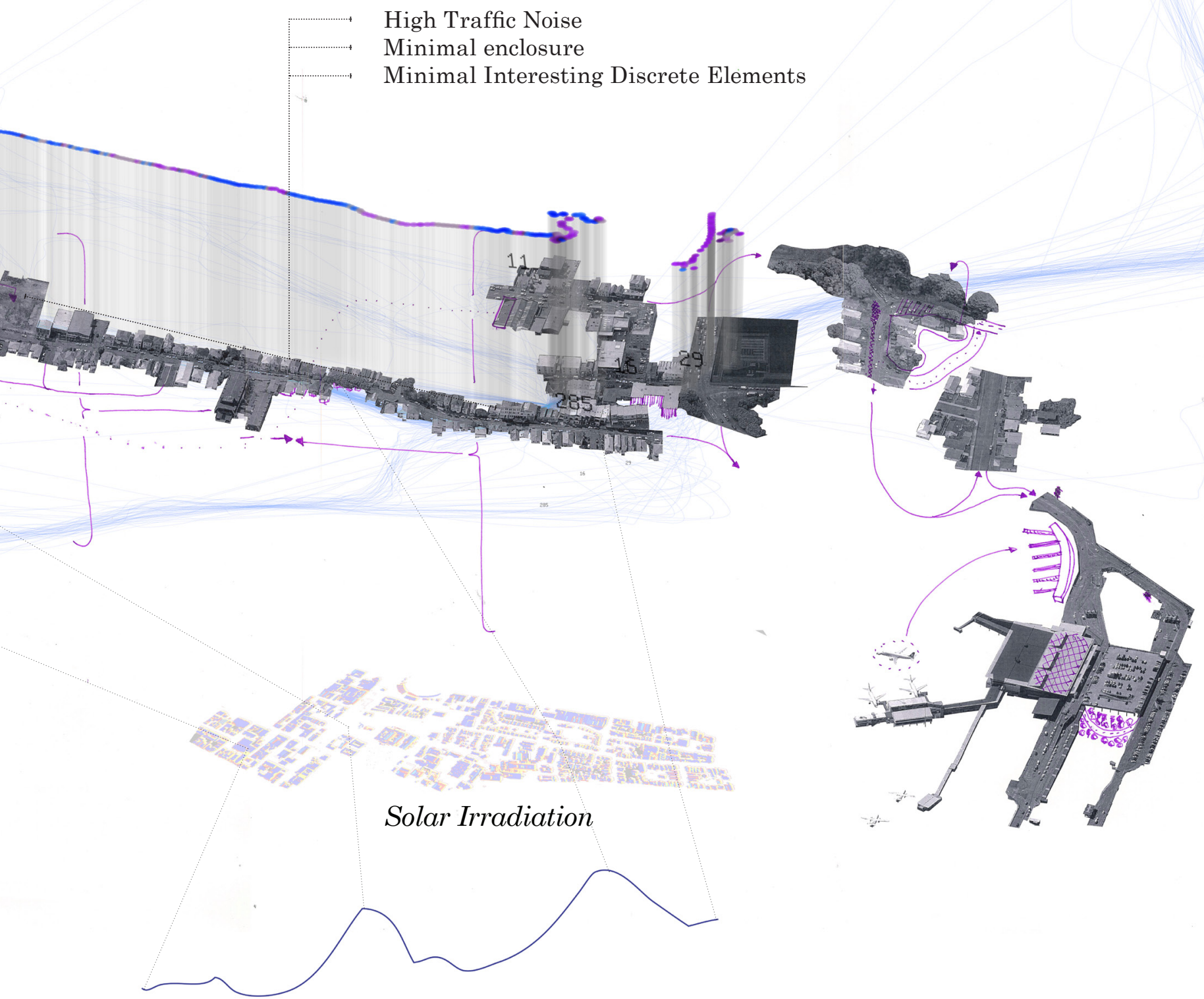

Elevation 


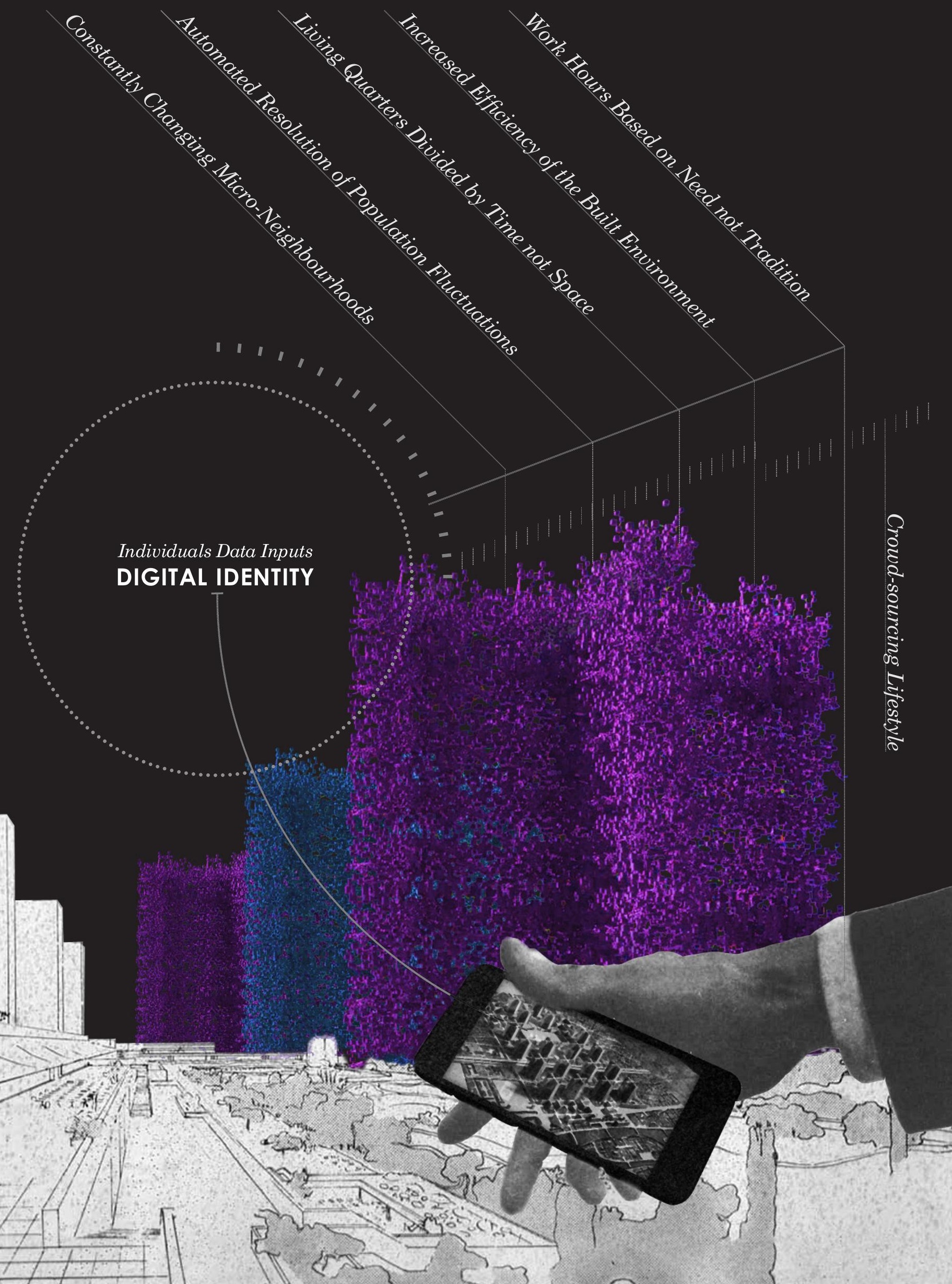




\subsection{DEVELOPING DATA-BASED MODES OF LIVING}

The idea of smaller, increasingly shared space is not a new idea. Apartments aim to provide a small but livable private space with shared amenities such as gyms, pools and in many cases laundry facilities. Le Corbusier's 'Radiant City' holds these ideals at it's heart and called this increased efficiency a "gift to us all from modern technology" (Imrie, 1999). The Radiant City paradigm has been widely criticized as an "overvaluation of mechanization and standardization" (Imrie, 1999), as well as ignorant of "civic and social character" (Mumford, 1968). Data has the potential to increase the efficiency while negating some of these criticisms of Le Corbusier's revolutionary concept. This could be done by creating considered connections between spaces and their inhabitants and allowing timesharing of facilities that were previously too unpredictable to share such as kitchens, lounges and studies. While time and location data would allow efficient sharing, identity data would allow more consideration of who the sharing occurs with. For example data on tidiness and taste could ensure sharing occurs predominantly between like-minded individuals and reduces problems associated with disparate personalities sharing space.

\footnotetext{
$\overline{\text { Figure_87 }}$

Digital identity as a tool for reshaping the residential built-environment demonstrated through an update of Le Corbusier's original attempt - the Ville Radieuse or Radiant City. $\leftarrow$

$\overline{\text { Figure_88 }}$

Conceptual high-density data-based building typology based on discrete elements being combined in multiple ways. $\curvearrowright$
} 


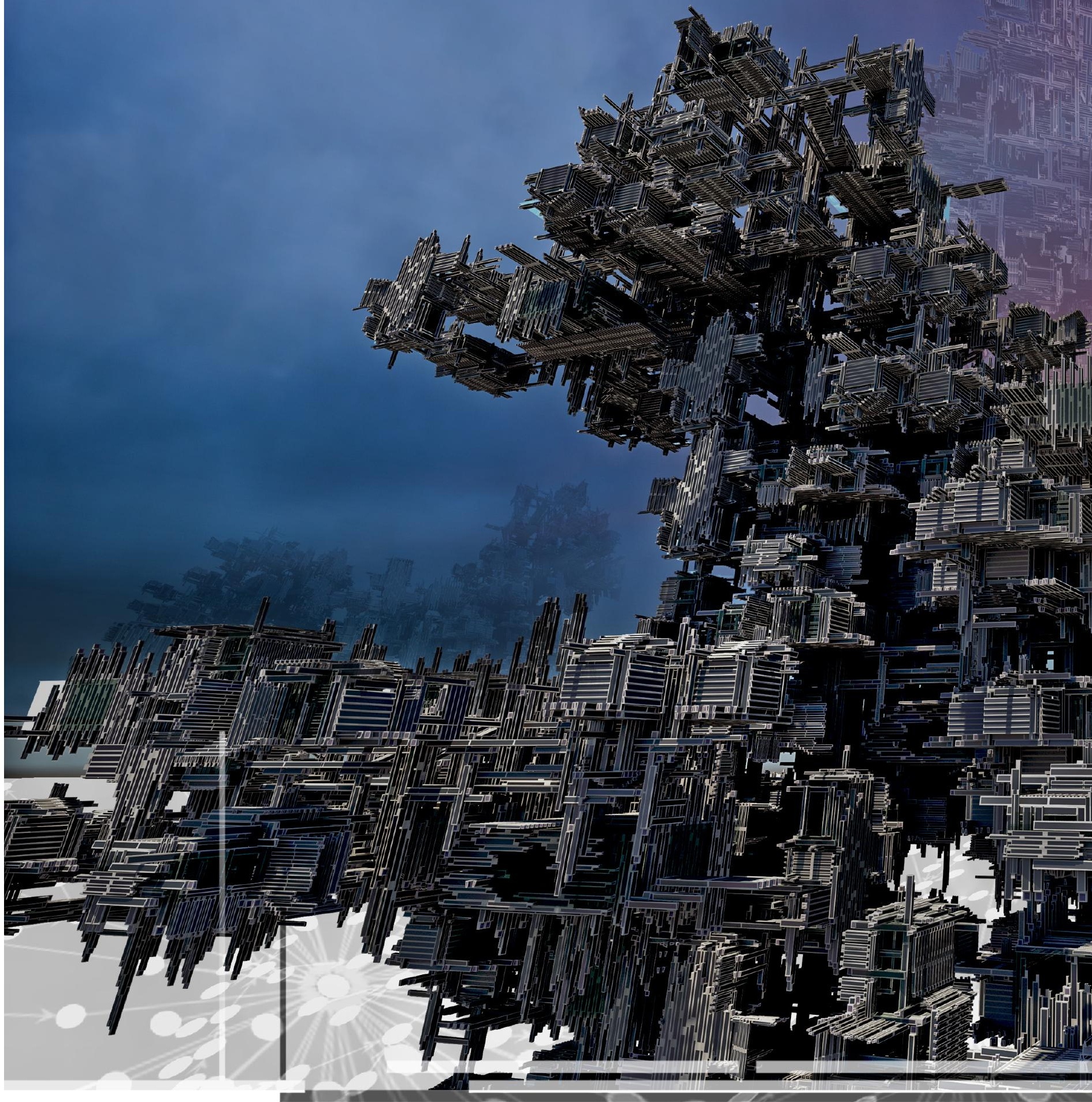




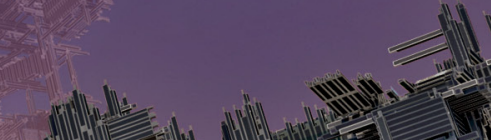<smiles>C1CCCCC1</smiles>

(20)

(1) (1) (1) 


\section{Passive inhabitance is replaced}

by active involvement.

In-line with media trends from passive

consumption, such as TV to social and

contributory media formats.

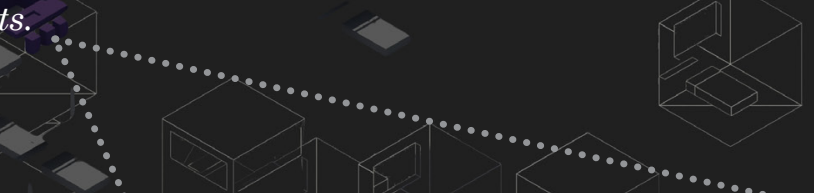

Social and economic hierarchy is dismantled.

Based on the superseding of sorting by search. People are no longer sorted, instead they are located dynamically at request.
Ownership becomes fluid and multi-faceted.

This is in-line with current online dataownership.

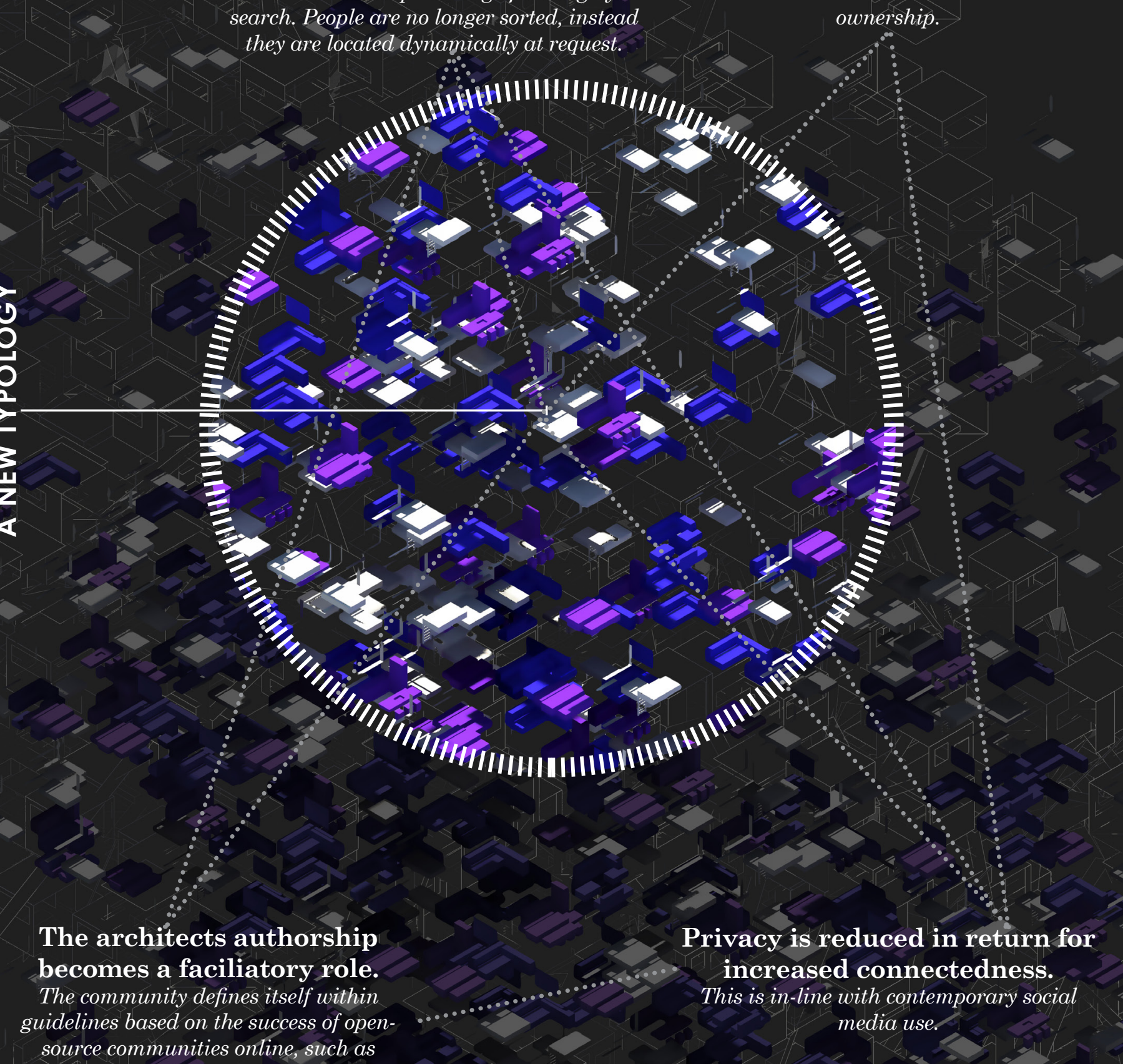

Wikipedia. 


\subsection{A NEW TYPOLOGY CONCEPT}

Initial reactions to shared space often center around privacy - a concept that the use of digital space and data has repeatedly proven less important to people than is assumed. A myriad of services collect and sell data on their users. This diminishes privacy but the success of this business typology is proof that the benefit the tools provide to individuals outweigh their inclination towards privacy. Similarly social media has been called a "reverse-peephole" as it gives the world access to view one's life in a way that only decades ago would have been considered invasive. It can be concluded that while privacy is a social norm it is not valued over convenience or self-expression at an individual level.

\footnotetext{
$\overline{\text { Figure_89 }}$

Digital identity as a tool for reshaping the residential built-environment demonstrated through an update of Le Corbusier's original attempt - the Ville Radieuse or Radiant City. $\leftarrow$

$\overline{\text { Figure_90 }}$

Combination of physical and digital space for myself and four generated personalities integrating the earlier experiments. $\curvearrowright$
} 
Geographic Translation Algorithm Assigns people physical locations based on places that they visit.

\section{Metrics:}

Time spent at places

Distance walked by Mood

Number of times visiting a place

Transportation Method
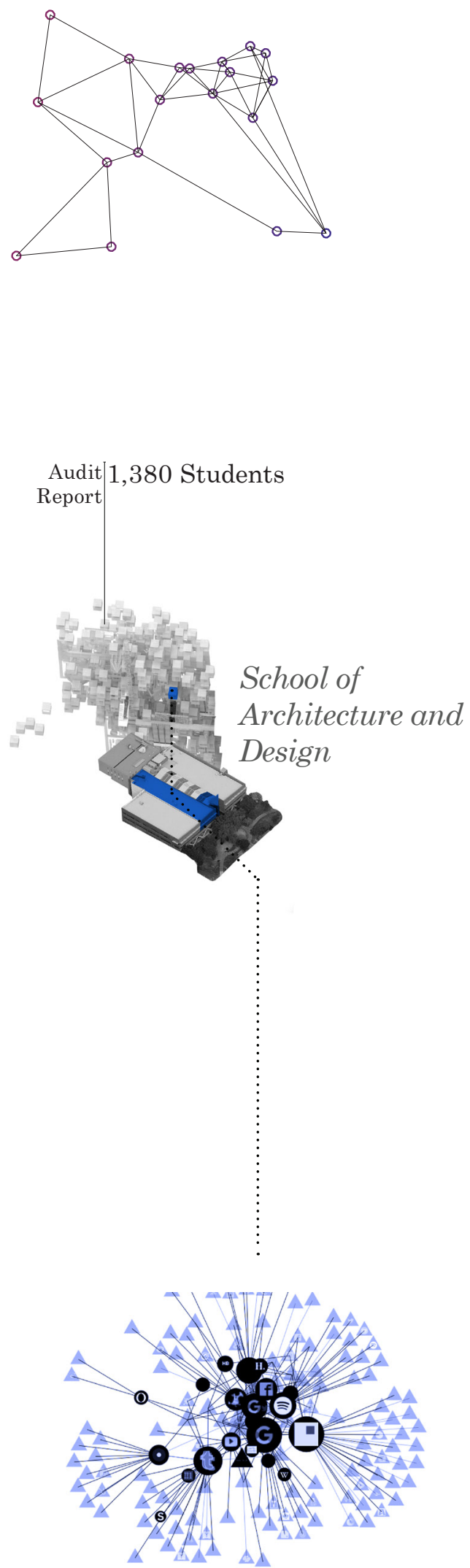

Data flow for 20 Minutes Online

Scott Meekings

Student

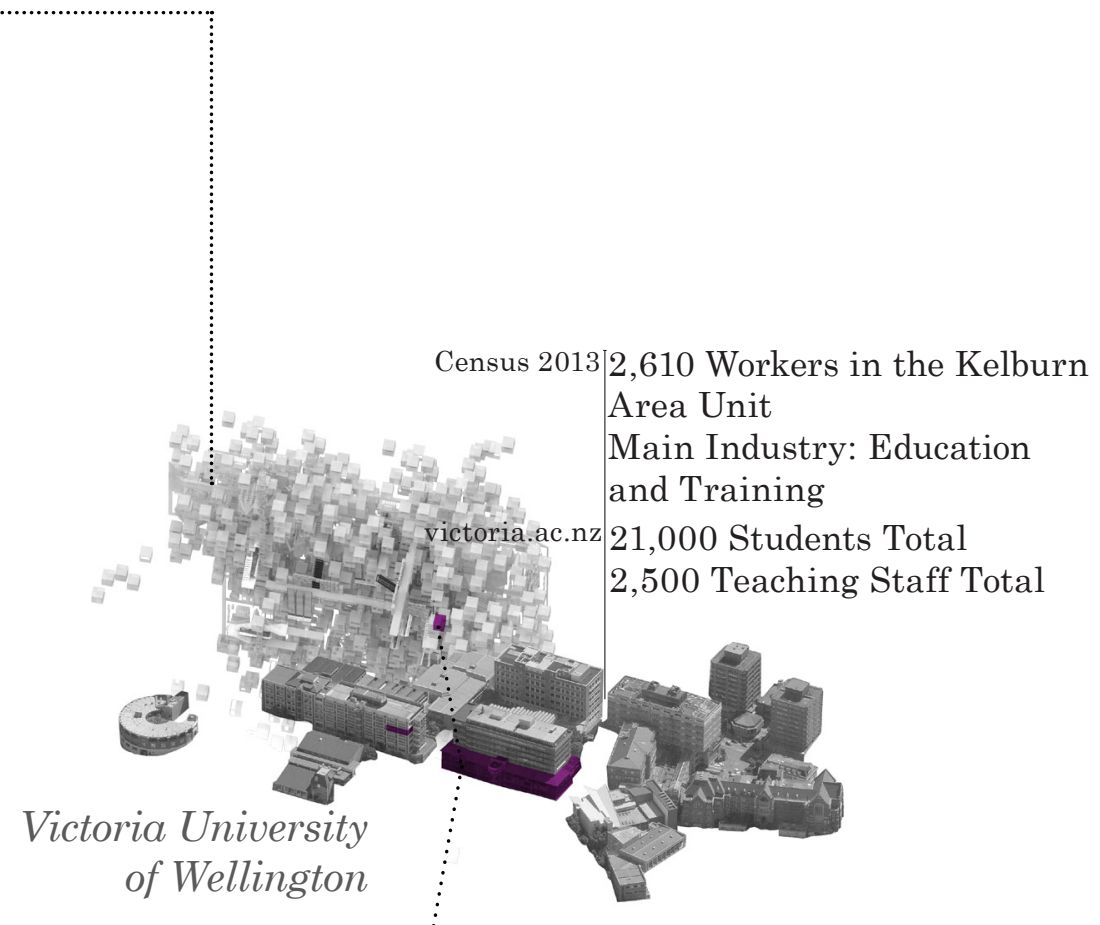

of Wellington

Area Unit

2,500 Teaching Staff Total
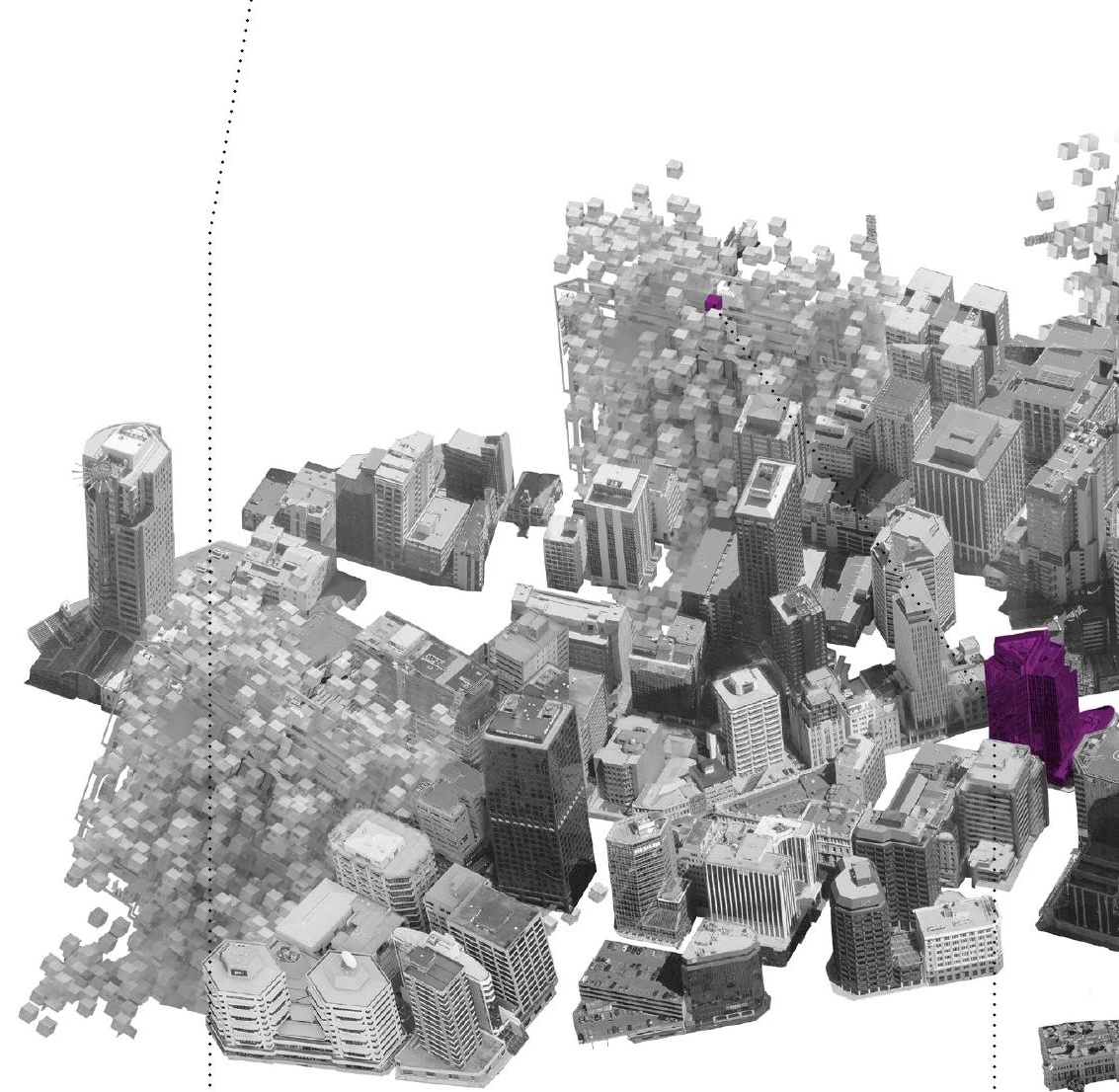

Wellington Central City
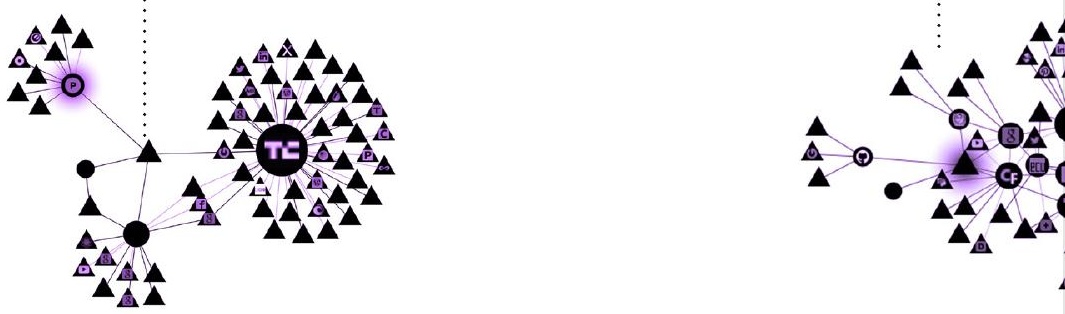

Simulated Data Flow

Sana Ferguson

Simulated Da

Mate $\mathrm{Va}$

Student 
Census 2013 127,464 Workers Total

43,281 Workers in the Lambton Area Unit Main Industry: Professional, scientific and technical services
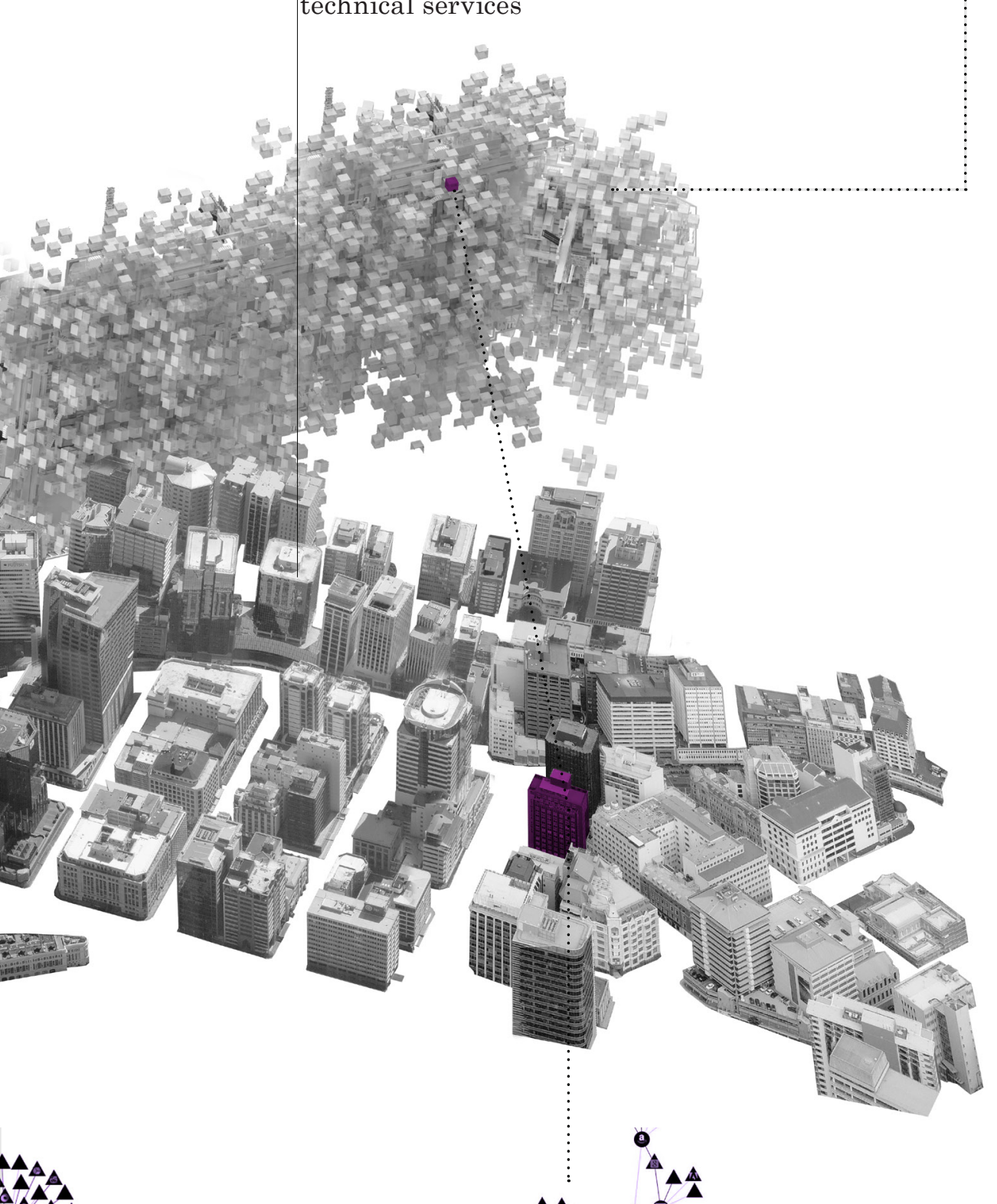

A

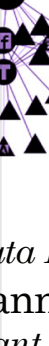

ta

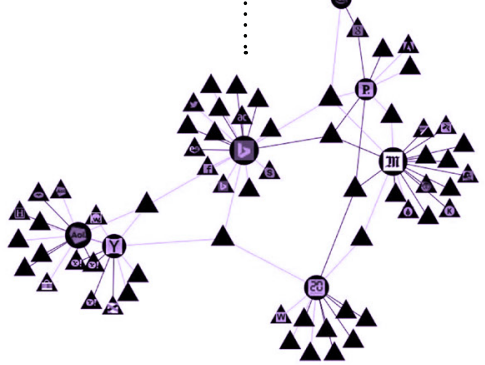

Simulated Data Flow Jerrold Leu Office Worker
Diffusion Limited Aggregation

Algorithm

Creates neighbourhoods within structures based on connections and similarity of data.

Aims to avoid homogenous or disparate groupings.

Metrics: Sentiment

Age

Gender

Schedule

Interests

Social Media Connections

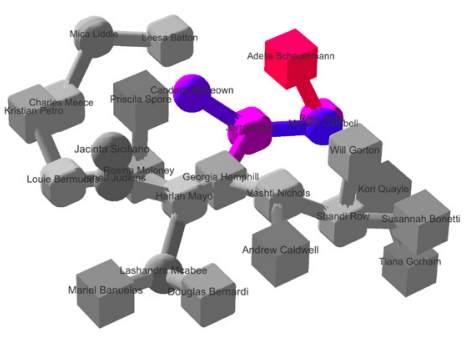

Census 2013 17,421 Workers in the Thorndon Area Unit Main Industry: Professionals + Legislators, Administrators and Managers

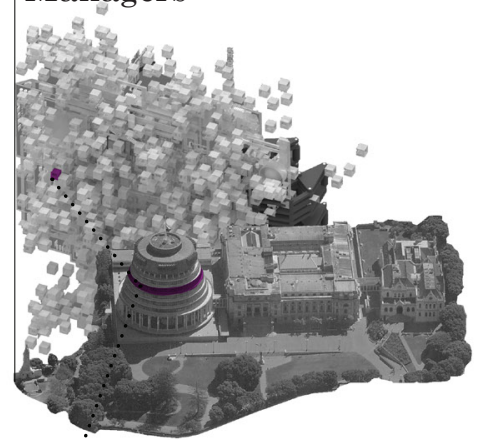

New Zealand Parliament

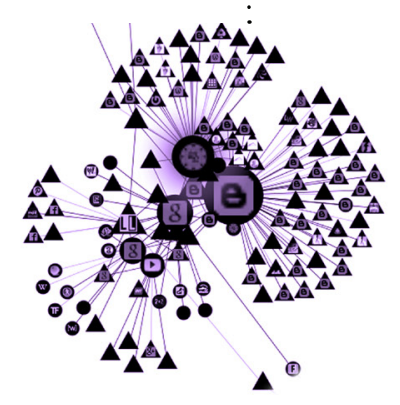

Simulated Data Flow

Cassandra Britton

Political Analyst 

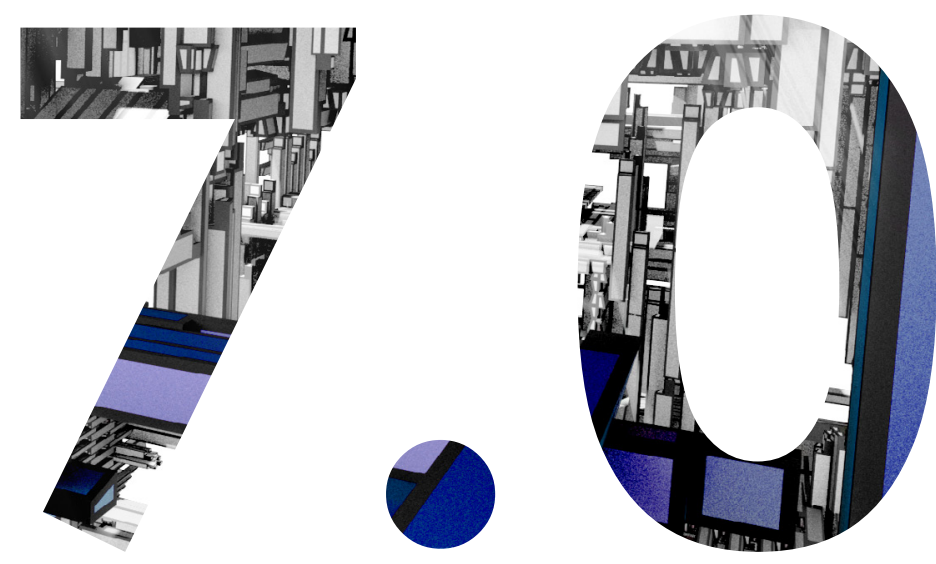

DISCUSSION 
As a whole this research has provided some insights into ways that current data trends may reflect on architectural design over the coming decades. It is important that these conclusions and the experiments that precede them are recognized as speculative and experimental in nature and do not intend to provide a solution that could be constructed.

Through a range of experiments the potential for data to allow a digital identity to manifest in architectural design has been confirmed. Enough detailed data can be collected to piece together ideas about which architectural spaces are likely to be favored, when they are likely to be inhabited and in what way. This is a useful finding that contributes to contemporary discussion on digital interactions. In terms of the conversion of digital identity to architecture this thesis has presented novel work in a niche that is still developing.

As a body of work there is a range of useful content that can be built upon. Three experiments were particularly useful; the DLAA, the Geographic Translation Algorithm and the Atmospheric Visualisation experiment. The diffusion limited aggregation algorithm provides a unique model for organizing architectural space and connections based on data and digital identity. This was used throughout the thesis for organization at a range of scales. The location translation system developed a way to optimize site locations based on digital identity and provides a new way of considering advantages and disadvantages of sites. The Atmospheric Visualisation experiment allowed place data to

$\overline{\text { Figure_91 }}$

Perspective of exterior space constructed from discrete elements and given colour and atmosphere from the earlier atmospheric experiments. $\curvearrowright$ 
be understood in a novel three-dimensional, atmosphere-based data visualization technique developed solely for this purpose. This provides an atmosphere based on user-favored locations and can be modified to further suit their preferences - for example the addition of colours from a user's photo allows the atmosphere to be personalised.

Together these algorithms act as a proof of concept that a digital identity could be used throughout the architectural design process. From locating sites and producing more efficient spatial layouts to providing the means for users to attach their aesthetic preferences to architecture. These experiments are in some ways pre-cursors to methods that will allow architecture to have further reach within society. Certainly the downside to this method of research is the lack of ability to test these outcomes in real-world scenarios to determine if they can fulfil the potential that is predicted here.

An important area that was not fully explored here is interaction and data ownership which is a very complex aspect of the big data phenomenon. It is an important consideration of personalizing space but in review it is not easily developed alongside architecture. The experiments based on interaction done here helped spur design and invoke interaction, but does not provide any sort of answer to data ownership questions.

There are similar impracticalities associated with the material and form experiments. Both were useful areas to test design ideas and the potential for data integration into data at a conceptual level but appear impractical for built work. For maximum effect these areas would require real-time updating, while projects such as the Aegis: Hyposurface demonstrate technical feasibility, it is highly impractical (Goulthorpe et al., 2001). These experiments show, however, that data can be architecturally incorporated through the build-up of many discrete elements. The conglomeration chapter focused too much on this and produced an installation from

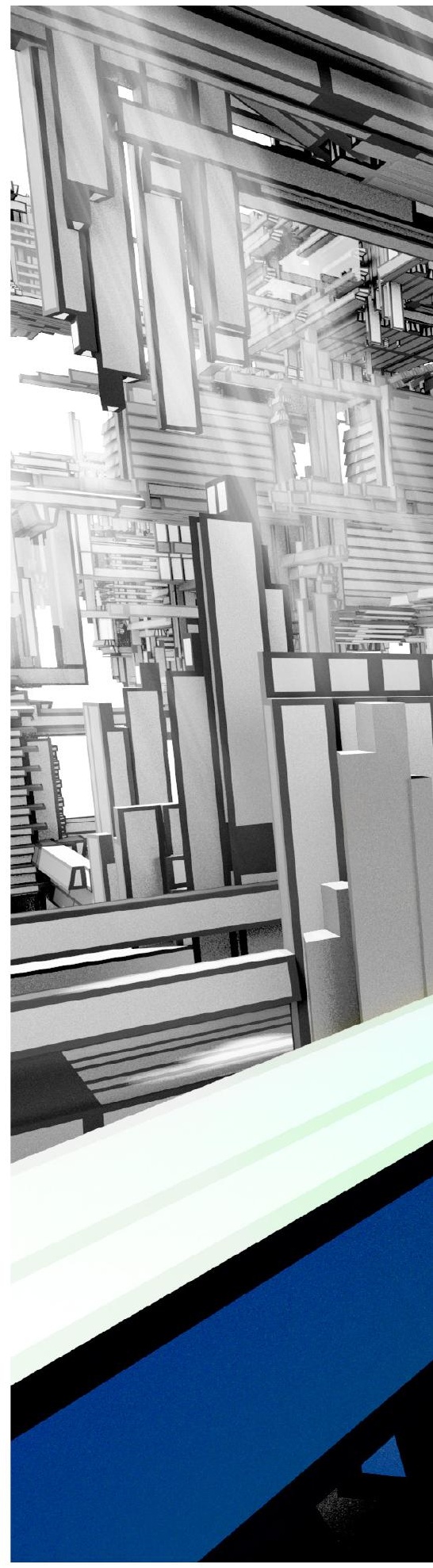




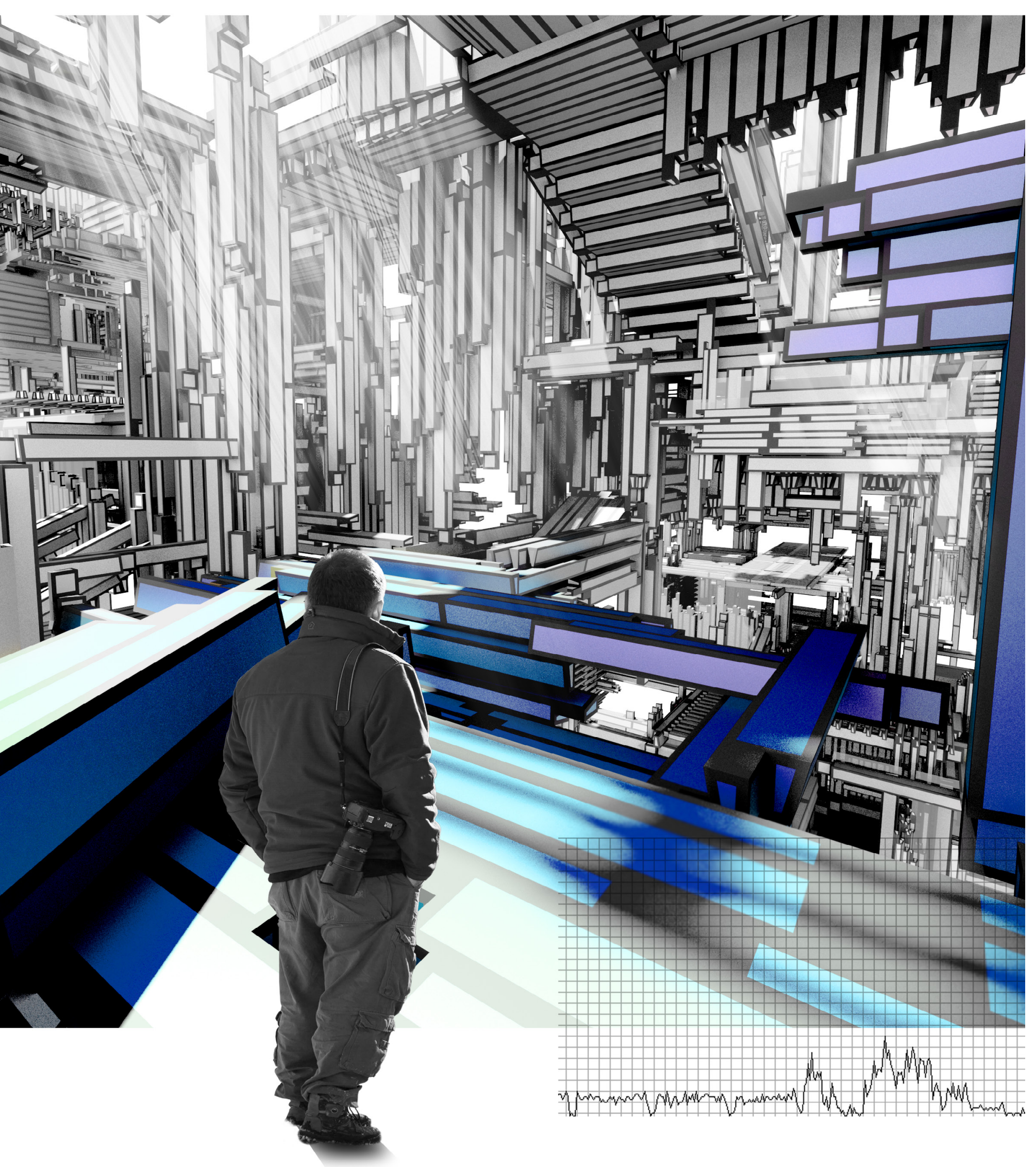


many small parts representing a large number of people. While successful, the result lacked personality and did not effectively use digital identity. This was rectified in the developed experiments.

Developing a residential typology that reflected current data necessitated a speculative outcome. The location algorithm suggested similar areas for many datasets, creating areas of high density. Combinations of people within these high-density areas were laid out through the DLA algorithm. Rather than using a single apartment per person, living spaces are split up into separate areas, sharing everything except bedrooms. The time a person uses a facility is factored into the layout with the aim that each facility is available when needed. Using time-location data it could be estimated when each facility, for example a kitchen, will be needed and two people who tend to use the kitchen at different times could share one. In hindsight this is a response to housing affordability issues. While apartments are one solution these are inefficient, generic solutions that compromise on space, rather than time, and remove architect-inhabitant engagement. The typology proposed here leaves questions over ownership, in-line with current ambiguity over data ownership. This is a paradigm that would be difficult to implement in architecture due to the high cost and risk of construction but should still be considered due to increased efficiency; supplementing this typology with data based decision making is crucial to reducing this risk. This research also predicts a reduction in privacy. The choice of convenience over privacy has been shown repeatedly by many social-media services, despite conflicting with general assumptions. Free services in return for data has become a common, contemporary business model and this research provides some evidence that architecture could follow suit.

As a whole, the speculative nature of the final proposal, based on digital identity and with decisions being data-driven, conclude there is a gap between data-driven design and the architecture industry. It is predicted that data-integration with the architecture 
industry is inevitable and will likely occur over the next decade. It may not happen for a time then occur rapidly. This is the process most industries have undergone when adopting data. This is plausible in architecture but has issues due to ingrained social factors. This would most likely happen by an already established company collecting data and building personalised living spaces that are cheaper and more effective, spurring industry innovation. Improving digital fabrication methods will make this increasingly plausible. More likely the transition will be a slow shift into data-driven design. This seems likely due to the slow introduction of new technology within the construction industry, presumably due to the high economic stakes. With international competition to push architecture-data integration (such as the UK BIM mandate), small advancements are likely to become increasingly common. Integration with architecture at a design level will take longer as it is more complex. As competition between conventional architectural practice and more data-intensive industries becomes fiercer conventional architectural design has the potential to be assimilated into other industries. 


\subsection{CRITICAL REFLECTION}

In hindsight this thesis has worked within a niche that is surprisingly large. This allowed for original thinking but also made the research less refined. With fewer precedents and a broad spread of related literature this work has attempted to span an array of fields, resulting in a less focussed body of work. While this research does bolster the relatively small body of design work relating data, digital identity and architectural design, the overarching weakness of this work is that it is too broad and tackles too many topics simultaneously to provide concrete solutions to any of them.

Throughout this research an optimistic slant has always been present - the potential for progress decided the direction of the research and where difficulties arose a best-case scenario was assumed. For example there is little rigour in explorations of how practices may acquire data, it is assumed that since technology companies do this already that it will be possible for architects to follow suit, which may not be plausible. This means there are likely many roadblocks to real-world implementation of this research that need further exploration.

It is hoped that this area will be pushed further than it is here, as architecture embraces the rapidly expanding digital influence on our lives. Solutions that have their basis solidly in 'real-world' construction will allow this topic to expand well beyond where this theoretical research concludes. The freedom from conventional architectural issues has produced novel architectural results but has also weakened the clarity of the impact data may have on architecture in the future. 

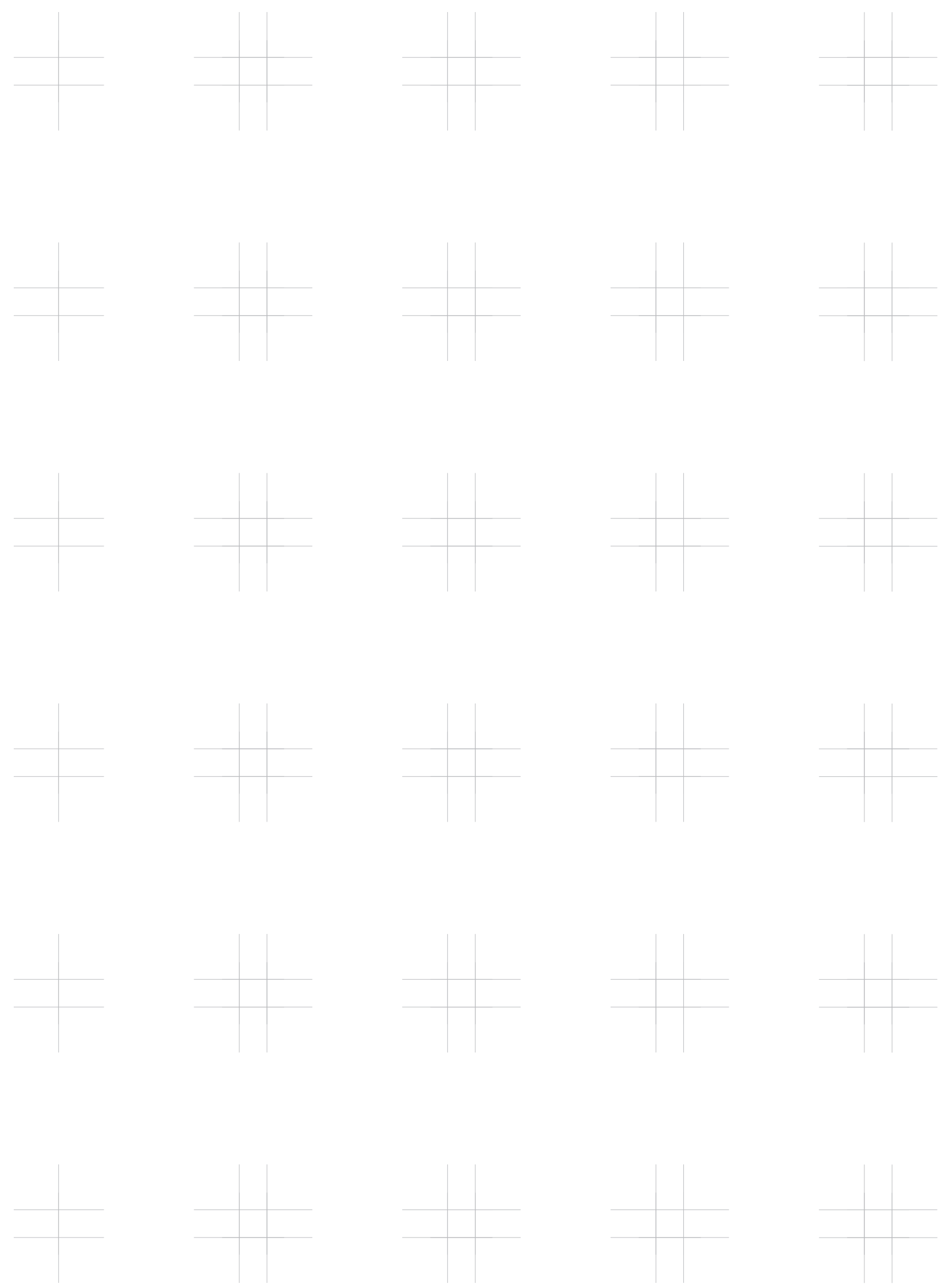


\subsection{BIBLIOGRAPHY}

ABEL, C. \& FOSTER, N. 2012. Architecture and identity, Routledge. ANDERS, P. 2001. Anthropic cyberspace: defining electronic space from first principles. Leonardo, 34, 409-416.

ARMSTRONG, R. 2008. Artificial Evolution: A Hands $\square$ Off Approach for Architects. Architectural Design, 78, 82-85.

BAUSCH, S. \& HAN, L. 2006. Social networking sites grow 47 percent, year over year, reaching 45 percent of web users. PR Newswire. Online: Nielson/NetRatings.

CHITTARANJAN, G., BLOM, J. \& GATICA-PEREZ, D. 2013. Mining large-scale smartphone data for personality studies. Personal and Ubiquitous Computing, 17, 433-450.

CHRISTENSEN, P. \& SCHNABEL, M. A. 2008. Spatial Polyphony Virtual Architecture Generated from the Music of JS Bach. In: MAHAEK, E., TEERAPARBWONG, K. \& NILKAEW, P. (eds.) Proceedings of the 13th International Conference on Computer Aided Architectural Design Research in Asia. Chiang Mai: CAADRIA. COHEN, L., WILKINSON, A., ARNOLD, J. \& FINN, R. 2005. 'Remember I'm the bloody architect!'Architects, organizations and discourses of profession. Work, Employment \& Society, 19, 775-796.

DARKE, J. 1979. The primary generator and the design process. Design studies, 1, 36-44.

DAVIS, D. 2014. Find Yourself and Get Ahead of Technology. ARCHITECT: The Journal of the American Institute of Architects. DEUTSCH, R. 2015. Data-driven Design and Construction: 25 Strategies for Capturing, Analyzing and Applying Building Data, John Wiley \& Sons.

FISHKIN, K. P. 2004. A taxonomy for and analysis of tangible interfaces. Personal and Ubiquitous Computing, 8, 347-358.

GEORGE, G., HAAS, M. R. \& PENTLAND, A. 2014. Big data and management. Academy of Management Journal, 57, 321-326. 
GOULD, H., TOBOCHNIK, J. \& WOLFGANG, C. 2005. An Introduction to Computer Simulation Methods: Applications to Physical Systems (3rd Edition), Boston, Addison-Wesley Longman Publishing Co., Inc. GOULTHORPE, M., BURRY, M. \& DUNLOP, G. 2001. Aegis Hyposurface: The Bordering of University and Practice. In: JABI, W. (ed.) ACADIA: Reinventing the Discourse. Buffalo, New York.

GU, N., KIM, M. J. \& MAHER, M. L. 2011. Technological advancements in synchronous collaboration: The effect of $3 D$ virtual worlds and tangible user interfaces on architectural design. Automation in Construction, 20, 270-278.

HAM, J. J. \& SCHNABEL, M. A. 2012. How social is the virtual design studio? A case study of a third year design studio. In: FISCHER, T. (ed.) CAADRIA 2012: Beyond Codes and Pixels: Proceedings of the 17th International conference on Computer Aided Architectural Design Research in Asia. Chennai: Association for Computer-Aided Architectural Design Research in Asia.

HORNSTEIN, S. 2011. Ashgate Studies in Architecture : Losing Site : Architecture, Memory and Place, Farnham, GB, Routledge.

IMRIE, R. 1999. The body, disability and Le Corbusier's conception of the radiant environment, New York: Routledge.

ISHII, H., LAKATOS, D., BONANNI, L. \& LABRUNE, J.-B. 2012. Radical atoms: beyond tangible bits, toward transformable materials. interactions, 19, 38-51.

JOYCE, R. \& GUPTA, G. 1990. Identity authentication based on keystroke latencies. Commun. ACM, 33, 168-176.

KUMAR, A. \& SEBASTIAN, T. M. 2012. Sentiment analysis on twitter. IJCSI International Journal of Computer Science Issues, 9, 372-373. KVAN, T. \& GAO, S. 2004. Problem framing in multiple settings. International Journal of Architectural Computing, 2, 444-460.

MANYIKA, J., CHUI, M., BROWN, B., BUGHIN, J., DOBBS, R., ROXBURGH, C. \& BYERS, A. 2011. Big data: The next frontier for innovation, competition, and productivity. McKinsey\&Company Business. Online.

MEEKINGS, S. S., MARC AUREL 2016. Big Data on Individuals in the Architectural Design Process: Combining Individual's Data with the Architects Toolset. International Journal of Parallel Emergent and Distributed Systems, 13-20. 
MERRICK, K. \& GU, N. 2011. Supporting collective intelligence for design in virtual worlds: A case study of Lego Universe. In: LECLERCQ, P., HEYLIGHEN, A. \& MARTIN, G. (eds.) Proceedings of CAAD Futures 2011.

MERRICK, K., GU, N., NIAZI, M. \& SHAFI, K. Motivation, Cyberworlds and Collective Design. In: HERR, C., GU, N., ROUDAVSKI, S. \& SCHNABEL, M. A., eds. Circuit Bending, Breaking and Mending: Proceedings of the 16th International Conference on Computer-Aided Architectural Design Research in Asia, 2011.

MINI NEXT 100. 2016. MINI Vision Next 100 [Online]. https://www. mini.co.uk/en_GB/home/explore/motorsport-vision/mini-visionnext100.html. [Accessed 11/08/2016.

MUMFORD, L. 1968. The urban prospect: essays, Harcourt, Brace \& World.

MYERS, M. 2011. The Impact of Social Media on Architecture. CRUCES [Online]. 2016].

NEEF, D. 2014. Digital Exhaust: What Everyone Should Know About Big Data, Digitization and Digitally Driven Innovation, USA, Pearson Education.

NIELSEN, F. A. 2011. A new evaluation of a word list for sentiment analysis in microblogs. Proceedings of the ESWC2011 Workshop on 'Making Sense of Microposts': Big things come in small packages 718 in CEUR Workshop Proceedings, 93-98.

ORI SYSTEMS. 2016. How Ori Works [Online]. http://orisystems. com/\#howoriworks. [Accessed 11 June 2016].

OXMAN, R. 2015. Computational Schema as a Facilitator for Crowdsourcing in a "Social $\square$ Motive” Model of Design. In: TAURA, T. (ed.) Principia Designae - Pre-Design, Design, and Post-Design. Tokyo: Springer.

OXMAN, R. \& GU, N. 2012. Crowdsourcing: theoretical framework, computational environments and design scenarios. eCAADe 2012 : The 30th International Conference on Education and research in Computer Aided Architectural Design in Europe. Prague, Czech Republic: eCAADe.

PARISI, L. 2012. Nanoarchitectures: The Synthetic Design of Extensions and Thoughts. In: KARATZOGIANNI, A. \& KUNTSMAN, A. (eds.) Digital Cultures and the Politics of Emotion. UK: Palgrave Macmillan. 
PAULINI, M., MAHER, M. L. \& MURTY, P. 2011. The role of collective intelligence in design. In: HERR, C. M., GU, N., ROUDAVSKY, S. \& SCHNABEL, M. A. (eds.) Circuit Bending, Breaking and Mending: Proceedings of the 16th International Conference on Computer-Aided Architectural Design Research in Asia CAADRIA. Hong Kong.

PIETRONERO, L. 2013. Fractals' Physical Origin and Properties, New York, Plenum Press.

PORTER, B. \& FEKETE, M. 2016. Facebook Algorithm Change History. Wallaroo Media [Online]. [Accessed 5 Dec 2016].

PRENSKY, M. 2001. Digital natives, digital immigrants part 1. On the horizon, 9, 1-6.

RETSIN, G. 2016. Something Else, Something Raw: From ProtoHouse to Blokhut-The Aesthetics of Computational Assemblage. Architectural Design, 86, 84-89.

RIEGER, U. 2008. [arc/sec]: Architecture per Second. Architectural Design Research: Project-Based Design Research and Discourse on Design, 3, 79-102.

SCHLANGEN, H., JONKERS, H., QIAN, S. \& GARCIA, A. Recent advances on self healing of concrete. FraMCos-7: Proceedings of the 7th International Conference on Fracture Mechanics of Concrete and Concrete Structures, 2010 Jeju Island, Korea.

SCHNABEL, M. A. \& HOWE, E. L. 2012. The changing face of problem-based learning: social networking and interprofessional collaboration. In: AL., S. B. E. (ed.) Problem-Based Learning in Clinical Education. New York: Springer.

SHIRKY, C. 2010. Cognitive surplus: Creativity and generosity in a connected age, Penguin UK.

STAMPS, A. 2013. Psychology and the aesthetics of the built environment, New York, Springer Science \& Business Media.

THAM \& VIDEGARD ARKITEKTER. 2015. The Hemnet Home [Online]. http://www.tvark.se/the-hemnet-home/. [Accessed 11 August 2016].

WEBB, A. 2015. Interspecial War and Love in the Post-Antropocene. Creative Mornings Albuquerque. Albuquerque: Amy Slater.

WISNESKI, C., ISHII, H., DAHLEY, A., GORBET, M., BRAVE, S., ULLMER, B. \& YARIN, P. 1998. Ambient displays: Turning architectural space into an interface between people and digital information. Cooperative buildings: Integrating information, organization, and architecture. New York: Springer. 

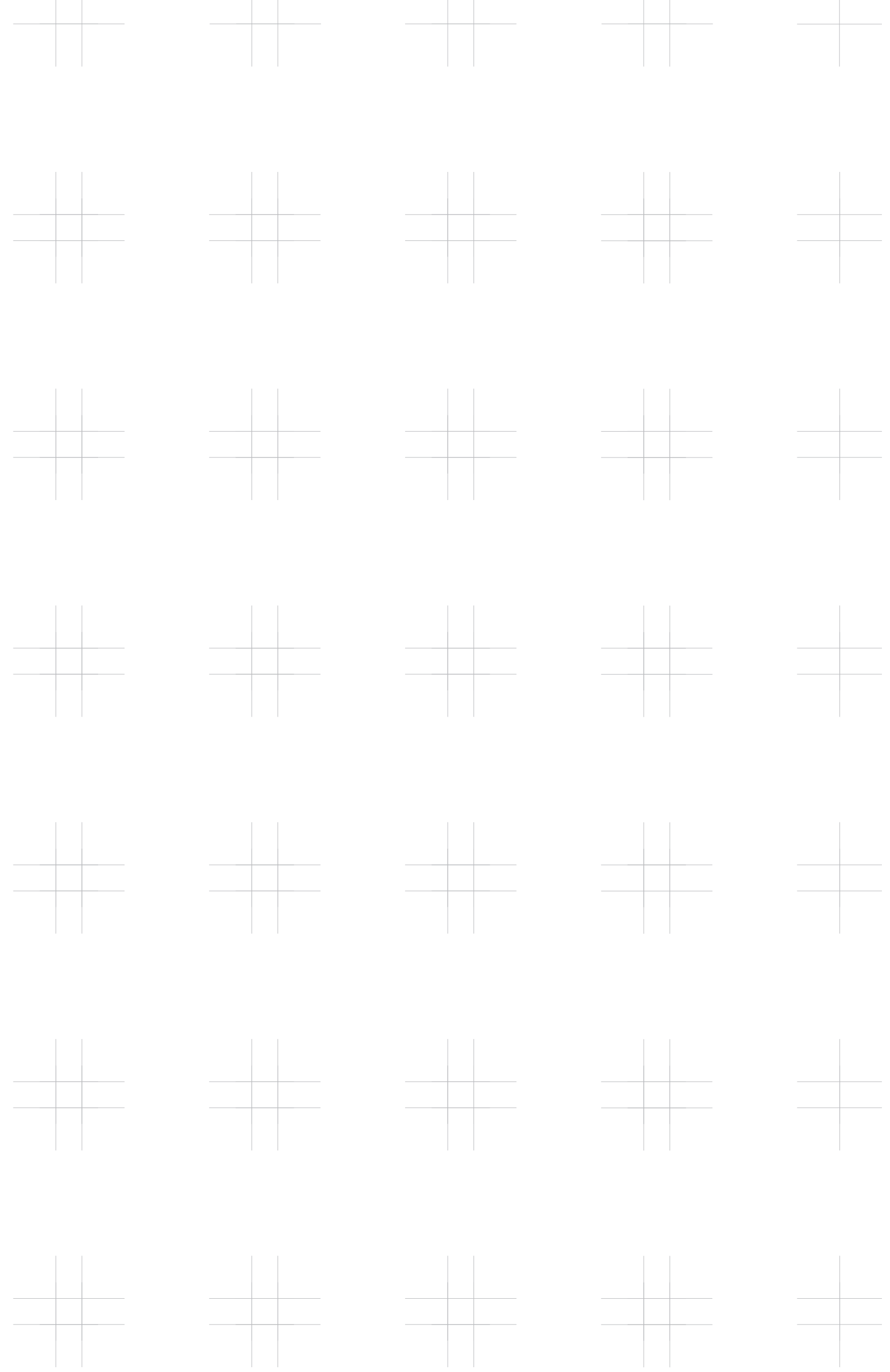


\subsection{APPENDIX}
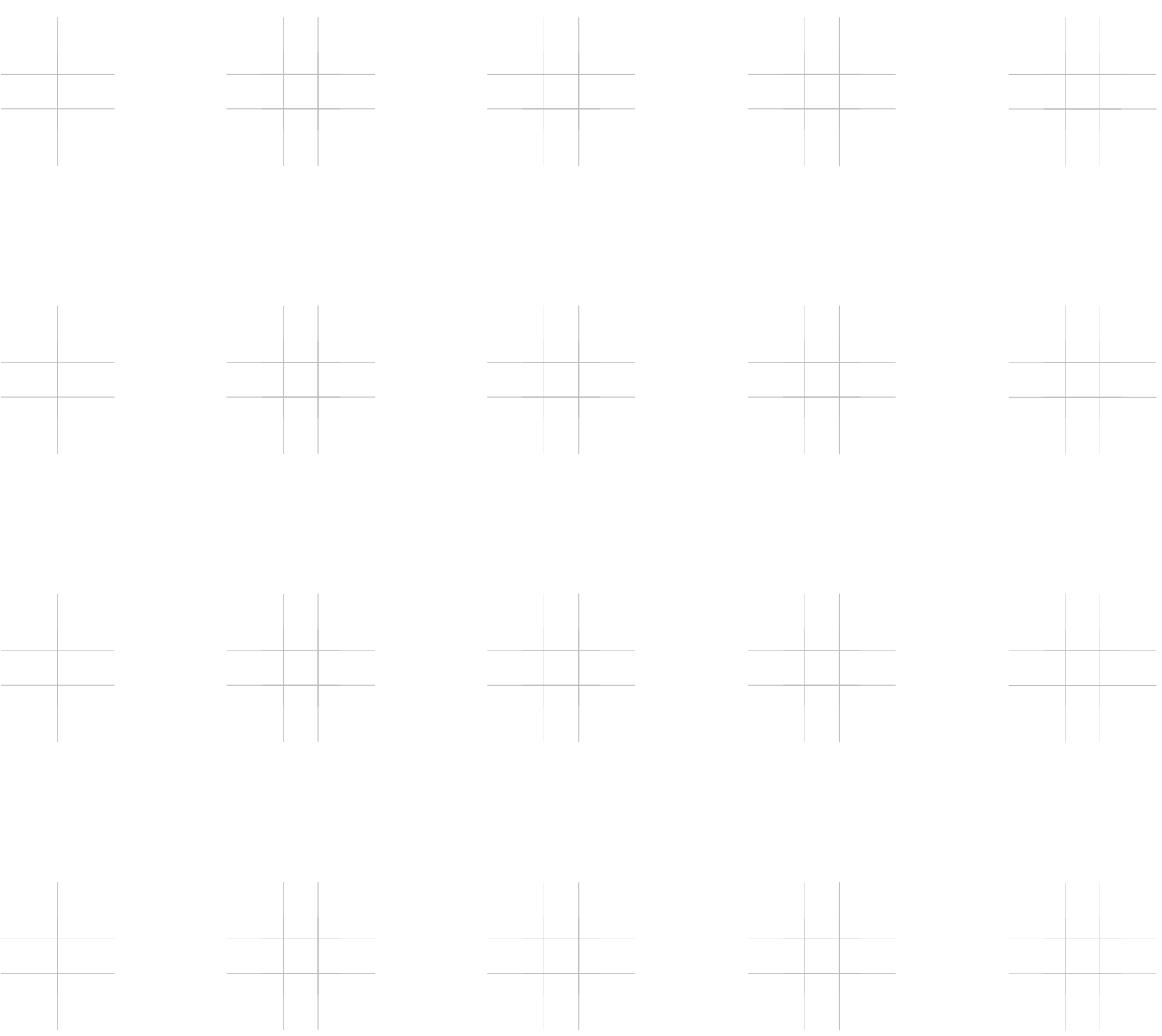


\begin{tabular}{|c|c|c|c|c|c|c|c|c|c|c|c|c|c|c|c|}
\hline 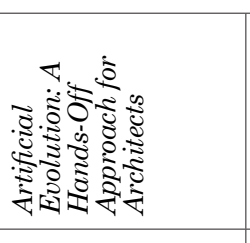 & 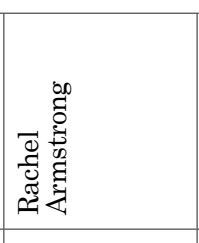 & $\frac{8}{30}$ & \begin{tabular}{l}
$\infty$ \\
$\stackrel{\infty}{0}$ \\
\multirow{2}{*}{}
\end{tabular} & 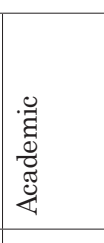 & $\overrightarrow{0}$ & $\infty$ & 0 & $\stackrel{9}{\ominus}$ & \begin{tabular}{l|l}
0 &
\end{tabular} & 0 & $\circ \stackrel{\circ}{\circ}$ & $\begin{array}{lll}0 & 0\end{array}$ & $0-$ & -1 & $\begin{array}{l}\text { Overview of self-producing and self-repairing } \\
\text { buildings through the use of nanotechnology } \\
\text { (nanomachines). Essentially buildings physically } \\
\text { composed of data } \\
\text { biotech, nanotech paper. References very } \\
\text { interesting project from HM Jonkers, Self-healing } \\
\text { concrete -wall tests, TU Delft, The Netherlands, } \\
2007 \text { about self-healing buildings }\end{array}$ \\
\hline 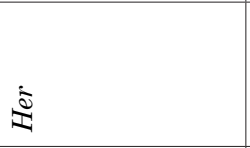 & 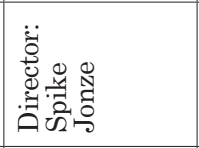 & 咅 & 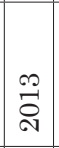 & 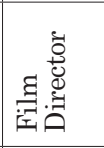 & 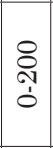 & 0 & $\neg$ & $\infty$ & 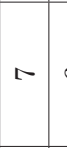 & 0 & $\because \infty$ & $\infty 10$ & $\begin{array}{lll}0 & 0 .\end{array}$ & 0 & $\begin{array}{l}\text { Film about man falling in love with an operating } \\
\text { system. Asks questions about artificial } \\
\text { intelligence, digital identity } \\
\text { Considers the ability for a computer to have a } \\
\text { personality based on data input }\end{array}$ \\
\hline 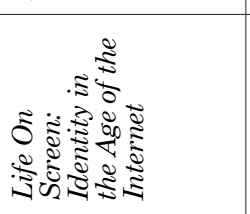 & 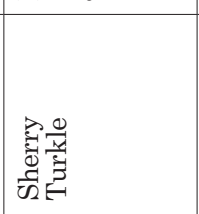 & $\stackrel{8}{3}^{8}$ & 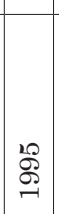 & 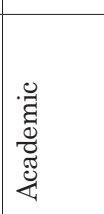 & 点 & 0 & $\neg$ & 0 & $\neg$ & $\begin{array}{ll}0 & 7\end{array}$ & $\rightarrow c$ & \begin{tabular}{l|l}
0 & 10
\end{tabular} & 0 & 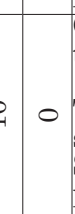 & $\begin{array}{l}\text { Outdated consideration of identity and the use of } \\
\text { the digital. } \\
\text { The authour interviews many people who are } \\
\text { strictly divided into the pro and con's of computers. } \\
\text { Some people like reality and some like the } \\
\text { potential of the speed / accuracy of the digital }\end{array}$ \\
\hline 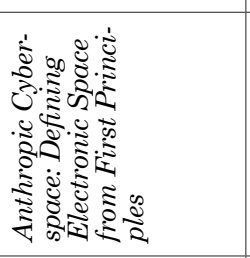 & 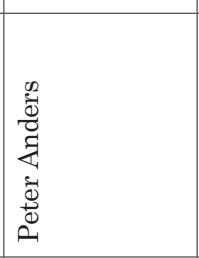 & $3_{3}^{0}$ & $\overrightarrow{\tilde{8}}$ & 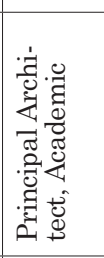 & $\mid \begin{array}{c}10 \\
0 \\
0\end{array}$ & 0 & $\sigma$ & 0 & $\stackrel{1}{9}$ & $r$ & $\rightarrow 7$ & $\begin{array}{rl}-1 & 0\end{array}$ & $\begin{array}{ll}0 & 0 .\end{array}$ & 0 & $\begin{array}{l}\text { Looks at how we interpret the digital, considers } \\
\text { the period of comprehension, cognition and } \\
\text { interaction with each other. "anthropology of space } \\
\text { and its emulation" } \\
\text { Very abstract take. Discuesses authentiticty } \\
\text { and artifact along with the relationship between } \\
\text { society space and technologuies place in between } \\
\text { these two. }\end{array}$ \\
\hline 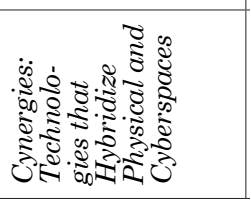 & 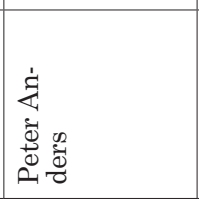 & $\begin{array}{l}\vec{\sharp} \\
\vec{\Sigma}\end{array}$ & 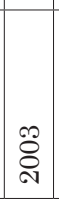 & 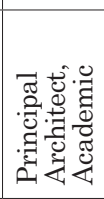 & $\begin{array}{l}0 \\
1 \\
0\end{array}$ & $\neg$ & 0 & $\stackrel{ }{\neg}$ & $\infty \begin{array}{lll}\infty & 1\end{array}$ & 100 & 0 - & $\begin{array}{rll}* & 0\end{array}$ & $\begin{array}{c}0 \\
0\end{array}$ & $v \rightarrow$ & $\begin{array}{l}\text { Overvewew of potential current technologies and } \\
\text { their future uses in architecture for projecting the } \\
\text { digital world into spacial form. } \\
\text { Draws heavily on Johnson } 2002 \text {, interesting } \\
\text { section on "display space" for the thesis }\end{array}$ \\
\hline 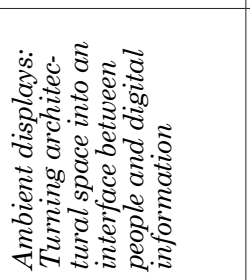 & 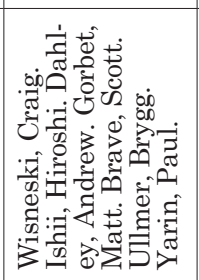 & 胥 & 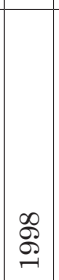 & 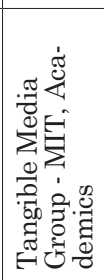 & is & 10 & $\neg$ & $\stackrel{9}{\sim}$ & $\sim$ & $\sim \sigma$ & $\infty \quad-$ & +7 & $-1-$ & -1 & $\begin{array}{l}\text { Overview of interaction between digital and } \\
\text { spatial fields with a focus on ambient design - } \\
\text { conveying data sub conciously, modelled on 'back } \\
\text { of the mind' style processing in real space. } \\
\text { Interesting - relevant to thesis, consider a } \\
\text { combination of concious and subconcious data } \\
\text { conveying techniques }\end{array}$ \\
\hline 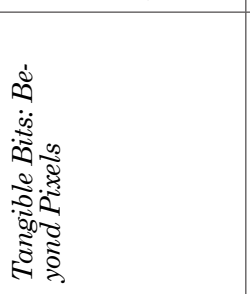 & 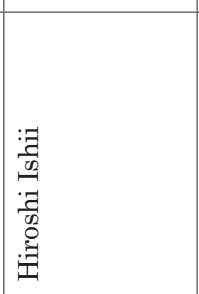 & $3_{3}^{0}$ & $\begin{array}{l}\infty \\
\stackrel{\infty}{0} \\
\text { | }\end{array}$ & 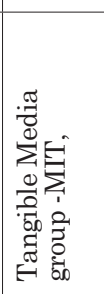 & $\overrightarrow{0}$ & 0 & -1 & 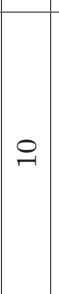 & \begin{tabular}{c|c|c|}
$\infty$ & 1
\end{tabular} & 100 & $\infty 1$ & 10 & $0-$ & $-\infty$ & $\begin{array}{l}\text { Overview of the 'tangible bits' program, overview } \\
\text { of interaction betwwen digital and physical and } \\
\text { how it has changed over time starting around } \\
1977 \text {. Feels that the spheres of data and physical } \\
\text { reality are separate but are coming together now. } \\
\text { This area of research is summed up in 'A } \\
\text { taxonomy for and analysis of tangible interfaces' } \\
\text { by Kennth P. Fishkin. }\end{array}$ \\
\hline 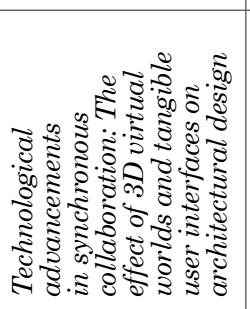 & 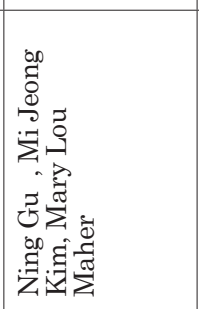 & . & 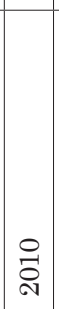 & .ु. & 5 & 0 & -1 & 0 & -1 & $\infty 16$ & 100 & $\circ \stackrel{\circ}{\circ}$ & 2 & -- & $\begin{array}{l}\text { Review of interaction between people in virtual } \\
\text { spaces vs physical space while collaborating on } \\
\text { design. } \\
\text { Topic is not easily summed up in the numbers } \\
\text { here - good reference for the differences between } \\
\text { guesture in physical and digital space along with } \\
\text { comparisions of TUI and GUI }\end{array}$ \\
\hline 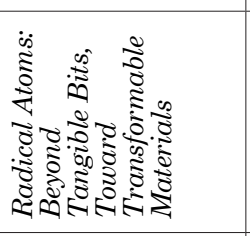 & 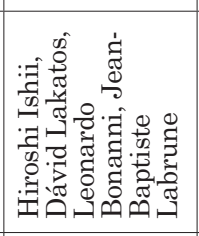 & ᄅe & $\begin{array}{l}\tilde{N} \\
\overrightarrow{\tilde{N}} \\
\end{array}$ & 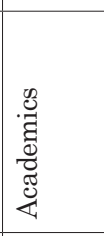 & $\frac{0}{0}$ & 0 & -1 & $\stackrel{\ominus}{\circ}$ & $\nabla 1$ & 100 & \begin{tabular}{l|l}
0 & 0
\end{tabular} & $\begin{array}{lll}6 & +\end{array}$ & +1 & 0 & $\begin{array}{l}\text { Overview of different ways we can interact with } \\
\text { data in the physical realm. Focuses more on } \\
\text { object-scale than arch-scale but has many good } \\
\text { examples of potentials formats. } \\
\text { Loads of interesting ways to interact with } \\
\text { data }\end{array}$ \\
\hline$\stackrel{\Xi}{*}$ & ఫ్ & : & 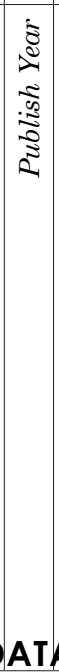 & 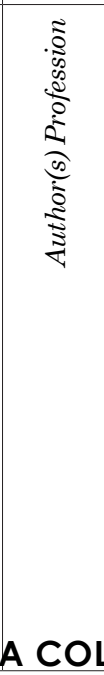 & 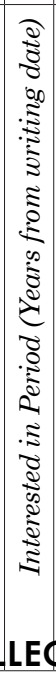 & 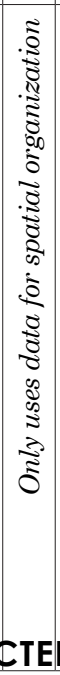 & 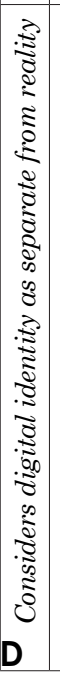 & 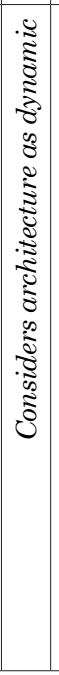 & 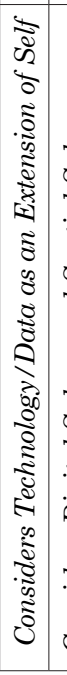 & 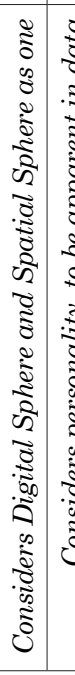 & 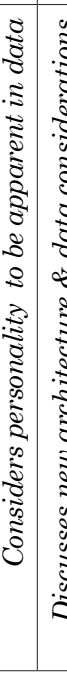 & 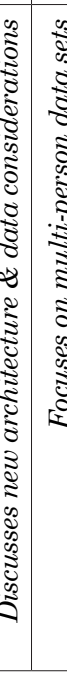 & 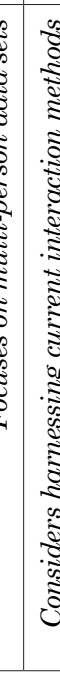 & 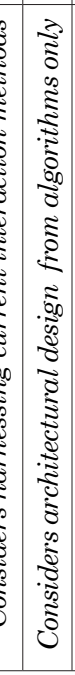 & 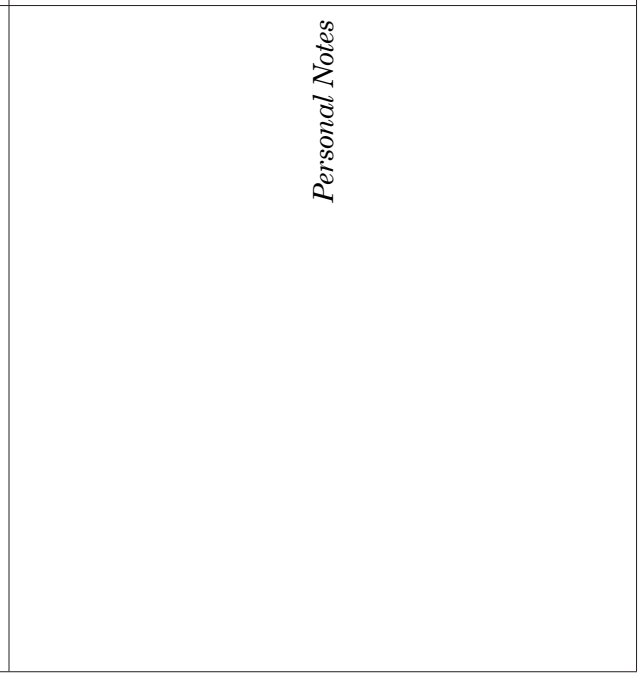 \\
\hline
\end{tabular}




\begin{tabular}{|c|c|c|c|c|c|c|c|c|c|c|c|c|c|c|c|c|}
\hline 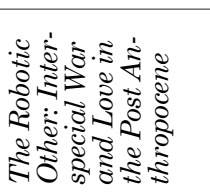 & 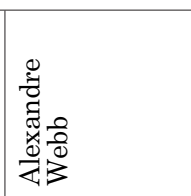 & $\frac{8}{8}$ & 章 & 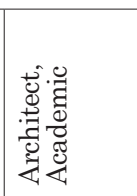 & $\begin{array}{l}10 \\
1 \\
0\end{array}$ & $\infty$ & 0 & $\infty$ & $\infty$ & -1 & N & $\sigma$ & 10 & 10 & 10 & $\begin{array}{l}\text { Overview of potential future uses of robotics on } \\
\text { architecture with some data based studies. } \\
\text { Thinks architecture should be designed not just by } \\
\text { robots and data but FOR robots and data. }\end{array}$ \\
\hline 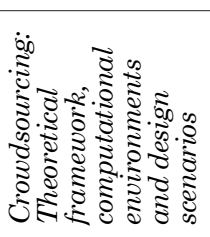 & 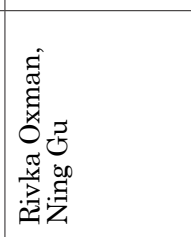 & $\vec{a}$ & 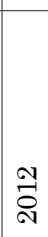 & 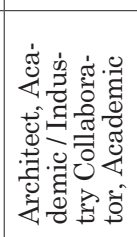 & $\begin{array}{l}2 \\
1 \\
0\end{array}$ & $\infty$ & $\infty$ & 0 & $\infty$ & $r$ & 0 & $\infty$ & $\infty$ & $\stackrel{9}{\rightarrow}$ & -1 & $\begin{array}{l}\text { Crowd-Sourcing Design through Digital Means } \\
\text { and Interaction. } \\
\text { Considers facebook, myspace etc as possible } \\
\text { precedents for digital engagement. Argues for a } \\
\text { potential collective intelligence of many. }\end{array}$ \\
\hline $\begin{array}{l}+ \\
+ \\
\stackrel{2}{a}\end{array}$ & 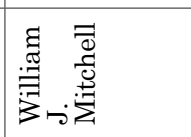 & $\cdot \vec{a}$ & 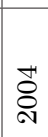 & 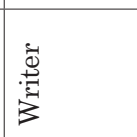 & \begin{tabular}{c}
8 \\
\hdashline \\
1 \\
0 \\
0
\end{tabular} & $\infty$ & 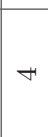 & $\infty$ & 으 & $\stackrel{ }{\sim}$ & 0 & 10 & 10 & 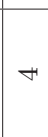 & $\infty$ & $\begin{array}{l}\text { Futurist overview of current technological climate } \\
\text { and predicted future. }\end{array}$ \\
\hline 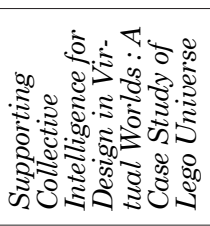 & 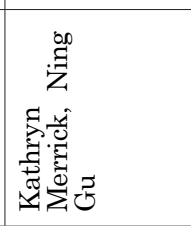 & $\vec{a}$ & ت्ञ & 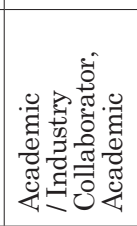 & $\mid \begin{array}{l}10 \\
1 \\
0\end{array}$ & 0 & 10 & 0 & 0 & -1 & 0 & 10 & 0 & $\stackrel{\circ}{\ominus}$ & -1 & $\begin{array}{l}\text { Crowd-Sourcing Design through Digital Means } \\
\text { and Interaction. } \\
\text { Argues for a potential collective intelligence of } \\
\text { many }\end{array}$ \\
\hline 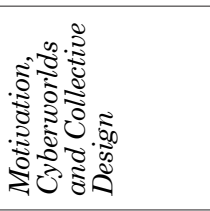 & 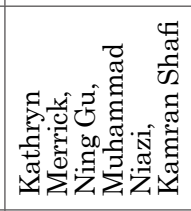 & $\vec{a}$ & $\overrightarrow{\tilde{S}^{2}}$ & 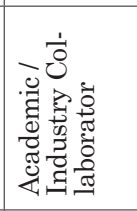 & $\mid \begin{array}{l}10 \\
1 \\
0\end{array}$ & 0 & $-r$ & 0 & -1 & -1 & 0 & $\sim$ & $\infty$ & $\stackrel{\circ}{9}$ & $-r$ & $\begin{array}{l}\text { Crowd-Sourcing Design through Digital Means } \\
\text { and Interaction. } \\
\text { Considers facebook, myspace etc as possible } \\
\text { precedents for digital engagement }\end{array}$ \\
\hline 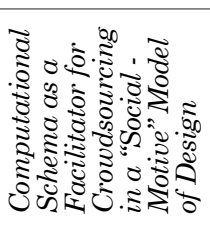 & 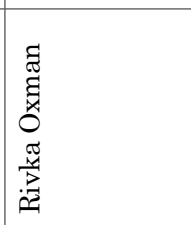 & $\vec{a}$ & 节 & 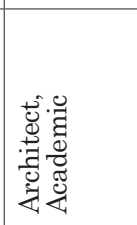 & $\left(\begin{array}{l}0 \\
1 \\
0\end{array}\right.$ & N & 0 & 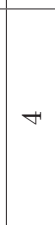 & -1 & $r$ & 0 & $\neg$ & $\infty$ & $\infty$ & -1 & $\begin{array}{l}\text { Crowd-Sourcing Design through Digital Means } \\
\text { and Interaction. } \\
\text { Argues for a potential collective intelligence of } \\
\text { many }\end{array}$ \\
\hline 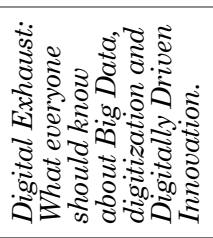 & 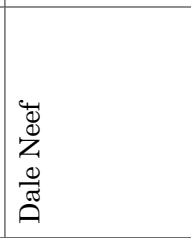 & $\vec{a}$ & 帘 & 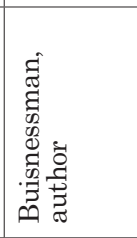 & \begin{tabular}{|l|}
10 \\
1 \\
0
\end{tabular} & 0 & $\neg$ & 0 & 10 & 0 & 10 & 0 & $\stackrel{ }{\sim}$ & 0 & 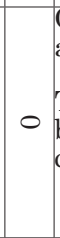 & $\begin{array}{l}\text { Overview of big data and its effects on non- } \\
\text { architecture industry. } \\
\text { Talks about unstructured data being less useful } \\
\text { but also the most common - is there something we } \\
\text { can do with loosely organized data?? }\end{array}$ \\
\hline 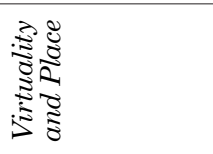 & 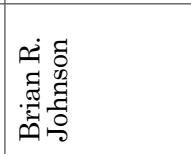 & $\vec{a}$ & 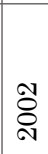 & 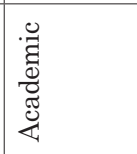 & $\begin{array}{l}8 \\
1 \\
0\end{array}$ & 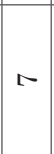 & 0 & $\stackrel{ }{-1}$ & 0 & $\stackrel{\circ}{\sim}$ & 0 & 10 & 0 & $\infty$ & $\sim$ & $\begin{array}{l}\text { Overview of augmented reality and why it is } \\
\text { better than VR or reality. Key piece in this area. } \\
\text { Somewhat Key piece for it's area }\end{array}$ \\
\hline 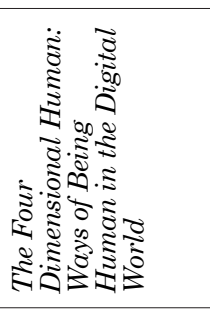 & 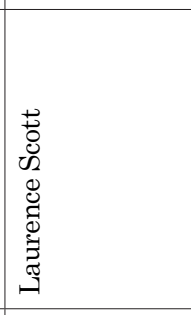 & $\overrightarrow{\vec{g}_{1}}$ & 量 & 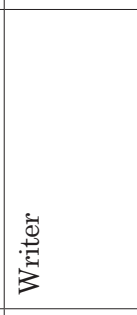 & ć & 0 & 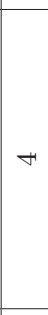 & 0 & 10 & 0 & $\Sigma$ & $\infty$ & 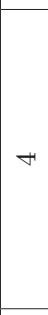 & 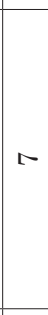 & 0 & $\begin{array}{l}\text { Philosofical overview of the current ramifications } \\
\text { of the digital world and our online presence. } \\
\\
\text { Many ideas, mostly profound. Key writing } \\
\text { on interaction between technology and us as } \\
\text { individuals. Melancholy view of contemporary } \\
\text { interactions with technology. Can draw } \\
\text { comparision between this fourth dimension and } \\
\text { the fourth dimension proposed by Edward T. Hall } \\
\text { "man has created a new dimension, the cultural } \\
\text { dimension" (1966). }\end{array}$ \\
\hline 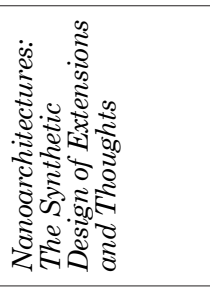 & 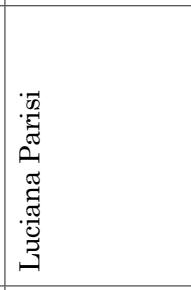 & $\vec{Z}$ & 華 & 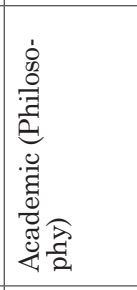 & $\begin{array}{l}8 \\
0 \\
1 \\
0\end{array}$ & $\infty$ & $\sigma$ & $\infty$ & $\mathrm{N}$ & $\infty$ & $\infty$ & $\infty$ & 0 & $r$ & 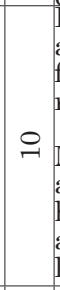 & $\begin{array}{l}\text { Interesting look at how nanotechnology (atoms } \\
\text { acting as data) can be programmed with "synthetic } \\
\text { feeling and thought" to act as physical (but tiny) } \\
\text { representations of architecture. } \\
\text { More science, biotech, nanotech ,etc than } \\
\text { architecture. Has thoughts on identity relating to } \\
\text { how these structures have a degree of autonomy } \\
\text { and identity about them and could blossom into } \\
\text { legitimate "actual machines of feeling-thought". }\end{array}$ \\
\hline$\underset{*}{\stackrel{*}{*}}$ & 离 & : & 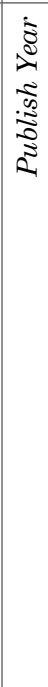 & 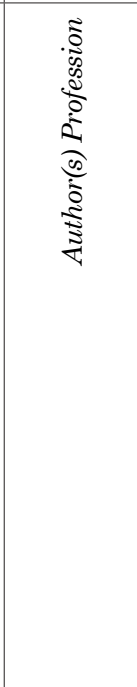 & 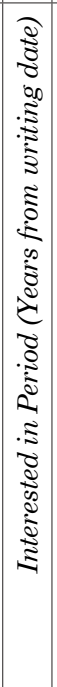 & 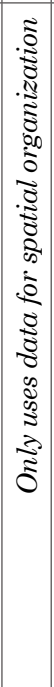 & 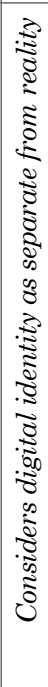 & 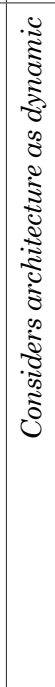 & 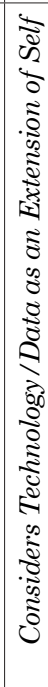 & 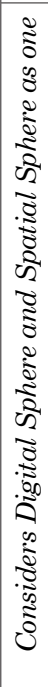 & 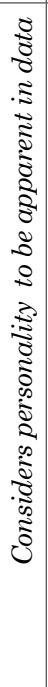 & 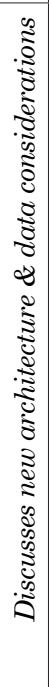 & 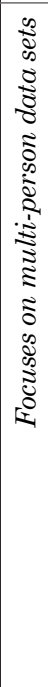 & 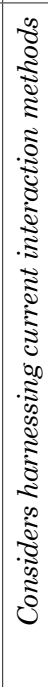 & 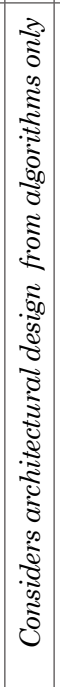 & 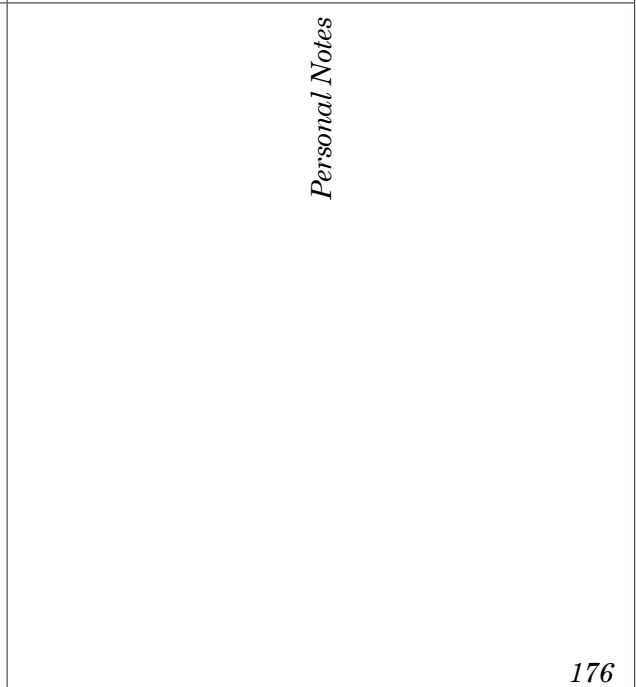 \\
\hline
\end{tabular}




\subsection{FIGURES}

Figures not cited here are the authors own

Figure_17

Figure_18

Figure_19

Figure_20

Figure_21 $a, b$

Figure_22 $a, b$

Figure_23a

Figure_23 b, $c$
ARMSTRONG, R. 2008. Artificial Evolution: A Hands-Off Approach for Architects. Architectural Design, 78, 82-85.

RIEGER, U. 2008. [arc/sec]: Architecture per Second. Architectural Design Research: Project-Based Design Research and Discourse on Design, 3, 79-102.

ULLMER, B. A. 1995. Models and Mechanisms for Tangible User Interfaces. Master of Science in Media Arts and Sciences, Massachusetts Institute of Technology.

MINI NEXT 100. 2016. MINI Vision Next 100 [Online]. https:// www.mini.co.uk/en_GB/home/explore/motorsport-vision/mini-visionnext100.html. [Accessed 11 August 2016].

MINI NEXT 100. 2016. MINI Vision Next 100 [Online]. https:// www.mini.co.uk/en_GB/home/explore/motorsport-vision/mini-visionnext100.html. [Accessed 11 August 2016].

THAM \& VIDEGÅRD ARKITEKTER. 2015. The Hemnet Home [Online]. http://www.tvark.se/the-hemnet-home/. [Accessed 11 August 2016].

CHROMOSAPIENS. 2014. Monolitt: des sentiments assez dégoulinants... [Online]. https://chromosapiens.blogspot. co.nz/2014/10/sentiments-degoulinants.html: chromosapiens. [Accessed 14 June 2016].

LAURITZSEN, S. 2014. MONOLITT [Online]. http://syverlauritzsen. com/\#/monolitt/. [Accessed 8 Oct 2016]. 


\subsection{EXTERNAL VIDEO LINKS}

Video_1

Video_2

Video_3

Video_4

Video_5

Video_6

Video_7

Video_8

Video_9 scottmeekings.com/data-gathering-gps-tracks

scottmeekings.com/initial-investigations

scottmeekings.com/diffusion-limited-aggregation-algorithm

scottmeekings.com/dla-physics-simulation

scottmeekings.com/atmospheres

scottmeekings.com/atmosphere2

scottmeekings.com/interaction

scottmeekings.com/atmosphere-interaction

scottmeekings.com/exploring-discrete-digital-space 